\title{
Is there life after hype for Jatropha? \\ Exploring growth and yield in Indonesia
}

\author{
Juliana Tjeuw
}




\section{Thesis committee}

\section{Promotors}

Prof. Dr K.E. Giller

Professor of Plant Production Systems

Wageningen University \& Research

Prof. Dr M. van Noordwijk

Chief Science Advisor

World Agroforestry centre (ICRAF) - Bogor, Indonesia

Special Professor Agroforestry

Wageningen University \& Research

\section{Co-promotor}

Dr M.A. Slingerland

Associate professor at Plant Production Systems Group

Wageningen University \& Research

\section{Other members}

Prof. Dr N.P.R. Anten, Wageningen University \& Research

Prof. Dr G. Cadisch, University of Hohenheim, Germany

Dr R.E.E. Jongschaap, Wageningen University \& Research

Dr J.A.C. Vel, Leiden University

This research was conducted under the auspices of the C.T. de Wit Graduate School of Production Ecology and Resource Conservation 


\title{
Is there life after hype for Jatropha? \\ Exploring growth and yield in Indonesia
}

\author{
Juliana Tjeuw
}

\author{
Thesis \\ submitted in fulfilment of the requirements for the degree of doctor \\ at Wageningen University \\ by the authority of the Rector Magnificus, \\ Prof. Dr A.P.J. Mol, \\ in the presence of the \\ Thesis Committee appointed by the Academic Board \\ to be defended in public \\ on Tuesday 20 June 2017 \\ at 11 a.m. in the Aula.
}


Juliana Tjeuw

Is there life after hype for Jatropha? Exploring growth and yield in Indonesia, 223 pages.

$\mathrm{PhD}$ thesis, Wageningen University, Wageningen, the Netherlands (2017)

With references, with summaries in English, Dutch, and Indonesian

ISBN 978-94-6343-192-7

DOI http://dx.doi.org/10.18174/413528

iv 
I dedicate this thesis to my husband for inspiring me to start and finish this $\mathrm{PhD}$ 


\begin{abstract}
Jatropha curcas L. is a biofuel crop that has not lived up to expectations due to a combination of hype and disappointment and biophysical factors. This $\mathrm{PhD}$ thesis is based on the plant production component of the JARAK programme which aimed to bridge the gap between truth and fiction. This study reviewed the jatropha hype and disappointment and further investigated the hypothesis that jatropha growth and yield are limited by biophysical factors of plant characteristics, cropping systems, and management. My review of the hype and disappointment shows that despite the high expectations fuelled by market pull and technology push, and numerous actors, the commercial potential for jatropha is limited by policy and governance, economics, social, technology, logistical, and environmental. A study of the biophysical components confirms that no current varieties suited to different cropping systems and locations are available. Jatropha aboveground biomass is partitioned predominantly into a structure of stem, branches, and twigs. The below to aboveground biomass ratio was 0.5 and fruit which was found only on productive twigs accounted for the smallest portion of biomass measured. Seed yields were disappointingly small (109 $\left.\mathrm{kg} \mathrm{ha}^{-1}\right)$ and were largest in monoculture, followed by intercropping and hedgerows in that order, although yields were influenced by age and management of pruning and fertiliser. Seed yield across the three cropping systems can be predicted using plant height and the number of productive twig/branch, although the number of inflorescence clusters per productive twig may be important. Intercropping between jatropha and maize (Zea mays L.) resulted in competition for resources both belowground and aboveground that reduced maize yields. Shoot pruning was effective in managing aboveground competition, while root pruning and root barriers effectively managed competition belowground. Leaf prunings provided a limited, but positive fertility effect on maize yield comparable to $21 \mathrm{~kg} \mathrm{~N} \mathrm{ha}^{-1}$. Jatropha - maize intercropping has potential for long-term productivity provided management practices such as fertiliser, pruning, and planting density can be developed to minimise competition and enhance complementarity. Based on my review of the jatropha hype and disappointment and my biophysical research results, the planting of jatropha by smallholders, or as a plantation crop cannot be recommended. Once the issues I highlight have been resolved and market confidence restored, jatropha may finally become a commercial source of biodiesel able to provide improved socio-economic and environmental benefits.
\end{abstract}

Key words: Aboveground biomass - Belowground biomass - Competition - Fertility - Hedge - Hype Intercropping - Leaf prunings - Market pull - Monoculture - Productive twig/branch - Pruning - Technology push 


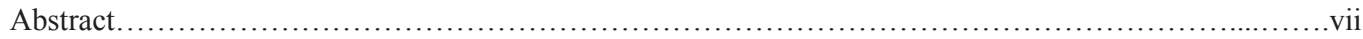

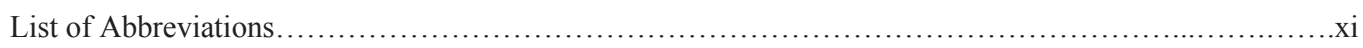

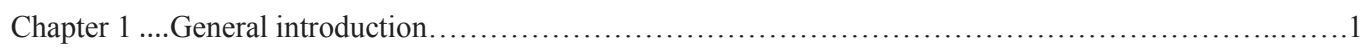

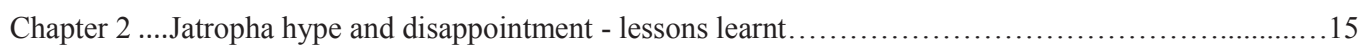

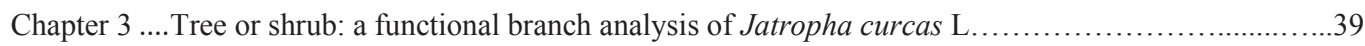

Chapter 4 ....Relationships among Jatropha curcas L. seed yield and vegetative plant components under different management and cropping systems in Indonesia.

Chapter 5 .... Resource competition between Jatropha curcas L. and maize when intercropped in Indonesia.81

Chapter 6....Trade-offs between Jatropha curcas L. and maize intercropping yield under different management scenarios using the WaNuLCAS model .................................99

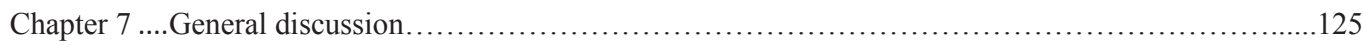

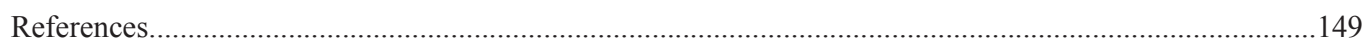

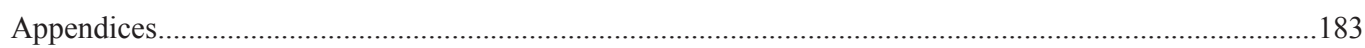

Summary

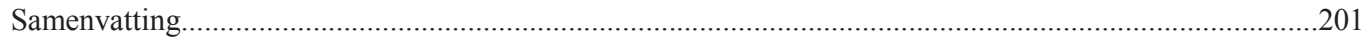

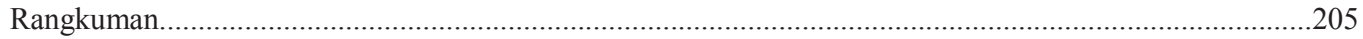

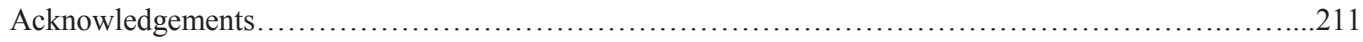

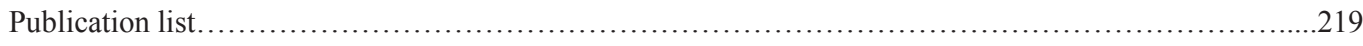

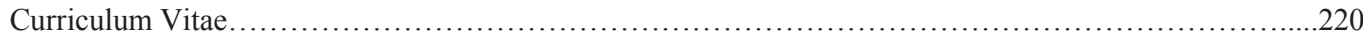

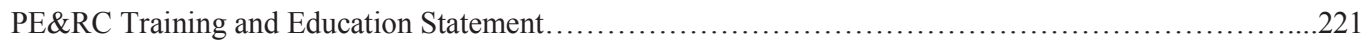

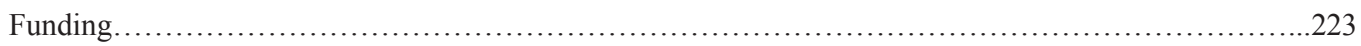




\section{List of Abbreviations}

\begin{tabular}{|c|c|}
\hline $40 \mathrm{~N} 40 \mathrm{P}$ & $\mathrm{N}+\mathrm{P}$ applied at $40 \mathrm{~kg} \mathrm{ha}^{-1}$ \\
\hline $45 \mathrm{~N}$ & $\mathrm{~N}$ applied at $45 \mathrm{~kg} \mathrm{ha}^{-1}$ \\
\hline $90 \mathrm{~N}$ & $\mathrm{~N}$ applied at $90 \mathrm{~kg}$ ha- ${ }^{1}$ \\
\hline $135 \mathrm{~N}$ & $\mathrm{~N}$ applied at $135 \mathrm{~kg}$ ha- ${ }^{1}$ \\
\hline $265 \mathrm{~N}$ & $\mathrm{~N}$ applied at $265 \mathrm{~kg}$ ha- ${ }^{1}$ \\
\hline A & Aboveground \\
\hline ASL & Above sea level \\
\hline B & Belowground \\
\hline $\mathrm{AbF}$ & Agriculture beyond Food \\
\hline $\mathrm{A}_{\mathrm{c}}$ & Area fraction allocation to the crop \\
\hline $\mathrm{BA}$ & Benzyl adenine \\
\hline $\mathrm{C}$ & Competition \\
\hline $\mathrm{C}_{\mathrm{O}}$ & Maize control \\
\hline $\mathrm{C}_{\mathrm{A}}$ & Competition aboveground \\
\hline $\mathrm{C}_{\mathrm{B}}$ & Competition belowground \\
\hline $\mathrm{C}_{\mathrm{CT}}$ & Competition effects of crop on tree yield \\
\hline $\mathrm{CD}$ & Coefficient of determination \\
\hline $\mathrm{CDM}$ & Clean Development Mechanism \\
\hline $\mathrm{Cm}$ & Maize control with jatropha leaf mulch \\
\hline CONAFOR & National Forestry Commission of Mexico \\
\hline CRM & Coefficient of Residual Mass \\
\hline $\mathrm{C}_{\mathrm{TC}}$ & Competition effects of tree on crop yield \\
\hline $\mathrm{D}$ & Diameter \\
\hline $\mathrm{DBH}$ & Diameter Breast Height \\
\hline $\mathrm{E}$ & Environment \\
\hline $\mathrm{EF}$ & Modelling Efficiency \\
\hline ESV & Energy Sufficient Villages \\
\hline EU & European Union \\
\hline $\mathrm{F}$ & Fertility \\
\hline FBA & Functional Branch Analysis \\
\hline $\mathrm{F}_{\mathrm{CT}}$ & Fertility effect of crop on tree yield \\
\hline FFA & Free fatty Acids \\
\hline $\mathrm{F}_{\mathrm{TC}}$ & Fertility effect of tree on crop yield \\
\hline FSPM & Functional Structural Plant Model \\
\hline G & Genotype \\
\hline GHG & Greenhouse Gas (emissions) \\
\hline
\end{tabular}




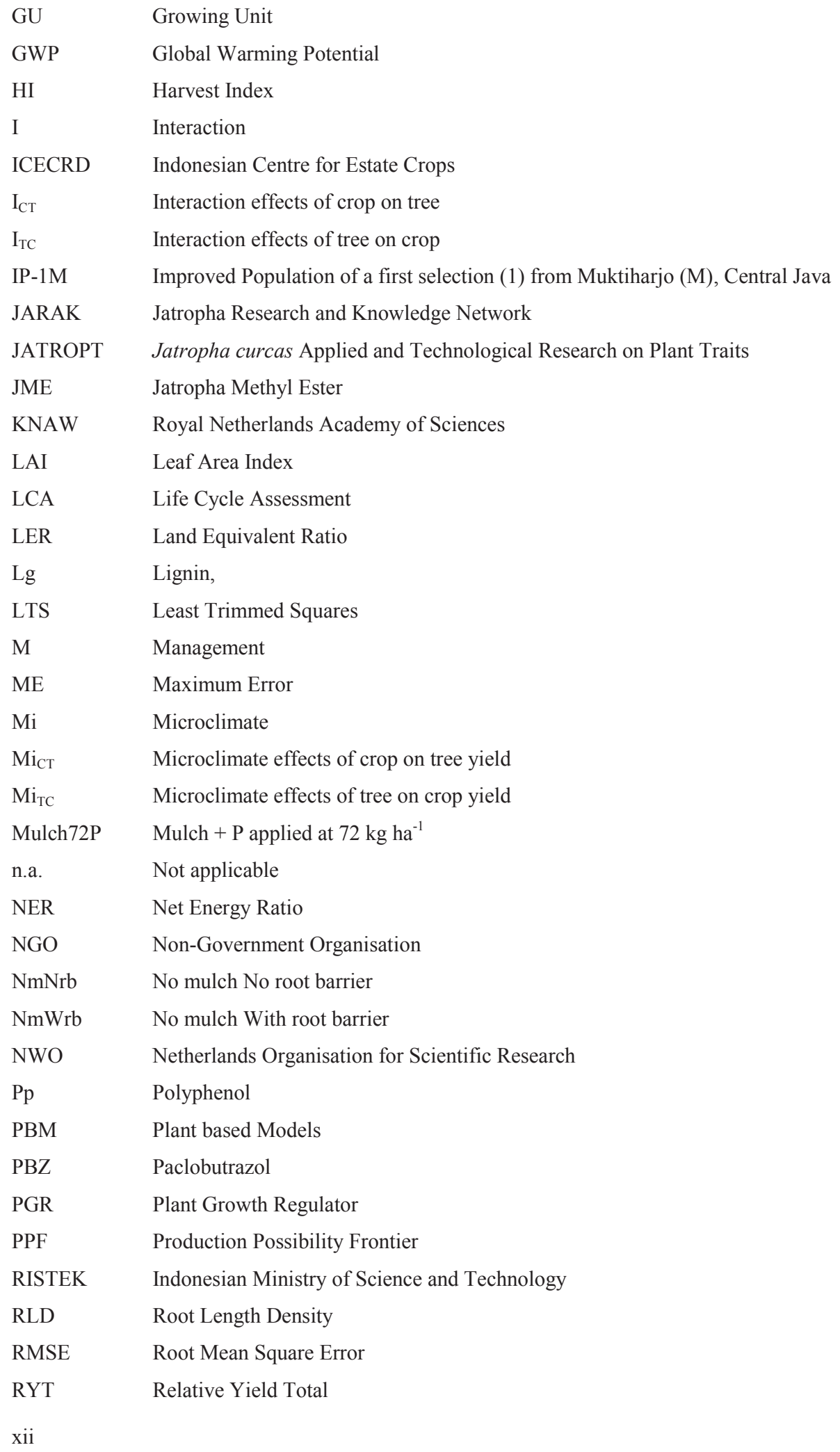


SD

SED

SLA

$\mathrm{U}_{\mathrm{TC}}$

WAP

WaNuLCAS

$\mathrm{WmNrb}$

WmWrb

$\mathrm{Y}_{\mathrm{C}}$

$\mathrm{Y}_{\mathrm{T}}$

$\mathrm{Y}_{\text {TOT }}$
Standard Deviation

Standard Error of Mean Differences

Specific leaf Area

Utility effect of tree yield relative to the crop

Weeks after Planting

Water, Nutrient and Light Capture in Agroforestry System model

With mulch No root barrier

With mulch With root barrier

Yield of crop when grown alone

Yield of tree when grown alone

Yield total 
Chapter 1 General introduction 


\subsection{General introduction}

Jatropha curcas L. further referred to simply as jatropha is a woody perennial with a history of several centuries of cultivation and spread across the tropics as a plant with medicinal value. It has in the last decade been promoted as a potentially environmentally and socio-economically sustainable biofuel crop for renewable energy. This has been triggered by the promise that jatropha would reduce political and economic dependence on imported and costly fossil fuels and its associated carbon emissions. Jatropha was seen as a way of resolving the food-vs-fuel debate by stating it could be grown on degraded soils not suitable for food crops. Jatropha came to be seen as a 'silver bullet' solution due to a combination of policy decisions regarding energy independency and rural socio-economic development, and investors' with aspirations for quick gains based on cheap land and low labour costs (Slingerland and Schut, 2014). Interest in jatropha occurred at a time when the stock market was booming and a lot of venture capital was being invested in biofuels. The worldwide hope for a jatropha-based solution, however, became a hype (Achten et al., 2010c; Kant and Wu, 2011; Vel, 2014a).

\subsection{The global jatropha hype}

For this study, I define hype as the intensive promotion of a specific solution by the exaggeration of its importance, benefits and potential. In this case, the specific solution was based on use of jatropha as a biofuel crop.

Starting in the mid-1990s there had been a dramatic increase in environmental awareness and concern regarding the impact of climate change and global warming. This has been further compounded by interests in energy security and increasing oil prices, necessitating governments to consider alternative fuel sources with lower security risks (Simandjuntak, 2014). The response has been an increase in public, political, and scientific concern, driven primarily by a desire to reduce $\mathrm{CO}_{2}$ emissions and reduce the dependency on fossil fuels (Verrastro and Ladislaw, 2007). Biofuels have been promoted as potential sources of energy that can be produced in an environmentally and socially sustainable way. An example of the impact of these concerns can be seen in the European Energy and Climate Change Policy that aims to cover $10 \%$ of the European transport fuel demand with biofuels by 2020 (Gui et al., 2008; Achten et al., 2010a; Pradhan and Ruysenaar, 2014).

Biofuels however are not without their critics who draw attention to the economic, social and environmental risks involved with large-scale use of biofuels, in particular the fuel versus food debate (Achten et al., 2010a; Van Eijck et al., 2014a). Jatropha was promoted as the ideal biofuel crop as it was claimed not to compete with food production, deplete natural carbon stocks or threaten biodiversity. Jatropha was depicted as being a non-edible, drought tolerant, high yielding species with low fertiliser requirements and having high tolerance to pests and diseases. The claimed potential to simultaneously reclaim wastelands, provide fuel and have positive socio-economic effects is what attracted so much attention (Abhilash et al., 2011). National Governments, Non-Government Organisations (NGOs), International/National Development Agencies, and 
International investors became aware of a global opportunity for having a clean and secure source of energy (Openshaw, 2000; Krijtenburg and Evers, 2014). Jatropha was put at the forefront of having the potential to help resolve these multi-faceted concerns (Von Maltitz et al., 2014) and provide a return on investment at the same time.

Interest in jatropha took off in developing countries, where governments started to develop policy frameworks to simultaneously provide investment incentives, and to regulate biofuel expansion. Governments were eager to reap the promised benefits of jatropha (Pradhan and Ruysenaar, 2014; Von Maltitz et al., 2014). Individual countries began to see jatropha as politically and morally the best biofuel option as it had no known negative impacts on food crop production.

India, the country where the initial positive reports on jatropha originated, developed a National Biofuel Policy designed to produce $20 \%$ of total diesel demand from plants by 2017 (Garg et al., 2011). Brazil developed what has become a very successful programme where the production, industrialisation, and use of biodiesel and biodiesel blends were nationwide goals. The aim was to provide and encourage rural employment and community development through the production of biofuel crops, but not at the expense of food security (Valdés Rodríguez et al., 2014). Jatropha was only one of many oil bearing plants considered (Ramos and Wilhelm, 2005). However, ultimately most biodiesel was produced from already existing soybean fields (Watanabe et al., 2012) while interventions aiming to introduce castor (Ricinus communis L.) as a new biodiesel crop to lift smallholders out of poverty largely failed to deliver its promises (Dal Belo Leite et al., 2013; 2014). In China, the government committed to reducing oil demand and greenhouse gas emissions through biofuel development especially from non-food and non-grain fuel ethanol, biodiesel, biogas, biohydrogen and other bioenergy products (Chen et al., 2016). Mozambique introduced a biofuel strategy aimed at the production of jatropha biofuel feed stocks for the domestic and European Union (EU) markets and as a means to develop its rural areas (Slingerland and Schut, 2014).

While the public sector was alive with local and international players examining the feasibility of producing biodiesel from jatropha, not all countries fully embraced the concept of planting jatropha. In Malaysia, for example the focus was on research and development, and in the commercialisation of biodiesel. The Malaysian government did not want to compromise palm oil production by planting large areas of land with jatropha (Kalam et al., 2012). Not all programmes succeeded. The Tanzanian Government, for example, developed three different jatropha biofuel models, a local rural development model, smallholder out growers, and plantations; however their involvement in the continued development was minimal (Van Eijck and Romijn, 2008).

\subsection{The jatropha hype in Indonesia and research opportunities}

By the end of 2005, the Indonesian government was viewing jatropha as a biofuel crop with the potential to combat increasing world crude oil prices. Oil prices were becoming a burden, made worse by the long 
history of subsidising fossil fuel retail prices (Bulman et al., 2008). The Ministry of Agriculture started to actively encourage farmers throughout the country to cultivate jatropha, by providing inputs and cash incentives, but without reliable facts on the performance that could be expected (Vel, 2014a).

Biofuel was further promoted with the 2006 Presidential Instruction on the supply and utilization of biofuel, a decree calling for a new 'National Energy Mix', and establishing a 'National Team for Biofuel Development to Accelerate Poverty and Unemployment Reduction' (Fatimah and Yuliar, 2009; Silitonga et al., 2011; Vel, 2014a). The government was reported to have committed US\$ 1.1 billion in the 2007 national budget for biofuel infrastructure subsidies, in addition to subsidies for plantation improvement, training, and research and development. The objective was for biofuels to meet $3.7 \%$ of total household and commercial use by 2010 (Dillon et al., 2008; Vel, 2014a). The down side to this was the fact that many of the jatropha claims were largely based on non-peer-reviewed reports (Jongschaap et al., 2007; Achten et al., 2014; Edrisi et al., 2015) and the underlying information could not be verified.

In Indonesia the price of jatropha seed was falling and the Indonesian Government's fossil fuel subsidies were effectively working as a price ceiling for jatropha oil. Farmers were disappointed, and traders no longer saw a profit in jatropha. For a while, it seemed as though the jatropha hype was over. Then surprisingly, private investors expressed renewed interest and presented business proposals for commercial jatropha projects. Despite this renewed interest it seems that many of the schemes proposed did not proceed. While there was some minor activity, there were few large-scale plantings (Vel, 2014a).

In 2009 a multidisciplinary Agriculture beyond Food (AbF) programme was set up by the Royal Netherlands Academy of Sciences (KNAW) and the Netherlands Organization for Scientific Research (NWO) with the Indonesian Ministry of Science and Technology (RISTEK) to foster Dutch-Indonesian research collaboration (Löffler et al., 2014). Given the mutual interest in research on agricultural production for bioenergy the Jatropha Research and Knowledge Network (JARAK) became one of the research clusters under the AbF programme. JARAK is also the Indonesian word for jatropha and is central to 'JARAK: The Commoditisation of an Alternative Biofuel Crop in Indonesia'. The JARAK programme was intended to bridge the current gap between the claims on jatropha and actually existing knowledge from legal, environment and governance, socio-economic, and plant production aspects that would justify them (Vel, 2014b).

This $\mathrm{PhD}$ was the only research that focused on the plant production component of the JARAK programme. In conjunction with this is a literature review of the hype and disappointment cycle presented using a modified Gartner model (Chapter 2). This chapter includes results of other JARAK researches that shed some light on how the jatropha hype in Indonesia started and was maintained, despite the uncertainty surrounding jatropha's performance. 


\subsection{Jatropha}

\subsubsection{Distribution}

There is general agreement that jatropha is native to the forests of coastal regions of Mexico and Continental America (Achten et al., 2010e). During the sixteenth century commercial plantations for soap and lamp oil were established by the Portuguese on the Cape Verde Islands and in Guinea Bissau (Heller, 1996). The Portuguese then took jatropha to their colonies in Africa (Mozambique, Angola) and eventually into Asia (India, China, and Indonesia) where jatropha is now well established and thriving (Achten et al., 2010e).

\subsubsection{Botanical description}

Jatropha (Jatropha curcas L.) (Euphorbiaceae) is a perennial shrub or small tree often with many secondary glabrous and stout branches located at the base, middle or top of a single straight stem. Leaves are green to pale-green, smooth, alternate to sub-opposite with a spiral phyllotaxis (Dehgan and Webster, 1979). Leaf morphology is variable with length $(5 \mathrm{~cm}$ to $15 \mathrm{~cm})$ and width $(5 \mathrm{~cm}$ to $22 \mathrm{~cm})$, while leaf shape may have 2 to $>6$ shallow lobes (Heller, 1996; Sunil et al., 2013). The latex is sticky, white, and normally poisonous (Kumar and Sharma, 2008). Seedlings generally have one primary taproot and four lateral roots that are distributed symmetrically; however, adult trees develop a more branched root system (Reubens et al., 2011). In contrast to this, roots that develop from cuttings do not have a taproot and lateral root development can be poor (Kumar and Sharma, 2008).

Jatropha is monoecious, occasionally hermaphroditic with greenish yellow unisexual male and female flowers on a racemose inflorescence with a dichasial cyme pattern. The paracladi are formed terminally. Jatropha seed yield is highly correlated to the ratio of male (staminate) flowers to female (pistillate) flowers (Raju and Ezradanam, 2002). The factors influencing sex expression and alteration are largely unknown although temperature, soil moisture and fertility are thought to influence the biochemical mechanisms responsible (Makwana and Robin, 2013). Flowering is normally cyclical and occurs during the wet season, although continuous flowering has been recorded (Achten et al., 2008). Jatropha is predominantly pollinated by insects, especially honey bees; however wind and rain do play minor roles (Divakara et al., 2010). Natural pollination has been shown to be more effective than artificial pollination (selfing) at $89.7 \%$ and $32.9 \%$ respectively, and only $50 \%$ of flowers set fruit with a fecundity rate of $53 \%$. Apomixis tends to be high at around $32 \%$ and the seed: ovule ratio is around $67 \%$ (Luo et al., 2007). Fruit are ovoid capsules greenish brown in colour, $4 \mathrm{~cm}$ long and $3 \mathrm{~cm}$ in diameter, and weigh $2.0 \mathrm{~g}$ to $3.5 \mathrm{~g}$ (Heller, 1996). There may be three, four, or even five seeds present inside a capsule. Fresh seeds have soft white kernels that when dry have oil content between $25 \%$ and $40 \%$ (Heller, 1996; Jongschaap et al., 2007; Divakara et al., 2010). With the exception of non-toxic genotypes, all parts of the plant including the seeds are inedible due to toxic phorbol esters, curcin, trypsin inhibitors, lectins, and phytates (Contran et al., 2013). 


\subsubsection{Uses and products}

All parts of the jatropha have some beneficial applications for humans and/or animals (Heller, 1996). The oil can be used as biodiesel or to make soap. The waste (press seed cake, fruit husk, seed shell) generated by the oil extraction process can be used for biogas production or as source of organic fertiliser. Seed cake that has been detoxified can be used as cattle feed (Achten et al., 2007; Kumar and Sharma, 2008; Contran et al., 2013) and proteins may have some potential in human nutrition (Lestari, 2012). Seeds from the non-toxic Mexican varieties can be eaten after roasting (Kumar and Sharma, 2008). Jatropha is often used by farmers as boundary hedges, or to protect crops from browsing animals (Kumar and Sharma, 2008; Brittaine and Lutaladio, 2010). Seedlings and not cuttings are effective in reducing soil erosion due to the taproot which cuttings do not have (Reubens et al., 2011).

\subsubsection{Growing environment}

Jatropha is widely distributed and adapted to tropical and subtropical regions, $30^{\circ}$ North and $30^{\circ}$ South of the equator (Jongschaap et al., 2007). Rainfall and temperature are known to affect growth and yield, with soil fertility (Openshaw, 2000) and light as contributing factors (Trabucco et al., 2010). While jatropha will grow in a wide range of soils, including marginal soils with low nutrient content, it does not grow well on waterlogged or poorly drained soils (Achten et al., 2008; Kumar and Sharma, 2008).

Jatropha occurs naturally in regions with a mean annual rainfall of $950 \mathrm{~mm}$, although it can be found in areas where the annual rainfall ranges from $300 \mathrm{~mm}$ to 3,000 mm (Achten et al., 2008). Optimal temperatures range from $10{ }^{\circ} \mathrm{C}$ to $45^{\circ} \mathrm{C}$; however when minimum rainfall and temperatures, or maximum rainfall and temperatures occur, growth and yields, including oil quantity and quality are compromised (Trabucco et al., 2010).

During periods of water deficit, jatropha responds by producing higher numbers of adaxial stomata, and any water lost through transpiration is replaced by reserves in the stem (Maes et al., 2009). Continued water stress leads to leaf fall to minimise transpiration loss (Heller, 1996; Kumar and Sharma, 2008; Maes et al., 2009). While jatropha is able to minimise drought stress by shedding its leaves and reducing stem, and root growth (Achten et al., 2010d; Díaz-López et al., 2012) there is a cost in lost yield (Yeh et al., 2011; Rao et al., 2012). Jatropha is insensitive to day length (Achten et al., 2008; Divakara et al., 2010) which means that it is possibly a day-neutral plant, a point that could be important in interspecies hybridisation with other similar jatropha genus (Basha and Sujatha, 2009).

In Indonesia, jatropha is found growing in areas with a mean rainfall in excess of 3,000 $\mathrm{mm}$ per year. These locations include Bogor, West Sumatra, and Minahasa (North Sulawesi). Plants growing in these conditions often have dense vegetative growth, but very few flowers and fruit. In the village of Cikeusik in Malingping, Banten, where the rainfall is slightly less than 2,500 $\mathrm{mm}$ to $3,000 \mathrm{~mm}$ per year, jatropha has 3 to 4 fruit per inflorescence (Rivaie et al., 2006). Research by Indonesian Centre for Estate Crops Research and 
Development (ICECRD) has highlighted the fact that climate has a significant impact on growth and production (ICECRD, 2006).

\subsubsection{Breeding}

Jatropha breeding is still in the early stages, progressing through conventional (Achten et al., 2010e; Divakara et al., 2010; Tripathi et al., 2015), mutation (Divakara et al., 2010; Dhakshanamoorthy et al., 2015), molecular (Ceasar and Ignacimuthu, 2011; Sun et al., 2012; Osorio et al., 2014; Maghuly et al., 2015), tissue culture, and transformation phases (Ceasar and Ignacimuthu, 2011; Joshi et al., 2013; Slingerland et al., 2014). The key will be to determine the extent of any genetic variation for the desired traits (Rao et al., 2008; Achten et al., 2010e) and to use this variation for commercial applications (Salvador-Figueroa et al., 2015).

Global germplasm collection, propagation, breeding, and genetic diversity studies involving hundreds of accessions from different continents and countries was carried out by Plant Research International, Wageningen University and Research Centre, the Netherlands (Jongschaap et al., 2007; Osorio et al., 2014) and by Plant Biotechnology Unit, University of Natural Resources and Life Sciences, Vienna, Austria (Maghuly et al., 2015). Germplasm collections, genetic diversity, and breeding studies have also been performed in many countries such as India (Basha and Sujatha, 2007; Basha et al., 2009; Maurya et al., 2015), China (Sun et al., 2008; Shen et al., 2010; Wen et al., 2010), Mexico (Ovando-Medina et al., 2011; Pecina-Quintero et al., 2011; Salvador-Figueroa et al., 2015), Brazil (Rosado et al., 2010; Grativol et al., 2011; Bhering et al., 2013), Malaysia (Arolu et al., 2012; Shabanimofrad et al., 2013), and Indonesia (Hartati et al., 2009; Hartati and Sudarsono, 2015; Maftuchah et al., 2015).

The germplasm found in Asia, Africa and South America has been shown to have limited genetic variation (Yi et al., 2010; Ovando-Medina et al., 2013) when compared to the Central America accessions, (Osorio et al., 2014; Maghuly et al., 2015). The phenotypic variation exhibited is likely to be epigenetic (Yi et al., 2010; Osorio et al., 2014; Maghuly et al., 2015), however if the variation is heritable then breeders have the opportunity to develop new, high yielding varieties (cultivars).

\subsubsection{Production systems}

Agriculture can be considered a system beginning with national/regional agricultural production systems which constitute the highest level organisation pertaining to economic and sociological aspects, to plant production systems which represent individual farm enterprises as cropping systems, livestock, aquaculture, fisheries, poultry, and forestry, to cropping systems with temporal sequences of crops and management practices in individual fields (Connor et al., 2011; Cochet, 2015). Jatropha cropping systems can include monocultures, intercropping, or hedges (GTZ, 2009; Wahl et al., 2009; Brittaine and Lutaladio, 2010). Monocultures are generally large intensively managed commercial plantings, while intercropping is often used by farmers wanting to maximise economic returns, while insuring against the loss or poor performance of one crop. Intercropping is of particular value if the two crops have different growth characteristics (Wahl 
et al., 2009; Brittaine and Lutaladio, 2010). Jatropha hedges are used to define property boundaries or as crop protection fencing (Henning, 2001; GTZ, 2009; Wahl et al., 2009).

Jatropha is readily established from seed or cuttings. Cuttings are genetically uniform with rapid establishment and early yield development, however they do not produce a taproot, and lateral root development is not as good as seedlings. This means greater susceptibility to uprooting by wind (Kumar and Sharma, 2008). Cuttings are also reported to have a shorter lifespan and a lower tolerance to water deficit (Achten et al., 2008; Brittaine and Lutaladio, 2010). As a result cuttings are not normally recommended for intercropping where root competition may be high (Brittaine and Lutaladio, 2010).

\subsubsection{Management}

There is little scientific data available to managers on the commercial growth and development of jatropha. Planting densities in monocultures can vary from 1,111 to 2,500 plants per ha (Achten et al., 2008; Wahl et al., 2009; Brittaine and Lutaladio, 2010). Plant spacing of $2 \mathrm{~m} \times 2 \mathrm{~m}, 2.5 \mathrm{~m} \times 2.5 \mathrm{~m}, 2 \mathrm{~m} \times 3 \mathrm{~m}$, and $3 \mathrm{~m} \times 3$ $\mathrm{m}$ are common. Intercrop planting densities can vary from 278 to 1,250 plants per ha with spacings of $2 \mathrm{~m} \times$ $4 \mathrm{~m}, 2 \mathrm{~m} \times 5 \mathrm{~m}, 3 \mathrm{~m} \times 4 \mathrm{~m}$, to $6 \mathrm{~m} \times 6 \mathrm{~m}$ (Achten et al., 2008). Hedges are normally planted as single or double rows of plants spaced anywhere from 5 to $50 \mathrm{~cm}$ apart (Wahl et al., 2009).

Pruning to control plant size and shape as well as increase the number of new branches that bear inflorescence and fruit is a common management practice (Achten et al., 2008; Rajaona et al., 2011). Techniques vary, however a common practice is to pinch out the terminal shoots at age six months or cut the main stem back to about $30 \mathrm{~cm}$ to $45 \mathrm{~cm}$ above ground. The objective is to induce lateral branching and increase inflorescence and fruit production (Achten et al., 2008; Rajaona et al., 2011). Branch tips can then be pruned again at the end of the first year and in subsequent years branches can be pruned by removing around two-thirds of their length. It is considered good practice to heavily prune jatropha to $45 \mathrm{~cm}$ above ground after 10 years to improve yield (Gour, 2006; Achten et al., 2008; Brittaine and Lutaladio, 2010).

Fertiliser application (Patolia et al., 2007; Mohapatra and Panda, 2011) and irrigation (Achten et al., 2008; Tikkoo et al., 2013) have been shown to improve yields, however reliable data is lacking. Optimal requirements have been shown to vary with age and location (Achten et al., 2008). A short term strategy would be to determine the nutrient value of the products removed and ensure replacement, with all noncommercial biomass retained in the field to improve the soil (Jongschaap et al., 2007). Regular weeding to reduce competition is important (Brittaine and Lutaladio, 2010).

\subsection{Constraints to jatropha production}

During the period of this study all across the world the jatropha hype was turning to disappointment. The claimed yields of $12 \mathrm{tha}^{-1}$ (Openshaw, 2000) or global yield predictions of $5 \mathrm{tha}^{-1}$ (Trabucco et al., 2010) did not materialise. Actual measured yields varied from $<0.5 \mathrm{tha}^{-1}$ to $2 \mathrm{t} \mathrm{ha}^{-1}$ (Edrisi et al., 2015) due in part to 
the lack of high yielding planting material (Iiyama et al., 2013; Achten et al., 2014; Edrisi et al., 2015). The problem is that reliable production data is lacking (Edrisi et al., 2015), especially in regards to breeding, management, and pest and disease susceptibility (Achten et al., 2010a; Achten et al., 2014; Van Eijck et al., 2014a; Edrisi et al., 2015).

While there are constraints to jatropha production, they can be considered particularly relevant to large-scale monoculture plantings. Intercropping has been proposed as a feasible alternative to monoculture (Achten et al., 2010a; Abhilash et al., 2011). Intercropping can be complementary (positive) or competitive (negative) (Rao et al., 1997) to the main crop so these interactions need to be brought into harmony if the intercropping is to succeed (Nair, 1993). In particular research is needed to examine yield trade-offs between jatropha and the other crops with which it is intercropped and the impact on long-term productivity.

\subsection{Hypothesis and aims}

The research in this thesis focuses on investigating the claims that jatropha is a high yielding crop irrespective of its production circumstances. Particular attention is given to the claim that jatropha performs well in intercropping. The key hypothesis for this thesis is that jatropha growth and yield are limited by biophysical factors of plant characteristics, cropping systems selected, and management practices imposed. Conceptually, the study was approached from three different perspectives: jatropha characteristics, system productivity, and management (Figure 1.1) each with its specific questions. The overall aims are first to understand the aspects of above and belowground biomass allocation using a modelling based approach that includes plant architecture. Second to use this knowledge to evaluate growth and yield in monoculture, hedge, and intercropping systems with different management options that can be incorporated into the final model to determine long-term productivity and trade-off analysis.

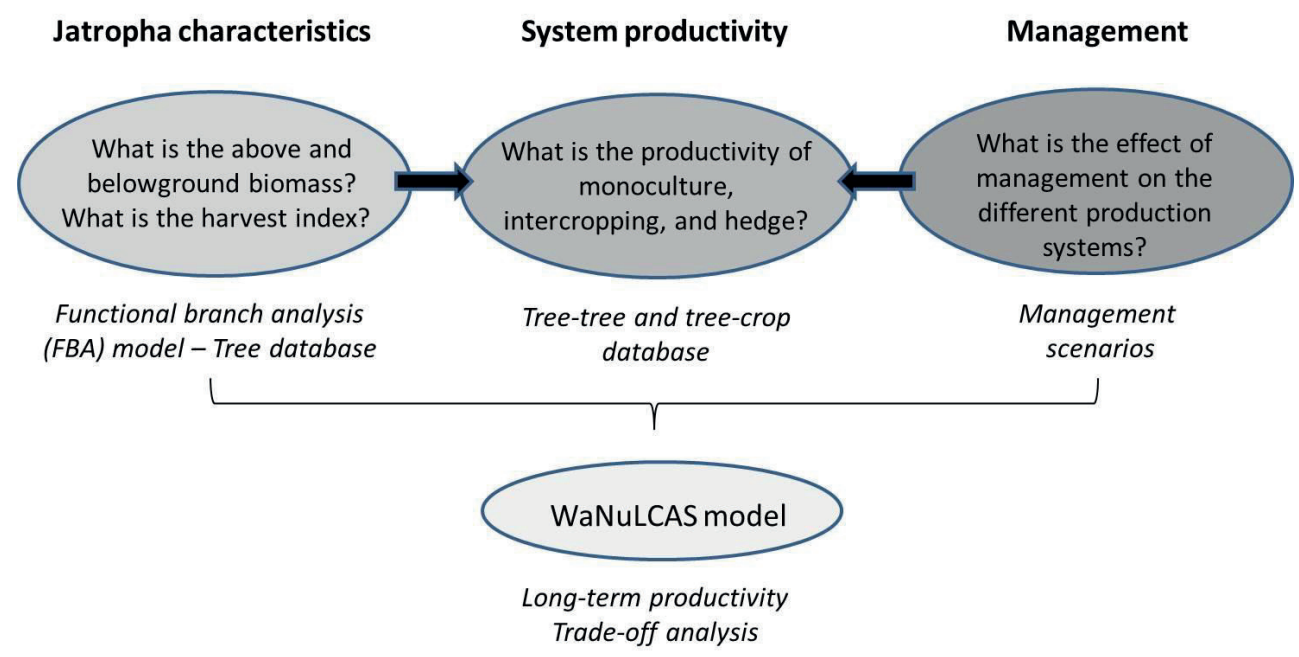

Figure 1.1 Flow-chart outlining the research strategy. 
In order to understand the potential and limitations on jatropha growth and yield, and to guide the research, the four following specific research questions were formulated:

- What are the above and the belowground biomass allocations, including the harvest index? (Chapter $3)$.

- What is the relationship between seed yield and vegetative plant components under different management and cropping systems? (Chapter 4).

- What types of interactions occur during tree-crop and tree-tree resource capture? (Chapter 5).

- What are possible long-term productivity and yield trade-offs under different management scenarios? (Chapter 6).

Specific hypotheses and objectives regarding jatropha performance and the usefulness of different models to assess this performance were developed to guide the research (Table 1.1).

Table 1.1 Specific hypotheses and aims for individual research chapters.

\begin{tabular}{|c|c|c|}
\hline Thesis & Hypothesis & Aims \\
\hline Chapter 3 & $\begin{array}{l}\text { Functional branch analysis (FBA) model that } \\
\text { takes plant architecture into account to } \\
\text { estimate above and belowground biomass, } \\
\text { including the harvest index. }\end{array}$ & $\begin{array}{l}\text { Determine allometric equations for above and } \\
\text { belowground biomass, including the harvest } \\
\text { index using FBA model (for tree database } \\
\text { construction). }\end{array}$ \\
\hline Chap & $\begin{array}{l}\text { The relationship between seed yield and } \\
\text { vegetative plant components can be } \\
\text { determined in different management (pruning } \\
\text { and plant spacing) and cropping systems } \\
\text { (monoculture, intercropping, and hedge). }\end{array}$ & $\begin{array}{l}\text { Determine seed yield and vegetative plant } \\
\text { components that influence seed yield under } \\
\text { different management and cropping systems. }\end{array}$ \\
\hline Chapter 5 & $\begin{array}{l}\text { Jatropha provides not only positive benefit to } \\
\text { the growth and yield of maize intercrop } \\
\text { through incorporation of mulch, but also a } \\
\text { negative effect to maize growth and yield } \\
\text { through below and aboveground resource } \\
\text { competition. }\end{array}$ & $\begin{array}{l}\text { Evaluate resource competition for belowground } \\
\text { (soil water and nutrient) and aboveground } \\
\text { (light capture) that influences maize growth } \\
\text { and yield in the jatropha - maize intercropping } \\
\text { system. }\end{array}$ \\
\hline Chapter 6 & $\begin{array}{l}\text { Tree-soil-crop simulation modelling } \\
\text { considering water, nutrient and light capture } \\
\text { in agroforestry systems (WaNuLCAS) can } \\
\text { estimate long-term productivity and yield } \\
\text { trade-offs under different management } \\
\text { intercropping scenarios. }\end{array}$ & $\begin{array}{l}\text { Evaluate long-term productivity and yield } \\
\text { trade-offs between jatropha and maize } \\
\text { intercropping under different management } \\
\text { scenarios using WaNuLCAS model. }\end{array}$ \\
\hline
\end{tabular}




\subsection{Study sites}

This study was conducted in two separate locations in Indonesia; monoculture and intercropping studies were conducted at the Mulo Village in the Wonosari District, Gunungkidul Regency of Special Province Yogyakarta. A hedge study was conducted at the Leseng Village in Moyo Hulu District, Sumbawa Besar Regency - Nusa Tenggara Barat Province (Figure 1.2).

Gunungkidul site has an equatorial rainforest climate (Kottek et al., 2006) with mean annual rainfall of 1,800 $\mathrm{mm}$, occurring predominantly from November to April with dry periods from June to August or September. Mean annual temperature and relative humidity are $26{ }^{\circ} \mathrm{C}$ and $70 \%$ respectively. The soils are Mollisols (Srijono and Sunarminto, 2005; Hanudin et al., 2012) with texture varying from clay, silty clay to silty clay loam. The soils are shallow, 10 to $50 \mathrm{~cm}$ deep with limestone beneath.

The Sumbawa site has an equatorial savannah climate (Kottek et al., 2006) with average annual rainfall of $1,450 \mathrm{~mm}$ from November to April or May and dry periods from June to August or September. The average annual temperature and relative humidity are $28{ }^{\circ} \mathrm{C}$ and $79 \%$. The soils are clay loam Inceptisols (Trianasari, 2009).

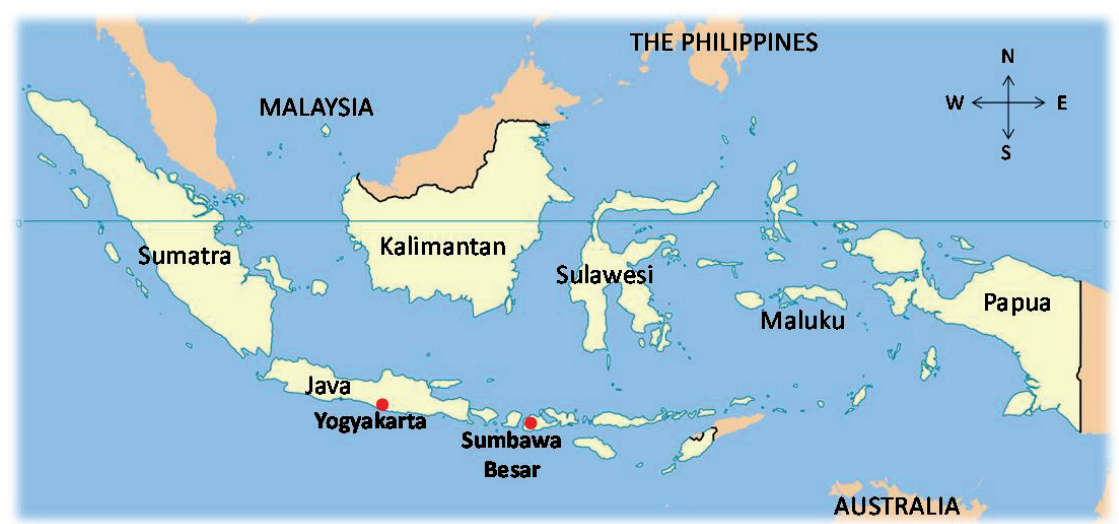

Figure 1.2 Map of Indonesia showing the Gunungkidul (Yogyakarta) and Sumbawa Besar research sites.

Substantial difficulties were experienced in identifying suitable experimental sites hence the necessity for different locations. This was partly due to many of the original jatropha plantings being removed or abandoned as a result of the disappointment during the period between proposal writing and actual start of the field research. I searched for sites based on the following criteria:

- Farmer and organisation with established jatropha plantings in different cropping systems and different areas. 
- University or government research stations open to the possibility for collaborative research and sharing of information on jatropha growth and yield.

- Companies willing to co-invest in research on jatropha management in their plantations with the aim to improve their performance in the longer term.

- University with open laboratory access and willing students to assist in data measurement and collection in return for site access for their thesis research.

- $\quad$ Access to a weather station within the local area.

- $\quad$ All weather road access and the availability of local transportation.

- Access to a reliable workforce to assist with daily management tasks.

- Location that is safe and secure where cattle are not grazed uncontrolled and wild fires are not a problem.

- $\quad$ Sites without land conflicts.

Although government institutions/research centres, companies, and farmers were willing to discuss their jatropha ventures, field visits were not always permitted. Concerns were raised regarding the possibility that Wageningen University would steal their planting material. Given the claimed large yields related to these planting materials the main fear may have been exposure that their claims were unjustified. There were also concerns from companies who were using imaginary or uprooted jatropha plantings as collateral for bank loans that they might be exposed. Sites that were visited often revealed jatropha plantings with large differences in height, development and performance of individual trees, irregular planting distances and pruning regimes, and hardly any maintenance. These sites were unsuitable for the establishment of experiments.

In Sumbawa a company was ready to co-invest in research on hedges and allowed the design and establishment of an experiment. In Gunungkidul access to an existing rather homogenous plantation of trees of different ages was successfully negotiated as well as access to spare land to design and establish the intercropping experiment. Originally the research was intended to be a combination of on-farm and onstation research. However, when considering the research with the on-farm cultivated jatropha it became clear that most farmers had uprooted and/or abandoned their jatropha hence no on-farm measurements were performed. Therefore, I chose to focus solely on the on-station sites. The reasons behind the uprooting and/or abandonment of jatropha are addressed in Chapter 2.

\subsection{Thesis outline}

This thesis is comprised of seven chapters.

Chapter 1 is the general introduction containing the background, problem statement, research gaps, and research hypotheses, objectives, and framework. 
Chapter 2 is a literature review of the jatropha hype and the disappointment that occurred during the duration of this study. The chapter uses the Gartner model to describe factors of market pull, technology push and in particular the factors that were instrumental in the jatropha disappointment. By addressing the reality cycle of the jatropha hype and disappointment we are able to explore the possibility of a continual decline or recovery.

Chapter 3 determines allometric equations for above and belowground biomass, including fruit biomass using FBA model. The FBA model is used because it is a non-destructive method and takes into account plant architecture and can be modified to determine the harvest index. FBA allometric equations generated in Chapter 3 are used in Chapter 4 to determine aboveground biomass, and will serve as tree database in the WaNuLCAS model for use in Chapter 6.

Chapter 4 investigates seed yield and vegetative plant component interactions under different management practices in monoculture, intercropping, and hedge cropping systems. This study tests the findings from Cgapter 3 under different management practices and cropping systems. Management practices used for monoculture are aboveground pruning and no pruning, for intercropping it is with and without mulch, and polythene root barriers, and for hedges it is pruning and no pruning in combination with different pruning heights (in monoculture hedge) and plant spacing (in mixed hedge).

Chapter 5 investigates maize growth and yield in response to direct competition for below and aboveground resources, or indirectly through modification of soil conditions that produce interaction in maize-jatropha intercropping systems. The effect and interaction components are explored by comparing a jatropha-maize intercropping system with maize monoculture, with and without mulch and polythene root barriers. A lack of jatropha intercropping research, including the effects of mulch and above and belowground pruning on annual crop performance prompted this study.

Chapter 6 investigates jatropha and maize long-term productivity and yield trade-off in intercropping systems using the WaNuLCAS model. Findings from Chapter 3, Chapter 4, and Chapter 5 are used to calibrate and validate the model under different management scenarios. Research relating to long-term jatropha productivity is limited, especially for intercropping systems and yield trade-off assessments.

Chapter 7 is a general discussion focussing on the plant production factors of jatropha as a biofuel crop. The study contributes to the body of scientific knowledge and existing knowledge gaps are identified for future research recommendations. In conclusion, I outline a series of constraints, challenges, and opportunities for jatropha development. 
Chapter 2 Jatropha hype and disappointment - lessons learnt 


\begin{abstract}
Interest in jatropha as a biofuel crop has been driven by economic concerns over limited oil reserves and the global price of crude oil. Jatropha was claimed to offer a clean source of renewable energy with advantages at the national to individual household levels. Jatropha proponents further claim that it does not impact on food security due to its toxicity, whilst offering the added benefits of erosion control, soil enrichment, water infiltration and flood reduction, carbon storing, and the possibility of earning carbon credits. Many of the claims put forward were based on optimistic assumptions, especially regarding yield and the early warning signs and calls for caution largely ignored, buried or overtaken by the wave of hype. The modified Gartner hype and disappointment cycle highlights that jatropha has been through multiple hype cycles dating back to 1945-50. The disappointment observed during the first hype could simply be attributed to a very specific need that was no longer required. The second and subsequent cycles share many similarities and resemble other miracle new crops. A combination of market pull (society, economy, environment and government mandates, subsidies, land allocation, and investors) and technology push factors (oil processing and value adding) that were not sufficiently well prepared or developed, and implemented within the framework and guidelines necessary for realistic commercial development were responsible for the disappointment. JARAK research in Indonesia further highlights the fact that many actors exploited the system for personal gain. Policies were often influenced by a network of powerful entrepreneurs who manipulated the process for personal gain. Companies and NGO's were able to access subsidies or bank loans and investment funds to develop large or smallholder jatropha plantations, while brokers successfully managed to get a piece of the subsidy cake. Researchers were able to access numerous research funds. While smallholders were often depicted as victims of land grab there were many who joined in the exploitation of jatropha. In hindsight it is easy to see why the jatropha hype ended in disappointment. From our review it is clear that jatropha was introduced without a comprehensive understanding of crop development and performance and market supply and demand.
\end{abstract}

Key words: Biodiesel - Biofuel - Disappointment - Gartner model - Hype - New crop - Supply chain - Value adding 


\subsection{Introduction}

Interest in jatropha as a biofuel plant is not new. In the first half of the $19^{\text {th }}$ century jatropha was cultivated commercially in Cape Verde, West Africa, and Madagascar with the seeds exported to Lisbon and Marseille for oil extraction and soap production. In Cape Verde some $16 \%$ of cultivated land was under jatropha, contributing up to $60 \%$ of its agricultural export value (Heller, 1996). The advent of cheaper synthetic detergents however soon meant jatropha production was no longer viable (Wiesenhütter, 2003).

During the Second World War shortages of fossil fuel renewed interest in jatropha, this time as a source of biodiesel. In Segou - Mali (Heller, 1996), Madagascar, Cape Verde, and Benin (Foidl et al., 1996) jatropha oil was produced for use in army tanks and in lamps (Koizumi, 2013), while its glycerine by-product was valuable for the manufacture of nitro-glycerine (Brittaine and Lutaladio, 2010). During Japanese colonisation of Indonesia the planting of jatropha and castor oil were mandatory. The seeds were sent back to Japan for oil extraction and military use (Afiff, 2014); however, once the war was over there was no longer a market for jatropha oil.

The Gulf war of 1980s saw a rise in the price of crude oil with Nicaragua (Foidl et al., 1996), Cape Verde (Wiesenhütter, 2003), India (Patil and Singh, 1991) and Mali (Henning et al., 1994) all experiencing interest in the cultivation of jatropha for biodiesel. Ultimately the jatropha hype turned to disappointment as the price of crude oil dropped. The price drop was compounded by low yields of what is essentially an undomesticated crop with high processing costs (Foidl et al., 1996; Jongschaap et al., 2007). Ultimately jatropha was once again found to be unprofitable (Nielsen et al., 2013) and many jatropha projects were abandoned (Gaul, 2012).

Then in the mid-2000s there was renewed interest in jatropha biodiesel, triggered once again by the high price of crude oil. The jatropha hype this time was more substantial as there were claims by governments, universities, and private companies and NGOs (Vel et al., 2013; Afiff, 2014; Simandjuntak, 2014) that jatropha was the miracle plant, or as some put it, green gold. Once again the price of crude oil plummeted and when combined with the low and inconsistent yields, it was obvious that there was no financial advantage in cultivating jatropha for biodiesel (Nielsen et al., 2013).

It is clear that the lessons of past jatropha hype and disappointment had not been learnt by those involved including governments, private sector, non-government organisations and research institutes. It seems that whenever there has been a crude oil crisis in the world due to reduced production and variations in demand and supply such as witnessed in 1990s, and 2000s, interest in jatropha oil as a potential source of energy resurfaces (Tahir et al., 2012). 
In this chapter I discuss the jatropha hype and disappointment from a global perspective using a modification of the Gartner's model (Fenn and Raskino, 2008). It discusses the jatropha hype and disappointment using market pull and technology push factors, identifies the current jatropha status, and outlines the lessons learnt. My primary focus is on jatropha biodiesel; however I sometimes use the broader term of biofuel; this encompasses biodiesel and other energy sources such as bioethanol. My objective is to review the factors responsible for the hype and disappointment and not to investigate detailed or specific differences between countries.

\subsection{Hype and disappointment cycle}

The hype and disappointment cycle has been used to study the excitement or expectations, and disappointment of many technological innovations such as stationary fuel cells (Ruef and Markard, 2010), biofuels, hydrogen, and natural gas (Alkemade and Suurs, 2012). Biofuel encompasses solids such as fuelwood, charcoal and wood pellets; liquids such as bioethanol, biodiesel, and pyrolysis or gases such as biogas that are predominantly produced from biomass (Demirbas, 2006; FAO, 2008).

The jatropha hype and disappointment should not be confused with the commodities boom and bust cycle (e.g. crude oil, gold, sugar, and palm oil) that happens periodically in the global economy. Despite the similarities of supply and demand and the availability of capital and future expectations, a true market for jatropha biofuel never really developed (Vel. 2014a). This aspect is important as the reference to market pull later in this article refers to a perceived need for jatropha and not to a real market. The term hype and disappointment cycle is therefore considered more appropriate, consistent with Affif (2004) and Vel (2014a).

To better understand jatropha in the context of the hype and disappointment cycle, I have used the framework developed by Gartner (Fenn and Raskino, 2008). Gartner's hype and disappointment model describes the path a technology takes over time in terms of expectations of the value of the emerging technology. The model proposes that technology progresses through successive stages. The first stage is the hype and is characterised by highly optimistic expectations which results in a peak of inflated expectations. This phase is followed by a performance and results phase that ultimately leads to a trough of disillusionment. It is here that progress in engineering and business maturity becomes important and may result in a slope of enlightenment and a mature technology and fast adoption leading to the plateau of productivity (Fenn and Raskino, 2008).

The Gartner model is not without its limitations. Borup et al. (2006) considered that the model was too general and did not allow for variation and unpredictability within different technologies, socio-economic contexts and actors involved. Steinert and Leifer (2010) found that the model produced imprecise, inconsistent and subjective predictions. It also does not address the fact that expectations can be negative (Van Noordwijk et al., 2010). Despite these limitations Dedehayir and Steinert (2016) considered that the hype dynamics could be captured through the identification of peak, disappointment, and recovery patterns. 
The Gartner hype-disappointment cycle has been adjusted and uses four specific stages; 1) pre-hype, 2) hype, 3) disappointment, and 4) reality check to better reflect jatropha's circumstances (Figure 2.1).

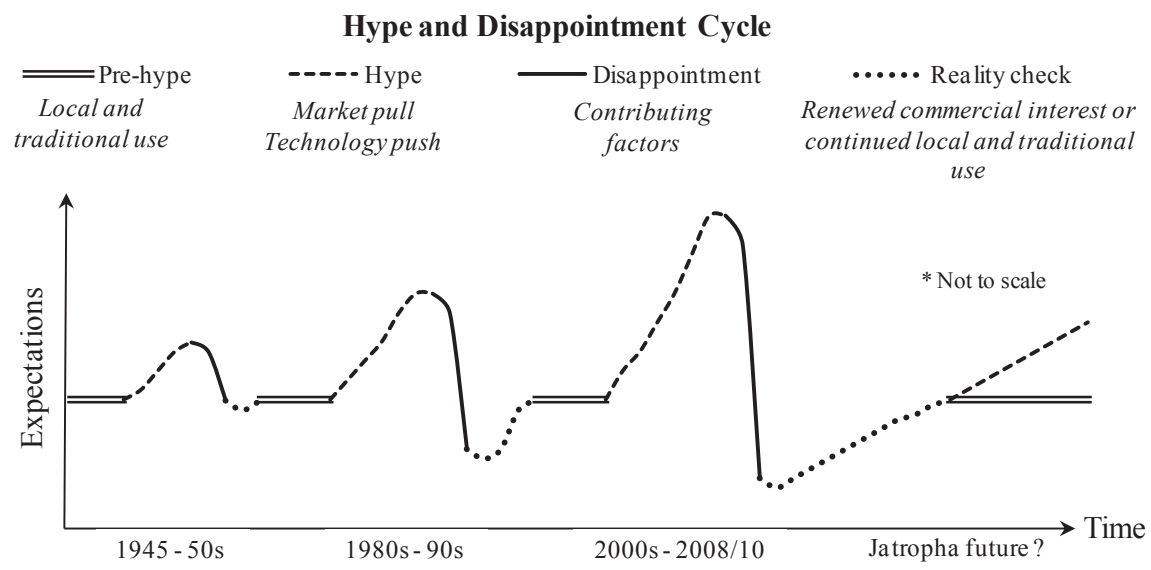

Figure 2.1 A generic hype and disappointment illustration of jatropha development from 1945s to present day [modified from the Gartner hype cycle based on Fenn and Raskino (2008)].

Pre-hype is the condition and usage prior to hype and it is often this aspect that triggers the initial interest. Hype is the rise in expectations triggered by market pull (Section 2.3.1) and technology push (Section 2.3.2) often heavily promoted by government, media, academia, researchers, investors, international organisations, and brokers (Vel. 2014a). Market pull refers to the need for a new product or a solution to a problem (Boehme, 1986; Bullinger, 1994; Brem and Voigt, 2009). A product, or a range of products, is then developed to solve this need. Technology push refers to the effect of research to drive development of the new product. It usually does not involve market research and often occurs by applying innovative technology to an existing product (Boehme, 1986; Bullinger, 1994; Brem and Voigt, 2009). Disappointment (Section 2.4) occurs when commercial expectations fail to meet performance and/or revenue expectations (Fenn and Raskino, 2008). A reality check is a necessity at the end of any hype and disappointment cycle. There are two possibilities; the first is renewed commercial interest which results in Gardner's slope of enlightenment with increased net benefits and motivation. The second possibility not mentioned in Gardner's model is the lack of any slope of enlightenment and/or a reversion to the status quo.

\subsection{Hype}

Pre-hype expectations for jatropha were limited to local and traditional medicinal use (Figure 2.1). While all parts of the jatropha plant i.e. leaf, bark, latex, root, and seeds are toxic they do have antimicrobial and blood coagulating properties that are of value for humans and animals (Heller, 1996). In many tropical and subtropical countries, jatropha is planted as hedges or living fences for land demarcation and/or as barriers protecting crops from browsing livestock (Kumar and Sharma, 2008; Brittaine and Lutaladio, 2010). The 
extracted oil has long been used to provide light in rural areas (Brittaine and Lutaladio, 2010) and in the production of soap.

\subsubsection{Hype: market pull}

Interest in jatropha increased with each hype cycle (Figure 2.1) to the point where the hype created by market pull was essentially driven by societal and economic concerns of limited oil reserves, and the expectation that extraction costs would continue to impact on the global price of crude oil. This concern fuelled the desire to reduce dependence on fossil fuels (Campiche et al., 2007; FAO, 2008; Al-Riffai et al., 2010; Moschini et al., 2012). In addition oil price instability due to regional conflicts and political turmoil in the Middle East and other oil-producing regions, were having negative impacts on the world economy (Campiche et al., 2007; FAO, 2008; Al-Riffai et al., 2010; Moschini et al., 2012). Environmental concerns over climate change and the need to reduce greenhouse gas (GHG) emissions further prompted many countries to reassess their bioenergy strategies as key elements in their efforts to mitigate climate change. Biofuels were seen as offering the potential for reducing GHG emissions (FAO, 2008). The claims and promotion of jatropha as a source of biodiesel were seen as a positive solution to the energy crisis problem. In addition to societal, economic, and environment concerns, the hype created by market pull was enhanced by government support in providing mandates, subsidies, and incentives designed to promote demand and create biodiesel market. This was particularly evident during energy crisis in 2000s.

\subsubsection{Societal, economic, and environmental drivers}

The societal and economic aspects of market pull for jatropha was mainly driven by the need to develop biodiesel as part of the energy crisis problem-solving. Jatropha was promoted to enhance socioeconomic development (Brittaine and Lutaladio, 2010) by creating employment, increasing revenues for poor rural farmers and offering energy self-sufficiency for small communities (Fairless, 2007; Van Eijck et al., 2014b; Fatimah et. al., 2015).

Jatropha was not seen as part of the food-versus-fuel debate because it was inedible and supposedly able to reclaim marginal and degraded soils (Reubens et al., 2011; Valdés-Rodríguez et al., 2013) without competing with food production, depleting natural resources or reducing ecosystem services (Francis et al., 2005; Fairless, 2007; Carels, 2009).

In Indonesia the concept of marginal land was broad covering degraded, underutilised, and neglected land. Combined with the claim that jatropha could flourish and be productive in dry and barren lands and could even improve soil conditions in degraded lands, the Indonesian Agency for Agricultural Research concluded in 2007 that 50 million hectares were suitable for jatropha growing (Gunawan, 2014). Maps were developed based on rainfall and altitude and used to support the belief that jatropha would be a good investment in marginal areas (Van Rooijen, 2014b). 
Jatropha was reported as being able to produce up to 12 tons of seed (Jones and Miller, 1993; Openshaw, 2000) which was equivalent to 3 tons of oil per hectare per year (Francis, 2012). Due to its toxicity jatropha is not browsed by animals allowing farmers to use the plant as living fences to protect food crops (Heller, 1996; Brittaine and Lutaladio, 2010). Other claimed advantages included jatropha's resistance to drought and pests, and its ability to grow with limited irrigation and agricultural inputs (Openshaw, 2000; Francis et al., 2005; Garcia-Almodovar et al., 2014). Jatropha offers a variety of potential by-products (Kumar and Sharma, 2008; Contran et al., 2013) such as jatropha seed cake which is a source of organic fertiliser rich in essential proteins. When detoxified it can be used as a high quality livestock feed (Openshaw, 2000; Martínez-Herrera et al., 2006).

Overall the production and use of jatropha biodiesel shows potential for reducing non-renewable energy requirements leading to reduced greenhouse gas emissions when compared with fossil diesel fuel (Ou et al., 2009; Achten et al., 2010b; Gmünder et al., 2012). The environment aspect of market pull was driven by the potential for the allocation of carbon credits through the establishment of small-scale reforestation projects (Van Rooijen. 2014b). Life cycle assessment (LCA) studies claimed that jatropha could be a promising crop for carbon sequestration (Achten et al., 2007), especially when grown on wastelands or degraded lands (Romijn, 2011) and had the potential to attract carbon credits under the clean development mechanism (CDM) (GEXSI, 2008; Ndong et al., 2009). Estimates concerning carbon capture from jatropha plantations varied substantially with age, management practices, and carbon content assessment (Romijn, 2011). In India for example, 3.5 year old jatropha at 1,667 plants per ha ${ }^{-1}$ would have an annual sequestration rate of approximately $0.9 \mathrm{t} \mathrm{CO}_{2} \mathrm{ha}^{-1} \mathrm{yr}^{-1}$ (Reinhardt et al., 2007; Romijn, 2011). While a similar planting density on degraded lands has a reported sequestration rate of $5.3 \mathrm{t} \mathrm{CO}_{2} \mathrm{ha}^{-1} \mathrm{yr}^{-1}$ (Wani et al., 2012).

Moreover the production and use of jatropha biodiesel or jatropha methyl ester (JME) in general show reductions in non-renewable energy requirement (e.g. net energy ratio, NER) and in GHG emissions or emission saving (e.g. global warning potential, GWP) (Ou et al., 2009; Achten et al., 2010; Gmünder et al., 2012) compared to fossil-fuels based. In India for example results show an $82 \%$ reduction in non-renewable energy requirement and a $55 \%$ reduction in GHG emissions compared to the fossil diesel fuel system (Achten et al., 2010b). In China however these results have been calculated at $75 \%$ reduction in nonrenewable energy requirement and a $49 \%$ reduction in GHG emissions (Ou et al., 2009).

A further motivation for jatropha biodiesel was the expectation that it would reduce erosion and retain soil moisture, especially as it could be grown successfully on marginal or degraded lands. An example of the environmental benefits of jatropha can be found in Ethiopia where for over 40 years jatropha has been used as living fences and hedges on contour lines across slopes and in gullies to conserve land and water and fight erosion (Portner et al, 2014). 


\subsubsection{Government support}

Government support comprised a combination of legislation, policies, subsidies and incentives, all designed to encourage investment from national, bilateral or multilateral sources (Jull et al., 2007). Many countries including Indonesia (Dillon et. at., 2008) introduced mandatory, voluntary, or indicative biofuel targets, together with specific subsidies (Hasan, 2012). By promoting jatropha through legislation, policies, and subsidies and in setting targets, governments were actively displaying commitment to the community and the environment (European Commission, 2007; Sorda et al., 2010; Rajcaniova et al., 2015).

It is important to understand that government actions may always be subject to political process and pressure from interest groups (Rajcaniova et al., 2015). This was most certainly evident in Indonesia (Affif. 2014; Simandjuntak, 2014). Vel et al. (2013) argues that policies are often influenced by a network of powerful entrepreneurs who influence or manipulate the policy process for personal gain. This belief is supported by previous research on agrarian change, state-society relations and local politics where societal change and policy implementation is considered simply as a technique between influential actors to gain mutual benefits within their networks'. For a more comprehensive overview of international biodiesel/biofuel policy and regulation the reader is directed to the following; FAO (2008), Sorda et al.(2010), Rajcaniova et al. (2015), and $\mathrm{Su}$ et al. (2015).

\section{Biodiesel policies and blending targets}

Many of the policies developed for jatropha biodiesel were based on claims that jatropha was the solution to the energy crisis. India and China for example developed biodiesel policies specifically for non-edible seed oils. In India, jatropha was regarded as suitable feedstock for production of biodiesel as it did not compete with food crops (Kumar and Sharma, 2011; Bandyopadhyay, 2015). In China where arable land was limited and populations dense, use of food-based crops for biodiesel was restricted (Weyerhaeuser et al., 2007) so jatropha was an alternative choice mainly to be planted on wasteland. In Indonesia, government interest focussed on the possibility of improving rural energy self-sufficiency and reducing the fuel-subsidy burden through the production of jatropha biodiesel (Fatimah et. al., 2015). In addition, this programme would foster job creation and poverty alleviation that came from energy self-sufficient villages (ESV).

The 2003 EU target of $5.75 \%$ share of biofuels in transport fuel by 2010 and $10 \%$ by 2020 (Directive 2003/30/EC) were perceived by investors as an opportunity to invest in biofuel production in developing countries (Von Maltitz et al., 2014) for import into the EU. Developing countries were interested in producing biofuels for their own markets as well. In 2003, the Indian government proposed a $5 \%$ biodiesel blending target beginning 2006-2007 aimed at planting jatropha in 0.4 million ha of wastelands, gradually raising it to $20 \%$ in 2011-2012 with 13.4 million ha (Government of India, 2003). Further the Indian Planning Commission anticipated that this would generate employment opportunity for rural areas (Ravindranath et al., 2011). 
In 2005, China initiated a renewable energy law to support biofuels by providing a set of directives encouraging the development of jatropha. This included national planting targets, blending targets, subsidies, tax relief or exemptions, and technological research and demonstration projects (Wang et al., 2010; Li et al., 2014b). The total jatropha planting target was 1.67 million ha on barren hills and wastelands over the next 10-15 years at Yunnan, Sichuan, and Guizhou of the Southwest China (Wu et al., 2010). Biodiesel blending targets ranged from $2 \%$ to $5 \%$.

In early 2006 the Indonesian government aimed to plant 1.69 million ha of jatropha (Dillon et al., 2008). In 2008 mandatory levels of biofuel consumption were introduced at $2.5 \%$ for 2010 aiming to reach $20 \%$ by 2025 (Dillon et al., 2008). The investments anticipated the creation of 100,000 skilled and up to 10 million unskilled jobs by 2009 (Dillon et al., 2008). Legowo (2008) reported that 121,000 plantation jobs had been generated in the jatropha industry by June 2008 .

\section{Subsidies for planting and/or oil processing}

In several countries governments introduced subsidies for planting and/or oil processing. It was intended that subsidies would offset the costs of production, thereby increasing supply and lowering market prices (Drabik, 2011) Subsidies were effective in motivating farmers to plant jatropha as it allowed them the opportunity to become involved without experiencing financial risk (Kumar et al., 2012; Van Eijck et al., 2014b). Subsidies for jatropha planting were for instance available in India (Axelsson et al., 2012), Southwest China (Weyerhaeuser et al., 2007), Mexico (Skutsch et al., 2011; Valdés Rodríguez et al., 2014), and Indonesia (Dillon et al., 2008).

In India, farmers were promised subsidies for purchasing and planting jatropha seedlings and direct financial support for land preparation, pitting and planting, irrigation, fertiliser and manure purchase, and pesticides (Axelsson et al., 2012). In China, the farmers received subsidies for each hectare of jatropha plantation (Wang, 2012), although only for the first year. Price guarantees for the purchase of jatropha seed were also available (Li et al., 2014b). Subsidies could also be obtained for the construction of jatropha refineries (Wang, 2012; Li et al., 2014b). Subsidies for jatropha in the first year were available in Mexico per ha planted as jatropha was classed as an afforestation species (CONAFOR, 2009). Free seeds and an offer of 120 minimum wages per year were on offer during 2008 and 2009, increasing to 135 minimum wages the next year. The support however was conditional on the establishment of at least four ha with 1,600 plants per ha and a survival rate of $70 \%$ during the first year (Valdés Rodríguez et al., 2014). In Indonesia in 2006 the government spent US\$ 860,000 on producing jatropha seeds for distribution. In the same year, US\$ 3.5 million was announced to be allocated to build five jatropha seedling facilities (Dillon et al., 2008). Subsidies were available for nursery establishment, planting, and fertilisers (Vel et al., 2013; Widjaya, 2014) and oil processing refineries (Van Rooijen, 2014b). 


\section{Incentives or other supporting instruments}

Incentives were implemented to encourage the production, use of jatropha through value added taxes, corporate taxes, and excise taxes as well as credit facilities or low-interest loans and loans for cultivation or for the construction of processing facilities (Jull et al., 2007).

In India in 2003 a package of tax reductions, credit provision through national banks that facilitated access to land was available for the development of jatropha or for contract farming schemes with smallholders (Lima, 2012). In China biodiesel was exempt from consumption tax and in 2008 it was announced that $90 \%$ of the income tax on biodiesel would be reduced. In addition if more than $70 \%$ of the raw material used was from plant oil or waste animal fat, the value-added tax would be refunded to producers (Wang et al., 2010). In 2006 the Indonesian government allocated US\$ 6.6 million for training to improve farming skills for producing jatropha seed (Dillon et al., 2008). In addition to this specific incentives relating to taxation and government charges were introduced to attract and motivate investors (Ariati, 2007). The biofuel programme in Indonesia in 2007 succeeded in receiving 67 contracts with an estimated investment value of US\$ 12.4 billion (Bromokusumo, 2007).

\subsubsection{Hype: technology push}

The technology push component of the jatropha hype refers to the research and development where the primary purpose was to enhance jatropha commercialisation. Technology push often starts with the development of an innovative technology and applying it to a product for marketing (Boehme, 1986; Bullinger, 1994; Brem and Voigt, 2009). The jatropha technology push was not only supported but as much invented by academia (Afiff, 2014), state-owned enterprise elite (Simandjuntak, 2014), government agencies, private companies, and engineering research centres (Widodo and Rahmarestia, 2008). The focus was primarily on research and development to improve the processing techniques, jatropha biodiesel properties and performance testing, developing standardisation, and engineering (see review in Koh and Ghazi, 2011; Atabani et al., 2013).

In 2004 jatropha biodiesel was used in India for vehicle tests covering 6,000 km (Ghosh et al., 2007a). In 2006 in Indonesia jatropha biodiesel cars covered a distance of 3,200 km as part of a promotion tour (Afiff, 2014). In each country the test drives using jatropha biodiesel and the huge media coverage of these events triggered widespread interest and enthusiasm (Afiff, 2014). At the international level in 2008 an Air New Zealand aircraft flew for two hours on a 50:50 blend of conventional jet fuel and jatropha oil. This raised hopes that jatropha oil might help reduce greenhouse gas emissions from aircrafts (Jha, 2008). Combined these events proved effective in convincing governments and interested parties to support, invest, and research jatropha biodiesel production (Afiff, 2014). 


\section{Oil processing}

Jatropha oil can be used directly as a fuel for lamps and stoves, however for use as biodiesel it needs a modified engine or blending with fossil diesel fuel or transesterification to JME (Nielsen et al., 2013). Improved jatropha oil processing technologies were developed to optimise extraction rates (Nielsen et al., 2013) and reduce free fatty acids (FFA) levels using a two-step pre-treatment process (Berchmans and Hirata, 2008), with $\mathrm{H}_{2} \mathrm{SO}_{4}$ acid catalyst (Tiwari et al., 2007). Alternative jatropha biodiesel transesterification processes included $\mathrm{KNO}_{3} / \mathrm{Al}_{2} \mathrm{O}_{3}$ solid catalyst (Vyas et al., 2009), and enzymatic (Tamalampudi et al., 2008), and ultrasonic processes (Deng et al., 2010). Research established optimum blending ratios (Sarghgin et al., 2007), which were tested in direct injection diesel engines (Kumar et al., 2003; Agarwal and Agarwal, 2007) to ensure compliance with biodiesel standards (Sarin et al., 2007; Atabani et al., 2013).

\section{Value adding beyond biodiesel}

The jatropha production chain has two basic end products, jatropha oil and a press cake by-product. Additionally the potential for jatropha value addition and niche marketing was proposed to support its commercial value. Technologies are already available to extend the production chain and utilise a variety of intermediate and end products such as biogas, soap, edible oils and even electricity (Haider et al., 2015) so the potential for jatropha was there to extend beyond the biodiesel market.

Jatropha seeds have been used as a purgative and the oil as a fish poison and pesticide. The seed husks can be used as cooking fuels, the branches, leaves and ashes to produce cooking salt and textile dyes and tannins. The leaves can be used as food garnish once steamed or stewed, while the bark is a source of wax. Jatropha can also be used to produce a soap that has very high anti-bacterial qualities. The seedcake is high in proteins but unable to be used as animal feed unless it is de-toxified. Finally all waste parts can also be used for biogas production (Karama, 2013).

Proteins extracted from jatropha seed/press cake or leaves can be utilised for cattle or poultry feed, proteinbased adhesives, or protein-based emulsifiers. Lestari (2012) showed that jatropha press cake proteins performed highly as surfactants, e.g. emulsifiers and foaming agents, and as paper adhesives. Jatropha leaf protein is a potential source of amino acids for animal feed, or as an intermediate for building blocks functionalising $\mathrm{N}$-containing chemicals. The valorisation of jatropha proteins could improve the total potential revenue per hectare of jatropha and increase the value of the seed. Further development of the value adding aspect of jatropha was seen as having the potential to attract farmers and investors. None of the mentioned options has made it into marketable products yet.

Concluding on the market pull and technology push the term discursive commodities' as proposed by Vel (2014a) comes to mind. The term is used for 'no action, talk only' commodities that bring benefits to proponents before or without actual trade in physical products. They have market value only as a result of the perception that science, technology, politics and business have created around them. These perceptions 
include land availability, high yielding varieties and seed oil content; high value by-products derived from press cake; and the potential for carbon credits. In essence jatropha hype exists only within the sciencepolicy discourse; which could become a source of high profit in the future.

So although there was strong vested interest in jatropha for different reasons supported by governments, universities, private companies, and NGOs, jatropha did not live up to expectations. The factors that promoted the hype in the first place were essentially the factors that contributed to the disappointment when they were evaluated. Government support in mandates, subsidies, incentives, and technology push factors such as oil processing and value adding effectively fuelled the belief that jatropha was a miracle crop and masked the reality that jatropha yields were not commercially viable, especially when cultivated on marginal lands.

\subsection{Disappointment: contributing factors}

The disappointment phase (Figure 2.1) was evident by a loss of confidence in jatropha over a relatively short period of time. Since 2010, the global consensus is that jatropha has been a failure (Kant and Wu, 2011; Nielsen et al., 2013). This disappointment has been documented for India (Ebrahim and Baker, 2012a; Kumar et al., 2012), China (Ebrahim and Baker, 2012b; Li et al., 2014b), Tanzania, the rest of East Africa (Kant and $\mathrm{Wu}, 2011$; Ebrahim and Baker, 2012c), and the Southern Africa (Slingerland and Schut, 2014; Von Maltitz et al., 2014).

Concerns over the value of jatropha as a miracle plant had already been raised in the 1990s with the failure of the Austrian-Nicaraguan project where jatropha genotypes 'Cape Verde' and 'Nicaragua' were planted in Nicaragua on a large scale. After three years and US\$ 3 million the plantings were deemed a failure and abandoned, primarily due to a lack of productivity (Nogueira, 2004). Weyerhaeuser et al. (2007) also found that jatropha was not the miracle everyone had hoped for. In 2007 a detailed analysis of jatropha strengths and weaknesses was presented by Jongschaap et al. (2007) downscaling the proposed yield expectations, especially in marginal lands. Jongschaap was further involved in an EU FP7 funded project 'Jatropha curcas Applied and Technological Research on Plant Traits (JATROPT)' that emphasised the need to improve plant characteristics by germplasm collection, breeding, developing and using new breeding tools (JATROPT, n.d.).

In essence there were six factors that contributed to the jatropha disappointment; policy and governance, economics, social, technology, logistical, and environment.

\subsubsection{Policy and governance}

Government policies and support for jatropha biodiesel were intended to reduce uncertainty and promote investment, by generating income for farmers, creating new jobs and improving the rural socioeconomic community. The situation of uncertainty did not lead to investigation of the claims related to the crops 
performance. Neither was there at any moment the acknowledgement that jatropha was not a confirmed technology just to be implemented, but should rather be approached as a learning process (Slingerland and Schut, 2014). Government support for jatropha biodiesel was largely approached as managing supply and demand so getting the balance wrong seriously impacted on the financial viability of the industry and burdened taxpayers with the bill (Weyerhaeuser et al., 2007).

While it might seem that governments and investors were very active in promoting jatropha, there was no long-term commitment, and no sanctions imposed for non-compliance to their promises. Under-developed biodiesel regulation and policies, late formulation of standards, and the absence of mandatory targets substantially contributed to the overall disappointment. In India and China, jatropha biodiesel targets were not mandatory and blending targets were introduced late (2011) while the renewable energy policy was implemented in 2005 (Li et al., 2014b). A similar mismatch in timing occurred in Mozambique (Slingerland and Schut, 2014). While slow or non-existence policies may have contributed to the disappointment (Wiggins et al., 2011; Li et al., 2014b), it was not always easy to align policies with ultimate outcomes.

In Indonesia, policy overlaps created confusion between ministers with outcomes opposite to that intended. For example, the policy from the Ministry of Energy and Mineral Resource was to drive biofuel utilisation to reduce fossil fuel use. However the 2013 Ministry of Trade policy focussed on low cost vehicles to stimulate the domestic automotive industry leading to an increase in vehicle numbers with a higher consumption of fossil fuels (Putrasari et al., 2016).

Wang (2008) concluded that the weak implementation of biodiesel subsidies was a problem. In India, jatropha biodiesel production was to receive subsidy and loan support (Government of India, 2003) and free seedlings (Axelsson et al., 2012), however many farmers were unable to participate. It was a similar situation in China where farmers seldom received their entitlements (Liu et al., 2012) with the majority of subsidy payments going to large enterprises. In Indonesia despite production policies and subsidies, and intense promotion of jatropha, it was only researchers, government officials, NGOs and broker companies, rather than farmers or plantation companies that were the major recipients (Vel et al., 2013).

A major expectation of the jatropha subsidies was employment and income generation, yet the extent of their contribution to rural development in particular was not obvious, especially when compared with other poverty alleviation and employment creation projects (Rajagopal, 2008). In China for example this lack of long-term financial support undermined any continuation of jatropha production at the farm level (Li et al., 2014b).

On a global scale up to 2011 jatropha project investment was estimated at around US\$ 270 million, invested in 97 projects worldwide; $41 \%$ in Asian projects, $37 \%$ in African projects; and $22 \%$ in Latin America and 
Caribbean projects (Wahl et al., 2013). It is clear that many of the contracts and investment policies and promises did not lead to actual investments.

\subsubsection{Economics}

Assessment of jatropha economic performance and feasibility highlighted the fact that profitability was marginal (Van Eijck et al., 2014a). This was due to poor yields, high production costs, low fossil fuel price (Van Eijck et al., 2014a), and a poor supply chain (Jupesta et al., 2011; Castro Gonzáles, 2015). This was further compounded by a lack of improved commercial varieties available to farmers (Weyerhaeuser et al., 2007; liyama et al., 2013).

Low yields were a common problem in all countries. In India, yields varied from $0.4 \mathrm{t} \mathrm{ha}^{-1}$ to $0.6 \mathrm{tha}^{-1}$ for rain-fed plantings to $2 \mathrm{t} \mathrm{ha}^{-1}$ to $2.6 \mathrm{t} \mathrm{ha}^{-1}$ for irrigated plantings. Yield differences for no fertiliser and $60 \mathrm{~g} \mathrm{~N}$ per tree application was $0.19 \mathrm{t} \mathrm{ha}^{-1}$ and $0.43 \mathrm{t} \mathrm{ha}^{-1}$ respectively (Gmünder et al., 2012). In China yields from jatropha planted on marginal lands were only around $0.29 \mathrm{t} \mathrm{ha}^{-1}$ (Weyerhaeuser et al., 2007) while overall annual production was about $1.5 \mathrm{t} \mathrm{ha}^{-1}$ (Wang et al., 2011). In Indonesia, jatropha yield varied from as little as 0.1 to $1 \mathrm{t} \mathrm{ha}^{-1}$ (for details see Chapter 4 ).

Land and labour resources also impacted on opportunity costs causing biased profitability expectations (Van Eijck et al., 2014a). Jatropha production is maintenance intensive and labour requirements and costs were often underestimated, particularly when yields were low (Borman et al., 2013). This was irrespective of tree age (Gasparatos et al., 2012). Jatropha was reported to be resistant to pests, although the crop succumbed in many projects and required spraying (De Jongh and Nielsen, 2011; Van Eijck et al., 2014b), as well as weeding if good growth was to be expected (Everson et al., 2013). Transport costs for jatropha projects located in remote areas when combined with low yields from scattered farmers were often underestimated (Arndt et al., 2012).

It was thought that the low profitability status of jatropha could only be justified if the CDM on the JME or jatropha oil price was included; however even this was doubtful. In India, Ariza-Montobbio and Lele (2010) determined that a minimum of $2.5 \mathrm{t} \mathrm{ha}^{-1}$ was required to make jatropha viable. They admitted however that their economic analysis did not include opportunity cost for land which would make the break-even point higher. Van Rooijen (2014b) investigated NGO funded jatropha projects on 'marginal lands' in Flores, Indonesia. The direct income from selling jatropha seeds was low, and without the anticipated income from carbon credits, farmers preferred to cultivate more productive crops. The conclusion reached was that the sustainability of such projects is questionable when their economic feasibility is dependent on the future financial value of a legally constructed commodity like carbon credits.

Price competition between biodiesel and fossil diesel fuel was also a major factor, especially where governments subsidised imported fossil fuel. Between 2000 and 2008 the global price of crude oil 
quadrupled only to decline suddenly, so it is easy to see why jatropha biodiesel struggled to be competitive (Wahl et al., 2013; Castro Gonzáles, 2015). In China, the price of fossil diesel fuel was subsidised by the state and remained relatively low compared with international diesel prices (GSI, 2008). India also subsidised fossil diesel fuel (Kumar et al., 2012). In China and India, fossil diesel fuel was about US\$ 0.6 (Wang et al., 2011) and US\$ 0.4 (Kumar et al., 2012) less respectively than jatropha biodiesel. In 2008 approximately $60 \%$ of Indonesian fossil fuels were subsidised (Dillon et al., 2008). It was not until after the 2008/10 disappointment that fuel subsidy reforms began to take place in countries such as China, India, and Indonesia; however this has done little to restore confidence in attractive prices for jatropha based biodiesel.

In addition there was no defined market or market strategy in many countries for jatropha seed and oils (Axelsson et al., 2012). Jatropha was essentially driven by government objectives rather than any specific demand for biodiesel. In many cases even when farmers did have oral or written purchase agreements and were able to harvest, they often did not understand market structures, possibilities or complexities. This resulted in farmers being unable to sell their harvest and being left with a miracle crop that struggled to progress beyond the planting stage (Axelsson et al., 2012).

\subsubsection{Social}

Three social aspects of the jatropha disappointment are discussed in this section; land and food security, labour and employment, and rural development.

\section{Land and food security}

Land and food security issues became important factors in jatropha development. During the hype, jatropha which is inedible was considered the most suitable energy crop as it would not compromise food security when planted on wastelands or marginal lands (Weyerhaeuser et al., 2007; Wu et al., 2010). Often the allocation of wastelands were however made without considering or checking the purpose of these wastelands which had a long history as traditional suppliers of food, fodder, fuel wood, building materials and other locally important resources (Rajagopal, 2008).

In several countries the promotion of jatropha was used by companies as an excuse to acquire or occupy (grab) large tracts of land (Cotula et. al. 2008). For example in Mozambique, governments were reported to facilitate land leases to large companies with the aim of reaping benefits from investments. These were often implemented without safeguarding or respecting the rights of smallholders or pastoralists not necessarily equipped to negotiate or defend their rights.

Fuzzy land ownership patterns, conflicts between customary and legal rights combined with a lack of land tenure security all made it possible for governments to claim large tracts of such lands for jatropha (GRAIN, 2008; Cotula et. al. 2008; Agoramoorthy et. al., 2009). In India there were no clear mandates available for the demarcation of non-cultivable wasteland feasible for jatropha plantations (Kumar et al., 2012). In China 
(Wu et al., 2010) and Indonesia (Van Rooijen, 2014b) although lands allocated to jatropha were barren grasslands, these were often used by farmers for livestock grazing. Not all wastelands were suitable for jatropha. Rocky and waterlogged soils (Ebrahim and Baker, 2012a), land too steep or with high fire risks, or with topsoil less than $10 \mathrm{~cm}$ deep (Weyerhaeuser et al., 2007; Ebrahim and Baker, 2012b) were often included during land evaluation. In India for example, only $10 \%$ of the original wasteland estimates were suitable for jatropha (Ebrahim and Baker, 2012a).

Despite the assurances by the jatropha advocates, very real concerns about the impacts of jatropha on food security in the developing world began to emerge. FAO (2006) defines food security as existing when 'all people, at all times, have access to sufficient, safe and nutritious food that meets their dietary needs and food preferences for an active and healthy life'. If land suitable for food crops is used to grow jatropha, then it impacts on food security (Green, 2009). For example, $82 \%$ of the farmers in Tamil Nadu and Andhra Pradesh in India planted jatropha on land previously used for cultivating food crops (Ariza-Montobbio and Lele, 2010; Axelsson et al., 2012). Effectively jatropha was competing directly with and replacing groundnut, their food and cash crop and source of edible oil (Ariza-Montobbio and Lele, 2010).

Increased yields and reduced production costs associated with fertile land serves as an economic incentive to plant jatropha on what should be land dedicated for food crops (Green, 2009). Land issues were often fuelled by economic incentives, promises of higher incomes, and pressure from the district authorities to substitute jatropha for food crops (Axelsson et al., 2012). Countries with abundant land but poor in other natural endowments found it difficult to ignore the new developmental opportunities jatropha offered (Cotula et al., 2008). Again in Tamil Nadu for example, $50 \%$ of villagers reported that the introduction of jatropha had reduced available cattle feed supplies (Ariza-Montobbio and Lele, 2010; Ariza-Montobbio et al., 2010). The allocation of land is a complex subject and has raised the issue that a complete ban on using arable, irrigated land for jatropha to avoid conflict between food requirement and fuel requirement is a real possibility (Kumar et al., 2012).

\section{Labour and employment}

Jatropha has often been promoted as crop for the poor (Brittaine and Lutaladio, 2010; Kuntashula et al., 2014) able to provide income and reduce household expenses in remote rural areas which would ultimately reduce rural-urban migration (Muok and Källbäck, 2008). In reality these claims have relied on optimistic assumptions (Achten et al., 2008) of jatropha projects as new sources of rural employment and as a reliable cash crop (Francis et al., 2005). Jatropha was expected to offer farmers an added value when used to provide energy where there is no electricity. For example, some initiatives focused on producing and selling soap made from jatropha oil (Favretto et al., 2012).

Labour requirements for jatropha production and harvesting are high as there are limited mechanisation opportunities available. While many processes can be delayed, crop maintenance is crucial for yield so 
cannot be delayed (Van Eijck et al., 2014a). Lack of yield uniformity (Kant and Wu, 2011) leads to the need for multiple harvesting rounds increasing labour costs. It was always inevitable that labour shortages would occur and lead to conflicts with food crops, especially if labour availability competed with labour demand for subsistence agriculture (Gasparatos and Stromberg, 2012).

While labour requirements of jatropha plantations contributed substantially to rural employment possibilities they came at a cost. For jatropha to be profitable it was important that a balance be established between profitability for a company and reducing poverty and improving rural livelihoods, a fact that would likely be determined by the minimum legal wage (German et al., 2010; Bormann, 2011). In Ghana jatropha had some success in creating employment; however the jobs were always short-term and seasonal (Acheampong and Campion, 2014). In Mozambique less than $2 \%$ of the anticipated 150,000 jobs were created between 2008 and 2011 (Slingerland and Schut, 2014).

In India it was expected that jatropha would generate employment for the poor and under privileged groups, especially where the impact of forest degradation and loss of natural resources was high (Government of India, 2003). The Indian biofuel policy programme aimed to produce $20 \%$ of total diesel demand from crops by 2017 . To reach this target some 35 million acres of tribal wasteland would need to be cultivated with jatropha alone. These so called wastelands accommodate $25 \%$ of India's rural population who depend on them for subsistence living. The associated wilderness areas contain large numbers of endemic and endangered flora. Policy implementation would result in large numbers of people being displaced and biodiversity lost (Agoramoorthy et al., 2009). It is hard to imagine an effective balance able to combine employment opportunities with current subsistence occupation and biodiversity functions of these wastelands.

\section{Rural development}

The possibility for jatropha to bring positive benefits to rural farmers was promising and met with enthusiasm. These benefits included improved access to electricity, reduced health problems associated with using wood for cooking, and access to water through biodiesel water pumps (Practical Action Consulting, 2009). Combine this with promises of schools, roads, and clinics for the people mobilised as labourers for large scale jatropha plantations in remote areas or in return for the use of farmers' lands for jatropha plantations (Slingerland and Schut, 214), it is easy to see the attraction. The problem was that many communities were deceived by these promises (Acheampong and Campion, 2014). In Tamil Nadu - India for example local livelihoods were lost when crops failed, investments failed and companies did not honour their commitment to purchase the jatropha seed (Ariza-Montobbio and Lele, 2010; Ariza-Montobbio et al., 2010). In Indonesia, the promise of energy self-sufficiency, improved production efficiency and people's welfare from small scale jatropha plantings did not eventuate (Afiff, 2014; Fatimah et al., 2015). 
Smallholders were often depicted as victims of land 'grab' (Cotula et. al., 2008) and in many cases this is justified, however there were occasions where they benefited from the incentives offered for planted jatropha (Widjaja, 2014; Gunawan, 2014). In South Sulawesi, Indonesia, many farmers joined a jatropha scheme by submitting photocopies of their land certificates to intermediaries to obtain a share of the 'incentives' without any intention to grow jatropha. They did not feel any loyalty or moral obligation towards the projects that would also provide benefits to all involved (Widjaja, 2014). In Gunungkidul on Java, Indonesia, farmers also participated in jatropha projects to receive incentives, which they received before the real planting started. Some farmers did not even plant the seedlings whereas most planted trees were already uprooted after one year due to disappointing performance. Farmers maintained a few trees well in sight of visitors to give the impression that the project still existed and to keep the door open to any new government projects in the future. 'The promotion of jatropha did not lead to its cultivation but confirmed farmers' strategy of using government programmes for generating income in the form of incentives' (Gunawan, 2014). While these comments may be true for some farmers the ultimate reality is the need to put food on the table or money in the pocket through actual cultivation of food and/or cash crops.

\subsubsection{Technology}

Technology during the jatropha hype concentrated on oil processing and value adding; however little work was done to maximise oil extraction rates and quality or to explore the potential for value adding which were aspects that were co-responsible for the disappointment.

\section{Oil processing}

The process of extracting jatropha oil from the seeds by crushing is well known; however there is always a trade-off between the acceptable complexity, costs of technology and the required oil quality, especially when improper handling and inappropriate storage conditions are involved (Berchmans and Hirata, 2008). Despite the advances that have been made in jatropha oil research there were still concerns over oil quality, quantity, availability and economics, irrespective of whether it is a domestic, national or international market (Wickens, 2001). In India for example little attention was paid by research and development laboratories, oil sector companies or engine manufacturers for using jatropha biodiesel in existing diesel engines (Kumar et al., 2012).

Technical issues for jatropha biodiesel refining include the use of acidic and alkaline catalysts which have the potential to cause environmental pollution (Min and $\mathrm{Du}, 2010$ ), while the development of biocatalysts for large scale production was limited (Li et al., 2008). In China a major problem for farmers who did produce seed was a lack of biodiesel refining capacity due to financial concerns (Weyerhaeuser et al., 2007). For jatropha biodiesel to be competitive the economic scale of seed production and refining will need to be determined. Farmers who produce a few tons of jatropha seeds on scattered marginal land face challenges in finding downstream processors willing to purchase their seed. To overcome this some form of vertical 
integration or cooperatives would be necessary. For some downstream processors buying small quantities of biodiesel or alternatively building small refineries did not make economic sense (Weyerhaeuser et al., 2007).

\section{Value adding beyond biodiesel}

While biodiesel is the primary objective for jatropha, technologies are available to extend the production chain and utilise a variety of intermediate and end products such as biogas, soap, edible oils, glycerol and even electricity (Haider et al., 2015). While there is a diverse range of products potentially available for niche marketing, little research has been initiated in this area and there are no established markets (Vel, 2014a). Interest has been shown in the production of fertiliser or biogas from jatropha residues (Jongschaap et al., 2007), and in the fruit exocarp as a fuel for fast-cooking stoves (Grimsby and Borgenvik, 2013) and for the production of soap (Favretto et al., 2012). Jatropha has important traditional, non-monetary functions such as medicinal uses and as living fences and grave markers (Heller, 1996; Orwa et al., 2009). Kuntashula et al. (2014) raises an interesting point in that traditional use and commercial potential may not necessarily be compatible. Value adding that increases the commercial attractiveness of jatropha needs to be weighed against the environmental impact. Palm oil is a classic example of an introduced species that has major negative impacts on the environment. While jatropha oil and associated by-products can be directed toward various applications, it will take serious research and innovation before farmers will benefit (Hunsberger and Alonso-Fradejas, 2016).

\subsubsection{Logistics}

There are two aspects relevant to the jatropha disappointment that will be discussed in this section; supply chain and infrastructure.

\section{Supply chain}

The lack of a defined supply chain structure that addressed the processes from the field to the consumer was a contributing factor to the jatropha disappointment (Trienekens et al., 2003; Bijman et al., 2009). A supply chain needs to integrate suppliers, manufacturers, distributors, and retailers who work together to acquire raw materials, convert these raw materials into specified final products, and deliver the final products to retailers (Beamon, 1998). In basic terms the jatropha biodiesel supply chain would compromise seed production and harvest through to oil production and distribution through to the end user (Goswami and Hazarika, 2016).

In India the supply chain was a major constraint as problems were experienced with insufficient seed production, poor seed processing and no established markets (Goswami and Hazarika, 2016). In China insufficient quantity and quality of non-agricultural and non-forest land, facilitation between smallholder farmers upstream and the oil and biodiesel processing industries, economics of growing and processing jatropha, government investment and the lack of research strategies were all seen as limiting factors (Weyerhaeuser et al., 2007). In Indonesia, conflicts of interest between the broader national agenda and specific personal gain contributed to the jatropha demise (Afiff, 2014) through poor prices, unfair contract farming agreements and the lack of genuine buy-back mechanisms. This was further compounded by 
governments who refused to acknowledge the factors driving the jatropha hype and their implications (Pradhan and Ruysenaar, 2014), effectively ignoring the fact that jatropha was a new crop and there was a need for a supply chain and associated infrastructure development.

\section{Infrastructure}

A lack of infrastructure support contributed to the jatropha disappointment as it seriously impacted on financial viability. Infrastructure for jatropha biodiesel involves the seed producer to the refinery, distributor, and market. It includes such aspects as irrigation, transportation, communication, storage systems, waste systems, machinery or refinery systems, and extension services.

In India for example difficult terrain and remote locations, and poor infrastructure increased seed delivery cost. The establishment of small, local processing plants were needed to reduce transportation and storage costs, yet finding investors to build these was a problem (Goswami and Hazarika, 2016). If constructed these small refineries still faced difficulties with securing reliable seed supplies. In China some state-owned energy companies delayed construction of refineries (Liu et al., 2010) due to financial concerns (Weyerhaeuser et al., 2007). In Indonesia jatropha development also suffered from inadequate infrastructure which discouraged investors and made it difficult for jatropha biodiesel production to meet the goals set by local governments for the benefits of their local communities (Amir et al., 2008).

\subsubsection{Environment}

The environmental impact of jatropha was an important factor in the jatropha hype disappointment. Jatropha environmental performance was evaluated and reviewed during its life cycle using the LCA approach (Van Eijck et al., 2014a; Jingura and Kamusoko, 2016). The objective was to identify the environmental impact of jatropha production and provide future direction for improvement (Achten et al., 2010b).

In Section 2.3.1.1 the examples of JME LCA on energy and GHG balance show reductions in non-renewable energy requirement or consumption and GHG emissions compared to fossil diesel fuel. While the LCA procedures are standardised (ISO 14044:2006), the results were influenced by former land use, planting density, cultivation intensity, processing efficiency, and final products and by-products allocation (Achten et al., 2010b; Van Eijck et al., 2014a). Prueksakorn and Gheewala (2008) calculated jatropha energy distributions at $60 \%$ for cultivation and $40 \%$ for oil processing. Ndong et al. (2009) and Achten et al. (2010b) however determined the energy distribution at $12 \%$ for cultivation and $88 \%$ for fuel processing. The differences between Prueksakorn and Gheewala (2008), Ndong et al. (2009), and Achten et al. (2010b) highlights the difficulties associated with calculating energy distribution and the need for more research.

Cultivation and fertiliser use were the primary contributors to GHG emissions, calculated at $52 \%$ by Ndong et al. (2009) and $84 \%$ by Achten et al. (2010b). $\mathrm{N}_{2} \mathrm{O}$ emission from fertiliser is the major contributor (Reinhardt et al., 2007; Achten et al., 2010b; Van Noordwijk et al., 2016), with a greenhouse effect per 
molecule that is 320 times that of $\mathrm{CO}_{2}$ (Zah et al., 2007). In the biodiesel production stage, transesterification accounts for $11 \%$ (Achten et al., 2010b) and $17 \%$ (Ndong et al., 2009) of total emissions. Land use change, where forest or woodland areas for example are converted to jatropha, can substantially increase GHG emissions (Bailis and McCarthy, 2011; Romijn, 2011) as can be seen from the biofuel carbon debts as identified by Fargione et al. (2008).

Despite the potential for jatropha to reduce fossil energy consumption and GHG emissions it is important to acknowledge the environmental effects of acidification and eutrophication and to understand that trade-offs likely take place (Reinhardt et al., 2007; Achten et al., 2010b; Gmünder et al., 2010). Ultimately the objective should be to minimise the environmental effects whilst maximising commercial potential.

\subsection{Reality check}

Reality checks are an essential part of any post hype and disappointment analysis. Potentially there are two basic outcomes. The first is a renewed commercial interest, while the second is reversion to traditional and local use that existed prior to the hype. Renewed commercial interest is only possible if there remain interested parties who continue to work to resolve the commercial deficiencies in jatropha. The primary objective will be to develop jatropha from a wild crop into commercial varieties able to produce high yields under controlled management.

It is clear that after the disappointment of the 1945-1950 and 1980-1990 hypes that interest in jatropha reverted back to the local/traditional level (Figure 2.1). Over time it seems that the disappointment aspect of the jatropha hype was forgotten and the cycle repeated itself. Contributing to this may be that the scientific literature generated during the hype phase is not matched by an equivalent documentation of the subsequent disappointment - something that this chapter tries to do.

While some diehard enthusiasts continue with jatropha, and may even experience some benefits, they are a minority. These hype and disappointment cycles should perhaps not be viewed as failures; rather they should be seen as a normal part of any new crop development.

There are however costs to society that need to be addressed, especially for the future development of other new crops. Lost investments, abandoned plantations that result in unclear future land use, landownership and unemployment, abandoned infrastructure of oil extraction and bio refinery and waste of taxpayers' money spent on subsidies that did not generate any public goods such as the expected decrease in GHG emissions to mitigate climate change are some of the associated costs. As our understanding of jatropha and the necessary technology grows, performance potential increases. 
While it might appear that that once again jatropha has reverted back to the traditional and local use level there may still be a positive future for jatropha. Whether jatropha will maintain the status quo or once again enter into Gartner's plateau of productivity, only time will tell.

\subsection{Conclusions and lessons learnt}

It is obvious that jatropha has some potential as a biofuel crop as is evident by the fact that it has been through multiple hype cycles. It is unfortunate that these hype cycles have been followed by disappointment. The disappointment observed during the first hype could simply be attributed to a very specific need that was no longer required. The second and subsequent cycles share many similarities and resemble other miracle new crops, such as Argania spinosa and Moringa oleifera (Achten et al., 2014).

At the national level the interest in jatropha was driven by societal and economic concerns of limited oil reserves and the expectation that extraction costs would continue to impact on the global price of crude oil. In addition jatropha would provide income and improved socio-economic conditions for rural areas (Brittaine and Lutaladio, 2010; Kuntashula et al., 2014). Jatropha was said to represent a source of clean, renewable energy with advantages at all levels from national to individual households (Achten et al., 2008). Jatropha would not impact on food security and the food versus fuel arguments due to its toxicity and its ability to produce on marginal lands (Van Rooijen, 2014a, b). Jatropha ia also claimed to have a place in controlling erosion (Reubens et al., 2011), enriching soils, promoting water infiltration and reducing flooding (Orwa et al., 2009; Brittaine and Lutaladio, 2010; Valdés Rodríguez et al., 2014; Van Rooijen, 2014b), storing carbon (McGrath, 2014) and in earning carbon credits (Van Rooijen, 2014b).

It is clear that many involved in the jatropha hype were able to relate to the individual claims or were easily swayed by the propaganda. While there may be some validity to certain individual claims, this does not explain the circumstances that led to the hype, especially given that trade-offs might be considered. There is no dispute that biodiesel produced from jatropha has the capacity to replace fossil diesel, but what are the costs both financially and environmentally, and will it really lead to lower GHG emissions when cultivation practices and direct or indirect land use change are taken into account? In the absence of improved varieties it is unlikely that jatropha will ever produce high yields in marginal locations. Jatropha is no different to any other crop as it needs water and nutrients to grow, develop and produce fruits. Thus despite its toxicity jatropha does compete with food crops.

At the local level farmers already grew jatropha as a fence to protect food crops from animals and as an energy source for improved food processing and storage (Achten et al., 2010c; Brittaine and Lutaladio, 2010). Their aim now was to produce jatropha seed for sale and ultimate conversion from jatropha oil to biodiesel. At a household level, jatropha pruned branches and seed hull biomass have long been used as fuelwood or charcoal for cooking and the oil used for lamps (Heller, 1996; Achten et al., 2010c; Brittaine and Lutaladio, 2010). The expectation now was that production of jatropha seed for biodiesel use would be 
instrumental in reducing rural-urban migration (Muok and Källbäck, 2008) and improving socio-economic conditions. Unfortunately many of the claims made about jatropha were based on optimistic assumptions, especially regarding yield (Achten et al., 2008). Farmers were misled into believing that jatropha was a reliable and viable cash crop (Francis et al., 2005) and that there was potential for value adding.

Government propaganda, academia and university research and its funders, private companies, and NGOs were all instrumental in fuelling the jatropha hype. It seems that early warnings by certain scientists (Jongschaap, 2007) to policy makers, companies and NGO's were largely ignored, buried or overtaken by the wave of hype. This shows the complex two-way relationship between evidence and policy that is linked to how research is funded and how its results are used. Biofuel policy with jatropha as an important component was promoted by many governments and a process of policy based evidence making rather than evidence based policy making took place. Research was commissioned and pieces of evidence were selectively picked in order to support or justify the policy which had already been decided upon. In a situation of evidence based policy making the policy would have only been formulated after the establishment of objective evidence through rigorous scientific methods.

From our review it is clear that jatropha was introduced without a comprehensive understanding of crop development and performance and market supply and demand. Market pull factors of society, economy, environment and government mandates, subsidies, land allocation, and investors as well as the technology push factors of oil processing and value adding were not sufficiently well prepared or developed and implemented to foster commercial development.

There was no long-term commitment and legal framework to protect industry participants. Jatropha yields were low and unreliable and there were few improved populations available. Low yields were compounded by high production costs and price disparities with subsided fossil diesel fuel. Jatropha was allocated to marginal or degraded land without first considering common-property resources and the loss by locals of access to food, fodder, and fuel wood on those lands caused conflicts and food insecurity. Labour demand for jatropha is high and seasonal and when the fact that it coincides with labour demand for food crops is factored in the situation becomes complicated. Inefficient and ineffective supply chain structure from field to consumer was another defining factor in the jatropha disappointment. Infrastructures such as refinery, irrigation, transportation promised by government or investor did not materialise.

Technology issues relating to oil quality such as viscosity, oxidation during storage, extraction efficiency, or value adding of seed cake detoxification for cattle or poultry feed are still at the laboratory stage of development. It was soon realised that contrary to popular belief jatropha biodiesel production could cause negative environmental impacts depending on the land use change and on cultivation management and that trade-offs would need to be considered and factored into any commercial development. 
The lessons learnt from the jatropha experience provide valuable insight into the future of jatropha and any similar 'silver bullet' crops that may emerge in future discussions. The difficult part is to know where to start as one of the aspects associated with hype seems to be the irrationality of all involved. I argue that while irrationality might be a factor it as much wishful thinking for public goods on the part of some and opportunistic behaviour for personal gain on the part of others. It is inevitable that no matter how much caution is advised there will always be some who will ignore the signs and are willing to face the risks in an effort to capitalise on the rewards associated with early entry. From work in the JARAK programme it is clear that some took advantage of the circumstances that accompanied the hype (Vel et. al., 2013, 2014a,b; Afiff, 2014; Simandjuntak, 2014; Widjaja, 2014; Gunawan, 2014; Van Rooijen, 2014). Vel et. al. (2013) speaks of the interests of a network of powerful policy entrepreneurs that influenced the policy process supporting investments in jatropha, allowing actors to gain mutual benefits within their networks. Companies and NGO's were able to access subsidies or bank loans and investment funds to develop large or smallholder jatropha plantations while brokers successfully managed to get a piece of the subsidy cake (Vel, 2014a). Researchers were not left out, able to access numerous research funds (Vel et. al., 2013). Smallholders were mostly depicted as victims of land 'grab' (Cotula et. al., 2008) but for some the opportunity to participate in the subsidies on offer was too tempting (Widjaja, 2014; Gunawan, 2014).

For jatropha to ever be successful there must first be well performing, high yielding varieties available. Next to this there must be secure financial and technical support and market access designed to foster energy development and improved socioeconomic conditions. Only then will there be the confidence necessary to adopt new crops and crop management systems. Our examples have highlighted the different and sometimes converging interests in the development of jatropha as a new crop. This is despite evidence showing jatropha's poor performance, and the differences in the policies, laws and regulations between countries and the extent to which they are able and willing to enforce the compliance.

At this stage with the uncertainty that surrounds jatropha yields and social benefits, jatropha will remain a minor player in tropical landscapes for a variety of uses, but for the reasons elaborated above it should not be promoted as a smallholder or plantation crop. Only when all concerns have been satisfied will we see improved jatropha socioeconomic conditions and an environment conducive to a successful jatropha biodiesel industry.

In Chapters 3 to 6, I address the biophysical factors of the jatropha hype and disappointment by advancing our understanding of jatropha plant characteristics, systems productivity, and management practices. 
Chapter 3 Tree or shrub: a functional branch analysis of Jatropha curcas $\mathbf{L}$.

This chapter has been published as:

Tjeuw J, Mulia R, Slingerland M, Van Noordwijk M. (2015) Tree or shrub: a functional branch analysis of Jatropha curcas L. Agroforestry Systems 89 (5): 841-856. 


\begin{abstract}
Jatropha is an oil-bearing semi-evergreen shrub or small tree with potential as a source of sustainable biofuel, yet information regarding vegetative and fruit biomass in relation to plant architecture is lacking. Research conducted in Indonesia used the tree based Functional Branch Analysis (FBA) model as a non-destructive method to estimate above and belowground biomass, and plant architecture. The FBA utility for shrubs was unknown and required modification. This research used destructive measurements to validate modifications to the FBA model that included sub-categorisation of the tapering coefficient for twig, branch, and wood diameter classes, and addition of a fruit load parameter in the distal link. The modified FBA model confirmed jatropha to be a shrub rather than a tree, producing variable estimates for aboveground biomass. This variation was due to morphological plasticity in the length-diameter relationship of the branches that diverged from fractal branching architecture. Fruit biomass variation between replicates was not well estimated and total proximal root diameter was a poor predictor of total root biomass, due to the proximal roots having enlarged water storage structures that do not follow fractal branching assumptions. Jatropha fruit was shown to predominate on twigs with a diameter between $0.9 \mathrm{~cm}$ and $1.4 \mathrm{~cm}$. Understanding the correlation between fruit development and plant architecture will be necessary for fine-tuning the FBA model for future commercial breeding and selection. The high degree of morphological plasticity displayed by jatropha requires consideration when determining plant biomass.
\end{abstract}

Keywords: Aboveground biomass - Allometry - Belowground biomass - Functional branching architecture Proximal root - Stem diameter 


\subsection{Introduction}

Jatropha is a semi-evergreen shrub or small tree with oil-rich seeds, belonging to the Euphorbiaceae (Divakara et al., 2010). In Indonesia, there is disagreement over whether jatropha is a tree or a crop. Foresters consider jatropha a crop or a plantation crop at best, while agronomists consider it a tree. The disagreement occurs because jatropha has a range of phenotypes; shrub-like, multi-stemmed growth habits with height $<5 \mathrm{~m}$, and tree-like, single-stemmed growth habits with height $>5 \mathrm{~m}$ (Sunil et al., 2013). This problem is not restricted to jatropha as Scheffer et al. (2014) found that $9.2 \%$ of the tree species assessed were classified as shrubs in the TRY (plant traits) database.

Jatropha is of interest for sustainable biofuel production, for socio-economic improvement, and for wasteland reclamation in tropical semiarid regions (Achten et al., 2010d; Divakara et al., 2010). Jatropha has been claimed to grow in marginal areas, without competing with food production and is viewed with hopes of providing carbon credits (Divakara et al., 2010; Wani et al., 2012). Many of the envisaged benefits have not materialised. Yields of $12 \mathrm{tha}^{-1}$ for example have been claimed and global predictions showed yields of only $5 \mathrm{tha}^{-1}$ (Achten et al., 2014). The problem is that expectations were not based on field performance and validated scientific knowledge (Edrisi et al., 2015). Although uncertainties remain, knowledge gaps are being filled as is evident by the fact that actual measured yields vary from $<0.5 \mathrm{tha}^{-1}$ to $2 \mathrm{tha}^{-1}$ (Edrisi et al., 2015). However an understanding of jatropha growth and reproductive biology in combination with breeding for available commercial high yielding planting material, optimum management practices, and suitable growing environment are still lacking (Achten et al., 2014; Edrisi et al., 2015).

To capitalise on the commercial potential of jatropha, basic understanding of plant structure, function, and biomass allocation is required. Biomass and fruit production follow from quantitative relationships between plant size and growth (Niklas, 1993). Empirical approaches include relationships between dimensional variables such as tree height and stem diameter, leaf area, weight and volume (Lacointe, 2000). Allometric equations can be generated from destructive measurements of tree component biomass as dependent variables with easily measured independent variable such as stem diameter at breast height (MacFarlane et al., 2014).

Plant-based models (PBM) (Vos et al., 2010), functional structural plant models (FSPM) (De Reffye et al., 2009), and functional branch analysis (FBA) or fractal branching models (Van Noordwijk and Mulia, 2002) have been used to quantify growth and biomass. PBMs view plant growth as a function of factors such as light, temperature, nutrients, water and ambient $\mathrm{CO}_{2}$ and their impact on leaves, stems and roots (Vos et al., 2010). PBMs use defined rules to simulate the physiological process and growth partitions to determine biomass. A limiting factor for PBMs is a lack of feedback between plant growth and plant architecture operating at the phytomer level such as seen in FSPM. In FSPM a phytomer or growing unit (GU) is defined as having one internode, one or more leaves, one or more axillary buds and possibly flowers that form an 
axis or shoot (De Reffye et al., 2009). FSPM is a virtual plant model based on plant architectural models of Hallé et al. (1978), mathematic models and the Lindenmayer L-System (Prusinkiewicz, 2004). FSPM views the plant as a set of phytomers with plant architecture used to integrate environmental responses with feedback between biomass production and biomass partitioning for both development and growth (Vos et al., 2010).

The FBA model (Van Noordwijk and Mulia, 2002) is a compromise between the PBM and FSPM approaches and uses the 'pipe-stem model' theory of fractal geometry of simple tree branching architecture. The pipe model hypothesis is that the cross-sectional area (sum of squared diameters) of branches is equal to that of the preceding stem or branch. FBA models produce equation coefficients that relate aboveground tree biomass to the stem diameter at breast height $(\mathrm{DBH})$ or root biomass to proximal root diameter (Van Noordwijk et al., 1994). This eliminates, or at least reduces, the need for destructive sampling to determine biomass. The FBA concept has been used to estimate shoot biomass, root length, and root biomass (Smith, 2001; Salas et al., 2004), to estimate tree component biomass using standing tree measurements (Santos Martin et al., 2010), and to derive species-specific and mixed-species biomass equations (MacFarlane et al., 2014). The model does not predict growth, but provides architectural boundary conditions for transport and support tissues to keep up with leaf and fine root development (Mulia et al., 2010).

Jatropha allometric research historically used empirical models and destructive sampling to determine aboveground biomass (Ghezehei et al., 2009; Achten et al., 2010d; Makungwa et al., 2013), with limited belowground data (Firdaus and Husni, 2012; Baumert and Khamzina, 2015). However, there are no data available for biomass partitioning in the generative stage (harvest index). The relationship between inflorescence size, sex ratio, fruit maturation (yield) (Negussie et al., 2014), and plant architecture is important. For instance, in apple and pear trees the reproductive and vegetative branches are different (Costes et al., 2006); while for coffee trees the branches bearing flowers and fruit grow horizontally from the stem (Van der Vossen and Herbert, 1985; Cilas et al., 2006). In coffee shorter internode length, without a reduction in the numbers of fruit per cluster is also a selection criteria for higher yielding cultivars (Gichimu and Omondi, 2010).

FBA has been used to estimate tree biomass but has not been adjusted for shrub architecture. Extension of the plant architectural model to derive potential fruit production has not yet been tested. We therefore set out to test this possibility. The aim of our study was to develop allometric equations for above and belowground jatropha biomass, as grown in Indonesia, using FBA. Four objectives were: 1) to gain an understanding of the complexity and relationship between jatropha biomass and FBA; 2) to develop improved allometric equations for FBA model in determining above and belowground biomass; 3 ) to evaluate the FBA model as a non-destructive method for estimating biomass; and 4) to explore whether FBA can be used to identify management practices that increase yield. 


\subsection{Materials and methods}

This study was conducted at a jatropha plantation in Mulo Village in the Wonosari District, Gunungkidul Regency of Special Province Yogyakarta in Indonesia ( $8^{\circ} 0^{\prime} \mathrm{N}, 110^{\circ} 34^{\prime} \mathrm{E}, 185 \mathrm{~m}$ above sea level - ASL). A local company, PT. JGE purchased the land and planted jatropha. No agricultural inputs were applied to the monoculture system and local farmers harvested grass on daily basis for cattle feed, while weeding was performed once a month. Planting material was seed propagated from IP-1M, an improved jatropha population of a first selection from Muktiharjo, Central Java (Hasnam and Hartati, 2006). Planting density was 2,500 plants ha ${ }^{-1}$, spaced $2 \mathrm{~m} \times 2 \mathrm{~m}$ from seedlings transplanted at three months.

The region has an equatorial rainforest climate with mean annual rainfall of $1,800 \mathrm{~mm}$, mostly occurring from November to April and months with less than $100 \mathrm{~mm}$ per month, mostly in May and October. Mean annual temperature and relative humidity under standard weather station conditions are about $26{ }^{\circ} \mathrm{C}$ and 70 $\%$ respectively. The soils are Mollisols with texture varying from clay, silty clay to silty clay loam, with poor drainage. Drainage canals were located around the study site to minimise water logging. The soils are shallow, $10 \mathrm{~cm}$ to $50 \mathrm{~cm}$ with limestone beneath. Top soil $(0-10 \mathrm{~cm}) \mathrm{pH}(1: 5)$ was 7.7 with $\sim 0.9 \%$ organic carbon (Walkley-Black method) and total nitrogen (Kjeldahl method), phosphorus (Olsen method), and potassium (ammonium acetate $\mathrm{pH} 7$ ) were $0.5 \mathrm{mg} \mathrm{kg}^{-1}, 13.8 \mathrm{mg} \mathrm{kg}^{-1}$ and $0.2 \mathrm{cmol}_{(+)} \mathrm{kg}^{-1}$ respectively.

\subsubsection{Tree selection}

This study used jatropha four-year-old from monoculture plantings. I selected ten unpruned jatropha in good health, with a single-main stem, and with minimum of 100 branching points (links). Because of the selection criteria, only four trees with fruit were available which affected fruit biomass estimation. Leaf biomass estimation was not affected as the study was performed before leaf fall commenced. At the site, flowering started at the end of October after a light-rain shower and continued until mid-June. Fruit harvesting started in mid to late January and continued through to mid-August. Leaf flush started at the end of October after the start of rainy season and reached its peak in mid-March, while leaf fall started at the end of June and continued to October. For the selected trees, destructive sampling followed the FBA measurement protocol.

\subsubsection{FBA measurements}

FBA aboveground field measurements started in mid April 2012 and finished at the end of May 2012. FBA belowground field measurements followed and were completed in August 2012. FBA details for field measurements are described in the Appendix 1. Biomass calculation using the FBA protocol and workbook are available at http://www.worldagroforestry.org/output/fba-fractal-branch-analysis-model.

\subsubsection{Destructive measurements}

Aboveground destructive measurements were performed after the FBA aboveground measurements were completed. Each jatropha was harvested to the base of the stem or until the top of root collar was reached. The aboveground biomass was separated into leaves, fruit, twig, branch, and wood or stem categories. 
Belowground destructive measurements were performed after roots were excavated and the FBA belowground measurements were completed. Roots were harvested and separated into stump plus tap root, fine roots, proximal roots for twig, branch, and wood categories. All the above and belowground biomass separated categories were subject to fresh and dry weight measurements.

\subsubsection{Fresh and dry weight measurements}

Fresh weights for each aboveground link category, including leaves and fruit were determined. Dry weights were determined for subsamples to generate a dry weight coefficient. All belowground roots for each of the links categories were weighed. No root washing was required as the soil was friable and only needed gentle rubbing with fingers or picking with forceps. Correction factors were necessary for fresh weight of fine roots and roots with twig category for moisture loss during schematic root drawings and measurements due to the time required from drawing to completing fresh weight measurement. The correction factor was determined from other jatropha roots of similar category measured without any delay after harvesting. Dry weight coefficient for above and belowground subsamples was obtained by drying the samples at $70{ }^{\circ} \mathrm{C}$ until a constant weight was achieved.

\subsubsection{Density measurements}

Density measurements for each link category were determined by measuring volume, and wet and dry weights. Volume was measured using single frustum equation (Valdés-Rodríguez et al., 2013). Wet field weights were determined for subsamples of all categories. Dry weights were determined by drying subsamples at $70{ }^{\circ} \mathrm{C}$ to a constant weight and applied to the remaining woody parts (Santos Martin et al., 2010).

\subsubsection{Leaf and fine root measurements}

Average leaf area was determined by sampling 100 leaves from each tree. Leaf area was estimated using allometric equation generated by Pompelli et al. (2012). Specific Leaf Area (SLA) was determined as leaf area per unit dry weight $\left(\mathrm{cm}^{2} \mathrm{~g}^{-1}\right)$. Leaf dry weight was determined after drying at $70{ }^{\circ} \mathrm{C}$ for $24 \mathrm{~h}$. To determine belowground structure required a full root assessment. Fine roots or feeder roots were determined as having a diameter $<0.1 \mathrm{~cm}$. Specific root length was total root length per dry weight $\left(\mathrm{cm} \mathrm{g}^{-1}\right)$ and determined after drying at $70{ }^{\circ} \mathrm{C}$ for $24 \mathrm{~h}$. Average root length was total root length divided by the number of roots.

\subsubsection{Tap root biomass estimation}

Belowground biomass estimated from FBA does not include biomass of taproot and roots that grew out from the taproot. An empirical biomass equation to fit regression model estimated taproot biomass (Equation 3.1):

$B=a D^{b}$ Equation 3.1

where $B$ is total biomass and $\mathrm{D}$ is root diameter while $(a)$ and $(b)$ are constants. The taproot biomass and diameter data were log-transformed prior to regression analysis using least trimmed squares (LTS) to 
account for heteroscedascity and potential outliers in the data. Predicted outputs were back-transformed and verified with a correction factor. Statistical analysis used SAS 9.3 (SAS Institute Inc., Cary, NC, USA).

\subsubsection{FBA validation}

Validation of predicted FBA biomass from destructive sampling was determined in 1:1 relationship. Because FBA does not use standard fitting techniques, statistical parameters for Maximum Error (ME), Root Mean Square Error (RMSE), Coefficient of Determination (CD), Modelling Efficiency (EF), and Coefficient of Residual Mass (CRM) are used (Appendix 2).

\subsection{Results}

\subsubsection{Tree parameters}

Tree parameters for aboveground biomass determination were generated from 1,754 links and belowground biomass derived from 3,182 links from 10 trees. Table 3.1 shows tree parameters for above and belowground with similar and contrasting values. Aboveground branching is an almost perfect bifurcation (2.01) with $p$ and $q$ values closest to the pipe model theory, $p=1.01$ and $q=0.66$. The first branching order from the stem shows a sympodial pattern but the next order of branching tends not to be situated opposite each other or following symmetrical dichotomous ramification, although it still has a bifurcation of nearly 2 . Sometimes branches alternate in a herringbone pattern with unequal distances between links, or situated only at one side in an unequal herringbone pattern (Appendix 3).

Average numbers of proximal roots for each tree varied from 7 to 12 with an average diameter of $2.41 \mathrm{~cm}$. This means that proximal roots had double the number of the initial roots. Initially jatropha seedlings propagated from seed show one taproot and four proximal roots that have perpendicular orientation. Over time the initial root structure changes and a more branching structure develops. Mature jatropha also develop 4 to 8 additional lateral roots that sometimes have oblique roots or lateral roots (sinker roots) that grow vertically similar to the taproot (Reubens et al., 2011).

Compared to aboveground parts, roots had more branches, 2.17 branches at each node and less conservation of cross-sectional area across a branching point $(p=1.71, q=0.76$; see Appendix 4). Distribution of $p$ for belowground values were $61 \%$ skewed toward $p>1.25$ that were $38 \%$ from the root diameter category corresponding to aboveground branches, $23 \%$ from the 'twig' root category, and $9 \%$ from the 'woody stem' root category. A high $p$ value indicates that the link cross-sectional area before branching was greater than the sum of the cross-sectional area of links after branching. When added to the fact that one branch had a greater cross sectional area (dominant branch) in comparison with the others ( $q$ value 0.76 ), this indicates a herringbone root branching pattern (Van Noordwijk et al., 1994). The herringbone pattern for jatropha root had one main axis (mother branch) that started at the base proximal root and branched to form smaller, daughter branches with fine roots at only one side, and continued for various lengths before branching into almost two equal size sub branches (dichotomous). The daughter branches maintained a similar iteration as 
the mother branch. According to Van Noordwijk and Purnomosidhi (2012) the distribution of $q$ values in a herringbone pattern shows a gradual decrease in value from 1 to 0.5 , similar to the pattern shown in Appendix 4.

Table 3.1 Average (SD) jatropha main branching parameters for FBA model.

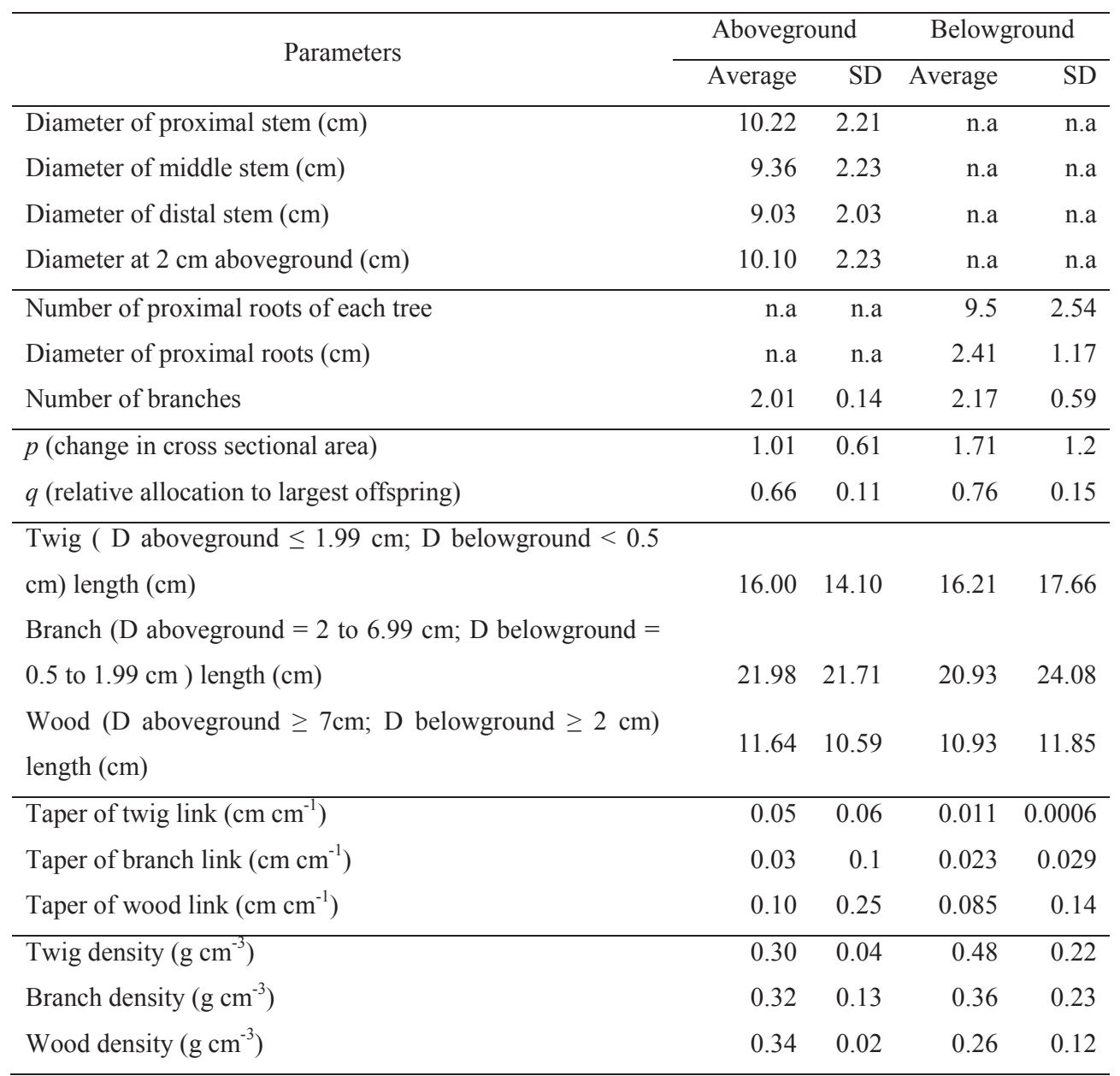

Note: $\mathrm{SD}=$ standard deviation, $\mathrm{n} . \mathrm{a}=$ not applicable, $\mathrm{D}=$ diameter

To apply fractal branching model, mean $p$ and $q$ for above and belowground parameters should have independency with the parent diameter as fractal is scale-independent (Van Noordwijk and Mulia, 2002). Regression analysis shows $R^{2}$ for each parameter is relatively independent and fractal branching model is applicable for jatropha.

The average link length for twig, branch, and wood categories for above and belowground had similar average and standard deviations (Table 3.1). Average length of twig was $16 \mathrm{~cm}(\mathrm{SD}=14 \mathrm{~cm}$ to $17 \mathrm{~cm})$, 
branch was $21 \mathrm{~cm}$ to $22 \mathrm{~cm}(\mathrm{SD}=21 \mathrm{~cm}$ to $24 \mathrm{~cm})$ and wood was 11 to $12 \mathrm{~cm}(\mathrm{SD}=11 \mathrm{~cm}$ to $12 \mathrm{~cm})$. It seemed for above and belowground link category, increased diameter from twig to branch was followed by increase of length of twig and branch, with the exception of wood category.

Analyses of length and diameter relationship for twig and branch however showed that the relationship was not linear (Appendix 5). For this reason, parameterisation of FBA did not use an average value for link length for all categories, but used an average link length for each category. Aboveground final/distal twig links had leaves or leaves and fruit, which means that not all twigs bear fruit. Fruit-bearing twigs were 0.9 $\mathrm{cm}$ to $1.4 \mathrm{~cm}$ in diameter (Figure 3.1) with lengths varying from $4 \mathrm{~cm}$ to $65 \mathrm{~cm}$.

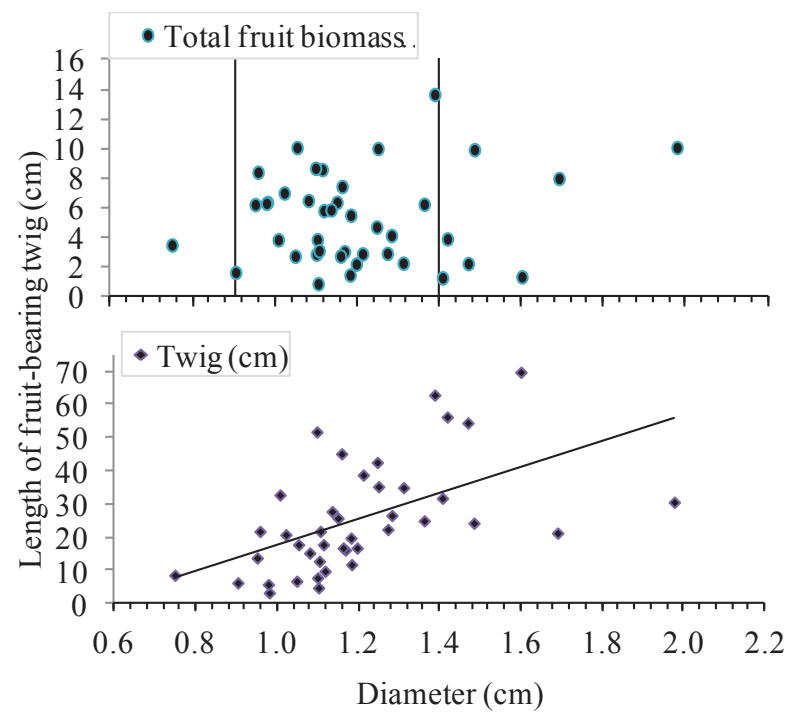

Figure 3.1 Relationship between length of fruit-bearing twig with diameter and total fruit biomass; vertical lines in-between fruit biomass show upper and lower limits for diameter boundary determination used for the FBA model; the sloping line relating the length of fruit-bearing twig to diameter indicates a proportionality factor.

Observations, schematic drawings and data from this study and other pruning and no pruning studies in monoculture, intercropping and hedge systems in Chapter 4 showed that approximately $90 \%$ of fruit produced grew on twigs with a vertical to oblique orientation. Twigs with horizontal orientation, especially if the twig originated from water-sprout branches, produced limited quantities of fruit. The majority of water sprout branches that grew horizontally gave rise to lateral twigs that grew vertically and produced fruit. In addition to the growth orientation of fruit-bearing twigs, branching order pattern did not determine the location of fruit-bearing twig. Fruit-bearing twigs were found on the first, second, third, and on higher branching order. Furthermore, multiple numbers of inflorescences or fruit clusters can occur on the same fruit-bearing twig. For instance, once the first inflorescence has developed and set on the young twig, the 
twig continues to grow or elongate, producing consecutive inflorescences, while the section where the first inflorescence was initiated develops fruit (Chapter 4).

Tapering for above and belowground link of different categories showed a similar pattern with wood having the greatest tapering coefficient compared to branches and twigs, although aboveground wood tapering $(0.1)$ was $18 \%$ greater than belowground wood tapering (0.085). Density for aboveground twig, branch, and wood was around $0.3 \mathrm{~g} \mathrm{~cm}^{-1}$ although wood had the greatest density at $0.34 \mathrm{~g} \mathrm{~cm}^{-1}$. The aboveground density values are very close to the density values determined for four month old jatropha seedlings by Achten et al. (2010d), $0.2 \mathrm{~g} \mathrm{~cm}^{-1}$ ( $\mathrm{SD}=0.01$ ) for stem and $0.26 \mathrm{~g} \mathrm{~cm}^{-1}(\mathrm{SD}=0.03$ ) for wood parts. On the contrary, density of wood for the belowground category had a lesser density $0.26 \mathrm{~g} \mathrm{~cm}^{-1}$ compared with the branch $\left(0.36 \mathrm{~g} \mathrm{~cm}^{-1}\right)$ and twig $\left(0.48 \mathrm{~g} \mathrm{~cm}^{-1}\right)$. Mujumdar et al. (2000) and Krishnamurthy et al. (2012) found jatropha roots had a well-defined cortex of which large parenchymatous cells arranged centripetally that were mostly for water storage and had xylem vessels with assorted sizes, but did not have xylem fibres. The absence of xylem fibres explains the light wood characteristic of jatropha.

\subsubsection{Adjustments to the FBA model}

As data showed that a single tapering coefficient was insufficient, three separate tapering coefficients for twig, branch, and wood were introduced. Estimates for fruit biomass were also included, based on distance between fruit on twigs of specified diameter.

\subsubsection{FBA output and allometric equations}

Figure 3.2 shows the predicted increase of above and belowground biomass with increased ratio of proximal root diameter to stem base diameter. The increase in total aboveground weight was much greater than total proximal root weight. For total aboveground weight, branch category made the biggest contribution to total aboveground weight followed by twig and leaf, and finally by fruit. The data serves as the basis for construction of allometric equations (Table 3.2). 


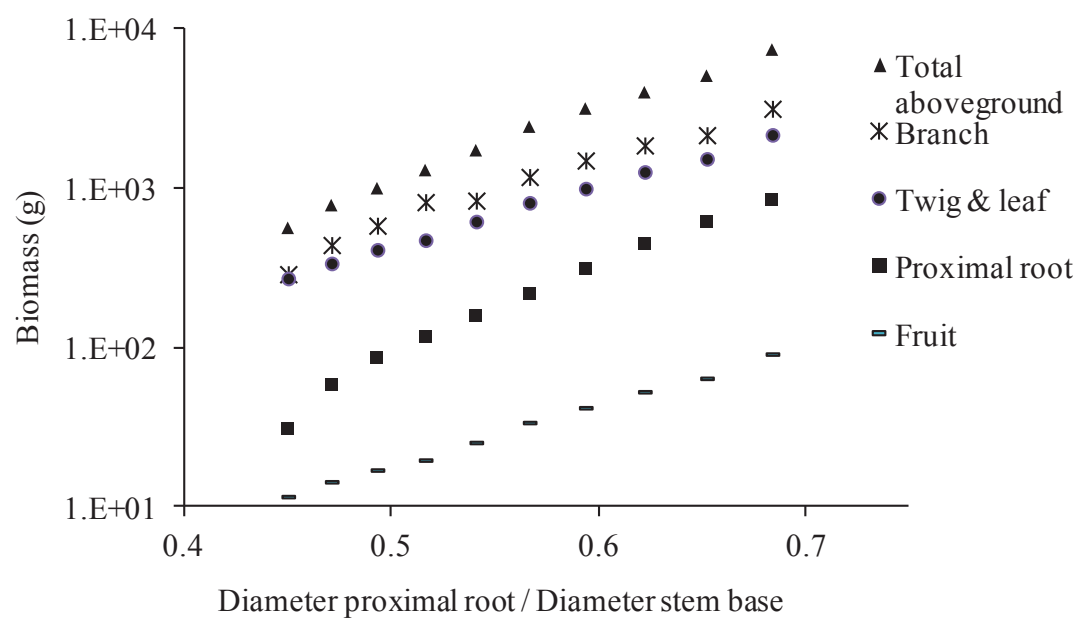

Figure 3.2 Relationship of biomass and ratio diameter of proximal root to stem base from FBA output.

The scaling coefficients derived for total aboveground biomass (2.58) were greater than proximal root biomass (Section 2.12). Twig and leaf biomass scaling was similar to fruit biomass. This is because twigs bear leaves and fruit.

FBA for belowground only simulates proximal root biomass, and not the remaining root biomass such as the taproot and other roots that originate from the taproot. For this reason, the scaling coefficient for the remaining roots required the use of an empirical allometric power equation with regression analysis. Analysis using LTS regression gave an allometric constant $(a)$ of 0.018 and scaling coefficient $(b)$ of 1.33 (p $>$.0001). See Appendix 6 for details.

Table 3.2 FBA allometric constants and scaling coefficients $\left(B=a D^{b}\right)$ for above and belowground biomass.

\begin{tabular}{llrr}
\hline FBA scaling coefficients & $a$ & $b$ \\
\hline \multirow{3}{*}{ Aboveground } & Total biomass & 0.0090 & 2.5825 \\
& Branch biomass & 0.0088 & 2.2666 \\
& Twig \& leaf biomass & 0.0085 & 2.1209 \\
& Fruit biomass & 0.0004 & 2.1127 \\
\hline Belowground & Proximal root biomass & 0.0097 & 2.1870 \\
\hline
\end{tabular}

\subsubsection{FBA validation}

Figure 3.3 shows a direct comparison around a 1:1 line for FBA predicted and measured values derived from destructive measurements. The FBA model was able to predict total aboveground biomass, branch biomass, and twig and leaf biomass for all jatropha except one. This exception had a much larger basal diameter and was outside the FBA range for the other samples. This outlier was retained within the analysis based on 
statistical advice as it provides a more realistic representation of the phenotypic or morphological plasticity (heterogeneity) that currently exists with the planting material. Until more uniform planting material can be developed through intensive breeding and selection, the high levels of heterogeneity will require careful statistical consideration. The residuals between measured and predicted (FBA model) for total aboveground jatropha biomass showed significant negative correlation with tree height $\left(R^{2}=0.89 ; P=0.015\right)$, crown height $\left(R^{2}=0.91 ; P=0.013\right)$ and width $\left(R^{2}=0.89 ; P=0.019\right)$. This resulted in a short crown being predicted as having a massive crown, while a long crown was predicted as having a small crown. Similar to crown height, a narrow crown was predicted as having a wide crown, while a wider crown was predicted as having a narrower crown. FBA for tree height was generated by adding crown height and length of stem/trunk, therefore bias in crown height resulted in bias in tree height as well.

A

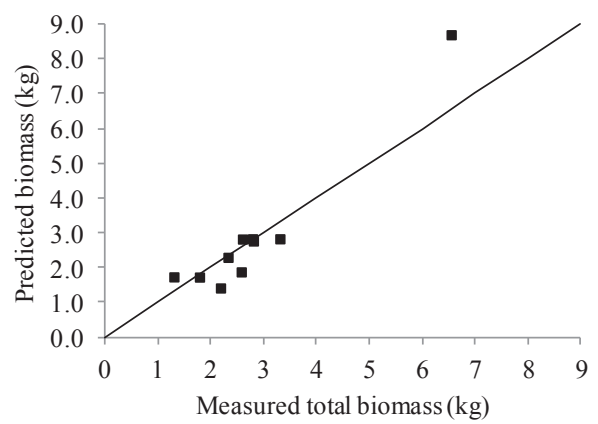

$\mathrm{C}$

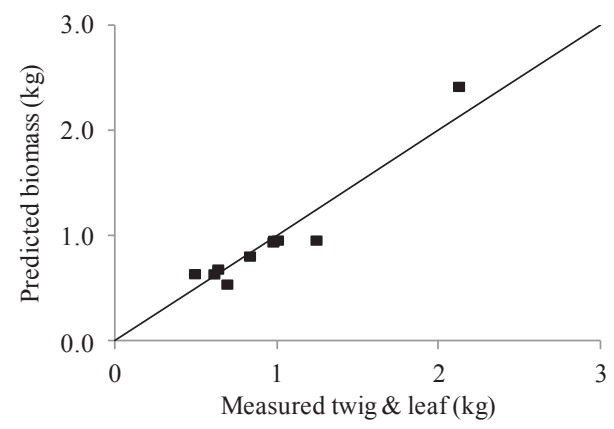

$\mathrm{B}$

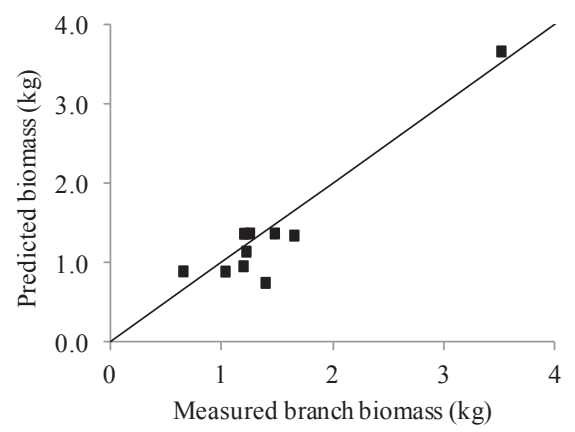

$\mathrm{D}$

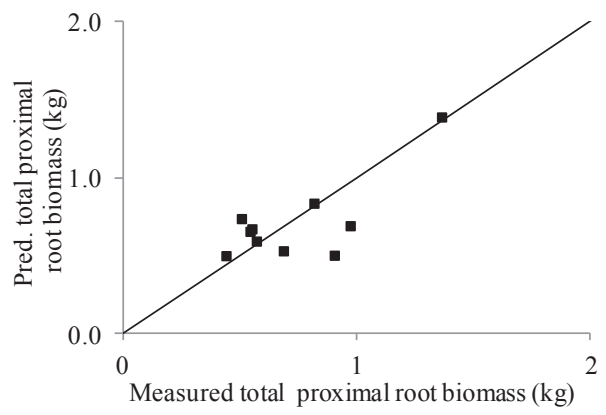

Figure 3.3 Comparison of predicted and measured aboveground tree biomass components: A) measured total biomass, B) measured branch biomass, C) measured twig and leaf biomass and for belowground D) measured total proximal root biomass.

Comparison of predicted and measured belowground biomass shows the model is able to predict total proximal biomass for total proximal root of some trees, but over-estimated small proximal roots in some, and under-estimated large proximal roots in others. Unlike links for the aboveground, the proximal root link for 
belowground had a different size, shape and length, especially for diameter of branch and wood category links.

Overall, statistical analysis for total aboveground biomass, branch biomass, and twig and leaf biomass indicate the model has an acceptable prediction range and is applicable for biomass estimation (Table 3.3). Statistical analysis of fruit biomass was not able to confirm viability of the FBA model. Fruit data were limited with only four of the ten trees having fruit. FBA generates fruit biomass based on fruit bearing twig diameter and information relating to this link was limited.

Table 3.3 Statistical validation of FBA model for above and belowground biomass estimation.

\begin{tabular}{|c|c|c|c|c|c|c|}
\hline \multirow{2}{*}{ Parameter } & \multirow{2}{*}{$\begin{array}{l}\text { Optimum } \\
\& \text { range } \\
\text { values }\end{array}$} & \multicolumn{4}{|c|}{ Aboveground biomass } & \multirow{2}{*}{$\begin{array}{c}\text { Belowground } \\
\text { biomass } \\
\text { Total proximal } \\
\text { root }\end{array}$} \\
\hline & & Total & Branch & $\begin{array}{c}\text { Twig \& } \\
\text { leaf }\end{array}$ & Fruit & \\
\hline $\mathrm{R}^{2}$ & $(1, \geq 0)$ & 0.93 & 0.90 & 0.92 & 0.05 & 0.56 \\
\hline Maximum error (ME) & $(0, \geq 0)$ & 2.16 & 0.64 & 0.29 & 0.04 & 0.39 \\
\hline Root mean square error (RMSE) & $(0, \geq 0)$ & 27.86 & 18.49 & 15.33 & 62.80 & 25.36 \\
\hline Modelling efficiency (EF) & $(1, \leq 1)$ & 0.66 & 0.86 & 0.89 & -0.06 & 0.52 \\
\hline Coefficient of residual mass (CRM) & $(0, \leq 1)$ & -0.03 & 0.06 & 0.003 & 0.19 & 0.02 \\
\hline Coefficient of determination (CD) & $(1, \geq 0)$ & 0.46 & 0.83 & 0.76 & 5.75 & 1.17 \\
\hline
\end{tabular}

Statistical analysis of total proximal root biomass for belowground showed that the proximal root diameter used in the FBA model only accounts for $56 \%\left(R^{2}=0.56\right)$ of the total proximal root biomass. The remaining percentage was attributable to other, unknown variable(s).

\subsection{Predictors for aboveground biomass}

According to the FBA model, above and belowground branching is interconnected and subject to the same rules, therefore stem base diameters relate to root collar diameter and sum of squared diameter proximal roots. Using these independent variables to predict aboveground total biomass of the ten sample trees, the result shows that stem base diameter is the best predictor; followed by square root of sum squared diameter proximal root, root collar diameter and number of proximal root (Table 3.4). 


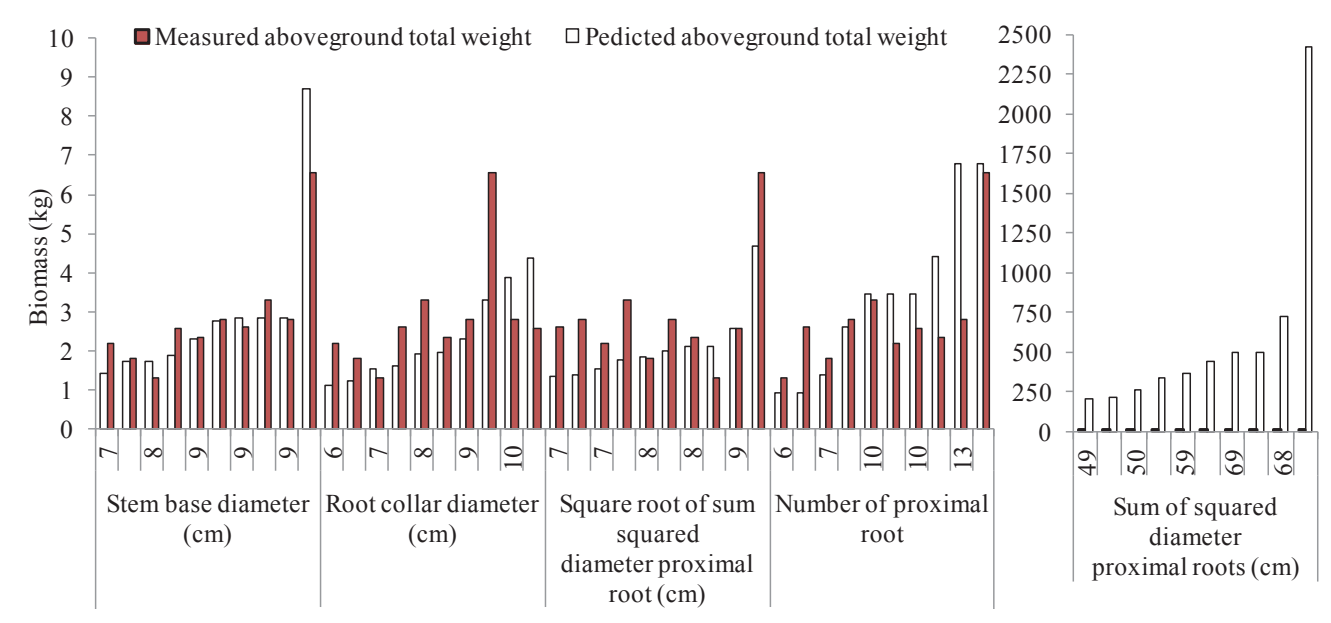

Figure 3.4 Biomass of measured and predicted aboveground total weight generated from several independent variables using FBA allometric coefficients in ten trees.

RMSE for stem base diameter is 27.9 , square root of sum squared diameter proximal root is 37.5 , root collar diameter is 50.1, and number of proximal root is 56.6. The sum of squared diameter proximal root overestimates aboveground biomass because the diameters include the structures that function as water storage units.

\subsubsection{Comparison with other jatropha allometric equations}

Empirical allometric equations are available for jatropha biomass from other studies (Table 3.4). Achten et al. (2010d) developed empirical allometric equations using stem diameter to estimate aboveground biomass based on data obtained from 41 jatropha seedlings (up to $3 \mathrm{~cm}$ stem diameter), while Ghezehei et al. (2009) used stem base diameter and other predictors to develop allometric equations for aboveground biomass estimation using 12 samples aged 16 to 24-month-old. Makungwa et al. (2013) developed two aboveground biomass allometric equations that were based on stem diameter measured at $10 \mathrm{~cm}$ aboveground. These were taken from 172 and 442 samples of one and three-year-old jatropha planted as smallholder crop boundary hedges, in five different regions. Firdaus and Husni (2012) determined allometric equations for aboveground and belowground biomass using stem diameter from 15 samples of 6 to 46-month-old jatropha. Baumert and Khamzina (2015) developed above and belowground biomass allometric equations using stem diameter measured at $20 \mathrm{~cm}$ aboveground. The allometric equations were classified as juvenile, adult, and mature based on stem diameter grouping. Data were collected from 141 jatropha plants aged 1 to 20 years, taken from various production systems. 
Table 3.4 Jatropha allometric equations from several sources.

\begin{tabular}{|c|c|c|c|c|}
\hline & Allometric scaling coefficients & Number of Sample & $a$ & $b$ \\
\hline \multirow{8}{*}{ Aboveground } & Achten et al. (2010d) & 41 & 0.029000 & 2.328 \\
\hline & Ghezehei et al. (2009) & 12 & 0.000907 & 3.354 \\
\hline & Makungwa et al. (2013) $1^{\text {st }}$ equation & 172 & 0.006700 & 2.891 \\
\hline & Makungwa et al. (2013) $2^{\text {nd }}$ equation & 442 & 0.005500 & 2.769 \\
\hline & Firdaus \& Husni (2012) & 15 & 0.002330 & 3.320 \\
\hline & Baumert \& Khamzina (2015) Juvenile stage & & 0.003000 & 2.740 \\
\hline & Baumert \& Khamzina (2015) Adult stage & 141 & 0.003000 & 3.030 \\
\hline & Baumert \& Khamzina (2015) Mature stage & & 0.016000 & 2.310 \\
\hline \multirow{4}{*}{ Belowground } & Firdaus \& Husni (2012) & 15 & 0.000880 & 3.110 \\
\hline & Baumert \& Khamzina (2015) Juvenile stage & & 0.001000 & 2.710 \\
\hline & Baumert \& Khamzina (2015) Adult stage & 141 & 0.001000 & 2.920 \\
\hline & Baumert \& Khamzina (2015) Mature stage & & 0.016000 & 1.880 \\
\hline
\end{tabular}

Note: $a=$ intercept, $b=$ power coefficient

In Figure 3.5 we present the intercept $(a)$ and power coefficient $(b)$ relationships for jatropha allometric equations from six authors, including our jatropha FBA. While the result shows a strong $a$ and $b$ relationship with only one degree of freedom it does not indicate any biological association. It does however suggest that for a particular value of $a$, only a limited range of values for $b$ might be exist, irrespective of any factors (Hairiah et al., 2011). In essence, this allows us to simplify matters and develop one jatropha biomass/diameter allometric equation.

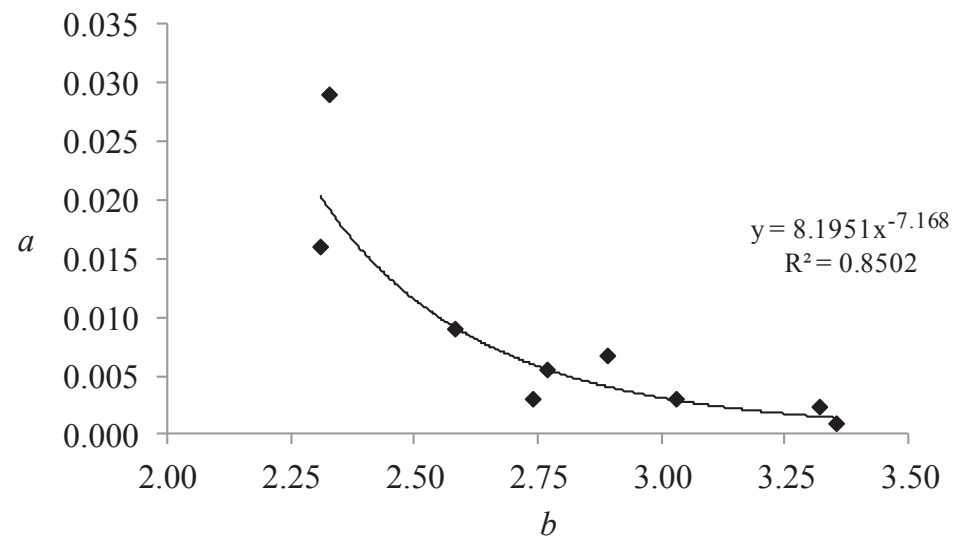

Figure 3.5 Relationship of intercept $(a)$ and power coefficient $(b)$ from allometric equations for jatropha from several sources. 
Despite the apparent differences in parameters, a comparison of total aboveground jatropha biomass in relation to stem base or stem diameter showed similar trends between published sources and the FBA results (Figure 3.6). Achten et al. (2010d), the first equation of Makungwa et al. (2013) and Firdaus and Husni (2012) share similar patterns with the highest aboveground biomass estimations, whereas Ghezehei et al. (2009) and juvenile stage of Baumert and Khamzina (2015) share the lowest aboveground biomass estimations. The second equation of Makungwa et al. (2013), jatropha FBA, adult and mature stage of Baumert and Khamzina (2015) are situated in the middle of previous two patterns. The grouping pattern for increasing biomass with increasing diameter is likely due to similarities in age. Moreover variations in jatropha biomass across different sources derived from empirical allometric and jatropha FBA can be caused by differences in planting material, site characteristics such as soil, vegetation and over-storey structure (MacFarlane et al., 2014), or in silvicultural practices and development stage or age at the time data were collected (Makungwa et al., 2013).

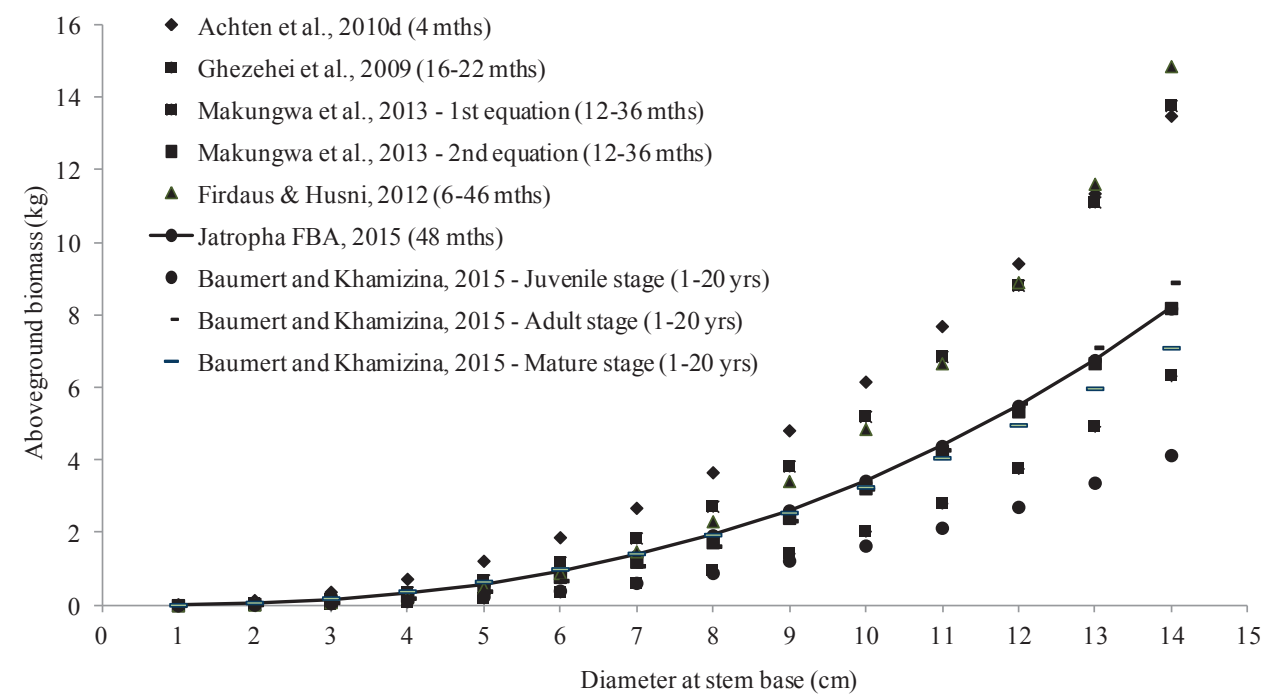

Figure 3.6 Relationship of aboveground biomass and diameter at stem base using different jatropha allometric equations from several sources.

As further explored in on-going research for allometric equations of other species (Harja, pers. comm.), a reformulation of the allometric model to $Y_{x}=\left(\frac{D}{x}\right)^{b}$, with a reference diameter $(x)$ of in this case about $14 \mathrm{~cm}$, can maximise statistical independence of the modified $a\left(Y_{x}\right)$ and the $b$ parameter for all jatropha results (Table 3.4 plus our study). The FBA result for $Y(14)$ is $15 \%$ lower than the mean of the previous studies.

\subsubsection{Ratio below to aboveground biomass}

The ratio of below to aboveground biomass or root to shoot ratio $(\mathrm{R} / \mathrm{S})$ is a widely used measure to estimate belowground biomass as it is much easier to measure biomass aboveground than belowground. The ratio 
between belowground to aboveground biomass for this study was determined at $0.5(\mathrm{SD}=0.13)$. The aboveground biomass explained $83 \%\left(R^{2}=0.83\right)$ of the variation in the belowground biomass (Figure 3.7).

Firdaus and Husni (2012) using destructive sampling determined the below to aboveground ratio to be 0.4 for seedlings aged 6 to 46 months in wasteland areas in Malaysia. Rao et al. (2013) also using destructive sampling, found the below to aboveground ratio to be around 0.3 for jatropha trees aged 8 years in Southern India. Wani et al. (2012) used a below to aboveground ratio of 0.2 to factor the belowground biomass for trees aged 3 to 5 years in Northern and Southern parts of India. Use of a 0.2 ratio clearly underestimated belowground biomass compared with empirical data.

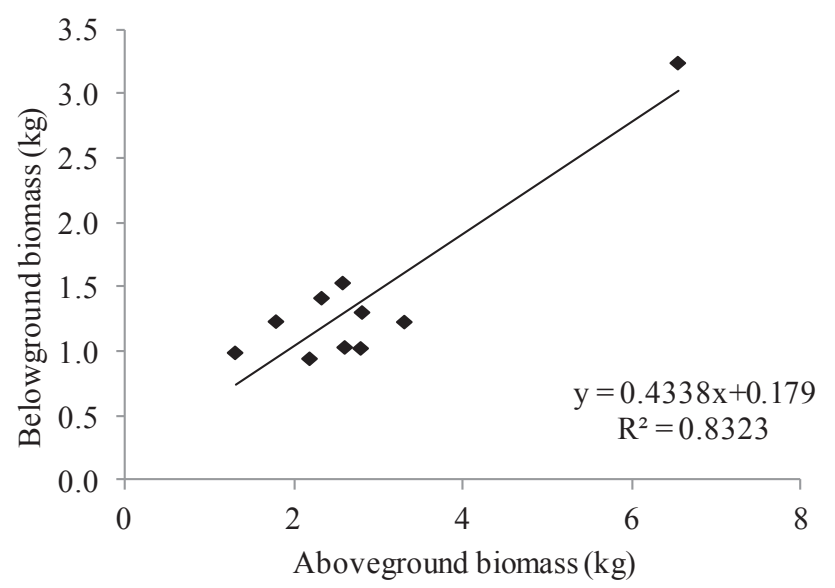

Figure 3.7 Relationship between belowground and aboveground biomass.

Differences in the below to aboveground ratio results can be due to planting material and tree age, also the agro-ecological conditions of soil, climate and management practises, but also measurement methods, especially for belowground biomass (Mokany et al., 2006; Kuyah et al., 2012).

\subsection{Discussion}

The FBA model produces both good and poor aboveground biomass estimates of jatropha. This is dependent on how well the jatropha fits the fractal-like allometric scaling dimensions. The poor estimation of aboveground biomass results from inconsistencies in the bias for crown height and width, and tree height estimations. FBA generates crown height by summing the length of links specified by length-diameter relationships. The way link length relates to link diameter is a key relationship in the FBA model calculations. Our data for twig, branch, and wood links did not linearly relate to link diameter and showed a wide variation between trees (Appendix 5), with the exception of twigs bearing fruit (Figure 3.1). In the absence of such relationship, FBA uses a single value for mean and variance, independent of diameter. Biologically, this relationship is complex as link length is determined by the development and disappearance (self-pruning) of branches, in the axes of (former) leaves. Enhanced development of side branches at the 
crown surface leads to shortening of link lengths, while shading of the lower branches leads to senescence of side branches (Mäkelä and Valentine, 2006) and secondary elongation of links as measured in the FBA protocol. Such trees can be thought of as 'disrupted fractals' where the lengths of links of different diameter branches are somewhat randomised due to historical branch development that effects link length (MacFarlane et al., 2014). This may explain why further statistical approaches using mean link length and measured variability were sufficient to reconstruct measured biomass for some (jatropha), but were still insufficient to predict biomass for others. Although, this technique provides more structure (predictability) in the location of shorter and longer links in the crown than FBA uses, it cannot fully capture the wide variation between jatropha links.

Jatropha in this study showed sympodial growth, some with dichasia, and others with multiple branching. The branching pattern follows Leeuwenberg's model (Hallé et al., 1978). Other branching patterns are possible due to the high phenotypic plasticity. Sunil et al. (2013) observed several branching habits and patterns between different germplasm in a monoculture planting at $2 \mathrm{~m} \times 2 \mathrm{~m}$, with no pruning, and receiving similar management treatments. Although aboveground phenotypes show a wide range of plasticity, genetic diversity is narrow (Divakara et al., 2010).

The FBA model generates the crown radius allometric coefficients using a vertical projection of the crown leaf area and assuming the shape is uniformly circular. This assumption does not hold for all jatropha so wide crowns may be underestimated while narrow crowns, overestimated. Jatropha grown in a plantation environment may not develop crowns that reach their full potential as they compete within a limited growing space for light, soil nutrient, and water (Mäkelä and Albrektson, 1992; Martin et al., 2012). For instance, competition for light between trees may result in shoot or tree crown clumping or self-pruning (Duursma and Mäkelä, 2007). Adding to the complexity of competition is the fact that the jatropha used in the FBA calculations showed substantial phenotypic plasticity. This is despite the fact that the planting material is from one improved population. Future biomass prediction with FBA model may benefit from stratified sampling based on different diameter classes, crown size and shape.

FBA calculates tree height by adding trunk/stem length with fractal crown height. The source of tree height bias for some jatropha came from the crown height bias, as there was no significant correlation between residuals of FBA stem height and measured stem height. Jatropha stem lengths used in this study varied from $2 \mathrm{~cm}$ to $40 \mathrm{~cm}$ from soil surface therefore DBH normally used for developing tree allometric equation was replaced with stem base diameter measured at the middle of the stem length. Moreover, jatropha used in this study was only four-year-old and had stem base diameters ranging from $7 \mathrm{~cm}$ to $14 \mathrm{~cm}$ therefore a reduction in the wood link diameter categorisation to $\geq 7 \mathrm{~cm}$ was required. Consequently, data for wood and main stem parameterisation were identical. The strong tapering found for the main stem did not apply to the branches, therefore the FBA model was adjusted to use separate tapering coefficients for twigs, branches, and wood. The tapering coefficient interacts with the proportionality factor $p$ of cross-sectional area before and after a 
branching point, in determining the cross-sectional area before the next branching point. When this aboveground structure is considered, jatropha approximates a shrub more than a tree.

FBA for forest trees construct a biomass for the crown wood, branches, twig and leaf, and add the trunk biomass separately as it is subject to other biological and management-related processes. Fractal (selfsimilarity) properties of the branches are restricted to the crown (Mäkelä, 2002; Mäkelä and Valentine, 2006). Similar to FBA for forest tree, jatropha biomass was constructed in the same way, with addition of fruit biomass.

The FBA model also using parameters for fruit-bearing twigs predicted an allometric scaling coefficient $(b)$ of 2.11 for fruit biomass relative to the stem base diameter. This is in agreement with a value of $<2.2$ for the allometric scaling coefficient for plant reproductive biomass when the stem tapered (Niklas, 1993). Although the predicted scaling coefficient for fruit biomass is in agreement with other studies, the fruit data for this study was limited and results for older plants may differ.

Corner's rule recognises a positive correlation between twig size and leaf, inflorescence, fruit, and seed size (Westoby and Wright, 2003; Chen et al., 2010). For fruit-bearing twigs in jatropha, twig length and diameter were correlated; twig diameter was better as predictor of fruit presence than link length, with twig diameters between $0.9 \mathrm{~cm}$ and $1.4 \mathrm{~cm}$ representing $83 \%$ of fruits observed. Chen et al. (2009) studied fruit-bearing twigs across 55 woody species and found that fruit and seed biomass were positively correlated with twig diameter, but negatively correlated with the ratio of twig length to diameter. Chen et al. (2009) also found that twig size was not significantly correlated with seed size, possibly due to the large variation in seed numbers per fruit and a negative relationship between seed size and number of seeds per fruit.

Although the study of fruit-bearing twigs in relation to reproductive biomass is still in the very early stages, this study highlights the importance of architecture, especially when trying to correlate fruit biomass with breeding and management practices. Research into the relationships between length and diameter for links bearing fruit, fruit dimensions, and pericarp to seed ratios is required for improved simulations. It will also be important to investigate the critical switching point for twigs with diameters between $0.9 \mathrm{~cm}$ and $1.4 \mathrm{~cm}$ to understand why some twigs bear inflorescences and others do not. Moreover, fruit-bearing twigs can be located anywhere on the tree regardless of the branching order and often bear multiple inflorescences or fruit clusters (Chapter 4). Contrary to the observations by Ghosh et al. (2011) our results show that branches situated in the lower part of the canopy and shaded by upper branches do flower and produce fruit, although at a reduced level. If light does determine flowering, then there must be a range over which it operates given that inflorescence initiation and fruit set occurs in areas where light is limited. Such a range is likely influenced by resource availability and allocation in combination with twig diameter. This possibility opens up an interesting area of research into flowering physiology in response to twig size and external stimuli such as light quality and/or quantity. 
It is important for plant breeders to understand age-related characteristics to be able to optimise genetic gains per unit of time, rather than waiting for a tree to start producing. An example of this is coffee breeding where yield prediction is possible through architectural development, as coffee only flowers and fruits on lignified plagiotrophic (horizontal) branches (Cilas et al., 2006). In coffee, the internode length between inflorescences on plagiotrophic branches is an important trait, as it not only determines carbohydrate allocation, but also carbohydrate distribution to inflorescences and fruit. Based on understanding of coffee tree architecture, selective branch pruning, branch-wounding (ring-barking) and grafting of productive plagiotrophic branches to other trees to increase yields is already standard management practice (AnimKwapong and Adomako, 2010). Plant architecture has proved commercially beneficial in coffee breeding and may prove useful for future jatropha breeding and management practices.

FBA belowground biomass estimation for total proximal root biomass had a greater bias compared with aboveground biomass. Proximal roots enlarge into structures that store water, a root structure not factored into the FBA pipe model theory. The theory determines that a pipe represents a 'bundle of unit pipes' each of which has a water and nutrient transport function (Mäkelä, 1986). The bundles of pipes are interconnected, one to the other where transport capacity is determined by the stem or proximal diameter (Van Noordwijk and Purnomosidhi, 1995).

FBA belowground biomass estimations do not take into account taproot or stump biomass, as these organs do not follow a fractal model; these organs, however contribute $30 \%$ of total measured belowground biomass in jatropha. For this reason, it is necessary to generate empirical allometric equations for the taproot using its diameter as the predictor variable. The estimated taproot weight can be added to estimated total biomass based on proximal roots as a predictor, to derive total belowground biomass.

Jatropha roots typically are intermediate in branching pattern between a herringbone and dichotomy pattern (Van Noordwijk et al., 1994). Herringbone root systems minimise intra-plant root competition so are more effective at resource acquisition, despite their roots being larger, and more resource demanding. Dichotomous root systems have higher intra-plant competition although they are smaller and require fewer resources (Fitter et al., 1991). It is apparent that jatropha is able to respond to differences in resources availability through root structure modification.

Implementation of the revised FBA model (with tapering coefficients depending on link diameter classes) for estimating jatropha biomass will be easier and cheaper than relying on destructive methods for further studies. For density measurements a small tree corer could be used to extract a sample, alternatively using previously published density values (MacFarlane et al., 2014). The revised FBA model offers estimations of biomass partitioning for fruit, twig and leaf, and branch, including total biomass. FBA also shows that aboveground fractals are interconnected with belowground fractals, and that root collar diameter and square 
root of sum squared proximal root diameter can be used to estimate aboveground biomass. The best estimation for aboveground biomass however comes from using stem base diameter.

Below to aboveground ratio is a function of genotype and a reflection of resource allocation and the limitations (stress) imposed within the environment (Taub and Goldberg, 1996; Aikio and Markkola, 2002). Although not fully understood above and belowground parts are functionally interdependent and able to maintain a dynamic biomass balance depending on resource availability. In basic terms when light is the predominant limiting factor, resources are allocated to aboveground growth, and when nutrients are the limiting factor, preference is given to belowground growth. Jatropha is a shade intolerant plant therefore a greater proportion of biomass is invested aboveground than belowground. In this study light was probably a limiting factor as canopy closure had already occurred in the four-year-old jatropha planted at $2 \mathrm{~m} \times 2 \mathrm{~m}$. The below to aboveground ratio is an indicator of functional plasticity (Aikio and Markkola, 2002) in response to growth-limiting resources. In jatropha the roots act as belowground storage organs as part of overall plastic response (Grams and Andersen, 2007).

\subsection{Conclusions}

From the FBA perspective, jatropha is categorised as a shrub more than a tree as it does not have prominent trunk. Implementation of a revised FBA model provides variable estimations of total aboveground biomass for twig, leaf and branch biomass depending on how well the jatropha fit the fractal branching architecture. The strength of this model is its application as a non-destructive technique for determining aboveground biomass. Fruit biomass was not well estimated so further research is required on fruit-bearing twigs and fruit dimensions to fine-tune the model. Proximal roots as a predictor of belowground biomass produced poor results because the cross sectional area of the proximal root do not follow the fractal branching pattern. One possible solution might be to use root diameters farther from the stem as basis for allometric equations. The measured below to aboveground ratio of 0.5 observed in this research was higher than in other jatropha studies. These differences highlight a degree of morphological plasticity that requires consideration when determining plant biomass. Below to aboveground ratio requires referencing against whole plant biomass for meaningful results. Relationships among jatropha seed yield and vegetative plant components under different management and cropping systems in Indonesia. 
Chapter 4 Relationships among Jatropha curcas L. seed yield and vegetative plant components under different management and cropping systems in Indonesia

This chapter has been published as:

Tjeuw J, Slingerland M, Giller K. (2015) Relationships among Jatropha curcas L. seed yield and vegetative plant components under different management and cropping systems in Indonesia. Biomass and Bioenergy 80: 128-139 


\begin{abstract}
An understanding of how jatropha seed yield relates to vegetative plant components under different management regimes is lacking. Such information is necessary to predict yields and design management strategies. This study investigated yield and vegetative plant component interactions, and the effects of management practices in monoculture, intercropping, and hedge cropping systems in Indonesia. Monoculture and intercropping experiments in Gunungkidul Regency used jatropha IP-1M material; hedge experiments in Sumbawa Regency used the Sumbawa provenance. In two-year-old monoculture, pruning significantly decreased yield from $109 \mathrm{~kg} \mathrm{ha}^{-1}$ to $28 \mathrm{~kg} \mathrm{ha}^{-1}$ due to a $40 \%$ decrease in canopy volume and leaf area index. In four-year-old jatropha intercropping, root barriers reduced yields $80 \%$ by limiting jatropha root access to soil moisture and nutrients in the maize plantings. Intercropping without root barrier and with leaf mulch produced the largest yields of $25 \mathrm{~kg} \mathrm{ha}^{-1}$. In hedge plantings, plant height influenced yield. Single rows of one-year-old monoculture produced $0.97 \mathrm{~g} \mathrm{~m}^{-1}$ at $10 \mathrm{~cm}$ spacing, $1.69 \mathrm{~g} \mathrm{~m}^{-1}$ at $30 \mathrm{~cm}$, and $0.14 \mathrm{~g} \mathrm{~m}^{-1}$ for 20 $\mathrm{cm}$ of mixed jatropha-gliricidia. Pruning significantly decreased leaf area index with $20 \mathrm{~cm}$ spacing indicating a higher proportion of aboveground biomass allocated for wood growth. Results indicate that seed yield across the three cropping systems can be determined by plant height and numbers of productive twig/branch, although number of inflorescence clusters per productive twig may be more important. Future research should focus on the transition of branches to reproductive phases, and on increasing numbers of productive twigs/branches and inflorescence clusters.
\end{abstract}

Keywords: Hedge - Intercropping - Monoculture - Productive twig/branch - Pruning 


\subsection{Introduction}

Jatropha has been promoted as a biofuel crop with the potential to bring about socio-economic benefits and wasteland reclamation in tropical semi-arid regions. It is reported to grow in marginal areas without competing with food production, and with the possibility of providing carbon credits (Van Eijck et al., 2014a). Although measured yields of $0.2 \mathrm{t} \mathrm{ha}^{-1}$ to $1 \mathrm{t} \mathrm{ha}^{-1}$ (Everson et al., 2013; liyama et al., 2013; Singh et al., 2013) are common and disappointing, recorded yields of $2 \mathrm{t} \mathrm{ha}^{-1}$ to $3 \mathrm{tha}^{-1}$ are encouraging (Achten et al., 2008; Van Eijck et al., 2014a).

Jatropha seed yield is determined by plant growth and biomass partitioning, and is a function of genotype (G), environment (E), and management (M). Research to improve yield has focused on genetic diversity (Yi et al., 2010; Osorio et al., 2014) using conventional breeding (Slingerland et al., 2014), interspecific hybridisation (Sujatha and Prabakaran, 2003; Basha and Sujatha, 2009), mutation breeding (Purwati and Hariyono, 2008), and genetic engineering (Slingerland et al., 2014). Improved planting material is then field tested in multi-locations to assess performance. In parallel with breeding research, improved management practices are developed. Pruning, plant spacing, fertiliser application, irrigation, and pest/disease management all play important roles in improving yield (Jongschaap et al., 2007; Ghosh et al., 2011; Rajaona et al., 2011; Everson et al., 2013; Singh et al., 2013).

Pruning can improve yield by maintaining branch architecture through optimised spatial arrangement of branches and leaves, tree size, canopy structure and shape (Rajaona et al., 2011). Jatropha inflorescences develop at the ends of the (new) branches and pruning induces branching, leading to a belief that more branches equals more fruit (Gour, 2006; Kaushik et al., 2007a; Brittaine and Lutaladio, 2010; Everson et al., 2013), larger yields and improved harvest index (HI) (Brittaine and Lutaladio, 2010).

In Chapter 3 using four-year-old jatropha planted at Gunungkidul in Indonesia, we determined aboveground and fruit biomass allocation relative to plant architecture using FBA. Using the FBA model, we classified the plant into three categories, wood, branch, and twig according to diameter size. Wood has a diameter $\geq 7 \mathrm{~cm}$, branch a diameter ranging from $2 \mathrm{~cm}$ to $6.99 \mathrm{~cm}$, and twig category a diameter $\leq 1.99 \mathrm{~cm}$. We found that jatropha fruit develop on twigs that in the majority of cases have diameters ranging from $0.9 \mathrm{~cm}$ to $1.4 \mathrm{~cm}$ (Chapter 3). We named these twigs, fruit-bearing or productive twigs as opposed to non-productive twigs. In addition, we developed allometric equations for estimating total aboveground, branch, twig and leaf, and fruit biomass based on stem diameter.

Knowledge gaps exist regarding the effects of management such as pruning on seed yield, especially in relation to vegetative plant components such as tree height, stem diameter and biomass, canopy size, leaf area, number of productive twigs, and branch length. 
Jatropha can be grown in monoculture, intercropping and as hedges (Wahl et al., 2009; Van Eijck et al., 2014a). The choice of cropping system is often determined by environment and socio-economic factors. Jatropha monocultures in general require greater capital inputs as they are often larger in extent and more intensively managed than either intercropping or hedge systems.

Intercropping jatropha with annual crops is a system that farmers use to maximise their economic return, while providing a degree of insurance against the loss or poor performance of one crop. The benefits of using the inter-row space, especially while the plants are still small, can be seen as an attractive proposition while waiting for first harvests (Wahl et al., 2009). When permanent intercropping is practiced, jatropha plants are often more widely spaced (Effendi et al., 2007). Growing trees or shrubs in combination with annual crops is a common agroforestry practice and has the advantage of improving soil fertility, recycling subsoil nutrients, reducing nutrient leaching, controlling soil erosion, and providing windbreaks (Ong et al., 1991). Disadvantages can however be experienced with competition for light, water, and nutrients depending on species selection. Pruning can be effective in minimising aboveground competition and the waste material used as mulch (Giller, 2001). Root pruning and root barriers can also be used to minimise belowground competition (Ong et al., 1991).

Jatropha hedges are often planted by farmers as single rows for demarcation of property boundaries or as crop protection fencing (Henning, 2001; GTZ, 2009; Wahl et al., 2009; Iiyama et al., 2013). Little regard is however paid to seed harvest or yield potential as hedges are often planted at relatively close spacing (Wahl et al., 2009). In Indonesia trees planted at distances of $10 \mathrm{~cm}$ or less are common. In Banten and Sumbawa, jatropha or mixed plantings of jatropha and gliricidia (Gliricidia sepium) hedges have been observed. Gliricidia leaves are used as fodder while the wood is used for poles or firewood.

The majority of information relating to jatropha seed yield and different cropping system practices is based on monoculture studies (Cholid et al., 2007; Santoso and Aryana, 2011; Suriharn et al., 2011; Everson et al., 2013; Iiyama et al., 2013; Retnowati and Surahman, 2013; Singh et al., 2013). Data for intercropping (Effendi et al., 2007) and hedge (GTZ, 2009; Wahl et al., 2009; Iiyama et al., 2013) systems are limited and do not investigate yield from a plant component perspective.

In Chapter 3, our findings were based on unpruned monocultures of jatropha and have not been tested in different management or cropping systems. For these reasons, the aim of this study was to determine jatropha seed yield, and to identify the vegetative plant components that influence seed yield under different management and cropping systems.

The research objectives were: 1) to determine seed yield in monoculture, intercropping, and hedge systems; 2) to understand which vegetative plant components significantly contribute to yield under different 
management practices; 3 ) to determine whether or not there is a vegetative plant component pattern across the different management practices that can be used to estimate seed yield.

\subsection{Materials and methods}

\subsubsection{Study sites and conditions}

The study was conducted in two locations in Indonesia. monoculture and intercropping studies were located at the Mulo Village in the Wonosari District, Gunungkidul Regency of Special Province Yogyakarta $\left(8^{\circ} 0^{\prime}\right.$ $\mathrm{N}, 110^{\circ} 34^{\prime}$ E, $185 \mathrm{~m} \mathrm{ASL}$ ). Hedge studies were conducted at the Leseng Village in Moyo Hulu District, Sumbawa Regency, Nusa Tenggara Barat, $\left(8^{\circ} 35^{\prime}\right.$ N, $117^{\circ} 27^{\prime}$ E, 76 m ASL).

Gunungkidul has an equatorial rainforest climate with mean annual rainfall of 1,800 mm, occurring predominantly from November to April with dry periods from June to August or September. Mean annual temperature and relative humidity are $26{ }^{\circ} \mathrm{C}$ and $70 \%$ respectively. The soils are Mollisols with texture varying from clay, silty clay to silty clay loam, with poor drainage. The soils are shallow, $10 \mathrm{~cm}$ to $50 \mathrm{~cm}$ with limestone beneath. Top soil $(0-10 \mathrm{~cm}) \mathrm{pH}(1: 5)$ was 7.7 with $\sim 0.9 \%$ organic carbon (Walkley-Black method) and total nitrogen (Kjeldahl method), phosphorus (Olsen method), and potassium (ammonium acetate $\mathrm{pH}$ 7) were $0.5 \mathrm{mg} \mathrm{kg}^{-1}, 13.8 \mathrm{mg} \mathrm{kg}^{-1}$ and $0.2 \mathrm{cmol}_{(+)} \mathrm{kg}^{-1}$ respectively. The site is located on land owned by PT. JGE.

Planting material was seed propagated from IP-1M, an improved population of a first selection from Muktiharjo, Central Java (Hasnam and Hartati, 2006). Seedlings were transplanted at three months, planted approximately $20 \mathrm{~cm}$ deep, and spaced at $2 \mathrm{~m} \times 2 \mathrm{~m}$ or 2,500 plants ha ${ }^{-1}$. No agricultural inputs were applied to the jatropha and local farmers' harvested grass all year round from the plots for cattle feed.

The Sumbawa site has an equatorial savannah climate with average annual rainfall of 1,451 mm from November to April or May and dry periods from June to August or September. The average annual temperature and relative humidity are $28{ }^{\circ} \mathrm{C}$ and $79 \%$. The soils are clay loam Inceptisols. In the top soil $(0$ $10 \mathrm{~cm}), \mathrm{pH}(1: 5)$ was 7.1 with $\sim 1.8 \%$ organic carbon and total nitrogen, phosphorus, and potassium were 1.0 $\mathrm{mg} \mathrm{kg}^{-1}, 9.3 \mathrm{mg} \mathrm{kg}^{-1}$ and $1.2 \mathrm{cmol}_{(+)} \mathrm{kg}^{-1}$. The site is a research field belonging to the University of Samawa and managed by PT. JORO. Planting material was seed propagated from local provenances with seedlings transplanted at around four months of age. Planting density was in accordance with treatments. No agricultural inputs were applied to the jatropha and mowed grass was left in the field.

\subsubsection{Experimental design}

All jatropha pruning was completed prior to the wet season and consisted of cutting back the trees to a height of $75 \mathrm{~cm}$ aboveground. Pruned trees were treated with fungicide $\left(2 \mathrm{~g} \mathrm{~L}^{-1}\right.$ Dithane-M45) and all cuts sealed with white, waterproof paint. To prevent Fusarium or Phythopthora infections, all jatropha in monoculture 
and intercropping systems received $200 \mathrm{~g}$ per plant of the bio-fungicide Trichoderma in split applications, while jatropha in hedges received $15 \mathrm{~g}$ per plant.

\subsubsection{Monoculture}

In October 2012 a pruning experiment was established in Gunungkidul using two-year-old monoculture jatropha. The treatments were pruning and no pruning in randomised complete blocks with four replicates. Each treatment plot was $10 \mathrm{~m} \times 8 \mathrm{~m}$ with 20 trees per plot planted at $2 \mathrm{~m} \times 2 \mathrm{~m}$. Data were collected from six trees in the middle of each plot.

\subsubsection{Intercropping}

The intercropping experiment involved four-year-old jatropha interplanted with maize and with all jatropha pruned. No unpruned jatropha treatments were included due to insufficient trees. Each plot was $5 \mathrm{~m} \times 12 \mathrm{~m}$ with 3 rows of 7 trees per row, planted at $2 \mathrm{~m} \times 2 \mathrm{~m}$. Data were collected from 15 trees in the middle of each plot. Three rows of maize were planted between the jatropha at a spacing of $25 \mathrm{~cm} \times 75 \mathrm{~cm}$ with maize edge rows positioned $75 \mathrm{~cm}$ from the jatropha. Two seeds were planted per hole and after two weeks, the less vigorous seedling was thinned out. P was applied at $72 \mathrm{~kg} \mathrm{ha}^{-1}$ and $\mathrm{K}$ at $120 \mathrm{~kg} \mathrm{ha}^{-1}$.

The experiment was a randomised complete block design with 3 replicates and 2 factorial treatments. The first treatment compared a clear polythene sheet $(400 \mu \mathrm{m})$ root barrier with no root barrier installed prior to tree pruning and maize planting. Trenches approximately $40 \mathrm{~cm}$ deep and $20 \mathrm{~cm}$ wide were dug $50 \mathrm{~cm}$ from the jatropha row on both alleys in the plot. Roots along the trenches were cut and $14 \mathrm{~m}$ lengths of polythene sheet installed. Polythene sheeting was retained $5 \mathrm{~cm}$ above the soil surface to prevent the spread of roots over the top of the barrier. The trenches were back filled with the subsoil returned first followed by top soil.

The second treatment compared jatropha leaf mulch with no leaf mulch. All leaves (leaflets with petioles) from the pruning treatment (equivalent to $3.5 \mathrm{Mg} \mathrm{ha}^{-1}$ ) were air dried and incorporated into the soil during maize bed preparation, two weeks before planting. The intercropping experiment was conducted over two planting seasons, the first from $21^{\text {st }}$ November 2012 to $3^{\text {rd }}$ March 2013; the second from $23^{\text {rd }}$ March 2013 to $2^{\text {nd }}$ July 2013.

\subsubsection{Hedge}

Two hedge experiments were established in April 2011. All hedges were single row plantings. The first experiment used jatropha seedlings in a split-split plot design with three replications. The main plots were planting distance, $10 \mathrm{~cm}$ and $30 \mathrm{~cm}$ with subplots of pruning and no pruning in the first year. In the second year the subplots were further divided into sub-subplots of pruned and not pruned. The second experiment used jatropha seedlings and $1 \mathrm{~m}$ gliricidia branch cuttings (planted $25 \mathrm{~cm}$ deep) in a split-split plot with four replications. The main plots were planting distance, $10 \mathrm{~cm}$ for jatropha monoculture and $20 \mathrm{~cm}$ for jatrophagliricidia in alternate or mixed plantings. There were two factorial treatments of pruning and no pruning in the first and second years. All pruning was performed $75 \mathrm{~cm}$ aboveground. 


\subsubsection{Plant measurements}

\subsubsection{Non-destructive measurements}

Data for plant and stem height and diameter at $10 \mathrm{~cm}$ and $15 \mathrm{~cm}$ aboveground, canopy height or depth (tree height minus bare stem height), canopy width (mean of two perpendicular canopy diameters), numbers of leaves, numbers of productive twig and number of non-productive twig, twig length, number of branches, branch length, length and width of representative leaves, numbers and weight of fruit and seeds (yield) were collected before and after pruning for all experiments.

For the purposes of this study a branch is defined as a woody structure directly attached to the stem, while a twig is defined as a smaller and younger developing structure attached to the branch. Differences in branching structure between monoculture, intercropping, and hedges necessitated the use of the term productive twigs for monoculture and intercropping, but productive branches for hedges. This is because no twig development was observed in the hedge system. Both terms relate to young woody parts that bear inflorescences or fruit. Non-productive twigs or branches do not bear inflorescences or fruit.

Yield is defined as the weight of dry seed produced. Three plants were randomly selected from each treatment for schematic drawings to record branching and flowering patterns.

After pruning, vegetative measurements for monoculture and hedge were conducted three times at three monthly intervals. Vegetative measurements for jatropha intercropping were conducted monthly for the two maize planting seasons. Fruit was harvested every 7 days to 10 days throughout the fruiting season for monoculture, intercropping, and hedge plantings.

\subsubsection{Destructive measurements}

Across experiments, wet field weight of jatropha pruned plant parts was determined separately and subsamples dried at $70{ }^{\circ} \mathrm{C}$ for $24 \mathrm{~h}$ to calculate a dry weight coefficient for biomass determination. For hedge experiments, three consecutive plants from each treatment were randomly selected and uprooted for biomass determination six months after pruning.

\subsubsection{Data analysis and statistics}

Average stem diameters at $10 \mathrm{~cm}$ and $15 \mathrm{~cm}$ aboveground were used as independent variables in allometric equations to calculate total aboveground biomass, branch, twig, and leaf and fruit biomass (Chapter 3). Canopy width and height were used to calculate canopy volume when the canopy was considered ellipsoid (Ghezehei et al., 2009). Leaf width and length were used to calculate leaf area (Pompelli et al., 2012) and together with number of leaves on representative branches, total branch numbers, and average branch length with leaves were used to calculate LAI (Larrauri, 2011). These data together with plant height, number of productive twig/branch, number of non-productive twig/branch and twig/branch length, and dry seed weight 
are presented as treatment means. Prior to statistical analysis data were checked for normality and were logtransformed $(\log (x+1))$. To better describe the results, the mean of treatments across different plant components are presented using back-transform values.

Initially the overall relationship between plant components and seed yield was determined using correlation and regression analysis. Similar analysis was performed according to treatment using selected parameters that were statistically significant $(P<0.05)$ in all treatments. Pearson correlation analysis and regression analysis were performed using SPSS statistics (V19, IBM Inc. Chicago, USA). Analysis of variance and post hoc test were performed using SAS 9.3 (SAS Institute Inc., Cary, NC, USA).

For monoculture, ANOVA was performed for independent samples using the TTEST procedure. For intercropping and hedge, ANOVA and multiple comparisons of means were performed using GLM. Test of normality for all data was performed using UNIVARIATE analysis. Finally, a multivariate stepwise regression analysis was used to determine plant components that significantly contributed to yield. This analysis was performed using multivariate regression from SPSS statistics (V19, IBM Inc. Chicago, USA). Equations from the analysis are not back-transformed but presented in log scale.

\subsection{Results}

Correlation and regression analysis across the three cropping systems and treatments showed seed yield to be positively and significantly correlated with plant height, number of productive twig/branch, canopy volume, LAI, and total aboveground biomass.

\subsubsection{Monoculture}

The t-test results as presented in Figure 4.1 show significant differences between pruning and no pruning treatments for yield $(P<0.01)$, plant height $(P<0.01)$, canopy volume $(P<0.01)$ and LAI $(P<0.05)$, but not for number of productive twigs $(P=0.087)$ and total aboveground biomass $(P=0.11)$.

It is clear that pruning reduces yield and plant components to varying degrees when compared with the unpruned treatments. Pruning reduced yield $75 \%$ compared with no pruning; 11 g per tree and $44 \mathrm{~g}$ per tree, SED 0.46 or equivalent to $28 \mathrm{~kg} \mathrm{ha}^{-1}$ and $109 \mathrm{~kg} \mathrm{ha}^{-1}$ respectively and decreased plant growth resulting in reduced plant height response. Pruning reduced the number of productive twigs to $50 \%$ compared with no pruning and pruning significantly reduced canopy volume and LAI by about $40 \%$, a response similar to aboveground biomass. 

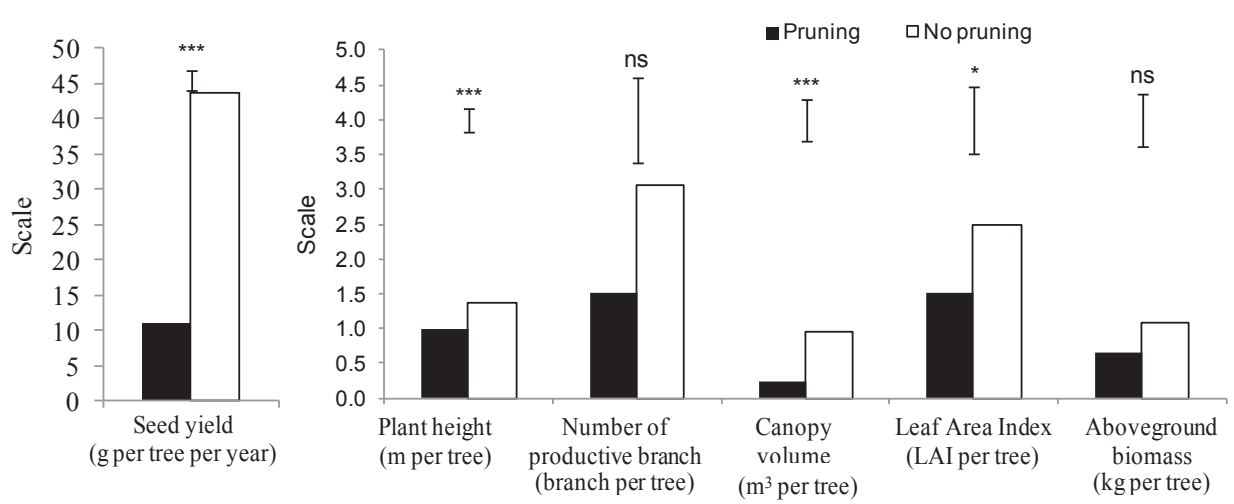

Figure 4.1 Mean seed yield and plant components of jatropha shrubs planted in monoculture system with pruning or no pruning treatments. ${ }^{* * *}$ Significant at $P<0.01$; *significant at $P<0.05$; ns $=$ not significant according to t-test. Error bars represent standard error of mean difference (SED).

In pruning and no pruning treatments respectively, $8 \%$ and $13 \%$ of productive twigs were observed to produce up to three sets of inflorescence clusters in one growing season (Figure 4.2). Overall $9 \%$ of productive twigs had three inflorescence clusters, $31 \%$ had two inflorescence clusters, and $61 \%$ had one inflorescence cluster. No significant differences were observed between pruning and no pruning treatments for numbers of inflorescence clusters.

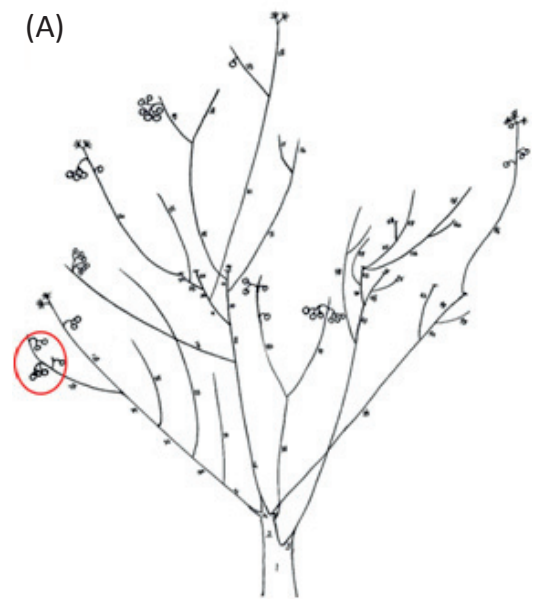

(B)

Figure 4.2 Schematic drawing of pruned (A) and no pruned (B) jatropha shrubs in monoculture system. The circles indicate a twig that bore 3 clusters of fruit or inflorescence.

Multivariate stepwise regression analysis for all data showed monoculture seed yield to be positively related $\left(R^{2}=0.53 ; \mathrm{SE}=0.44\right)$ to plant height and number of productive twigs (Equation 4.1). A similar relationship 
was found for the no pruning treatment (Equation 4.2) where $R^{2}$ was $0.46(\mathrm{SE}=0.41)$. However, for the pruning treatment (Equation 4.3), yield was proportional to the number of productive twig and LAI (3) with $R^{2}=0.51(\mathrm{SE}=0.44)$.

Logseed yield $=-0.619+(0.498 \log$ plant height $)+(0.351 \log$ no. of productive twig $)$ Equation 4.1

Logseed yield $=-0.268+(0.383 \log$ plant height $)+(0.472 \log$ no. of productive twig $)$ Equation 4.2 Logseed yield $=-0.383+(0.485 \log$ no. of productive twig $)+(0.485 \log \mathrm{LAI})$ Equation 4.3

\subsubsection{Intercropping}

Intercropping treatments with no root barrier and with mulch (Figure 4.3A) produced the highest yields (25 $\mathrm{kg} \mathrm{ha}^{-1}$ ), canopy volume (Figure 4.3D) and LAI (Figure 4.3E). Interestingly plant height (Figure 4.3B) and aboveground biomass (Figure $4.3 \mathrm{~F}$ ) were only about $10 \%$ larger. This response was consistent for all plant components, except number of productive twigs (Figure 4.3C) where no significant differences were observed between treatments. Rather the results were due to increased numbers of inflorescence clusters and fruit set on limited numbers of productive twigs. In the intercropping experiment, $1 \%$ of the plants produced five inflorescence clusters in one growing season, $3 \%$ produced four clusters, $14 \%$ produced three clusters, and $33 \%$ produced two clusters while $49 \%$ had only one cluster.

Root barriers reduced yield $80 \%$ by limiting root access to soil moisture and the nutrients in the area where maize was grown. Yield was not significantly different between no root barrier with mulch ( $10 \mathrm{~g}$ per tree or equivalent to $\left.25 \mathrm{~kg} \mathrm{ha}^{-1}\right)$ and no root barrier with no mulch ( $5 \mathrm{~g}$ per tree or equivalent to $\left.12 \mathrm{~kg} \mathrm{ha}^{-1}\right)$, despite the $60 \%$ reduction. Differences between mulch and no mulch for no root barrier were significant for canopy volume (Figure 4.3D) and LAI (Figure 4.3E) indicating mulch may have provided nutrients and helped retain soil moisture resulting in increased plant growth.

Multivariate stepwise regression analysis for all data showed yield was positively related to plant height and the number of productive twig (Equation 4.4), although the relationship was not strong $\left(R^{2}=0.201 ; \mathrm{SE}=\right.$ 0.55). Canopy volume, LAI, and aboveground biomass did not contribute significantly to seed yield determination. Further analysis of root barrier and mulch treatments shows that for root barrier with mulch (Equation 4.5) the $R^{2}$ value is $0.642(\mathrm{SE}=0.31)$ and without mulch (Equation 4.6) the $R^{2}$ value is $0.371(\mathrm{SE}=$ $0.31)$, both are significant for the relationship between seed yield and the number of productive twigs. No significant plant component relationships for yield were observed in the treatments with and without mulch and no root barrier.

Logseed yield $=-2.469+(0.242 \log$ plant height $)+(0.801 \log$ no. of productive twig $)$ Equation 4.4

Logseed yield $=0.106+(0.801 \log$ no. of productive twig $)$ Equation 4.5

Logseed yield $=0.247+(0.609 \log$ no. of productive twig $)$

Equation 4.6 
(A)

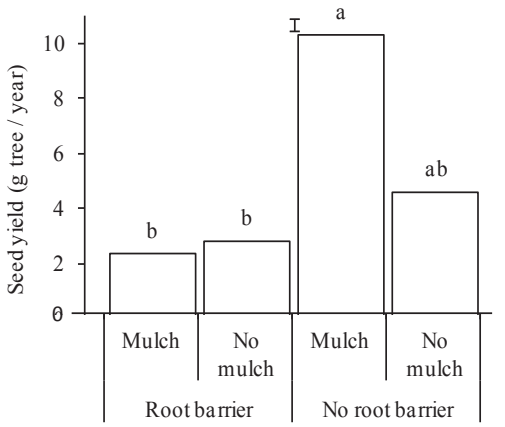

(C)

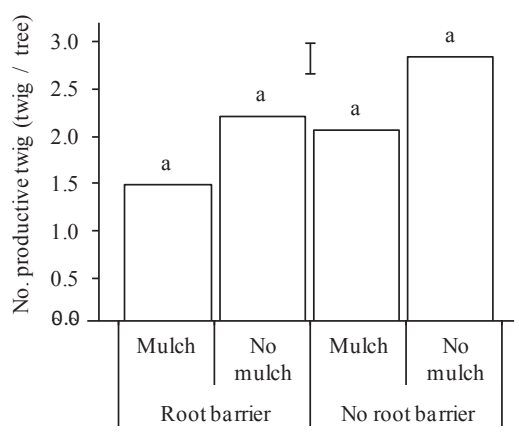

(E)

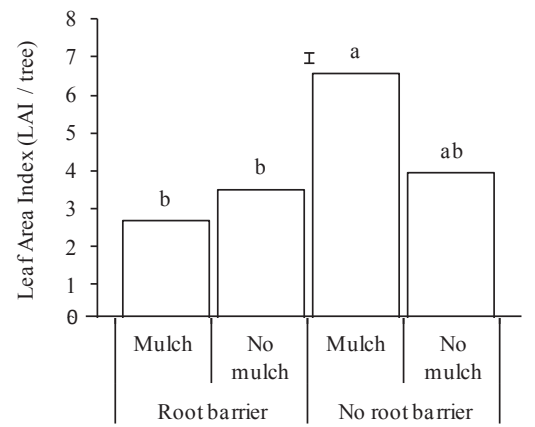

(B)

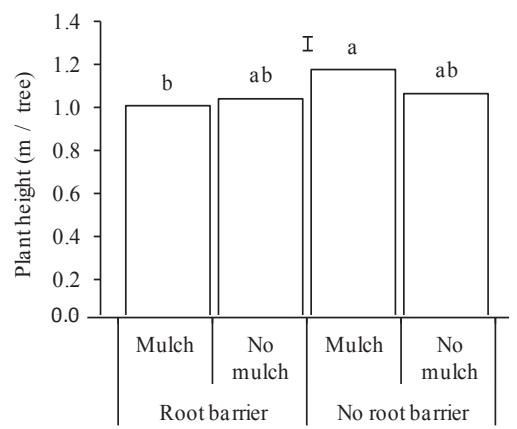

(D)

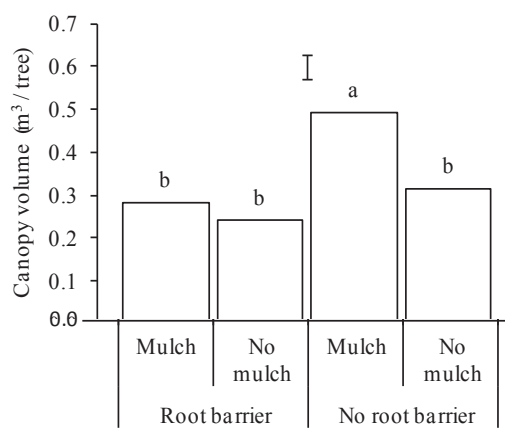

(F)

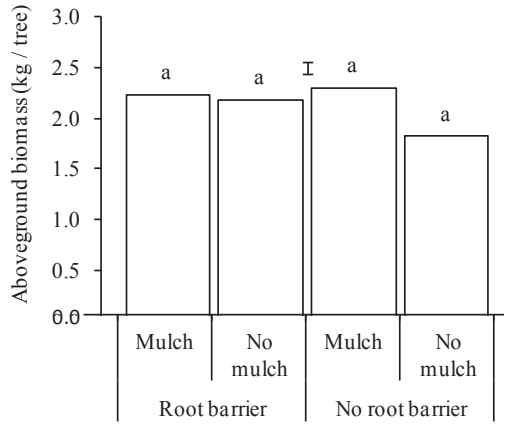

Figure 4.3 Mean seed yield and plant components of jatropha shrubs in intercropping system with combinations of root barrier and mulch treatments. Means with the same letter are not significantly different. Error bars represent standard error of mean difference (SED).

\subsubsection{Hedge}

Results for the hedge study are from the first pruning as the second pruning in the following year failed to produce seed. 


\subsubsection{Hedge with spacing of $10 \mathrm{~cm}$ and $30 \mathrm{~cm}$}

Seed yield (Figure 4.4A), number of productive branches (Figure 4.4C), canopy volume (Figure 4.4D) and LAI (Figure 4.4E) were all largest at $30 \mathrm{~cm}$ spacing after the first pruning treatment. At $30 \mathrm{~cm}$ spacing, the difference between pruned and unpruned plants was only significant for canopy volume.

(A)

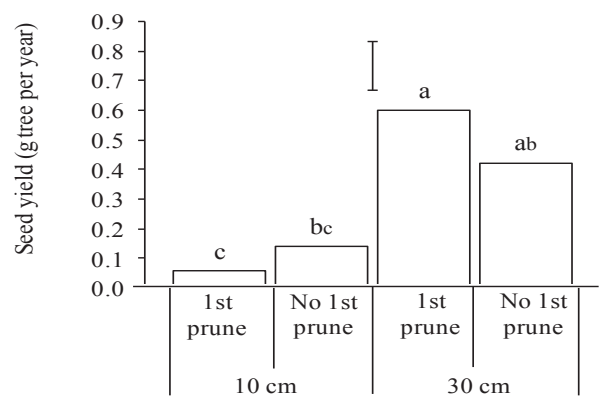

(C)

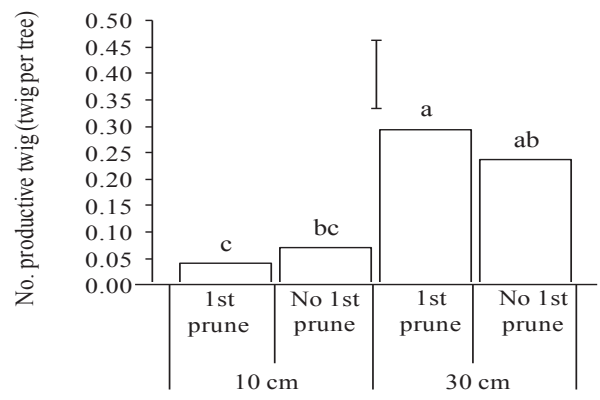

(E)

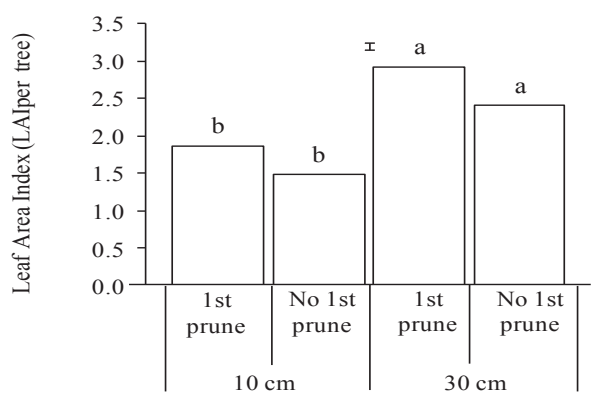

(B)

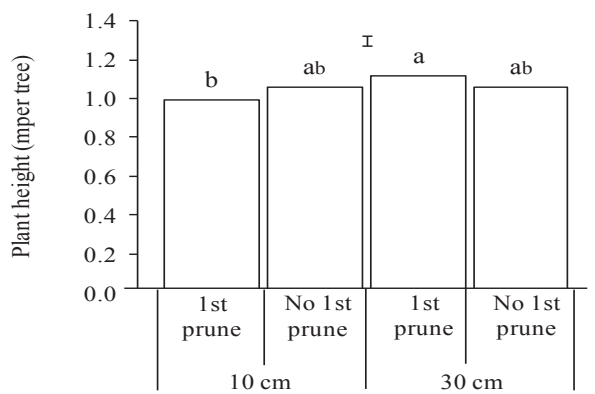

(D)

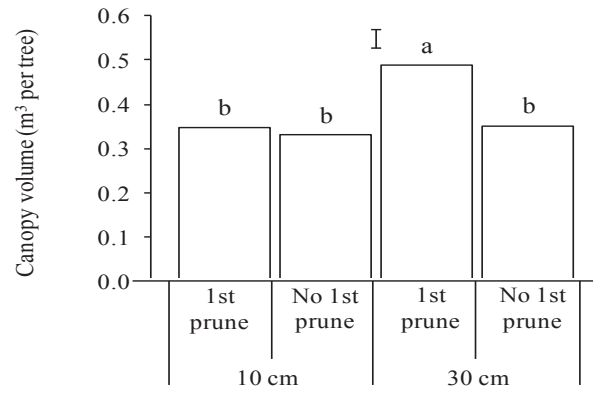

(F)

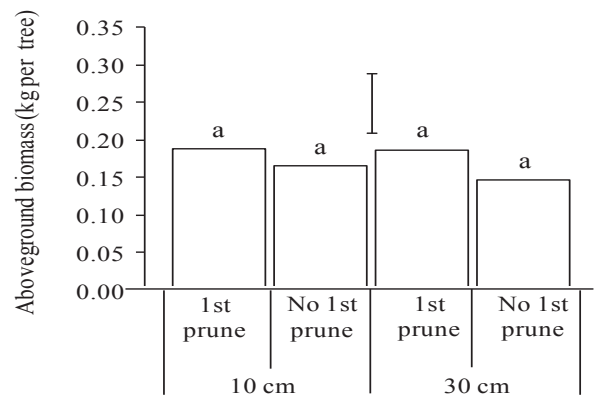

Figure 4.4 Mean seed yield and plant components of jatropha shrubs in hedge system with combination of plant spacing of $10 \mathrm{~cm}$ or $30 \mathrm{~cm}$ and pruning treatment. Means with the same letter are not significantly different. Error bars represent standard error of mean difference (SED). 
Plants at $10 \mathrm{~cm}$ spacing yielded significantly less seed, fewer productive branches, and had a smaller canopy volume and LAI than at $30 \mathrm{~cm}$ spacing. No significant differences between pruning treatments were observed. Numbers of productive branch (Figure 4.4C) followed a similar pattern to seed yield (Figure 4.4A).

In hedges, multiple inflorescence clusters also occurred per productive branch (16 \% three clusters, $27 \%$ two clusters, $57 \%$ one cluster), but were not the only or main determining factor. In contrast with monoculture and intercropping, the number of productive branches for hedges was not identified as a determinant of seed yield.

Overall multivariate stepwise regression analysis for hedge data showed that plant height was most strongly related to yield (Equation 4.7), $R^{2}=0.247$ ( $\mathrm{SE}=0.32$ ). Similar yield relationships held when taking into account planting density and pruning treatments, but with varying strength of the relationship between the plant height and seed yield. The $R^{2}$ for $10 \mathrm{~cm}$ spacing after first pruning (Equation 4.8) was 0.098 (SE = 0.16 ) and without first pruning (Equation 4.9) was $0.185(\mathrm{SE}=0.25)$, while the $R^{2}$ for $30 \mathrm{~cm}$ spacing after first pruning (Equation 4.10) was $0.375(\mathrm{SE}=0.43)$ and without first pruning (Equation 4.11) was 0.234 (SE $=0.32)$.

Logseed yield $=-2.185+(0.497 \log$ plant height $)$

Equation 4.7

Logseed yield $=-0.975+(0.312 \log$ plant height $)$

Equation 4.8

Log seed yield $=-1.708+(0.43 \log$ plant height $)$

Equation 4.9

Logseed yield $=-4.808+(0.613 \log$ plant height $)$

Equation 4.10

Logseed yield $=-2.864+(0.484 \log$ plant height $)$

Equation 4.11

\subsubsection{Hedge $10 \mathrm{~cm}$ monoculture and hedge $20 \mathrm{~cm}$ mixed}

No significant differences were observed for yield (Figure $4.5 \mathrm{~A}$ ) at either $10 \mathrm{~cm}$ or $20 \mathrm{~cm}$ spacing irrespective of the jatropha pruning treatment. Although yield was less after the first pruning for the $20 \mathrm{~cm}$ mixed planting, both the $10 \mathrm{~cm}$ and $20 \mathrm{~cm}$ spacing share a similar pattern for the numbers of productive branches (Figure 4.5C). While smaller yields may be a pruning response where a reduced LAI and slowed growth provides a disadvantage compared to no pruning, plant height (Figure 4.5B) was not affected. Plant height, canopy volume, and aboveground biomass in $20 \mathrm{~cm}$ mixed plantings were significantly larger than for $10 \mathrm{~cm}$ monoculture, but no significant differences were observed with pruning. The majority (59\%) of productive branches had two inflorescence clusters, $34 \%$ had one cluster and $7 \%$ had three clusters.

Interestingly no link between number of productive branches and canopy volume was observed (Figure 4.5C $\&$ D). Despite taller plants and greater canopy volume, LAI (Figure 4.5E) was reduced in the $20 \mathrm{~cm}$ mixed 
plantings with a significant difference between pruning treatments. Increases in aboveground biomass were predominantly associated with stem wood production and did not produce more productive branches or increase yield. No significant differences were observed between pruning treatments at either spacing.

Regression analysis of all data shows only plant height was related to yield, although the $R^{2}$ value was very small, $0.01(\mathrm{SE}=0.13)$ so no further analysis is presented.

(A)

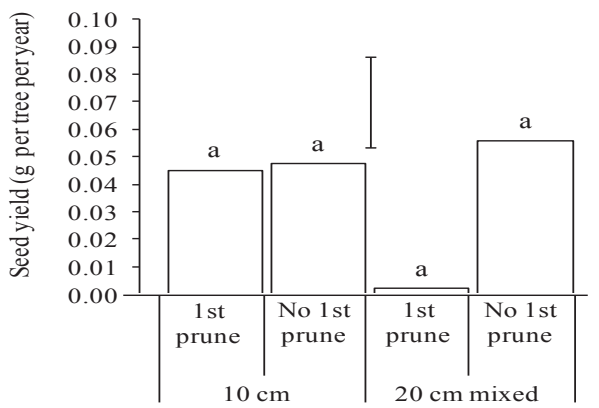

(C)

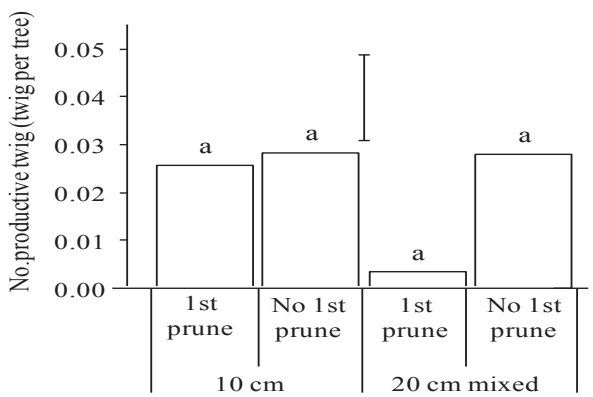

(E)

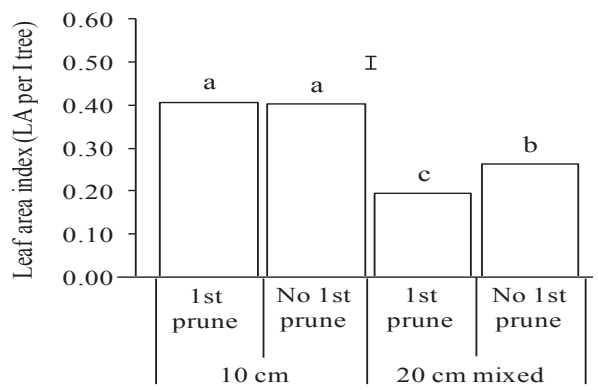

(B)

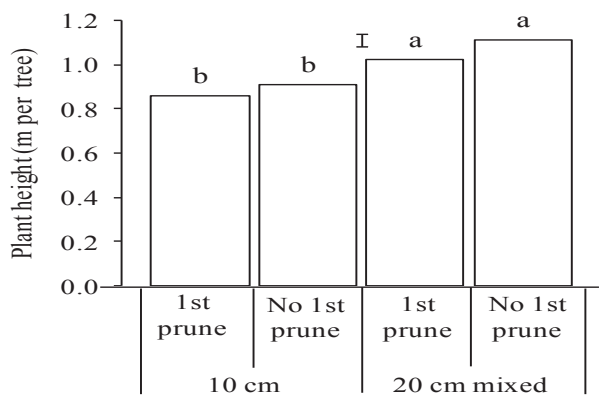

(D)

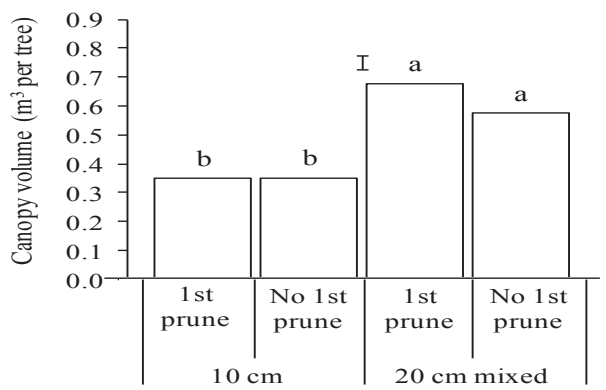

(F)

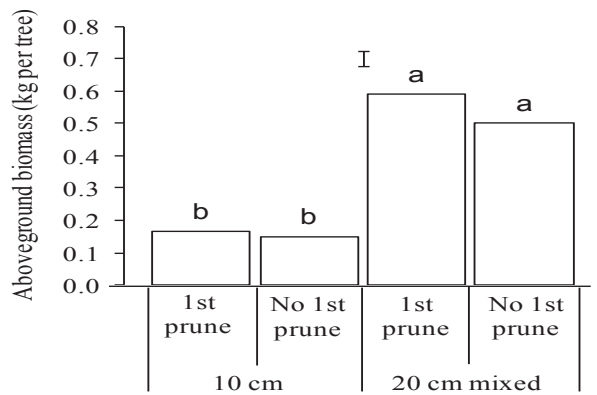

Figure 4.5 Mean seed yield and plant components of jatropha shrubs in hedge system with combination of plant spacing of $10 \mathrm{~cm}$ monoculture or $20 \mathrm{~cm}$ mixed and pruning treatment. Means with the same letter are not significantly different. Error bars represent standard error of mean difference (SED). 


\subsection{Discussion}

\subsubsection{Pruning effect on seed yield and plant components}

Pruning prior to the wet season or after leaf shedding increased seed production 6 to 8 months later through inflorescence development on new branch and twigs (Gour, 2006; Brittaine and Lutaladio, 2010; Van Eijck et al., 2010; Everson et al., 2013). For this study, all jatropha was pruned to $75 \mathrm{~cm}$ aboveground, a common practice in Indonesia, India, South Africa and Thailand. Pruning to other specific heights is also practiced (Ghosh et al., 2011; Suriharn et al., 2011; Everson et al., 2013; Singh et al., 2013). From 2004 to 2008 when investment in jatropha was intense (hype), growers in Indonesia often retained only two or three primary branches then prune again the following year, retaining the next two or three new branches (Cholid et al., 2007; Hariyadi et al., 2011). The objective was to develop a tree that has a total of 40 final branches which was considered optimal for fruit and seed production (Cholid et al., 2007). This idea was based on observations of young (one-year-old) jatropha with dichotomous branching of three or four branches. This plant produced more than 50 fruit per tree per year, the equivalent of around $0.3 \mathrm{t} \mathrm{ha}^{-1}$ seed at a planting density of $2 \mathrm{~m} \times 2 \mathrm{~m}$. It was assumed that increased yield (fruit and seed production) would result from the arithmetic multiplication associated with the dichotomous branching, producing predicted yields of $4 \mathrm{t} \mathrm{ha}^{-1}$ to $5 \mathrm{tha}^{-1}$ at five years of age (Cholid et al., 2007).

Our study shows that pruning two-year-old monoculture jatropha reduced vegetative growth and yield in comparison to no pruning (Figure 4.1) by changing the contribution of plant components to yield determination. After pruning, plant height makes no significant contribution to yield, although numbers of productive twig and LAI do (Equation 4.3). This is possibly because pruning was performed only at $75 \mathrm{~cm}$ aboveground resulting in similar sized plants. Our findings align with those of Cholid et al. (2007) who found reduced tree height after pruning although it was in one-year-old jatropha, but with new branch development twice that of the control. This was observed in all pruning treatments where branches were cut at $30 \mathrm{~cm}, 45 \mathrm{~cm}$, and $60 \mathrm{~cm}$ aboveground. Interestingly Singh et al. (2013) recorded significant decreases in new branch development as pruning heights increased from $30 \mathrm{~cm}, 45 \mathrm{~cm}$, to $60 \mathrm{~cm}$ aboveground; however this was in only one of seven sites. No mention is made of the cause of these differences between sites as neither author relate plant height or branch development to seed yield.

It is difficult to compare pruning effects on yield with other research as not all published studies included an unpruned control (Suriharn et al., 2011; Everson et al., 2013). Furthermore differences in planting material, tree age, planting density, fertiliser applications, and pruning heights or techniques add complexity to yield comparisons (Jongschaap et al., 2007). As the effect of pruning on plant components differed between authors and relations between plant components and seed yields were not established, the use of their results for improving seed yields is extremely limited. 
In the intercropping experiment, all plants were pruned at four years of age. Overall pruned plants with root barrier and mulch treatments showed that plant height and number of productive twigs contribute to seed yield determination (Figure 4.3). In the intercropping experiment, increased yield was not a function of increased number of productive twigs, but rather of productive twigs having multiple inflorescence clusters. After pruning the productive twigs produced terminal inflorescences, however after inflorescence set, branch development continued resulting in multiple inflorescence clusters.

Although yield and productive twig/branch is significantly related across the three cropping systems, it does however seem that for intercropping under root/mulch treatments there is a shift in the distribution of inflorescence clusters when compared with the monoculture. The differences in inflorescence distribution between intercropping and monoculture may be due to different age and aboveground competition. In monoculture, the jatropha is two-year-old and experienced aboveground intra-species competition. Plants with this condition showed an increase in flowering on new productive twigs. In intercropping, the jatropha is four-year-old and experienced aboveground inter-species competition with maize. Instead of allocating resources to flowering in more new productive twig, it allocated more flowering to the already existing productive twig. Although this hypothesis has not been tested, as we did not have control of four year-old jatropha in the intercropping, it does provide some new insight into jatropha reproductive behaviour and highlights a possible future research direction.

In Chapter 3 unpruned jatropha $(\mathrm{n}=10)$ in four-year-old monoculture plantings, the aboveground biomass allocation to different plant parts shows partitioning to fruit is $1 \%$, to leaf $8 \%$, and to stem, branch and twig is $91 \%$. It is therefore not surprising that pruning influences vegetative structures as opposed to generative and yield, as was shown in the second hedge experiment (Figure 4.5), at least in the short term.

It seems the two plant components consistently contributing to yield determination in all cropping systems are plant height and numbers of productive twig/branch. Plant height response may indicate a level of tree maturity crucial to productive twig development; however, this cannot be confirmed without further research. As for productive twig/branch, it is defined as the section of a branch where inflorescences and fruit develop and grow so logically it contributes to yield.

Prior to this study it was assumed that pruning would increase new branches and promote inflorescence development. However our results, and results from Chapter 3 show that not all new jatropha branches produced inflorescences. On the other hand, already productive twig/branches may increase their number of inflorescence clusters. Despite an extensive literature search, no studies were found that assess the effects of pruning on twig/branch productivity.

Pruning techniques have been used successfully in fruit trees to maximise yields. Pruning has two basic structures, formative pruning to create a strong framework to support heavy fruit loads, and maintenance 
pruning to remove superfluous vegetative growth and promote generative growth (Brunner, 1990; Grossman and DeJong, 1998; Van Eijck et al., 2010). Techniques used include open-centre crown (vase shape) pruning for peach, nectarine, and plum trees (Brunner, 1990; Grossman and DeJong, 1998), and spindle crown (central leader) pruning for apple and pear trees (Brunner, 1990). Coffee is another example where selective pruning and grafting of productive horizontal (plagiotrophic) branches with shorter internodes and high numbers of fruit clusters has been successful (Anim-Kwapong and Adomako, 2010; Gichimu and Omondi, 2010). The suitability of these pruning techniques for improving yield in jatropha remains to be investigated.

Our findings imply that future research to increase seed yield needs to focus on understanding the processes that lead to 1) increasing numbers of productive twig/branch and 2) number of inflorescences per productive branch. Based on this knowledge appropriate breeding and selection goals, and pruning techniques to maximise seed yield can be developed.

\subsubsection{Seed yield and pruning effect in relation to resource availability}

In monoculture, reductions in vegetative growth and yield due to pruning were in response to long time requirements for new branch, twig, leaf, fruit, and seed development. The experimental site had low soil fertility, which might help explain this slow growth response.

In the intercropping system, pruning in combination with jatropha leaf mulch applied to maize without root barriers produced the highest seed yields $\left(25 \mathrm{~kg} \mathrm{ha}^{-1}\right)$. A yield response due to mulch was expected given jatropha leaf $\mathrm{N}$ analysis ranged from $2 \%$ to $3.6 \%$ (Jongschaap et al., 2007; Ghosh et al., 2011), equivalent to an additional $\mathrm{N}$ application of $70 \mathrm{~kg} \mathrm{ha}^{-1}$ to $126 \mathrm{~kg} \mathrm{ha}^{-1}$. Without a root barrier the roots of jatropha had unlimited access to the $\mathrm{P}$ and $\mathrm{K}$ applied to the maize intercrop. In addition to yield, height, and canopy volume, LAI also increased with resource availability. This is in line with the negative effect of pruning on vegetative growth and seed yield in the resource poor environment in the monoculture experiment.

In the jatropha hedges, wider spacing increased yield. While the higher yields are likely due to increased access to soil moisture and nutrients, hedges are single row plantings therefore each plant already has unlimited access to resources either side of the planting. Close spacing might however lead to intraspecies root competition. The greater aboveground biomass for $20 \mathrm{~cm}$ jatropha-gliricidia plantings may be due to positive interactions between the jatropha and gliricidia. Gliricidia is a nitrogen fixing tree that can increase nitrogen and organic matter availability to jatropha through leaf and root turnover (Giller, 2001).

Although our study was conducted at two contrasting sites using two jatropha genotypes, it appears that nutrient availability might favour yield response in relation with pruning treatment. Future research to investigate a range of nutrient levels, possibly in combination with water provision may well provide valuable information for improving yield and management practices. 


\subsubsection{Pruning, planting density, plant components, and seed yield}

Literature related to hedge management using pruning height and planting density in jatropha is very limited. In hedge plantings at $10 \mathrm{~cm}$ and $30 \mathrm{~cm}$ spacing, differences were observed for canopy volume and LAI without corresponding differences in aboveground biomass. This indicates a less dense and possibly more elongated canopy for the $30 \mathrm{~cm}$ spaced plants, which may not be conducive to the production of inflorescence clusters.

LAI was lower for the $20 \mathrm{~cm}$ spacing mixed hedge plantings than for the $10 \mathrm{~cm}$ spacing monoculture hedges. The smaller LAI is in response to more vigorous growth in the jatropha as it outgrew the gliricidia. Regardless of treatment combination, yield was correlated with plant height. Where plants are situated close to one another light availability is an important and a potentially yield-limiting factor. Species dominance may become a problem in the future for mixed hedges not pruned.

\subsubsection{Seed yield comparison between genotypes and cropping systems}

While the experiments might be considered to have a strong management emphasis, the fact that limited jatropha breeding development has been done raises questions relating to natural variation. Currently there are no elite jatropha genotypes available for planting as breeding research is still in the early stages. Developmentally the jatropha are still wildlings.

In the four-year-old monoculture and intercropping, a single genotype, IP-1M, an improved population (IP) of a first selection (1) from Muktiharjo (M), Central Java (Hasnam and Hartati, 2006) was used. This planting material has vigorous vegetative growth and may be more suited to revegetation and remedial purposes (pers. comm. Purwati). Hedge planting material was a Sumbawa provenance and different to that used for monoculture and intercropping. All hedge planting materials were propagated from seed and not cuttings which can mean that trees took longer to mature and produce seed.

Seed yield from our two-year-old monoculture plantings on poor soils and grown without any additional inputs was $11 \mathrm{~g}$ per tree for pruned and $44 \mathrm{~g}$ per tree for non-pruned trees. These results are in line with a study of one-year-old IP-1M jatropha conducted by Retnowati and Surahman (2013) where in the first year, non-pruned jatropha planted at $2 \mathrm{~m} \times 2 \mathrm{~m}$ produced $17 \mathrm{~g}$ per tree when planted on acid soils with addition of manure and fertiliser at Bogor in Indonesia. Yield response from other provenances varied significantly from $7 \mathrm{~g}$ per tree to $68 \mathrm{~g}$ per tree (Retnowati and Surahman, 2013). Published yields in Indonesia for two-year-old monoculture plantings are consistently around $0.2 \mathrm{t} \mathrm{ha}^{-1}$ to $0.9 \mathrm{t} \mathrm{ha}^{-1}$ or $80 \mathrm{~g}$ per tree to $360 \mathrm{~g}$ per tree when planted at $2 \mathrm{~m} \times 2 \mathrm{~m}$ (Purwati and Hariyono, 2008; Hariyadi et al., 2011; Slingerland et al., 2014). Claims of

$4 \mathrm{tha}^{-1}$ to $5 \mathrm{tha}^{-1}$ and up to $12 \mathrm{tha}^{-1}$ are consistent with mature plantings age five years or older (Openshaw, 2000; Achten et al., 2008). 
No hedge data are available for seed comparison; however, seed yield from a Sumbawa provenance in the first year monoculture planted at $2 \mathrm{~m} \times 2 \mathrm{~m}$ and with manure and fertiliser applied was recorded at $220 \mathrm{~g}$ per tree to $340 \mathrm{~g}$ per tree (Santoso and Aryana, 2011). Iiyama et al. (2013) estimated jatropha hedge seed yield in Kenya at about $100 \mathrm{~g}$ per tree from trees of one to three-year-old, while GTZ (2009) observed in Kenya, hedges aged one to two years produced $2 \mathrm{~g}$ per tree to $36 \mathrm{~g}$ per tree. Henning (2001) estimated hedge seed yield in Mali at about $800 \mathrm{~g} \mathrm{~m}^{-1}$ year $^{-1}$ with older pruned hedges producing about $200 \mathrm{~g} \mathrm{~m}^{-1}$ year $^{-1}$.

Our hedge studies produced much lower yields, ranging from $0.97 \mathrm{~g} \mathrm{~m}^{-1}$ to $1.69 \mathrm{~g} \mathrm{~m}^{-1}$ in hedges planted at 10 $\mathrm{cm}$ and $30 \mathrm{~cm}$ respectively (Figure 4.4), and $0.46 \mathrm{~g} \mathrm{~m}^{-1}$ in monoculture hedges at $10 \mathrm{~cm}$ spacing and $0.14 \mathrm{~g}$ $\mathrm{m}^{-1}$ at $20 \mathrm{~cm}$ spacing in jatropha-gliricidia hedges (Figure 4.5).

Although there were two hedge studies conducted at the same location, using the same planting material and treatments $(75 \mathrm{~cm}$ height and planting distance of $10 \mathrm{~cm}$ ), seed yield for the first hedge study was double that of the second. This result shows that in hedges, management may not be the dominant factor responsible for seed yield. Possibly, any genotype plasticity within jatropha, either as individuals, or collectively has a greater contribution to seed yield.

The smaller yield in our hedges compared with the literature may be due to differences in planting material and age, pruning heights, weeding practices, soil moisture, nutrient availability, and climatic conditions (Iiyama et al., 2013; Singh et al., 2013). In terms of yield our hedges were relatively young at one-year-old, and when combined with different pruning heights and different soil and climatic conditions, these may have been contributing factors.

Overall our yield is situated at a lower end of the scale in comparison with the global yield and expectations (Achten et al., 2008; Trabucco et al., 2010; Van Eijck et al., 2014a). Global yield results such as those reported by Van Eijck et al. (2014a), by Achten et al. (2008), and by Trabucco et al. (2010) also showed extensive variation, from $(0.003$ to 8$) \mathrm{tha}^{-1},(0.1$ to 12$) \mathrm{tha}^{-1} \mathrm{year}^{-1}$, and (0.2 to 4$) \mathrm{tha}^{-1}$ year ${ }^{-1}$ respectively.

Future jatropha breeding research is crucial and will need to concentrate on developing a balance between vegetative and generative growth. Jatropha seems to come in many different phenotypes (Sunil et al., 2013) showing a large amount of developmental plasticity (Yi et al., 2010; Osorio et al., 2014). Hence breeding for hedges, intercropping, and monoculture cropping systems may need to identify different phenotypes or target genotype-pruning combinations; keeping in mind above and belowground inter and intraspecies competition. Furthermore genotypes to be used for revegetation, remediation, firewood or fencing might require different traits than genotypes for seed yield. 


\subsection{Conclusion}

Seed yield was highest in monoculture, intercropping, and hedges in that order. Overall results indicate that seed yield across the three cropping systems can be determined by plant height and numbers of productive twig/branch, although number of inflorescence clusters per productive twig may be more important. Unexpectedly the pruning technique of cutting all branches back to $75 \mathrm{~cm}$ aboveground reduced yields. This effect may be due to interactions between genotype, planting age, and soil water and nutrient availability. Available soil water and the addition of soil nutrients will favour seed yield as observed for pruned trees in the intercropping experiment. If hedges are to be considered as viable options for jatropha seed production, growers will need to consider lower planting densities and increased nutrient management. 
Chapter 5 Resource competition between Jatropha curcas L. and maize when intercropped in Indonesia 


\begin{abstract}
Annual crops inter-planted during the early stages of tree (or shrub) plantations interact through direct competition for below and aboveground resources, and indirectly by modification of soil conditions and microclimate, combining to produce a net interaction effect on the crop, as well as tree. I explored the net effects and a number of interaction components by comparing a jatropha-maize intercropping system with maize monoculture over two growing seasons, with and without mulch and with and without polythene root barriers to reduce belowground competition. Root barriers had variable effects on maize yield. Belowground competition was estimated at $-15 \%$ of control crop yield for first season (Season 1) which experienced high rainfall and $36 \%$ for the second season (Season 2) which had adequate rainfall. Aboveground competition was $-20 \%$ for Season 1 and $-29 \%$ for Season 2. The results showed competition to be dependent on soil fertility. Fertility minus below or aboveground competition allowed for two interaction factors to be calculated. Interaction 1 produced positive values for Season 1 (32\%) and Season $2(51 \%)$, however Interaction 2 produced a positive value for Season 1 (28\%) and a negative value for Season $2(-14 \%)$. Jatropha prunings applied as mulch were effective in supplying $\mathrm{N}$ to the maize crop, equivalent to an application of $21 \mathrm{~kg} \mathrm{~N} \mathrm{ha}^{-1}$. Yield for the monoculture maize treatments increased with mulch (30\%) and with inorganic $\mathrm{N}$ at $45 \mathrm{~kg} \mathrm{ha}^{-1}$ (58\%), $90 \mathrm{~kg} \mathrm{ha}^{-1}(123 \%)$ and $135 \mathrm{~kg} \mathrm{ha}^{-1}$ (156\%) relative to the control. Further understanding of the dynamics of these interactions using plant modelling is required to assess longterm productivity.
\end{abstract}

Keywords: Competition - Fertility - Interaction - Leaf mulch - Root barrier 


\subsection{Introduction}

Jatropha has been promoted in many countries as a biofuel crop (Openshaw, 2000; Wahl et al., 2009; Bailis and McCarthy, 2011), including Indonesia (Vel et al., 2013). While the popularity of jatropha in Indonesia has risen and fallen (Vel et al., 2013) many plantings such as those in Gunungkidul - Yogyakarta (Gunawan, 2014), in Sikka - East Nusa Tenggara (Van Rooijen, 2014a), and in Sumbawa - West Nusa Tenggara, Indonesia have been abandoned.

Jatropha plantings are currently unprofitable primarily due to a combination of poor yields and commodity prices, further compounded by resource limitations, poor soil fertility, and accessibility (GTZ, 2009; Wahl et al., 2009; Iiyama et al., 2013). Some farmers in Sikka and Sumbawa were observed to continue maintaining their jatropha, utilising the pruned leaves as mulch for annual crops such as peanut (Arachis hypogaea), rice (Oryza sativa), and maize. This suggests that jatropha may have some intercropping potential, yet little published research has examined this.

Intercropping involves complex tree, crop, and soil interactions (Kang and Wilson, 1987; Van Noordwijk et al., 1998) where soil fertility and competition are important factors for maximising net returns (Singh et al., 1989; Ong et al., 1991; Jose et al., 2000). A basic equation relates the total yield ( $\left.\mathrm{Y}_{\text {tot }}\right)$ to the area fraction allocated to the crop $\left(A_{C}\right)$, the yield of crop and tree when grown alone ( $Y_{C}$ and $Y_{T}$, respectively). $U_{T C}$ is a weighing factor for the utility of the tree yield relative to that of the crops, and $\mathrm{I}_{\mathrm{TC}}$ and $\mathrm{I}_{\mathrm{CT}}$ are two interaction terms respectively for effects of tree ( $\mathrm{T}$ ) on crop (C), and vice-versa (Equation 5.1).

$Y_{\text {tot }}=A_{C} Y_{C}+\left(1-A_{C}\right) U_{T C} Y_{T}+I_{T C}+U_{T C} I_{C T}$

Equation 5.1

Ong $(1995,1996)$ developed an equation to determine this tree-crop interaction (Equation 5.2). For both the $\mathrm{TC}$ and $\mathrm{CT}$ interactions, the interaction term (I) can be interpreted as:

$$
I_{T C}=F_{T C}+C_{T C}+M i_{T C} \text { and } I_{C T}=F_{C T}+C_{C T}+M i_{C T}
$$

$\mathrm{I}_{\mathrm{TC}}$ and $\mathrm{I}_{\mathrm{CT}}$ are the interaction effects, measured in the units of crop and tree yield respectively, proportional to the area planted with the tree or crop respectively. $\mathrm{F}_{\mathrm{TC}}$ and $\mathrm{F}_{\mathrm{CT}}$ are the total positive effects of tree on crop yield (and vice-versa, respectively) through soil fertility improvement. The competition terms $\left(\mathrm{C}_{\mathrm{TC}}\right.$ and $\left.\mathrm{C}_{\mathrm{CT}}\right)$ represent negative yield effects resulting from reduced resource access. The $\mathrm{Mi}_{\mathrm{TC}}$ and $\mathrm{Mi}_{\mathrm{CT}}$ terms represent yield effects through modification of microclimate. For example lower maximum soil temperature and reduced soil evaporation can influence resource competition.

Soil fertility improvement is a facilitation effect that integrates multiple interactions of water and nutrient uptake (Magcale-Macandog and Abucay, 2007) with recycling of biomass as surface mulch. Soil nutrient 
availability can be increased through inorganic fertilisers, the use of which will depend on uptake efficiency and input/output price ratio (Kang and Wilson, 1987; Mupangwa et al., 2012; Castellanos-Navarrete et al., 2015). Mulch is a feasible alternative that can provide significant benefits for soil fertility (Kang et al., 1990). Mulch high in $\mathrm{N}$ and low in lignin and polyphenols release nutrients rapidly, whereas mulch low in $\mathrm{N}$ and high in lignin and polyphenol release nutrients more slowly, or can even immobilise them (Palm, 1995), stabilising the soil surface for a longer period of time (Palm et al., 2001).

Interspecific competition can combine to create unique, complex and competing interactions by restricting nutrient, water, and light capture for each of the components measured (Ong, 1995; Sanchez, 1995; Van Noordwijk et al., 1998). Managing tree and crop aboveground competition through plant spacing and/or pruning is easier than managing belowground competition. Negative effects on plant growth from belowground competition for water and nutrients can be reduced by increasing nutrient and water availability, and by tree root pruning and/or the installation of vertical polythene root barriers (Ong et al., 1991; Ong et al., 1996; Jose et al., 2000).

Understanding above and belowground competition in relation to soil fertility, and the direction and magnitude of tree and crop interactions is crucial to developing a feasible intercropping system. While these aspects have not been adequately explored in jatropha intercropping systems, some intercropping experiments have been reported (Sharma and Rana, 2014; Da Silva Neto et al., 2015). Maize is the predominant annual cash crop preferred by farmers in our experimental location (Gunungkidul) and formed the basis of our study.

The aim of this study was to explore the interactions of jatropha-maize intercropping focusing on maize yield. The two primary objectives were:

1. To determine yield response of the maize crop component in a jatropha-maize intercropping system.

2. To determine fertility, competition, and interaction effects of jatropha leaf mulch and polythene root barriers on maize yield in jatropha-maize intercropping.

\subsection{Materials and methods}

\subsubsection{Study site and conditions}

The study was conducted in Gunungkidul Regency of Special Province Yogyakarta $\left(8^{\circ} 0^{\prime} \mathrm{N}, 110^{\circ} 34^{\prime} \mathrm{E}, 185\right.$ m ASL) during the 2012 and 2013 growing seasons. Gunungkidul has an equatorial rainforest climate with rainfall occurring predominantly from November to April and dry periods from June to August or September. Total annual rainfall in 2012 was $1,400 \mathrm{~mm}$, distributed over 78 rain days, while total annual rainfall in 2013 was 2,160 mm, distributed over 131 rain days. Mean annual temperature and relative humidity in 2012 and 2013 were $27.4{ }^{\circ} \mathrm{C}$ and $72 \%$ and $27.9^{\circ} \mathrm{C}$ and $79 \%$ respectively. 
The soils, around $40 \mathrm{~cm}$ deep with limestone beneath are Mollisols with texture varying from clay, silty clay to silty clay loam, with poor drainage. Top soil is $0 \mathrm{~cm}$ to $10 \mathrm{~cm}$ while soil $\mathrm{pH}$ (1:5 soil : water) was 7.7 with $\sim 0.9 \%$ organic carbon (Walkley-Black method). Total nitrogen (Kjeldahl method), phosphorus (Olsen method), and potassium (ammonium acetate $\mathrm{pH}$ 7) were $0.5 \mathrm{mg} \mathrm{kg}{ }^{-1}, 13.8 \mathrm{mg} \mathrm{kg}^{-1}$ and $0.2 \mathrm{cmol}^{(+)} \mathrm{kg}^{-1}$ respectively.

\subsubsection{Experimental design}

The experiment was a randomised complete block design with three replicate blocks, each consisting of nine treatments and established in an existing four-year-old (seedling) jatropha plantation (Table 5.1).

Table 5.1 Experimental treatments.

\begin{tabular}{lll}
\hline No. & Code & \multicolumn{1}{c}{ Treatment details } \\
\hline 1 & WmWrb & maize - jatropha intercropping With mulch and With root barrier \\
2 & NmWrb & maize - jatropha intercropping with No mulch and With root barrier \\
3 & WmNrb & maize - jatropha intercropping With mulch and No root barrier \\
4 & NmNrb & maize - jatropha intercropping with No mulch and No root barrier \\
5 & $\mathrm{C}_{\mathrm{O}}$ & monoculture maize Control \\
6 & $\mathrm{Cm}$ & monoculture maize with jatropha leaf mulch \\
7 & $45 \mathrm{~N}$ & monoculture maize with N applied at $45 \mathrm{~kg} \mathrm{ha}^{-1}(33 \%$ of the recommended rate $)$ \\
8 & $90 \mathrm{~N}$ & monoculture maize with N applied at $90 \mathrm{~kg} \mathrm{ha}^{-1}(66 \%$ of the recommended rate $)$ \\
9 & $135 \mathrm{~N}$ & monoculture maize with N applied at $135 \mathrm{~kg} \mathrm{ha}^{-1}(100 \%$ of the recommended rate $)$ \\
\hline
\end{tabular}

Using data from the four maize monoculture treatments $\left(\mathrm{C}_{\mathrm{O}}, 45 \mathrm{~N}, 90 \mathrm{~N}\right.$, and $\left.135 \mathrm{~N}\right)$ an $\mathrm{N}$ response curve was calculated. Treatments WmWrb, WmNrb, NmWrb, NmNrb were used to determine fertility $\left(\mathrm{F}_{\mathrm{TC}}\right)$ and belowground competition $\left(\mathrm{C}_{\mathrm{TC}, \mathrm{B}}\right)$ effects, while treatments WmWrb, NmWrb, Mulch, and $\mathrm{C}_{\mathrm{O}}$ (Control) were used to determine aboveground competition and microclimate effects $\left(\mathrm{C}_{\mathrm{TC}, \mathrm{A}}+\mathrm{Mi}_{\mathrm{TC}}\right) . \mathrm{F}_{\mathrm{TC}}, \mathrm{C}_{\mathrm{TC}}$, $\mathrm{B}$, and $\mathrm{C}_{\mathrm{TC}}, \mathrm{A}$ $+\mathrm{Mi}_{\mathrm{TC}}$ were used to generate the interaction (I) effects as shown in Table 5.2 and Table 5.3.

$\mathrm{F}_{\mathrm{TC}}$ (further described as $\mathrm{F}$ ) is the measure of the change in maize yield in response to the application of mulch in the intercropping where the smaller the positive value the greater is the fertility effect. Competition is the measure of change in maize yield in response to the installation of $400 \mu \mathrm{m}$ polythene root barriers. Competition normally involves a negative value, while a zero value indicates a balance or neutral effect. A positive effect would indicate a degree of complementarity; however, the separation between complementarity and facilitation will be difficult; as the focus is on the net effect rather than the resource access. 
Table 5.2 Combination treatments for Fertility $\left(\mathrm{F}_{\mathrm{TC}}\right)$, above and belowground Competition $\left(\mathrm{C}_{\mathrm{TC}}\right.$, $\mathrm{B}$ and $\mathrm{C}_{\mathrm{TC}}$, A,) and Microclimate $\left(\mathrm{Mi}_{\mathrm{TC}}\right)$ effects for the jatropha-maize intercropping and maize monoculture.

\begin{tabular}{llllll}
\hline \multicolumn{1}{c}{ Treatment } & & $\mathrm{F}_{\mathrm{TC}}$ & $\mathrm{C}_{\mathrm{TC}, \mathrm{B}}$ & $\mathrm{C}_{\mathrm{TC}, \mathrm{A}}$ & $\mathrm{Mi}_{\mathrm{TC}}$ \\
\hline With mulch With root barrier & $(\mathrm{WmWrb})$ & + & - & + & + \\
No mulch With root barrier & $(\mathrm{NmWrb})$ & - & - & + & + \\
With mulch No root barrier & $(\mathrm{WmNrb})$ & + & + & + & + \\
No mulch No root barrier & $(\mathrm{NmNrb})$ & - & + & + & + \\
Monoculture planting with mulch & $(\mathrm{Cm})$ & + & - & - & - \\
Monoculture (Control) & $\left(\mathrm{C}_{\mathrm{O}}\right)$ & - & - & - & - \\
\hline
\end{tabular}

Note: (+) indicates available fertility or competition effects, while (-) sign indicates no fertility or competition effects.

Two competition responses, $\mathrm{C}_{\mathrm{TC}, \mathrm{B}}$ (further described as $\mathrm{C}_{\mathrm{B}}$ ) and $\mathrm{C}_{\mathrm{TC}, \mathrm{A}}+\mathrm{Mi}_{\mathrm{TC}}$ (further described as $\mathrm{C}_{\mathrm{A}}$ ) were calculated. $C_{B}$ is the net effect of belowground competition of tree and crop with and without root barriers (with mulch at high soil fertility level and without mulch at low soil fertility level). $\mathrm{C}_{\mathrm{A}}$ calculated aboveground competition and microclimate effect in monoculture and intercropping (with mulch at greater soil fertility level and without mulch at low soil fertility level). Interaction is the measure of the change that has occurred in yield taking into account $F$ and $C$. $F$ in combination with $C_{B}$ or $C_{A}$ allowed the two interaction results, $I_{1}$ and $I_{2}$ to be were calculated. A positive interaction indicates that $F>C$ and a net complementarity effect advantageous for crop production. A negative interaction indicates that $\mathrm{F}<\mathrm{C}$ and a net competition effect that is disadvantageous (Ong et al., 1996; Van Noordwijk et al., 1996; Van Noordwijk et al., 1998). The greater the interaction value the greater is the interaction effect, with a zero value indicating no interaction.

Table 5.3 Equations used to calculate fertility, competition, and interaction effects on maize yield over two planting seasons.

\begin{tabular}{lcl}
\hline \multicolumn{2}{c}{ Component } & \multicolumn{1}{c}{ Calculation } \\
\hline Fertility & $(\mathrm{F})$ & $((\mathrm{WmWrb}+\mathrm{WmNrb})-(\mathrm{NmWrb}+\mathrm{NmNrb})) / 2$ \\
Competition 1 & $\left(\mathrm{C}_{\mathrm{B}}\right)$ & $((\mathrm{WmWrb}+\mathrm{NmWrb})-(\mathrm{WmNrb}+\mathrm{NmNrb})) / 2$ \\
Competition 2 & $\left(\mathrm{C}_{\mathrm{A}}\right)$ & $\left((\mathrm{WmWrb}+\mathrm{NmWrb})-\left(\mathrm{Cm}+\mathrm{C}_{\mathrm{O}}\right)\right) / 2$ \\
Interaction 1 & $\left(\mathrm{I}_{1}\right)$ & $\mathrm{I}(1)=\mathrm{F}+\mathrm{C}_{\mathrm{B}}$ \\
Interaction 2 & $\left(\mathrm{I}_{2}\right)$ & $\mathrm{I}(2)=\mathrm{F}+\mathrm{C}_{\mathrm{A}}$ \\
\hline
\end{tabular}

Both the monoculture and intercropping plots had two maize BISI-2 hybrid seeds planted per hole at a spacing of $0.25 \mathrm{~m} \times 0.75 \mathrm{~m}$, with the less vigorous seedling thinned out after two weeks. The maize monoculture plot was $3 \mathrm{~m} \times 4.5 \mathrm{~m}$, while for jatropha-maize intercropping the maize plot size was according to the jatropha planting spacing. All maize plants received $72 \mathrm{~kg} \mathrm{ha}^{-1}$ of $\mathrm{P}$ and $120 \mathrm{~kg} \mathrm{ha}^{-1}$ of $\mathrm{K}$ 
(recommended doses) while $\mathrm{N}$ was applied according to the treatments. $\mathrm{P}$ and $\mathrm{K}$ fertilisers were applied 7 days after planting, while $\mathrm{N}$ fertiliser treatments were applied as split applications, 7 and 35 days after planting. Maize is normally fertilised every year therefore the treatments are practical and relevant, as any likely residual effect of $\mathrm{N}$ fertiliser in the humid climate of the site studied would be small. No assessment was made of the cumulative effects on jatropha yield. During the growing period, all plots were hand weeded monthly. Rust was controlled using Mancozeb as a foliar spray $\left(2 \mathrm{~g} \mathrm{~L}^{-1}\right)$, while Diazinon was applied as a foliar spray $\left(2 \mathrm{~g} \mathrm{~L}^{-1}\right)$ to control armyworm (Spodoptera $\mathrm{sp}$.).

Jatropha planting material was seed propagated IP-1M and planted aged three months at $2 \mathrm{~m} \times 2 \mathrm{~m}$. No agricultural inputs were applied to the jatropha and grass was harvested from the jatropha plots by local farmers for cattle feed. At the start of the first wet season all jatropha were pruned $75 \mathrm{~cm}$ aboveground and treated with Mancozeb at $2 \mathrm{~g} \mathrm{~L}^{-1}$, and all cuts sealed with white, waterproof paint. To prevent Fusarium or Phythopthora infections all jatropha received $200 \mathrm{~g}$ per plant Trichoderma applied to the soil in split applications, while maize received $10 \mathrm{~g}$ per plant of Trichoderma. Trichoderma applications were to a depth of $15 \mathrm{~cm}$ under the jatropha drip line and to $10 \mathrm{~cm}$ in the maize planting.

Jatropha plot size of $5 \mathrm{~m} \times 12 \mathrm{~m}$ had three rows of seven trees with three rows of maize planted between (Figure 5.1). The root barrier treatment used a clear polythene sheet $(400 \mu \mathrm{m})$ installed in a trench approximately $14 \mathrm{~m}$ long, $40 \mathrm{~cm}$ deep, $20 \mathrm{~cm}$ wide and positioned $50 \mathrm{~cm}$ from the jatropha row on both alleys, and installed prior to jatropha pruning and maize planting.

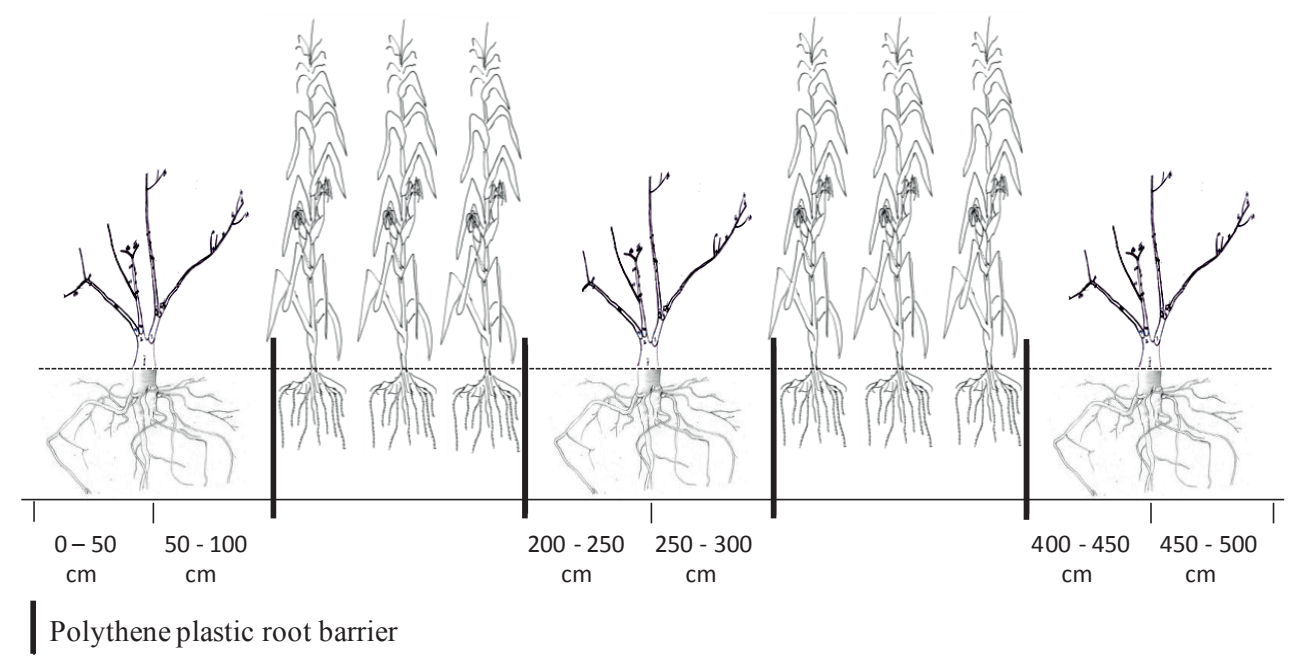

Figure 5.1 Schematic drawing of jatropha - maize intercropping showing the location of the root barrier treatments. 
Polythene sheeting was retained $5 \mathrm{~cm}$ above the soil surface to prevent the spread of the roots over the top of the barrier and the trenches back-filled with the subsoil returned first followed by top soil.

Air-dried jatropha leaf prunings (leaflets with petioles) equivalent to $3.5 \mathrm{t} \mathrm{ha}^{-1}$ were incorporated into the top $15 \mathrm{~cm}$ of soil using hand hoes two weeks before maize planting. Application was according to the treatment and in amounts proportional to the size of the experimental plots. Table 5.4 provides an analysis of the nutrient status of the jatropha leaf mulch.

Table 5.4 Nutrient composition of jatropha leaf applied as mulch.

\begin{tabular}{|c|c|c|c|c|c|c|c|c|c|c|c|c|c|}
\hline$\%$ & C-organic & C:N & $\mathrm{N}$ & $\mathrm{Lg}$ & $\mathrm{Pp}$ & Lg:N & $(\mathrm{Lg}+\mathrm{Pp}): \mathrm{N}$ & $\mathrm{P}$ & $\mathrm{K}$ & $\mathrm{C}$ & $\mathrm{Mg}$ & $\mathrm{Na}$ & $\mathrm{S}$ \\
\hline Average & 40.91 & 15.70 & 2.61 & 15.84 & 3.71 & 4.45 & 7.50 & 0.18 & 1.14 & 4.04 & 0.79 & 0.34 & 0.05 \\
\hline SD & 1.59 & 0.80 & 0.24 & 1.89 & 0.89 & 1.21 & 0.05 & 0.10 & 0.78 & 0.76 & 0.41 & 0.11 & 0.01 \\
\hline
\end{tabular}

Note: $\%$ analysis is based on $\mathrm{mg}$ per $1 \mathrm{~g}$ dry weight; $\mathrm{n}=3, \mathrm{Lg}=$ Lignin, $\mathrm{Pp}=$ Polyphenol; $\mathrm{SD}=$ standard deviation

The experiment used the same plots and treatments over two planting seasons, the first starting on $21^{\text {st }}$ November 2012, and finishing on $3^{\text {rd }}$ March 2013; with the second starting on $23^{\text {rd }}$ March 2013 and finishing $2^{\text {nd }}$ July 2013.

\subsection{Maize measurements}

Starting three weeks after planting (WAP) three replicates, two in the outer rows and one in the centre row, were measured for height, stem diameter at $10 \mathrm{~cm}$ high, and number of open leaves. Three random samples taken from each treatment at 4, 8, and 12 WAP provided data on LAI, root length density (RLD), and root, shoot, and total biomass. Maize yield for the intercropping and monoculture was calculated. Maize cobs were manually separated from the stover and sun-dried before placing in netting bags for threshing. After threshing, grain moisture content was determined and grain weight recorded at $12 \%$ to $13 \%$ moisture content. Dried stover weight determined HI.

Maize $\mathrm{N}$ uptake at harvest was determined from three random samples of grain and stover taken from the monoculture treatments. Grain and stover samples were ground separately and passed through $1 \mathrm{~mm}$ mesh sieve for $\mathrm{N}$ analysis (Kjeldahl method). Total maize $\mathrm{N}$ uptake was determined by multiplying $\mathrm{N}$ concentration by the total dry biomass. Yield (dry grain) $\mathrm{N}$ uptake was determined by multiplying grain $\mathrm{N}$ concentration by yield. N recovery was calculated using Equation 5.3 from Mafongoya and Nair (1997).

$\% N$ recovery $=\frac{\mathrm{N} \text { uptake of treatment }-\mathrm{N} \text { uptake of control }}{\mathrm{N} \text { initially applied }} \times 100 \%$

Equation 5.3 


\subsection{Data analysis and statistics}

All data tested normal and were $\log$-transformed $(\log \mathrm{x}+1)$ prior to analysis. All results were backtransformed to improve analysis description. Maize yield response to applied $\mathrm{N}$ was determined by fitting $\mathrm{N}$ application rates and maize yield for control, $45 \mathrm{~N}, 90 \mathrm{~N}$, and $135 \mathrm{~N}$ with a quadratic function (Van Raij and Cantarella, 1996; Kimetu et al., 2004). The $\mathrm{N}$ equivalent for mulch was determined using Equations 5.4 and 5.5 .

$Y=a X^{2}+b X+c$ Equation 5.4

$X=\frac{-b \pm \sqrt{b^{2}-4 a c}}{2 a}$ Equation 5.5

Where $Y$ is maize yield, $X$ is $\mathrm{N}$ application rate, while $a$ (quadratic coefficient), $b$ (linear coefficient), and $c$ (intercept) are constants obtained from the quadratic equation of the response curve. By replacing Equation 5.4 with Y $\max$ and Xmax (Equation 5.6) maximum maize yield and rate of $\mathrm{N}$ application, respectively can be determined.

$X \max =\frac{b}{-2 a}$ Equation 5.6

Data were analysed using SAS 9.3 (SAS Institute Inc., Cary, NC, USA). Field data for grain yield and HI were analysed using the PROC MIXED and repeated measurement procedures (Littell et al., 2006) where sample date was treated as a non-random variable over time. Mean differences $(P<0.05)$ were determined using the Tukey's test. Fertility effects, competition, and interactions were determined from contrasting means.

\subsubsection{Results}

A total of 1,182 mm rain fell over 62 rain days for Season 1 and $575 \mathrm{~mm}$ over 42 rain days for Season 2 (Figure 5.2). 


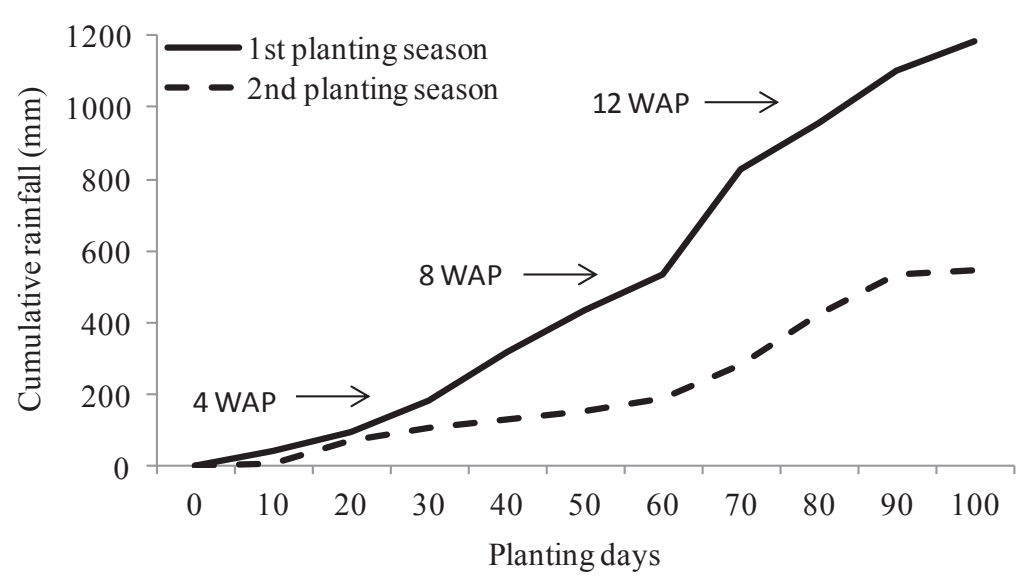

Figure 5.2 Cumulative rainfall distribution for the two planting seasons of 100 days and showing rainfall at 4,8 and 12 weeks after planting (WAP).

Season 1 had twice the total rainfall of Season 2 although Season 2 had proportionally more rain days. Cumulative rainfall during the two seasons was similar at 4 WAP, although there was a slightly greater rainfall in Season 1. Cumulative rainfall at 8 WAP and 12 WAP in Season 1 were approximately double in Season 2.

\subsubsection{Maize yield response}

Table 5.5 shows maize yield and HI for Season 1 and Season 2. There were significant season and treatment interactions for grain yield with all treatments $(P<0.01)$ showing a $59 \%$ increase in grain yield from Season 1 to season 2, and a clear pattern of increasing yield with increasing $\mathrm{N}$ application rates. The exception was for mulch, which had a greater addition of $\mathrm{N}$ than the control, although yield was less in Season 1. Overall intercropping treatments produced $21 \%$ greater and $13 \%$ lower yields than the control in Season 1 and 2 respectively. Yield for treatments with mulch in Seasons 1 and 2 were not significantly different to the control, irrespective of a root barrier. However, the yield increases observed between Season 1 and Season 2 is noteworthy. Treatment WmWrb increased by $35 \%$, NmWrb by $188 \%$, NmNrb by $8 \%$, while WmNrb decreased by $8 \%$. A comparison of average yield for intercropping with the control over two seasons showed that treatment WmWrb increased by $7 \%$, while NmWrb, NmNrb and WmNrb decreased by $23 \%$, $37 \%$, and $9 \%$ respectively.

Furthermore, the addition of mulch and root barrier treatments resulted in larger yields in the maize centrerows, on average $36 \%$ greater than the edge-rows. In treatments WmWrb and NmWrb, yield in the edgerows did not increase as expected. Yield for the centre-rows was consistently 42 to $45 \%$ greater than for the edge-rows. When no root barrier was present, yield variation was greater (16 \% to $31 \%)$. 
Table 5.5 Maize grain yield and harvest index for intercropping and monoculture (control) plantings over the two planting seasons.

\begin{tabular}{llllllcc}
\hline \multirow{2}{*}{ Treatment } & & \multicolumn{3}{c}{ Grain yield $\left(\mathrm{t} \mathrm{ha}^{-1}\right)$} & & \multicolumn{2}{c}{ Harvest Index } \\
\cline { 3 - 7 } & & Season 1 & Season 2 & Mean & Season 1 & Season 2 & Mean \\
\hline With mulch With root barrier & $(\mathrm{WmWrb})$ & $1.52 \mathrm{efg}$ & $2.06 \mathrm{de}$ & $1.82 \mathrm{de}$ & $0.31 \mathrm{defg}$ & $0.31 \mathrm{defg}$ & $0.31 \mathrm{~cd}$ \\
No mulch With root barrier & $(\mathrm{NmWrb})$ & $0.65 \mathrm{~h}$ & $1.88 \mathrm{def}$ & $1.30 \mathrm{ef}$ & $0.26 \mathrm{~g}$ & $0.29 \mathrm{fg}$ & $0.28 \mathrm{~d}$ \\
With mulch No root barrier & $(\mathrm{WmNrb})$ & $1.60 \mathrm{efg}$ & $1.47 \mathrm{efgh}$ & $1.54 \mathrm{ef}$ & $0.36 \mathrm{abcdef}$ & $0.38 \mathrm{abc}$ & $0.37 \mathrm{ab}$ \\
No mulch No root barrier & $(\mathrm{NmNrb})$ & $1.03 \mathrm{gh}$ & $1.11 \mathrm{fgh}$ & $1.07 \mathrm{f}$ & $0.34 \mathrm{abcdef}$ & $0.39 \mathrm{ab}$ & $0.37 \mathrm{ab}$ \\
Control & $(\mathrm{C})$ & $1.52 \mathrm{efg}$ & $1.87 \mathrm{defg}$ & $1.70 \mathrm{de}$ & $0.32 \mathrm{cdefg}$ & $0.32 \mathrm{cdefg}$ & $0.32 \mathrm{~cd}$ \\
Mulch & $(\mathrm{Cm})$ & $1.25 \mathrm{efgh}$ & $3.15 \mathrm{bc}$ & $2.20 \mathrm{~cd}$ & $0.31 \mathrm{defg}$ & $0.32 \mathrm{cdefg}$ & $0.32 \mathrm{~cd}$ \\
$\mathrm{~N}$ applied at $45 \mathrm{~kg} \mathrm{ha}^{-1}$ & $(45 \mathrm{~N})$ & $1.81 \mathrm{efg}$ & $3.54 \mathrm{~b}$ & $2.68 \mathrm{c}$ & $0.29 \mathrm{fg}$ & $0.33 \mathrm{bcdefg}$ & $0.31 \mathrm{~cd}$ \\
$\mathrm{~N}$ applied at $90 \mathrm{~kg} \mathrm{ha}^{-1}$ & $(90 \mathrm{~N})$ & $2.67 \mathrm{~cd}$ & $4.90 \mathrm{a}$ & $3.79 \mathrm{~b}$ & $0.30 \mathrm{efg}$ & $0.37 \mathrm{abcd}$ & $0.34 \mathrm{bc}$ \\
$\mathrm{N}$ applied at $135 \mathrm{~kg} \mathrm{ha}^{-1}$ & $(135 \mathrm{~N})$ & $3.68 \mathrm{~b}$ & $5.01 \mathrm{a}$ & $4.35 \mathrm{a}$ & $0.37 \mathrm{abcde}$ & $0.40 \mathrm{a}$ & $0.38 \mathrm{a}$ \\
\hline Mean & & $1.75 \mathrm{~b}$ & $2.79 \mathrm{a}$ & & $0.32 \mathrm{~b}$ & $0.35 \mathrm{a}$ &
\end{tabular}

Note: Values followed by the same letter within columns and rows of each parameter are not significantly different $(P<0.05)$.

Monoculture yields showed significant and proportional increases from Season 1 to Season 2. Overall yields were $79 \%$ and $140 \%$ greater than the control in Seasons 1 and 2 respectively. Average monoculture yields relative to the control showed that mulch increased yield by $30 \%, 45 \mathrm{~N}$ by $58 \%, 90 \mathrm{~N}$ by $123 \%$, and $135 \mathrm{~N}$ by $156 \%$. When comparing the differences between Season 1 and Season 2, yield for the control increased by $23 \%$, mulch by $151 \%, 45 \mathrm{~N}$ by $96 \%, 90 \mathrm{~N}$ by $83 \%$, and $135 \mathrm{~N}$ by $36 \%$.

Average HI was $9 \%$ greater in Season 2 than in Season 1. Overall, there was little difference in the results between the intercropping and monoculture treatments and between seasons. This is because the interaction between seasons and treatments had a probability value close to the cut-off point of $5 \%(P<0.048)$, although still significant. Increases in $\mathrm{N}$ application rate resulted in increases in $\mathrm{HI}$ with largest value observed in treatment $135 \mathrm{~N}$ (mean 0.38 ).

\subsubsection{Fertility, competition, and interactions effects jatropha leaf mulch and polythene root barriers on maize yield in jatropha - maize intercropping.}

Table 5.6 shows the combinations of fertility, competition, and interactions for the intercropping treatments and the monoculture control and mulch treatments. 
Table 5.6 The effect of fertility, competition, and interaction on maize yield over two planting seasons.

\begin{tabular}{lccccc}
\hline \multicolumn{1}{c}{ Component } & & \multicolumn{2}{c}{ Season 1 } & \multicolumn{2}{c}{ Season 2 } \\
& & $\begin{array}{c}\text { Treatment } \\
\text { response }\end{array}$ & \% of control & $\begin{array}{c}\text { Treatment } \\
\text { response }\end{array}$ & \% of control \\
\hline Fertility & $(\mathrm{F})$ & 0.72 & 47 & 0.27 & 14 \\
Competition 1 & $\left(\mathrm{C}_{\mathrm{B}}\right)$ & -0.23 & -15 & 0.68 & 36 \\
Competition 2 & $\left(\mathrm{C}_{\mathrm{A}}\right)$ & -0.30 & -20 & -0.54 & -29 \\
Interaction 1 & $\left(\mathrm{I}_{1}\right)$ & 0.49 & 32 & 0.95 & 51 \\
Interaction 2 & $\left(\mathrm{I}_{2}\right)$ & 0.42 & 28 & -0.27 & -14 \\
\hline
\end{tabular}

Note: Maize monoculture control grain yield; Season $1=1.52 \mathrm{t} \mathrm{ha}^{-1}$ and Season $2=1.87 \mathrm{t} \mathrm{ha}^{-1}$

\subsubsection{Fertility}

The fertility response of F with mulch was greater in Season 1 than in Season 2 with yield for Season 1 calculated at $47 \%$ of the control and $14 \%$ for Season 2 . The addition of mulch in the monoculture treatment resulted in an average yield of $2.20 \mathrm{tha}^{-1}$ for Season 1 and Season 2 compared with the control at $1.70 \mathrm{t} \mathrm{ha}^{-1}$.

A quadratic $\mathrm{N}$ response equation developed from the results of the control, $45 \mathrm{~N}, 90 \mathrm{~N}$, and $135 \mathrm{~N}$, and from the average maize grain yield (Figure 5.3A) provided insight into the amount of $\mathrm{N}$ contributed by the mulch.

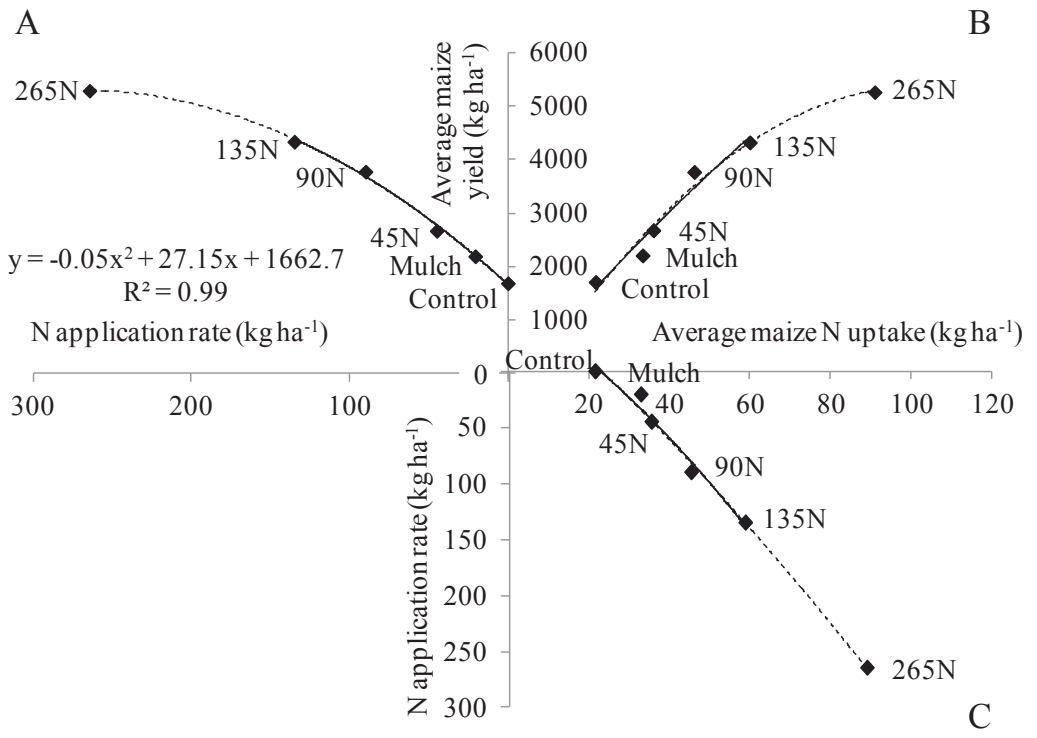

Figure 5.3 A three-quadrant diagram of maize response to $\mathrm{N}$ fertiliser applications. Quadrant (A) shows average maize yield in response to $\mathrm{N}$ application rate, quadrant (B) represents average yield per unit of $\mathrm{N}$ taken up by maize, and quadrant (C) shows the relationship between $\mathrm{N}$ uptake and $\mathrm{N}$ application rate. 
By inserting the average mulch yield of $2.20 \mathrm{t} \mathrm{ha}^{-1}$ over two planting seasons into the quadratic equation it was determined that mulch contributed the equivalence of $21 \mathrm{~kg} \mathrm{ha}^{-1} \mathrm{~N}$. Extrapolation analysis estimates a theoretical maximum yield of $5.3 \mathrm{tha}^{-1}$ with an $\mathrm{N}$ application rate of $265 \mathrm{~kg} \mathrm{ha}^{-1}(265 \mathrm{~N})$.

Figure 5.3B shows average $\mathrm{N}$ uptake in response to average maize yield. The increase is in line with increased yield and $\mathrm{N}$ level. Average $\mathrm{N}$ uptake for the control was $22 \mathrm{~kg} \mathrm{ha}^{-1}$, mulch was $33 \mathrm{~kg} \mathrm{ha}^{-1}, 45 \mathrm{~N}$ was $36 \mathrm{~kg} \mathrm{ha}^{-1}, 90 \mathrm{~N}$ was $46 \mathrm{~kg} \mathrm{ha}^{-1}, 135 \mathrm{~N}$ was $60 \mathrm{~kg} \mathrm{ha}^{-1}$, and for theoretical $265 \mathrm{~N}$ it was $91 \mathrm{~kg} \mathrm{ha}^{-1}$. Total N uptake for total biomass across the different $\mathrm{N}$ treatments was about $40 \%$ greater than yield $\mathrm{N}$ uptake. Figure 5.3C shows average maize $\mathrm{N}$ uptake in response to different $\mathrm{N}$ application rates. The slope of the $\mathrm{N}$ uptake curve represents $\mathrm{N}$ recovery. $\mathrm{N}$ recovery for mulch was $56 \%$ followed by $45 \mathrm{~N}$ at $32 \%$ with $90 \mathrm{~N}$ and $135 \mathrm{~N}$ at $28 \%$. N recovery for $265 \mathrm{~N}$ was the lowest at $22 \%$.

\subsubsection{Competition}

The effect of belowground competition for $\mathrm{C}_{\mathrm{B}}$ was $-15 \%$ in Season 1 and $36 \%$ in Season 2 when compared with the control. Smaller yield combinations for the root barrier treatments caused the negative value observed in Season 1. For $\mathrm{C}_{\mathrm{A}}$ the effect of aboveground competition was $-20 \%$ in Season 1 and $-29 \%$ in Season 2. Greater aboveground competition in Season 2 was a consequence of jatropha pruning in Season 1 but not in Season 2.

\subsubsection{Interaction}

Interaction effects used the $\mathrm{F}$ and $\mathrm{C}$ intercropping differences. For $\mathrm{I}_{1}\left(\mathrm{~F}+\mathrm{C}_{\mathrm{B}}\right)$ there was a $157 \%$ increase in yield from Season $1(32 \%)$ to Season $2(51 \%)$. For $\mathrm{I}_{2}\left(\mathrm{~F}+\mathrm{C}_{\mathrm{A}}\right)$ there was a decrease in yield from Season 1 (28\%) to Season $2(-14 \%)$. The negative value for Season 2 was due to greater aboveground competition where $\mathrm{C}_{\mathrm{A}}$ was greater than $\mathrm{F}$.

\subsection{Discussion}

\subsubsection{Maize yield response}

In this study, maize yields were different in Season 1 and Season 2, characterised by two distinct growth environments resulting from differences in cumulative rainfall (Figure 5.2). The optimum rainfall for maize growth is between $500 \mathrm{~mm}$ to $800 \mathrm{~mm}$ (Steduto et al., 2012). In Season 1 high rainfall it is likely that a lack of aeration limited root growth, allowing the maize to increase root growth in the upper soil layers, including the development of nodal or adventitious roots (Lizaso and Ritchie, 1997; Lizaso et al., 2001). High rainfall also accelerates mulch decomposition (Swift et al., 1979; Palm, 1995; Mugendi and Nair, 1996). As rainfall increases so does the potential for losses in available $\mathrm{N}$ through leaching and denitrification (Meyer et al., 1987).

Our results (analysis not shown) indicate that the effect of high rainfall on maize is dependent on the growth stage (i.e. 4 WAP to $12 \mathrm{WAP}$ ) and $\mathrm{N}$ rates (i.e. low $\mathrm{N}$ in intercropping treatments, control, and mulch; 
greater $\mathrm{N}$ in $45 \mathrm{~N}$ to $135 \mathrm{~N}$ in monoculture). Maize is more susceptible to water and nutrient stress during the early vegetative development or before tasseling (from 4 WAP to 8 WAP) than during the late vegetative stage (from 8 WAP to 12 WAP) (Zaidi et al., 2004). The timing and extent of the stress influences growth and can have dramatic effects on biomass and grain yield (Mukhtar et al., 1990; Pandey et al., 2000; Zaidi et al., 2004) as silking can be reduced up to $50 \%$, and may even result in barren plants (Zaidi et al., 2008).

At low $\mathrm{N}$ rates, WmWrb was expected to perform the best, and while the average was greater than the control, the differences were only small (Table 5.5). This shows that while jatropha mulch provides a positive benefit, it is limited. The poor yield for $\mathrm{NmWrb}\left(0.65 \mathrm{t} \mathrm{ha}^{-1}\right)$ in Season 1 is particularly interesting, especially given that yield in Season 2 was similar to the control. If we compare the response observed for $\mathrm{NmWrb}$ with WmWrb $\left(1.52 \mathrm{t} \mathrm{ha}^{-1}\right)$ it becomes apparent that the only difference was the mulch. The poor yield for NmWrb (also had the lowest LAI) may be the result of the Season 1 high rainfall and the root barrier causing impeded drainage. It is possible that mulch (WmWrb) made a positive contribution by helping to alleviate water logging. Soils with mulch are known to effectively store rainfall two times greater than soils with no mulch treatment (Unger, 1978), especially in heavy textured soils (Lal, 1974; Ji and Unger, 2001).

If we look at treatments $\mathrm{WmNrb}\left(1.60 \mathrm{t} \mathrm{ha}^{-1}\right)$ and $\operatorname{NmNrb}\left(1.03 \mathrm{t} \mathrm{ha}^{-1}\right)$ we again see a positive mulch effect. The next logical step was to eliminate the effect of the polythene root barrier, achieved by assessing treatments WmWrb $\left(1.52 \mathrm{t} \mathrm{ha}^{-1}\right)$ and $\mathrm{WmNrb}\left(1.60 \mathrm{t} \mathrm{ha}^{-1}\right)$. The results are not different so I assume that jatropha mulch incorporated into the soil was beneficial during the periods of high rainfall in Season 1. A small exception is apparent when comparing the control $\left(1.52 \mathrm{t} \mathrm{ha}^{-1}\right)$ and monoculture mulch $\left(1.25 \mathrm{t} \mathrm{ha}^{-1}\right)$ treatments.

Studies have shown that mulch does not always increase maize yield. Yield reductions in response to applications of mulch may be caused by a decrease in N fertility effect (Unger, 1986), often compounded by cool weather or periods of high rainfall (Wicks et al., 1994). The effect of mulch on soil moisture conservation and evaporation is often variable and depends on the soil characteristics, evaporative demand and the frequency and quantity of rainfall (Lal, 1974; Tolk et al., 1999). Mulch applied to the soil can reduce soil evaporation by shading and the creation of a boundary layer; however the thickness of the mulch will determine the rate of soil drying (Steiner, 1989).

As for root barrier treatments, they were effective in removing the jatropha-maize belowground competition; however, the root barrier effectively reduces the soil volume available for the maize edge rows by limiting root development on one side. Maize in the centre-rows had no such limitations. In essence, mulch and root barriers provided an intercropping yield advantage. 
HI was expected to increase with increasing applications of N (Moser et al., 2006); but our study showed HI to be variable (Table 5.5). One explanation is that $\mathrm{HI}$ is influenced by management, and environment (Hay, 1995; Hay and Gilbert, 2001) as well as N uptake and use efficiency (Sinclair, 1998; Fageria et al., 2005; Moser et al., 2006). In the tropics, HI is usually lower than in temperate areas, which is usually above 0.50 (Hay and Gilbert, 2001; Moser et al., 2006). Efendi and Suwardi (2010) used a maize hybrid similar to that used in our study to investigate the effects of increased planting density and $\mathrm{N}$ application rates. In their study, the control had a $\mathrm{HI}$ around 0.30 , while $\mathrm{N}$ at $150 \mathrm{~kg} \mathrm{ha}^{-1}$ and $225 \mathrm{~kg} \mathrm{ha}^{-1}$ resulted in $\mathrm{HI}$ of 0.37 and 0.39 respectively. In general, our results are consistent with their findings however, the lower HI (0.28) associated with our hybrid was due to the poor response by treatment NmWrb in Season 1.

\subsubsection{Fertility, competition, and interaction effects of jatropha leaf mulch and polythene root barriers on maize yield in jatropha - maize intercropping}

The small fertility response for Season 1 and Season 2 (high and optimum rainfall respectively) are interesting and consistent with an increase in maize yield from Season 1 to Season 2. According to Van Noordwijk et al. (1998), the fertility effect will be small in a soil that does not have nutrient limitations. One of the difficulties however might be in determining if an improved fertility effect is due to nutrients, or to improved soil water holding capacity. In essence, both are facilitation effects, but to be able to differentiate would be an advantage. The fact that $\mathrm{F}$ improved from Season 1 to Season 2 may be a result associated with greater mineralisation of $\mathrm{N}$ and possibly less leaching. Mulch mineralisation is dependent on the litter quality (Swift et al., 1979; Handayanto and Giller, 1994; Palm, 1995; Mafongoya et al., 1997) and on the method of application (Jama and Nair, 1996; Mafongoya and Nair, 1997). Using the tree decision flow chart developed by Palm et al. (1997), jatropha leaf mulch can be categorised as a high quality organic resource with immediate mineralisation potential. This is because the $\mathrm{N}$ is $>26 \mathrm{~g} \mathrm{~kg}^{-1}$ and lignin + polyphenol: $\mathrm{N}$ ratio $<$ 10 , although the lignin and polyphenol content are at the upper limits.

In conjunction with mineralisation it is important to ensure nutrient demand synchronisation is achieved to prevent periods of temporary shortage or surplus (Meyer et al., 1987; Mafongoya et al., 1997). The reduction in $\mathrm{F}$ values between Season 1 and Season 2 may also indicate improved synchronisation of $\mathrm{N}$ mineralisation and crop uptake. The high $\mathrm{N}$ recovery from the monoculture mulch further supports our results.

The timing for the incorporation of the dry leaf mulch into the soil was based on work by Abugre et al. (2011) who reported that in Ghana $50 \%$ decomposition of jatropha leaf litter was obtained after 25 days in an open canopy and 32 days in a closed canopy. In total $97 \%$ to $99 \%$ of leaf litter had decomposed after 120 days, which was consistent with the maize nutrient requirements. Based on leaf analysis, mulch applied at $3.5 \mathrm{t} \mathrm{ha}^{-1}$ was determined as an $\mathrm{N}$ equivalent of $91 \mathrm{~kg} \mathrm{ha}^{-1}$, $\mathrm{P}$ equivalent of $6.2 \mathrm{~kg} \mathrm{ha}^{-1}$, and $\mathrm{K}$ equivalent of $39.8 \mathrm{~kg} \mathrm{ha}^{-1}$ (Table 5.4). The analysis established that these rates were insufficient to meet the full maize nutrient requirements estimated at $\mathrm{N} 135 \mathrm{~kg} \mathrm{ha}^{-1}$, P $72 \mathrm{~kg} \mathrm{ha}^{-1}$, and $\mathrm{K} 120 \mathrm{~kg} \mathrm{ha}^{-1}$. With the objective being to 
determine the effect of the jatropha mulch in providing an inorganic source of $\mathrm{N}$ for the maize intercrop, an additional $72 \mathrm{~kg} \mathrm{ha}^{-1}$ of $\mathrm{P}$ and $120 \mathrm{~kg} \mathrm{ha}^{-1}$ of $\mathrm{K}$ was added to the mulch treatment.

The three-quadrant diagram in Figure 5.3 (Van Keulen, 1982; De Wit, 1992) represents various N relationships with application rate, maize yield and uptake. The high rainfall in Season 1 was responsible for the positive quadratic coefficient generated in Figure 5.3A. Effectively mulch provides a source of $\mathrm{N}$ equivalent to $21 \mathrm{~kg} \mathrm{ha}^{-1}$, and the maximum expected yield at $265 \mathrm{~kg}$ ha-1 $\mathrm{N}$ was $5.3 \mathrm{t} \mathrm{ha}^{-1}$. If a comparison is made between the yield for $135 \mathrm{~N}\left(4.3 \mathrm{tha}^{-1}\right)$ and the yield for $265 \mathrm{~N}\left(5.3 \mathrm{tha}^{-1}\right)$ then to increase maize yield by $22 \%$ requires an additional $96 \% \mathrm{~N}$.

Although no maize $\mathrm{N}$ content data was available to generate $\mathrm{N}$ uptake during the growing stage, harvest $\mathrm{N}$ uptake increased in line with increasing $\mathrm{N}$ application rate until $135 \mathrm{~N}$ treatment. The $\mathrm{N}$ uptake of $22 \mathrm{~kg} \mathrm{ha}^{-1}$ for the control shows the inherent soil fertility. The $\mathrm{N}$ uptake from mulch application was $33 \mathrm{~kg} \mathrm{ha}^{-1}$ and this value was greater than predicted mulch $\mathrm{N}$ equivalent of $21 \mathrm{~kg} \mathrm{ha}^{-1}$. The difference $\left(12 \mathrm{~kg} \mathrm{ha}^{-1}\right)$ may be due to the contribution of $\mathrm{N}$ mineralisation from soil and/or bias from using average yield in two seasons to generate the $\mathrm{N}$ response curve. $\mathrm{N}$ uptake at the theoretical maximum $(265 \mathrm{~N})$ was $91 \mathrm{~kg} \mathrm{ha}^{-1}$. Increases in $\mathrm{N}$ uptake associated with increasing application rates is a function of $\mathrm{N}$ demand, the result of rapid leaf area expansion and development of reproductive structures (Ciampitti and Vyn, 2012). This assumes that $\mathrm{N}$ availability for the roots is sufficient as $\mathrm{N}$ remobilisation between root and shoot are interconnected (Peng et al., 2010).

Using $\mathrm{N}$ uptake differences between the control and increasing application rates (Figure 5.3B), $\mathrm{N}$ recovery was determined. $\mathrm{N}$ recovery decreased as $\mathrm{N}$ application rates increase. The high $\mathrm{N}$ recovery rate for the mulch treatment may be the result of rapid biomass decomposition and $\mathrm{N}$ mineralisation (Palm, 1995; Mafongoya and Nair, 1997). A high N recovery may also mean a degree of application synchrony with crop nutrient demand (Mafongoya and Nair, 1997). Moreover the addition of mulch prior to maize planting in Season 1 and 2 may have initiated a priming effect where soil $\mathrm{N}$ mineralisation was stimulated, allowing for increased maize N uptake in Season 2 (Hauck and Bremner, 1976; Jenkinson et al., 1985; Cadisch et al., 1998).

Lower $\mathrm{N}$ recovery as $\mathrm{N}$ increases may be due to immobilisation, denitrification, or leaching (Oikeh et al., 2003). Interestingly, $\mathrm{N}$ recovery for $90 \mathrm{~N}$ and $135 \mathrm{~N}$ are similar which may indicate that $135 \mathrm{~N}$ was in excess of maize requirements, or that more $\mathrm{N}$ was lost at $135 \mathrm{~N}$. The low $\mathrm{N}$ recovery by maize at high $\mathrm{N}$ applications may be due to asynchrony between the release of $\mathrm{N}$ and the demand of $\mathrm{N}$ by the crop, leading to high losses of N (Myers et al., 1994; Myers et al., 1997). When N uptake increased, maize yield increased proportionally (Figure 5.3C). When yield is extrapolated to a theoretical $265 \mathrm{~N}$ application rate, yield is $5.2 \mathrm{t} \mathrm{ha}^{-1}$; however $\mathrm{N}$ recovery rate is $22 \%$ lower than at $135 \mathrm{~N}$. Any decision to increase $\mathrm{N}$ from $135 \mathrm{~N}$ to $\mathrm{N} 265$ to gain an extra $20 \%$ yield should take into account not only economic, but also $\mathrm{N}$ recovery. 
The competition effects of $\mathrm{C}_{\mathrm{B}}$ and $\mathrm{C}_{\mathrm{A}}$ from Season 1 to Season 2 were different, although both experienced improved soil fertility associated responses. Potentially contributing factors were soil moisture and light competition effects. The positive $C_{B}$ value in Season 2 is likely due to an increase in $F$ that resulted in complementarity. However, this does not mean that there was no belowground competition. In Season 1, the root barrier compounded the effect of the heavy rainfall and increased water logging. In Season 2, the rainfall was more optimal therefore; water logging was not an issue.

Increases in $\mathrm{C}_{\mathrm{A}}$ for Season 2 were possibly due to increased competition for light, brought about by the effect of jatropha shading on maize. In Season 1, aboveground competition for light between maize and jatropha was low as the jatropha canopy was just starting to re-grow after pruning. Aboveground pruning is used to manage aboveground competition (Duguma et al., 1988), but is also effective in decreasing belowground competition for water and nutrients (Vanlauwe et al., 2002). In Season 2, no pruning was undertaken which meant that the jatropha canopy growth was well advanced and caused a more pronounced competition for light. Jatropha canopy shading can modify the microclimate effect on maize thereby affecting belowground competition. It was not possible with the equation used to discern aboveground competition from the microclimate effect.

From the two competition effects, it is clear that increased resource availability in the form of $\mathrm{N}, \mathrm{P}, \mathrm{K}$, and in improved soil water retention by the mulch resulted in a more vigorous maize vegetative growth. Increased demand for resources led to an increase in below and aboveground intercrop competition. This aspect highlights the fact that below and aboveground competition are inter-related, and that all resources must be in balance to maximise yield potential.

For $\mathrm{I}_{1}$, the best result occurred in Season 2 when the $\mathrm{F}$ value was small and $\mathrm{C}$ had a positive value. A small $\mathrm{F}$ value indicates a soil that has no major nutrient limitations while positive $\mathrm{C}$ indicates reduced competition or increased complementarity. Ultimately the negative effects of light and soil moisture will always remain on the negative side of the equation (Van Noordwijk et al., 1998). For example, for $I_{1}$ in Season 2 there were no water and nutrient limitations therefore there may have been some masking of the competition by the positive effect of soil nutrient and water availability. It seems that the net balance for $I_{1}$ favours the soil fertility effect.

$\mathrm{I}_{2}$ produced the best result when the $\mathrm{F}$ value was moderate and the $\mathrm{C}$ value was weakly negative. In this case, resource availability was sufficient to complement the combined system. The negative $I_{2}$ interaction value resulted from increased soil fertility followed by increased aboveground competition. In general competition only becomes a problem if it affects the desired outcome, albeit commercial or otherwise (Van Noordwijk et al., 1996). The results from this study agree with Sanchez (1995) and Giller (2001) who state that for tree and crop intercropping to be successful, soil fertility should be good and rainfall adequate. 


\subsection{Conclusion}

Jatropha is a relatively new biofuel crop considered by many to have the potential to improve the socioeconomic lives of farmers. In Indonesia a combination of low yields and low commodity prices, further compounded by resource limitations, low soil fertility, and accessibility have led to many abandoned jatropha monoculture plantings. Alternatives to jatropha monocultures where farmers intercrop jatropha with maize offer distinct possibilities.

Pruning was effective in managing aboveground competition however to determine if pruning on a yearly basis is optimal will require further research. Root pruning and root barriers effectively managed competition belowground however, they are expensive and time consuming to install. In the short-term jatropha leaf prunings incorporated into the maize intercrop soil as mulch provides a limited, but positive fertility effect. In the maize monoculture system, the addition of jatropha leaf mulch increased yield. Based on our results the regular use of jatropha mulch may result in yield increases comparable with $21 \mathrm{~kg} \mathrm{ha}^{-1}$ of applied fertiliser N. Because above and belowground competition are inter-related the exploration and validation of a range of management scenarios to investigate net fertility and competition effects using modelling will be invaluable in refining jatropha-maize intercropping management guidelines. 
Chapter 6 Trade-offs between Jatropha curcas L. and maize intercropping yield under different management scenarios using the WaNuLCAS model 


\begin{abstract}
Jatropha monoculture on poor soils is currently a high-risk venture due to market uncertainty and key knowledge gaps. Intercropping has been proposed as an alternative to monoculture; yet high yielding jatropha varieties are currently not available, and published information to optimise agronomic and management practices is limited so long-term outcomes are unknown. I used the WaNuLCAS (Water, Nutrient and Light Capture in Agroforestry System) model to evaluate relative jatropha and relative maize yields in response to different combinations of fertiliser, pruning, and planting density over a 20 -year period. Intercropping performance was characterised by production possibility frontiers with attention to two specific points; jatropha yield when maize yield is maximised, and maize yield when jatropha yield is maximised. Fertiliser for the maize crops included mulch with $\mathrm{P}$ applied at $72 \mathrm{~kg} \mathrm{ha}^{-1}$, mulch, $\mathrm{N}$ and $\mathrm{P}$ applied at $40 \mathrm{~kg} \mathrm{ha}^{-1}$, and a no-fertiliser no-mulch (control). Pruning scenarios included no pruning, pruning every year and pruning alternate years. Planting density comprised 14 combinations generated from five intra-rows ( $1 \mathrm{~m}$ to $5 \mathrm{~m}$ ) and four inter-row $(2 \mathrm{~m}$ to $5 \mathrm{~m}$ ) spacing. Our results show application of mulch with $\mathrm{P}$ applied at $72 \mathrm{~kg} \mathrm{ha}^{-1}$ gave the maximum yields for both jatropha and maize. Maximum jatropha relative yield of $250 \%$ of a non-fertilised sole crop comparator plus a relative maize yield of $35 \%$ was obtained from no pruning with a $2 \mathrm{~m}$ inter-row spacing when compared with monocultures. Maximum maize relative yield of $101 \%$ and a jatropha relative yield of $62 \%$ of the sole crop were obtained from pruning every year. Inter-row distance did not affect maize yield when jatropha was pruned each year. There is considerable scope for jatropha and maize intercropping, especially when fertiliser, pruning, and planting density management is considered. Different management practices can reduce jatropha and maize competition and/or enhance complementarity, responding to shifting farmer priorities within the production possibility frontier.
\end{abstract}

Keywords: Competition - Complementarity - Fertiliser - Plant spacing - Production possibility frontier Pruning 


\subsection{Introduction}

Over the past ten years, jatropha has received much international attention as a potential biofuel crop. Jatropha has been promoted as a drought resistant perennial plant with a lifespan up to fifty years, and with the capability to grow on marginal soils with minimum management requirements and inputs (Brittaine and Lutaladio, 2010). For these reasons jatropha was assumed to have potential to bring socio-economic benefits without competing with food production, promote wasteland reclamation in tropical semi-arid regions, and possibly as a source of carbon credits (Van Eijck et al., 2014a).

Much jatropha research has focused on commercial monoculture plantings (Achten et al., 2010a; Abhilash et al., 2011; Silitonga et al., 2011; Van Eijck et al., 2014a) with the expectation of good economic returns on investment. These returns have not been realised as actual yields are often $<0.5 \mathrm{t} \mathrm{ha}^{-1}$ to $2 \mathrm{t} \mathrm{ha}^{-1}$ as opposed to expected yields of $12 \mathrm{t} \mathrm{ha}^{-1}$ (Edrisi et al., 2015). Poor yields are further compounded by high capital inputs necessary for establishing and managing productive monocultures (Van Eijck et al., 2014a), especially on poor soils. Under optimal conditions jatropha can produce seed yields of $2 \mathrm{tha}^{-1}$ to $4 \mathrm{tha}^{-1}$, yet when planted on marginal land yields are often $<1 \mathrm{t} \mathrm{ha}^{-1}$ (Van Eijck et al., 2014a). The farm gate prices may not justify the fertiliser use needed to increase yield on degraded soils.

The problem therefore is that for jatropha to be successful, growers may encroach on fertile lands or risk financial ruin (Achten et al., 2010a; Abhilash et al., 2011). Expansion into agriculture land is both economically and environmentally undesirable as it competes directly with food crop production (Achten et al., 2010a; Abhilash et al., 2011) and may negatively influence food security (Van Eijck et al., 2014a). In combination with the market uncertainty and knowledge gaps in agronomy, breeding, and management, monocultures are susceptible to increased pests and diseases (Achten et al., 2010a; Achten et al., 2014; Van Eijck et al., 2014a; Edrisi et al., 2015). But monocultures are not the only way that jatropha can be introduced into cropping systems.

Agroforestry systems using jatropha intercropping have been proposed (Achten et al., 2010a; Abhilash et al., 2011). Intercropping may have commercial potential, whilst providing farmers with a safe guard against harvest loss or poor performance of a single crop. Using the vacant land between the jatropha to grow annual crops such as rice, maize or groundnuts is an attractive and potentially viable proposition, especially while the jatropha are young or not yet bearing fruit (Achten et al., 2008; Wahl et al., 2009; Jingura, 2012), or when planted at wide spacing (Effendi et al., 2007). The intensification and diversification associated with intercropping may reduce pest and disease risk. For these reasons, species choice and spacing will be important (Mshandete, 2011). Intercropping is a common technique used when assessing new crops, at least before mechanisation favoured monocultures (Francis, 1989; Anders et al., 1994). In understanding such practices, agronomists have generally used sole crops as point of reference. 
Although forms of jatropha intercropping are already common practice in Indonesia (Effendi et al., 2007), India (Singh et al., 2007; Sharma and Rana, 2014), and Africa (liyama et al., 2013; Minengu et al., 2015), published information and data related to optimal agronomic and management practices are limited. Little or no data on the long-term effects of jatropha intercropping is available (Brittaine and Lutaladio, 2010).

Growing trees, shrubs or perennial plants in combination with annual crops can bring positive and negative effects (Rao et al., 1997). Positive interactions are improved soil fertility and structure through litter fall or mulching with prunings, recycling subsoil nutrients, reducing nutrient leaching and soil water evaporation, controlling soil erosion and improving infiltration rate, as well as reducing soil erosion. Negative interactions include increased competition for available water and nutrient resources and shading (Ong et al., 1991). Management must therefore bring these complex and competing factors into harmony if the system is to succeed (Nair, 1993).

Analysis of intercropping performance commonly builds on the concept of replacement series through the Relative Yield Total (RYT) (De Wit and Van den Bergh, 1965). RYT uses the sum of yields for each species relative to its yield in monoculture in a comparison where total plant density is kept constant. When RYT $=1$ there is no yield advantage for intercropping, when RYT $>1$ there is a degree of complementarity, and when RYT < 1 competition prevails (Ranganathan, 1992; Anders et al., 1994). A closely related concept to RYT is the Land Equivalent Ratio (LER) developed by Willey and Osiru (1972). LER is the area of land under monoculture that is required to produce the yields obtained in intercropping (Equation 6.1):

$L E R=\frac{\text { Yield species } 1 \text { in mixture }}{\text { Yield species } 1 \text { in monoculture }}+\frac{\text { Yield species } 2 \text { in mixture }}{\text { Yield species } 2 \text { in monoculture }}$ Equation 6.1

LER $>1$ indicates a net intercropping advantage in terms of land sparing by the mixed system. While RYT analysis is restricted to constant total plant density of plants of similar stature, LER can be used where plant density and management are optimised separately for the monocultures and the mixed systems. Results are usually presented as a bivariate diagram (Figure 6.1A) (Ranganathan, 1992; Ong, 1996). It is important that the monoculture (denominator) planting density for each species should be optimal and realistic for farmer practice (Mead and Willey, 1980; Francis, 1989; Ong, 1996). The production possibility frontier (PPF) analysis (Figure 6.1B) offers an alternative representation of all possible plant density combinations by focussing on the maximum relative yield possibilities for any combination of two species (Ranganathan et al., 1991; Ranganathan, 1992). When relative values of the two yields are known, an economically optimised choice can be made. 
A)

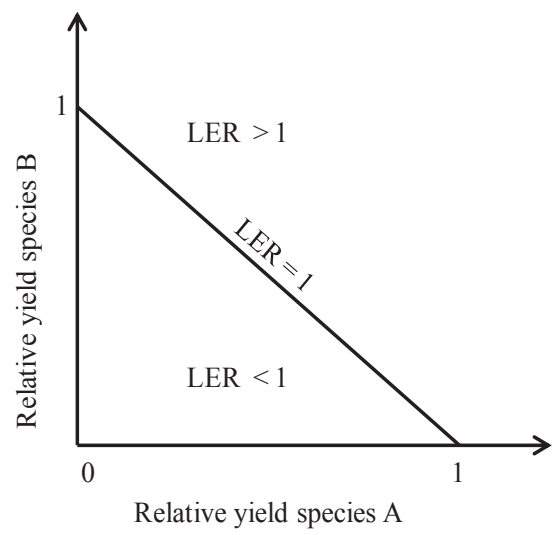

B)

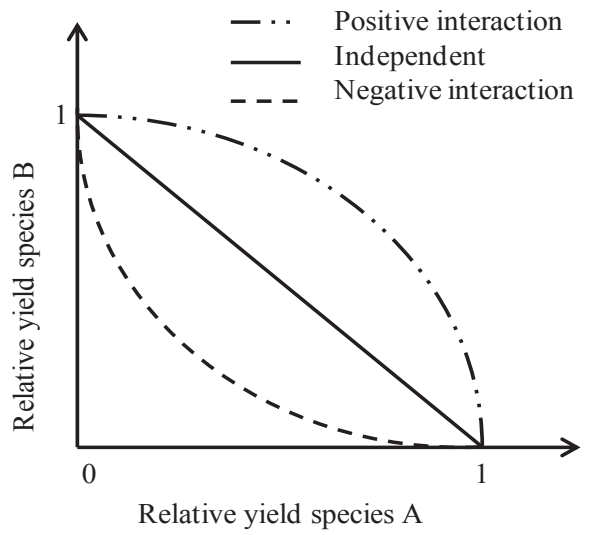

Figure 6.1 Yield advantage measurements with bivariate diagrams representing A) land equivalent ratio (LER) and B) production possibility frontier (PPF).

By plotting the relative yield of any two competing species it is possible for yield trade-off to be determined. The shape of the trend line indicates the nature of the relationship between species. If the curve is convex (positive) the interaction is complementary, if it is concave (negative) the interaction competitive.

Intercropping is often credited with increased total biological productivity per unit area of land; however, this increase in productivity should also take into account different situations such as farmer or smallholder aims and objectives. Willey (1979) categorised three different scenarios for assessing yield advantage in intercropping. The first requires full yield of the main (dominant) crop and some yield of a second crop, the second requires that the combined intercrop yield exceeds the greater sole crop yield, and the third requires that the combined intercrop yield exceeds a combined sole crop yield.

In Chpater 5 of this study I investigated resource competition in a jatropha - maize intercrop system in Indonesia. Net effects of four-year-old jatropha intercropped with maize were compared with maize monoculture (control) over two growing seasons, with and without mulch and polythene root barriers. Fouryear-old jatropha, planted at $2 \mathrm{~m} \times 2 \mathrm{~m}$ was interplanted with three rows of maize at $0.25 \mathrm{~m} \times 0.75 \mathrm{~m}$. The three rows of maize were situated in the $1 \mathrm{~m}$ middle inter-row. To reduce aboveground competition jatropha were pruned at $75 \mathrm{~cm}$ aboveground, and to reduce belowground competition jatropha were root pruned and $400 \mu \mathrm{m}$ polythene root barriers installed. To improve soil conditions, leaf mulch equivalent to $3.5 \mathrm{t} \mathrm{ha}^{-1}$ was incorporated into the soil. Treatments with $\mathrm{N}$ applied at $45 \mathrm{~kg} \mathrm{ha}^{-1}(45 \mathrm{~N}), 90 \mathrm{~kg} \mathrm{ha}^{-1}(90 \mathrm{~N})$, and $135 \mathrm{~kg} \mathrm{ha}^{-1}$ $(135 \mathrm{~N})$ were also included. All maize intercropping and monoculture treatments (except control) received an application of $\mathrm{P}$ at $72 \mathrm{~kg} \mathrm{ha}^{-1}$, and $\mathrm{K}$ at $120 \mathrm{~kg} \mathrm{ha}^{-1}$. 
Our results confirmed that jatropha has potential for intercropping. Applications of jatropha leaf mulch from prunings to maize monoculture increased yield comparable with application of $\mathrm{N}$ at $21 \mathrm{~kg} \mathrm{ha}^{-1}$ (Chapter 5), with potential effects through reduced soil evaporation plus nitrogen mineralisation. Pruning was effective in managing aboveground competition, while root pruning and root barriers managed competition belowground. However below and aboveground competition are inter-related so care and understanding are required to maintain an optimal balance.

To understand the complex tree and crop interactions using experimental research is time consuming and expensive. The use of tree and crop models is a cost effective technique to explore a wide range of options in a given context (Matthews and Stephen, 2002). Van Noordwijk and Lusiana (1999) developed WaNuLCAS, a process based model designed to improve understanding of agroforestry systems. This model allows for the simulation and extrapolation of nutrient dynamics, water balances, light and nutrients use, crop and tree biomass and yield. The WaNuLCAS model was used in this study because it can evaluate a range of management options and produce strategies necessary for long-term productivity analysis. Furthermore, the model has also been parameterised based on tree-soil-crop experiments conducted in Indonesia.

To extrapolate beyond the jatropha and maize intercropping experiments, models can explore and evaluate long term productivity and trade-offs under different management scenarios. However a jatropha parameter file is needed to make such simulations. In Chapter 3, jatropha biomass and fruit production were parameterised using the FBA model. The allometric scaling relations derived from FBA can be used directly in the WaNuLCAS tree library.

This chapter has two objectives:

1. To evaluate long term productivity of jatropha and maize in response to different management scenarios under soil and climate similar to those in the experiments.

2. To quantify trade-offs between jatropha and maize yield under different management scenarios and to determine the shape of the production possibility frontier.

\subsection{Materials and methods}

\subsubsection{Study site and conditions}

Climate, soil, and crop performance data for this study were obtained from the PT. JGE plantation located in Mulo Village in the Wonosari District, Gunungkidul Regency of Special Province Yogyakarta in Indonesia $\left(8^{\circ} 0^{\prime} \mathrm{N}, 110^{\circ} 34^{\prime} \mathrm{E}, 185 \mathrm{~m} \mathrm{ASL}\right)$. No agricultural inputs were applied to jatropha plantings and local farmers' harvested grass on a daily basis for cattle feed. Weeding was performed once a month. Planting material was derived from seed propagated from IP-1M, an improved jatropha population of a first selection from Muktiharjo, Central Java (Hasnam and Hartati, 2006). Seedlings were transplanted at age three months, 
and planting density was 2,500 plants $\mathrm{ha}^{-1}$ with a spacing of $2 \mathrm{~m} \times 2 \mathrm{~m}$. All references to other plant spacing combinations use intra-row spacing followed by inter-row spacing.

The study site has an equatorial rainforest climate with mean annual rainfall of $1,800 \mathrm{~mm}$, occurring from November to April, periods of $<100 \mathrm{~mm}$ per month occurring from May to October. Mean annual temperature and relative humidity is $26^{\circ} \mathrm{C}$ and $70 \%$ respectively.

\subsubsection{The WaNuLCAS model features}

The WaNuLCAS version 4.01 was used for this study and can be found at: http://www.worldagroforestry.org/output/wanulcas-model-water-nutrient-and-light-captture-agroforestrysystem. For a theoretical background the reader is referred to Van Noordwijk and Lusiana (1999), and for a practical background to Van Noordwijk et al (2011). The WaNuLCAS model comprises two parts, a Microsoft Excel workbook for deriving model parameters, and a stm file for dynamic simulations. The model is based on the STELLA platform (flow chart based modelling software) with core modules of climate, management (planting schedule and density), tree and crop characteristics, soil water and nutrients. In addition to the core modules, there are additional modules for management (e.g. pruning and fertiliser rates), labour use and profitability, and pests and diseases.

WaNuLCAS emphasises belowground interactions, where competition for water and nutrients ( $\mathrm{N}$ and $\mathrm{P}$ ) depend on effective root length densities and uptake demand. Within the model, there are four soil profiles and four spatial zones. The soil profile is represented as four horizons, the depth of which can be defined within the model, together with specified physical properties and initial water and nitrogen contents for each compartment. The model assumes that trees and crops occupy specific zones. For example in an alley with two hedgerows, zone 1 and 4 are for trees while zones 2 to 3 are for crops that can be planted at a specific time, or planted within a defined sequence. The zone widths within the model are adjustable allowing different planting spacing to be easily evaluated.

\subsubsection{Model parameterisation and calibration}

Prior to running WaNuLCAS, baseline data relating to climate, soil characteristics, tree and crop characteristics and management practices were updated. Model calibrations were performed using three data sets derived from Chapters 4 and 5. The first calibration was for a two-year-old jatropha monoculture with no pruning and one-year climate data (Chapter 4). The second calibration was for the maize monoculture using control treatment with a two-year climate data; and thirdly for the pruned four-year-old jatropha intercropped with maize, with and without mulch, and with or without root barrier treatments, and with oneyear climate data (Chapter 5). 


\subsubsection{Climate conditions and soil profile}

Daily rainfall, evapotranspiration, and soil temperature were recorded on site for the duration of the maize growing season. Climate data outside the 2012 and 2013 growing seasons were obtained from the Playen District Weather Station Gunungkidul approximately $10 \mathrm{~km}$ from the study site. Soil data representing the four horizontal profiles were determined prior to the start of the experiment (Table 6.1).

Table 6.1 Soil characteristics for the study site.

\begin{tabular}{lcccccccc}
\hline $\begin{array}{c}\text { Soil depth } \\
(\mathrm{cm})\end{array}$ & $\begin{array}{c}\text { Clay } \\
(\%)\end{array}$ & $\begin{array}{c}\text { Silt } \\
(\%)\end{array}$ & $\begin{array}{c}\text { Sand } \\
(\%)\end{array}$ & $\begin{array}{c}\text { Organic } \\
\text { matter } \\
(\%)\end{array}$ & $\begin{array}{c}\text { Bulk } \\
\text { density } \\
\left(\mathrm{g} \mathrm{cm}^{-3}\right)\end{array}$ & $\begin{array}{c}\mathrm{P}_{\text {Bray }} \\
\left(\mathrm{mg} \mathrm{cm}^{-3}\right)\end{array}$ & $\begin{array}{c}\mathrm{NH}_{4} \\
\left(\mathrm{mg} \mathrm{cm}^{-3}\right)\end{array}$ & $\begin{array}{c}\mathrm{NO}_{3} \\
\left(\mathrm{mg} \mathrm{cm}^{-3}\right)\end{array}$ \\
\hline $0-10$ & 46.33 & 48.33 & 5.33 & 1.02 & 1.01 & 36 & 0.19 & 0.09 \\
$10-20$ & 50.33 & 48.33 & 1.33 & 0.86 & 0.98 & 15.5 & 0.18 & 0.08 \\
$20-30$ & 64.33 & 34.67 & 1.00 & 0.85 & 0.95 & 16.5 & 0.14 & 0.07 \\
$30-40$ & 54.33 & 45.33 & 0.33 & 0.68 & 0.85 & 14.5 & 0.12 & 0.06 \\
\hline
\end{tabular}

Soil physical and chemical characteristics were used for pedotransfer function in the module to generate soil hydraulic properties. For the soil bulk density and organic matter, soil sampling data were used.

\subsubsection{Tree and crop parameters}

Jatropha characteristics were not available within the WaNuLCAS 'Tree Library' therefore it was necessary to first parameterise these. Parameterisation was performed using data from a four-year-old monoculture planted at $2 \mathrm{~m} \times 2 \mathrm{~m}$ as no suitable jatropha agroforestry systems were available. The limitations associated with the parameterisation are acknowledged, however this is considered a firm base on which future research can build.

I used FBA to develop allometric equations to estimate above and belowground plant biomass (Appendix 7). Aboveground biomass allometric equations in conjunction with plant measurements for growth stage, canopy width and height, LAI, fruit biomass, $\mathrm{N}$ and $\mathrm{P}$ content in the plant organs, litter quality, RLD were used as input parameters. Other 'Tree Library' parameters such as maximum growth rate, ratio of maximum and minimum LAI, and cumulative litter fall equations were calibrated by fitting predicted to observed biomass results. See Appendix 8.

Maize parameters are available in the WaNuLCAS 'Crop Library' however; the default parameters were modified to increase the length of the generative stage from 30 to 40 days. This increased the total growing period from the 90-day default to a 100-day default, which is consistent with current practice at the research site. See Appendix 9. 


\subsubsection{Management options}

Management parameters used to calibrate the model included planting date, planting density and alley width, pruning, and fertiliser. Growth periods were expressed in Julian days. Planting density for jatropha was 2,500 trees $\mathrm{ha}^{-1}$ and divided equally between zones one and four. Maize was planted in the second and third zones. The width of first and fourth zones was $0.5 \mathrm{~m}$; therefore, the alley width for maize was $1 \mathrm{~m}$. The jatropha canopy fraction pruned was 0.9 or pruning to $0.75 \mathrm{~m}$ aboveground. This amounted to the equivalent of $3.2 \mathrm{t}$ $\mathrm{ha}^{-1}$ and was used as mulch. For mulch treatments, $\mathrm{P}$ was also added and applied at $72 \mathrm{~kg} \mathrm{ha}^{-1}$. Control treatments without fertiliser and mulch were also factored into the model calibration. For jatropha with root barrier treatments, calibration was performed by setting the second and third zones to a zero value to indicate that no jatropha roots were present in the alley where the maize was grown.

\subsubsection{Model validation}

To evaluate the model's ability to simulate growth and yield of jatropha and maize in monoculture and intercropping systems, predicted results were compared against observed results. For the jatropha monoculture, comparisons were made with the jatropha pruning treatment, while for the maize monoculture the simulation results were compared with the maize-mulch treatment results. For intercropping, the simulation results were compared with mulch and root barrier treatments. To determine model goodness of fit between predicted and observed results, we used statistical parameters of ME, RMSE, CD, EF, and CRM developed by Loague and Green (1991). See Appendix 2.

\subsubsection{Simulation scenarios}

Different management scenarios were evaluated to determine their effects on the different cropping systems. The objective was to develop a series of realistic options that could be adopted for longer production periods. Table 6.2 shows the range of simulation scenarios evaluated for jatropha and maize in monoculture and intercropping systems.

Jatropha monoculture without pruning and with pruning at alternate years and every year were selected for simulation scenarios based on observations during field visits. Maize monoculture without mulch and fertiliser, and jatropha intercropping with pruning, mulch, and $\mathrm{P}$ application at $72 \mathrm{~kg} \mathrm{ha}^{-1}$ were based on Chapter 5. Jatropha mulch was obtained from leaf pruning $\left(3.5 \mathrm{t} \mathrm{ha}^{-1}\right)$ and leaf nutrient analysis showed that mulch had an equivalent $\mathrm{N}$ input of $91 \mathrm{~kg} \mathrm{ha}^{-1}$, P input of $6.2 \mathrm{~kg} \mathrm{ha}^{-1}$, and $\mathrm{K}$ input of $39.8 \mathrm{~kg} \mathrm{ha}^{-1}$. In that study the application of mulch resulted in an increase in maize yield comparable with the application of $\mathrm{N}$ at $21 \mathrm{~kg} \mathrm{ha}^{-1}$. The $\mathrm{N}$ balance of mulch is discussed in Section 5.2 and shown in Table 5.4. 
Table 6.2 Land use simulation scenarios for jatropha monoculture, maize monoculture, and jatropha/maize intercropping covering a 20 year period or 40 cropping cycles.

\begin{tabular}{|c|c|c|c|c|}
\hline Simulation scenarios & Pruning & $\begin{array}{c}\text { Jatropha } \\
\text { mulch }\end{array}$ & $\begin{array}{l}\text { Fertiliser } \\
\left(\mathrm{kg} \mathrm{ha}^{-1}\right)\end{array}$ & Plant \\
\hline \multirow{2}{*}{ Jatropha monoculture } & Yes & - & - & \multirow{2}{*}{ Jatropha } \\
\hline & No & - & - & \\
\hline \multirow{4}{*}{ Maize monoculture } & - & - & - & Maize \\
\hline & - & With mulch & - & Maize \\
\hline & - & With mulch & $P$ at $72(72 P)$ & Maize \\
\hline & - & - & $\mathrm{N}$ and $\mathrm{P}$ at $40(\mathrm{~N} 40 \mathrm{P} 40)$ & Maize \\
\hline \multirow{8}{*}{ Jatropha/maize intercropping } & Yes & - & - & Jatropha + maize \\
\hline & Yes & With mulch & - & Jatropha + maize \\
\hline & Yes & With mulch & $\mathrm{P}$ at $72(72 \mathrm{P})$ & Jatropha + maize \\
\hline & Yes & - & $\mathrm{N}$ and $\mathrm{P}$ at $40(\mathrm{~N} 40 \mathrm{P} 40)$ & Jatropha + maize \\
\hline & No & - & - & Jatropha + maize \\
\hline & No & With mulch & - & Jatropha + maize \\
\hline & No & With mulch & $\mathrm{P}$ at $72(72 \mathrm{P})$ & Jatropha + maize \\
\hline & No & - & $\mathrm{N}$ and $\mathrm{P}$ at $40(\mathrm{~N} 40 \mathrm{P} 40)$ & Jatropha + maize \\
\hline
\end{tabular}

Note: $\mathrm{P}=$ phosphorus; $\mathrm{N}=$ nitrogen.

For jatropha intercropping with pruning and mulch, and jatropha intercropping with pruning and $\mathrm{N}$ and $\mathrm{P}$ applications each of $40 \mathrm{~kg} \mathrm{ha}^{-1}$ scenarios were selected based on local farmer practice. Finally, jatropha intercropping without pruning was based on research literature (Brittaine and Lutaladio, 2010) or while jatropha is young (Achten et al., 2008). In this simulation, mulch was applied once a year at the end of dry season, and before the first cropping season started, while both $\mathrm{N}$ and $\mathrm{P}$ were applied together for each cropping season.

Little or no data are available for jatropha yield beyond 10 years of age; therefore, simulations were run for periods of 20 years or 40 maize cropping seasons to gain an understanding of the long-term productivity response. A range of jatropha plant spacing combinations (Table 6.3) was simulated to evaluate the effect on growth and yield of jatropha and maize under different planting densities. For each inter-row distance scenario, the first and last $50 \mathrm{~cm}$ were allocated as jatropha zone, zones 1 and 4 respectively, while the middle inter-row distance was allocated for maize in zone 2 and 3. For example, when jatropha had $2 \mathrm{~m}$ inter-row, the $1 \mathrm{~m}$ space in the middle of the inter-row (alley) was allocated for maize planting. 
Table 6.3 Jatropha planting distance scenarios.

\begin{tabular}{|c|c|c|c|}
\hline $\begin{array}{c}\text { Intra-row } \\
\text { distance }(\mathrm{m})\end{array}$ & $\begin{array}{c}\text { Inter-row } \\
\text { distance (m) }\end{array}$ & $\begin{array}{l}\text { Planting pattern } \\
\qquad(\mathrm{m} \times \mathrm{m})\end{array}$ & $\begin{array}{c}\text { Jatropha density } \\
\left(\text { trees } \mathrm{ha}^{-1}\right)\end{array}$ \\
\hline \multirow{4}{*}{1} & 2 & $1 \times 2$ & 5,000 \\
\hline & 3 & $1 \times 3$ & 3,333 \\
\hline & 4 & $1 \times 4$ & 2,500 \\
\hline & 5 & $1 \times 5$ & 2,000 \\
\hline \multirow{4}{*}{2} & 2 & $2 \times 2$ & 2,500 \\
\hline & 3 & $2 \times 3$ & 1,667 \\
\hline & 4 & $2 \times 4$ & 1,250 \\
\hline & 5 & $2 \times 5$ & 1,000 \\
\hline \multirow{3}{*}{3} & 3 & $3 \times 3$ & 1,111 \\
\hline & 4 & $3 \times 4$ & 833 \\
\hline & 5 & $3 \times 5$ & 667 \\
\hline \multirow{2}{*}{4} & 4 & $4 \times 4$ & 625 \\
\hline & 5 & $4 \times 5$ & 500 \\
\hline 5 & 5 & $5 \times 5$ & 400 \\
\hline
\end{tabular}

Note: $\mathrm{m}=$ metre; All plant spacing combinations have the intra-row first followed by the inter-row.

When jatropha had $3 \mathrm{~m}$ inter-row, the $2 \mathrm{~m}$ alley in the middle of the inter-row was allocated for maize, and so forth until the $5 \mathrm{~m}$ jatropha inter-row which had a $4 \mathrm{~m}$ alley in the middle for maize planting. The model was calibrated based on a $1 \mathrm{~m}$ inter-row with 3 rows of maize which gives a maize planting density of 26,667 plants per ha. Therefore, increases in inter-row distance of jatropha spacing reduced jatropha planting density but increased maize planting density.

\subsubsection{Scenarios evaluation}

Output from simulation scenarios were analysed using trade-off analysis between jatropha and maize yield. Biological productivity trade-offs between tree and crop for intercropping were evaluated by plotting relative jatropha yield on one axis and relative maize yield on the other (Figure 6.1). If the tree-crop response result is above the 1:1 line, then there is a net positive (complementarity) interaction. If however the result is below the 1:1 line, then there is a net negative (competition) interaction (Ranganathan et al., 1991).

\subsection{Results}

All jatropha monoculture scenarios (Figure 6.2A) show that denser planting reduced yield and sparser planting densities increased yield. 

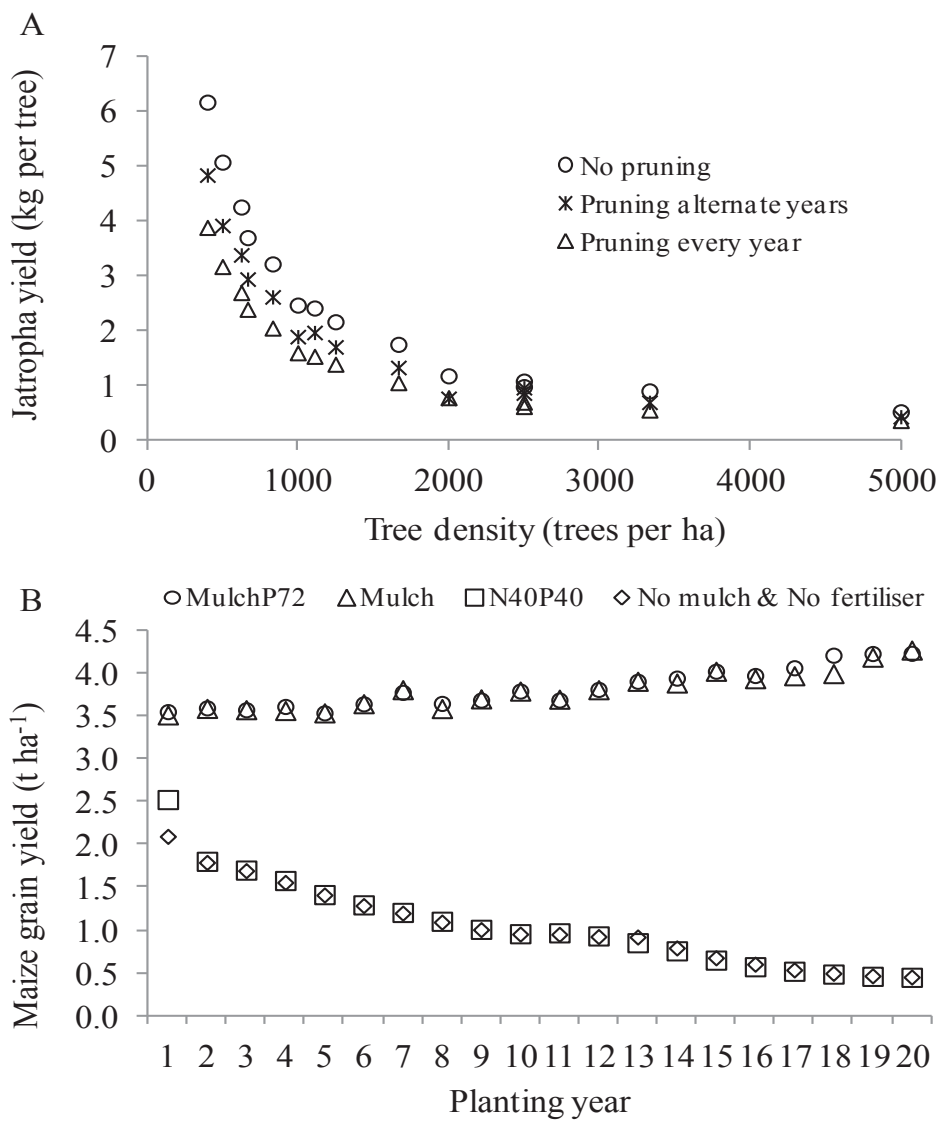

Figure 6.2 (A) Monoculture jatropha yield at different density with several pruning treatments and (B) monoculture maize yield in several treatments over 20 years.

The average differences between points across pruning and planting densities show that pruning at alternate years decreased yield by $21 \%$ compared with no pruning, while pruning every year decreased yield by $37 \%$ when compared with no pruning.

Maize monoculture across different fertiliser scenarios (Figure 6.2B) shows that greater yields are possible using mulch and mulch72P than 40N40P, and no mulch and no fertiliser. Yields for mulch and mulch72P shared a similar pattern, gradually increasing over time. Yields for mulch, and 40N40P also shared a similar pattern, but gradually decreased over time, although 40N40P had a $20 \%$ greater yield in the first planting year. Jatropha and maize intercropping for all fertiliser, pruning, and planting density scenarios show similar component yield patterns.

Figure 6.3 is an example of how the PPF envelopes input factors such as mulch72P, and no mulch and no fertiliser scenarios for unpruned jatropha. Different planting density scenarios produce a range of maximum 
yield outputs for cumulative component jatropha and maize yields. For scenarios without pruning, mulch or fertiliser application, various planting densities appear to favour greater jatropha yield than maize yield. Variations within jatropha yields were observed by keeping specific intra-row fixed at different spacing and varying the inter-row distance. Jatropha yield increased only until a $3 \mathrm{~m}$ inter-row was reached. Planting density scenarios with $3 \mathrm{~m}$ inter-row produced approximately equal jatropha yields compared with average yields from unfertilised monoculture without pruning (see black arrow in Figure 6.3). Other planting density scenarios produced jatropha yields that were less than the average from jatropha monoculture unfertilised and no pruning scenarios. For maize, the two largest yields were obtained from $2 \mathrm{~m}$ inter-row such as $1 \mathrm{~m} \times$ $2 \mathrm{~m}$ and $2 \mathrm{~m} \times 2 \mathrm{~m}$, after that yields remained constant. If we compare yields from no mulch and no fertiliser with mulch72P, it seems the latter resulted in better combinations for maximum yields.

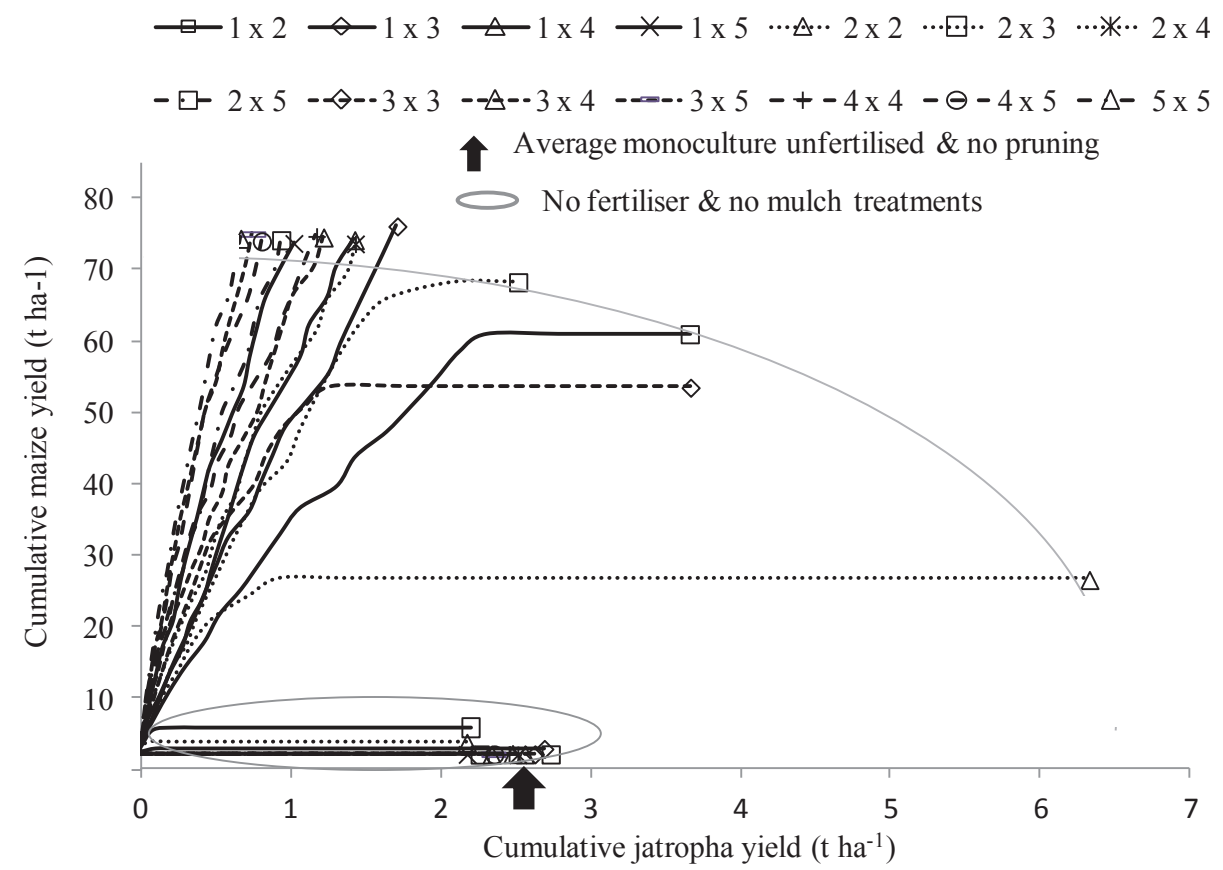

Figure 6.3 Jatropha and maize cumulative yield that shows production possibility frontier (PPF) for no pruning with mulch and $\mathrm{P}$ applied at $72 \mathrm{~kg} \mathrm{ha}^{-1}$, and no pruning with no mulch and no fertiliser scenarios at various planting density combinations.

Mulch72P at various planting densities showed a wider range of jatropha and maize yields. A narrow interrow $(\leq 3 \mathrm{~m})$ combined with all intra-row options benefited jatropha yields and the greatest yields especially came from combination with $2 \mathrm{~m}$ and $3 \mathrm{~m}$ intra-rows. For example, $2 \mathrm{~m} \times 2 \mathrm{~m}$ scenario gave $6.5 \mathrm{t} \mathrm{ha}^{-1}$ jatropha and $26 \mathrm{t} \mathrm{ha}^{-1}$ in the whole simulation period. The increase in jatropha yield was the result of maize no longer being a productive intercrop. A wider inter-row $(\geq 4 \mathrm{~m})$ combined with all intra-row options 
favoured maize yields. The PPF that frames the mulch72P scenarios makes it possible to determine optimal planting densities needed to maximise yields.

To determine the trade-offs between jatropha and maize yields in intercropping with monoculture jatropha and maize yield, relative (component) jatropha and maize yields are used (Figure 6.3). All scenario combinations for relative jatropha and maize yield produced four PPFs, two PPFs, mulch72P and mulch only scenarios have complex shapes, which indicate that jatropha and maize interact positively and are complementary. This also means that intercropping provides increased benefits compared with monoculture. The other two PPFs, 40N40P, and no mulch and no fertiliser scenarios have concave shapes indicating that jatropha and maize interact negatively and are competitive. Yields situated on the 1:1 line indicate that intercropping or monoculture can produce equal yields, while yield scenarios situated inside the 1:1 line indicate that yields for monoculture will be greater than for intercropping. Almost all intercropping yields were greater for monoculture with the exception of some scenarios within $40 \mathrm{~N} 40 \mathrm{P}$ and no mulch and no fertiliser. Details are in Section 6.4.4. This also means that intercropping provides increased benefits compared with monoculture. The other two PPFs, 40N40P, and no mulch and no fertiliser scenarios have concave shapes indicating that jatropha and maize interact negatively and are competitive.

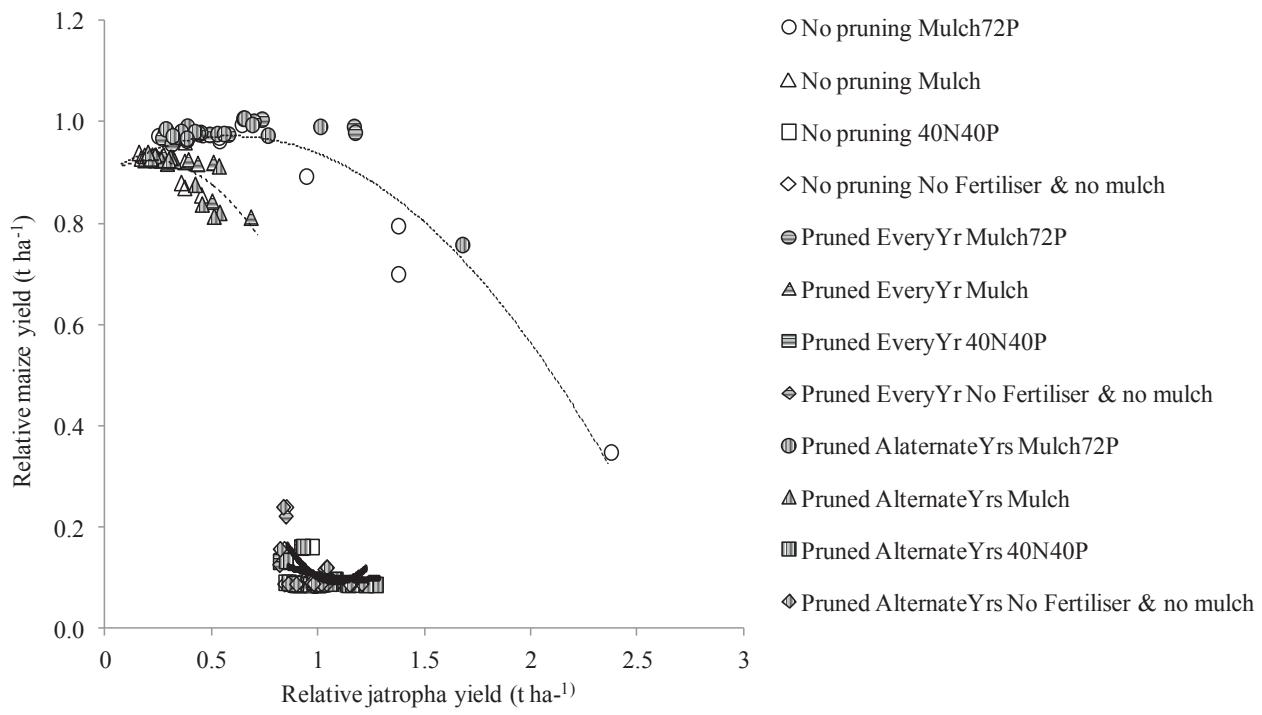

Figure 6.4 Production possibility frontiers (PPF) that show relative jatropha and maize yield trade-offs from pruning and fertiliser scenarios that were generated from various planting density combinations.

Yields situated on the 1:1 line indicate that intercropping or monoculture scenarios can produce equal yields, while yield scenarios situated inside the 1:1 line indicate that yields for monoculture will be greater than for intercropping. Almost all intercropping yields were greater than monoculture with exception some scenarios within 40N40P and no mulch and no fertiliser. Details are discussed in Section 6.3.4. 


\subsubsection{Fertiliser}

When the fertiliser effect is measured across all scenarios, mulch72P gave the largest contribution for relative jatropha yield of $63 \%$ and $95 \%$ for relative maize yield. Mulch gave a relative jatropha yield of 33 $\%$ and relative maize yield of $91 \%$. 40N40P gave the largest relative jatropha yield of $98 \%$ and relative maize yield of $11 \%$, while no mulch and no fertiliser gave a relative jatropha yield of $96 \%$ and a relative maize yield of $10 \%$.

The pooled results for fertiliser scenarios as the main effect show that better yields for jatropha and maize were obtained from mulch72P as opposed to mulch only. However, when fertiliser inputs are sufficient such as from mulch72P and mulch, maize produces an overall relative yield of 1.5 to 3 times greater than jatropha, which means maize is dominant. In contrast, if there is little or no additional fertiliser such as in 40N40P and no mulch and no fertiliser, then relative jatropha yield was 10 times larger than relative maize yield, and jatropha is dominant.

When the pooled $\mathrm{N}$ and $\mathrm{P}$ nutrient balance from the WaNuLCAS are analysed there was an increase in maize $\mathrm{N}$ and $\mathrm{P}$ uptake, especially for the mulch or mulch72P scenarios. These two scenarios show maize $\mathrm{N}$ and $\mathrm{P}$ uptake was larger for intercropping than for monoculture. For mulch in intercropping, there was a $12 \%$ increase in the average $\mathrm{N}$ uptake, and was an $11 \%$ increase in the average $\mathrm{P}$ uptake compared with monoculture maize. For mulch72P in intercropping on average, there was a $16 \%$ increase in average $\mathrm{N}$ uptake and a $20 \%$ in average $\mathrm{P}$ uptake compared with monoculture maize.

The effect of mulch in the WaNuLCAS simulations relates not only to increased $\mathrm{N}$ and $\mathrm{P}$ uptake, but also to a reduction in soil moisture evaporation. Evaporation for the pooled mulch $72 \mathrm{P}$ was $71 \%$, for mulch $43 \%$, for $40 \mathrm{~N} 40 \mathrm{P}$ it was $34 \%$, and for no mulch and no fertiliser, $37 \%$ less than for monoculture. As water is needed for transport of nutrients, less evaporation may have contributed to better water availability and nutrient uptake.

The WaNuLCAS simulation expresses the number of stress related days as a percentage of the simulation period for jatropha or maize. A 20-year simulation across all scenarios shows that overall the resource limiting factors for maize growth are $\mathrm{N}$ ( $52 \%$ of the total simulated period), followed by water (17\% of the total simulated period), and P (6\% of the total simulated period). The overall resource limiting factors for jatropha growth and yield are water (52\% of the total simulated period), followed by P (35\% of the total simulated period), and $\mathrm{N}$ ( $23 \%$ of the simulated period).

\subsubsection{Pruning}

In general, all pruning scenarios show similar results for relative jatropha and maize yield. The best relative jatropha yield (75\%) was for pruning at alternate years with a relative maize yield of $52 \%$. No pruning was 
next with $72 \%$ relative jatropha yield and $50 \%$ relative maize yield. Finally, pruning every year gave a $71 \%$ relative jatropha yield and $52 \%$ relative maize yield.

The pooled results for pruning scenarios as the main effect show that overall relative jatropha yield was $40 \%$ greater than relative maize yield. However, pruning frequency does not substantially influence relative jatropha or maize yield for intercropping. While pruning at alternate years increased relative jatropha yield by $3 \%$, pruning every year decreased relative jatropha yield by $2 \%$, and both pruning scenarios increased relative maize yield by $3 \%$ compared with no pruning.

\subsubsection{Planting density}

The pooled results for planting density as the main effect show an advantage for jatropha with overall relative yield $40 \%$ greater than relative maize yield. However, variations in planting density show contrasting, but consistent patterns for jatropha and maize, especially when the relative yields were assessed by varying the intra-or inter-row distance.

Jatropha produced the most yields when intra- or interspecific competition was least intense. For example the $2 \mathrm{~m} \times 2 \mathrm{~m}$ spacing (2,500 jatropha per ha) produced largest relative jatropha yield of $98 \%$ but at a $1 \mathrm{~m} \times 2 \mathrm{~m}$ spacing (5,000 jatropha per ha) relative jatropha yield reduced to $88 \%$. The $3 \mathrm{~m} \times 3 \mathrm{~m}$ spacing $(1,111$ jatropha per ha) produced relative jatropha yield of $84 \%$ but at a $1 \mathrm{~m} \times 3 \mathrm{~m}$ spacing $(3,333$ jatropha per ha), relative jatropha yield reduced to $82 \%$. For the $2 \mathrm{~m} \times 2 \mathrm{~m}$ and $1 \mathrm{~m} \times 4 \mathrm{~m}$ spacing, jatropha planting density is the same, 2,500 plants per ha. However, there is a threefold increase in maize planting area, which resulted in a reduction of relative jatropha yields to $71 \%$, but a $15 \%$ increase in relative maize yield.

Pooled planting density scenarios show the greatest relative maize yield (55\%) was obtained from $1 \mathrm{~m} \times 2 \mathrm{~m}$ (5,000 jatropha per ha) spacing. Increasing the intra-row to $2 \mathrm{~m}(2,500$ jatropha per ha) reduced relative maize yield to $45 \%$. Maize at $3 \mathrm{~m}$ inter-row followed a similar pattern, but with a smaller reduction in relative yield which levelled off for the $4 \mathrm{~m}$ and $5 \mathrm{~m}$ inter-row plantings.

At high planting densities, the shading effect of the jatropha canopy reduced soil evaporation. For example when jatropha and maize were intercropped at $1 \mathrm{~m} \times 2 \mathrm{~m}$ (5,000 jatropha per ha), soil evaporation was $30 \%$ lower than for the jatropha monoculture, and $43 \%$ lower than the maize monoculture. At $2 \mathrm{~m} \times 2 \mathrm{~m}(2,500$ jatropha per ha), soil evaporation was $33 \%$ lower than the jatropha monoculture, and $42 \%$ lower than the maize monoculture.

\subsubsection{Combination scenarios for fertiliser, pruning, and planting density}

In the three previous sections I examined the effects individual management variables of fertiliser, pruning, and planting densities and how they affected jatropha and maize intercropping yields. This section presents the results for combined management scenarios. This was followed by mulch $72 \mathrm{P}$ with pruning at alternate 
years where jatropha yield was $180 \%$ and maize yield $75 \%$. For mulch $72 \mathrm{P}$ with pruning every year jatropha yield was $130 \%$ and maize yield was $98 \%$.

The mulch72P had $\mathrm{N}$ and $\mathrm{P}$ uptake 3 times larger than jatropha monoculture, while water uptake was $8 \%$ greater than jatropha monoculture. For mulch72P with pruning at alternate years, the $\mathrm{N}$ and $\mathrm{P}$ uptake was 77 $\%$ and $57 \%$ greater than jatropha monoculture, while the water uptake was $21 \%$ smaller. For mulch $72 \mathrm{P}$ with pruning every year, $\mathrm{N}$ and $\mathrm{P}$ uptake was $40 \%$ and $20 \%$ respectively larger than jatropha monoculture, while the water uptake was $27 \%$ smaller.

The mulch72P largest relative jatropha yields were obtained from the $2 \mathrm{~m}$ x $2 \mathrm{~m}$ spacing, which had a larger yield than the $1 \mathrm{~m}$ inter-row. At the smaller inter-row spacing, nutrient leaching, especially $\mathrm{N}$ was less than at $5 \mathrm{~m}$. Increasing the inter-row distance from $2 \mathrm{~m}$ to $5 \mathrm{~m}$ resulted in a gradual increase in $\mathrm{N}$ leaching, with differences of approximately $14 \%$ for no pruning, and $19 \%$ for pruning at alternate years and every year.

For the mulch72P with pruning every year scenario, alternate years, and no pruning led to similar jatropha and maize yields of $101 \%$ to $99 \%$ and $62 \%$ to $57 \%$ respectively. For mulch $72 \mathrm{P}$ with pruning every year, different inter-row distance reduced maize yield only 3 to $4 \%$. It seems when jatropha is fertilised with mulch72P, and is pruned every year, increased inter-row distance did not compensate for larger yields. The largest maize yield of $101 \%$ was produced at $2 \mathrm{~m} \times 3 \mathrm{~m}$ spacing, which decreased to $98 \%$ for the $2 \mathrm{~m} \times 2 \mathrm{~m}$ and $97 \%$ for $2 \mathrm{~m} \times 4 \mathrm{~m}$. Mulch only, pruning every year, and no pruning produced similar yield patterns, however the reduction was slightly larger than for mulch72P. Mulch72P and mulch provided nutrients and reduced soil evaporation by $55 \%$ for pruning every year, by $57 \%$ for pruning alternate years, and by $58 \%$ for no pruning when compared with maize monoculture.

For mulch $72 \mathrm{P}$ with pruning alternate years, a minimum inter-row spacing of $3 \mathrm{~m}$ is required otherwise relative maize yields are reduced by $25 \%$, while for mulch $72 \mathrm{P}$ with no pruning the minimum inter-row spacing is $4 \mathrm{~m}$ otherwise maize yield is reduced by $20 \%$ to $65 \%$.

When jatropha is pruned every year, maize growth limitation by light interception (relative to maize monoculture) is only $2 \%$ to $9 \%$. If jatropha is pruned in alternate years, the smallest inter-row limits potential maize growth by $14 \%$, while the wider inter-row spacing's only reduce yield by $3 \%$ to $9 \%$. If jatropha is not pruned, the smallest inter-row spacing limits maize yield by $40 \%$, while the wider spacing limits yield by $4 \%$ to $11 \%$.

In the mulch scenario, the general PPF trend shows that mulch tends to favour relative maize yield rather than relative jatropha yield. For instance, the pooled results of mulch with no pruning, pruning every year, and pruning alternate years, produced relative jatropha yields of $27 \%, 34 \%, 38 \%$, and relative maize yields 
of $92 \%, 90 \%$, and $90 \%$ respectively. Both maize $\mathrm{N}$ and P uptake in mulch scenarios was $12 \%$ greater than maize monoculture, while jatropha $\mathrm{N}$ and $\mathrm{P}$ uptake was $27 \%$ and $54 \%$ smaller than uptake under jatropha monoculture respectively. For jatropha, $\mathrm{P}$ was the second most limiting factor after the water. P limitation across the different pruning scenarios covered $35 \%$ of the simulation period. The mulch scenario shows overall maize water uptake was $14 \%$ greater than maize monoculture while overall jatropha water uptake was $61 \%$ lower than jatropha monoculture.

In the mulch scenario, the largest relative jatropha yield was obtained from pruning at every year combined with the smallest inter-row of $2 \mathrm{~m}$, and with $2 \mathrm{~m}$ intra-row that had larger yield than $1 \mathrm{~m}$ intra-row. At $2 \mathrm{~m}$ inter-row, relative jatropha yield was $72 \%$ while relative maize yield was $77 \%$. Other pruning scenarios also followed this pattern with reduced relative jatropha yield but increased relative maize yield. For example under similar conditions, pruning at alternate years had a relative jatropha yield of $55 \%$ and a relative maize yield of $85 \%$. For mulch and $2 \mathrm{~m}$ inter-row, combined with pruning every year gave the best water uptake for jatropha compared with other pruning scenarios. Jatropha water uptake for pruning every year, alternate years, and no pruning was $43 \%, 54 \%$, and $66 \%$ respectively, smaller than jatropha monoculture.

To maximise maize yield, mulch in combination with no pruning and the widest inter-row $(5 \mathrm{~m})$ gave a greater yield than the smaller inter-row. Following no pruning was pruning at alternate years, and pruning every year in similar planting density scenarios. Overall mulch scenarios across the different pruning scenarios shows that inter-row distance provides increased benefits for relative maize yield, at least up to and including $4 \mathrm{~m}$, after which yield reached a plateau. For jatropha, however increased inter-row distance reduced jatropha density and relative yield. For example, for no pruning, a $2 \mathrm{~m}$ inter-row had relative maize yield of $91 \%$ with $44 \%$ relative jatropha yield, while $4 \mathrm{~m}$ or $5 \mathrm{~m}$ inter-row had relative maize yield of $93 \%$ with $22 \%$ relative jatropha yield. Widening the inter-row distance increases N, P, and water uptake for maize, but decreases N, P, and water uptake for jatropha. For no pruning in a $2 \mathrm{~m}$ inter-row, maize N, P, and water uptake was $5 \%$ less than maize monoculture and jatropha N, P, and water uptake was $24 \%$ larger, 40 $\%$ and $66 \%$ smaller than jatropha monoculture. At $5 \mathrm{~m}$ inter-row, maize N, P, and water uptake was $53 \%$ greater than maize monoculture respectively. As for jatropha, the $\mathrm{N}, \mathrm{P}$, and water uptake were $34 \%, 62 \%$, and $85 \%$ smaller than jatropha monoculture respectively. It is clear that increasing the inter-row distance reduces the number of jatropha per ha and this is not compensated by an increase in yield per tree.

For the 40N40P, no mulch and no fertiliser scenarios, there was competition between jatropha and maize, with jatropha out-competing maize. Pruning alternate years produced the greatest relative jatropha yield at $121 \%$ with $9 \%$ relative maize yield. This was followed by equal yields in the pruning every year and no pruning scenarios at $99 \%$ for jatropha relative yield and $9 \%$ relative maize yield. For pruning alternate years, relative jatropha yield increased when the spacing increased from $4 \mathrm{~m}$ to $5 \mathrm{~m}$ inter-row in combination with $>3 \mathrm{~m}$ intra-row. Maximum jatropha relative yield was achieved at $5 \mathrm{~m} \times 5 \mathrm{~m}$ planting density, which 
means when grown in an intercropping scenario, jatropha produces greater yields than when grown as monoculture. In contrast, the smaller inter-row distances of $2 \mathrm{~m}$ and intra-row distances of $1 \mathrm{~m}$ and $2 \mathrm{~m}$ produced lower yields (89 \%) when grown as intercropping. In this situation, it is therefore more advantageous to grow jatropha as a monoculture.

When jatropha was pruned every year or was not pruned, the smallest intra-row $(1 \mathrm{~m})$ in combination with 2 $\mathrm{m}$ and $3 \mathrm{~m}$ inter-row produced an equal benefit (100\% relative jatropha yield) when grown either as intercropping or monoculture. As for relative maize yield, the smallest inter-row (2 m) in combination with intra-row of $1 \mathrm{~m}$ and $2 \mathrm{~m}$ produced similar yields across the different pruning scenarios. These relative maize yields were however only $12 \%$ to $24 \%$ of the largest relative maize yield produced in the mulch or mulch72P scenarios.

\subsection{Discussion}

The WaNuLCAS model proved to be a useful tool for simulation of long-term productivity for a wide range of management scenarios in jatropha-maize intercropping based agroforestry systems. Our results show a substantial scope for intercropping jatropha and maize, especially if maize is fertilised and assessed in combination with jatropha pruning and planting density management.

I assessed yield trade-offs by comparing jatropha and maize grown as monoculture and intercropping. I used Willey's (1979) first scenario to assess the yield advantage. This is where intercropping gives full yield of the main crop and some yield for the secondary crop. For this scenario, I used two distinct options. The first was to treat jatropha as the main crop and maize as the secondary crop with the aim of maximising jatropha yield. Currently, this situation is somewhat unlikely from farmer's perspective given the current commercial circumstances where jatropha yields and price are both low and uncertain (Van Eijck et al., 2014a). Given that this situation may change in future, there is a need to consider the second option. This was to treat maize as the main crop and jatropha as the secondary crop with the objective to maximise maize yield. This is the predominant situation for local farmers who plant jatropha primarily as a means of gaining extra income, minimising their risk or aiming for yield stability.

To determine maximum yield for jatropha or maize, our simulated results are framed within the PPF developed by Ranganathan et al. (1991) and Ranganathan (1992). This enables us to determine maximum yield outputs for jatropha or maize based on various inputs such as fertiliser, pruning, and planting density scenarios and its combinations. In addition to yield, the PPF highlights any dominance effect between jatropha and maize in the intercropping and monoculture systems. 


\subsubsection{Fertiliser}

The addition of leaf mulch as a source of nutrients and organic matter in the alley or inter-row is a common agroforestry practice in alley cropping or intercropping systems (Kang et al., 1981; Palm, 1995; Rao et al., 1997). Our simulations for maize monoculture (Figure 6.2B) show that the addition of jatropha leaf prunings as mulch or mulch with $\mathrm{P}$ applied at $72 \mathrm{~kg} \mathrm{ha}^{-1}$ (mulch72P) can sustain jatropha and maize long-term productivity.

Jatropha mulch nutrient analysis showed that it has sufficient $\mathrm{N}\left(91 \mathrm{~kg} \mathrm{~N} \mathrm{ha}^{-1}\right)$ theoretically to meet maize requirements, but that it supplies only small amount of $\mathrm{P}\left(6.2 \mathrm{~kg} \mathrm{ha}^{-1}\right)$ which is insufficient (Chapter 5). The addition of $\mathrm{P}$ combined with organic matter for annual crop production will be necessary, especially if the soils are deficient in P (Palm, 1995; Sanchez, 1995; Rao et al., 1997). Therefore, I included mulch72P in this study. Results from Chapter 5 showed addition of mulch72P in maize monoculture increased yield comparable with equivalent of $\mathrm{N}$ application at $21 \mathrm{~kg} \mathrm{ha}^{-1}$. The simulation results with mulch72P and mulch scenarios showed a major portion of $\mathrm{N}$ added from mulch was tied up in the soil organic matter and lost through $\mathrm{N}$ leaching. Therefore mulch is beneficial in the long-term soil fertility as it increases the amount of organic $\mathrm{N}$ in the soil (Palm, 1995).

Our simulations are in line with various studies that show the addition of $\mathrm{P}$ in combination with organic matter can increase maize $\mathrm{N}$ and $\mathrm{P}$ uptake and consequently lead to greater maize yields (Gachengo et al., 1999; Nziguheba et al., 2000; Kwabiah et al., 2003) in intercropping than in monoculture (Akinnifesi et al., 2007; Mukuralinda et al., 2010). Simulations for 40N40P, and no mulch and no fertiliser affect maize yield more than jatropha yield. Maize yield in these scenarios were the smallest compared with the mulch and mulch72P scenarios, yet jatropha yield was comparable with mulch or mulch72P scenarios. Mulch72P and mulch also effectively reduce soil evaporation by minimising the impact of solar radiation, and by minimising soil surface air flow (Riha and McIntyre, 1999). Mulch72P had less soil evaporation than mulch, possibly because the addition of $\mathrm{P}$ enhanced rooting close to the soil surface thereby increasing root water uptake (Riha and McIntyre, 1999).

In the simulations, the most limiting factor for jatropha was water, while for maize it was $\mathrm{N}$. The results are understandable as maize is an annual crop with a short life cycle, occupying a small soil volume for water and nutrient extraction. Maize has been bred for high yield with high nutrient demand, especially N, therefore if $\mathrm{N}$ is limited; growth and finally yield are low and will decline over time. Unlike maize, jatropha is a perennial with a longer lifespan. Jatropha also has the advantage that its roots can utilise a larger volume of belowground resources (Van Noordwijk et al., 1996). This is especially true if the jatropha root system is established before the maize is planted. If we take into account jatropha that has not been pruned then the jatropha advantage in capturing resources from a larger area and in enhancing soil physical and chemical properties under its canopy is greater (Ong et al., 1996). The jatropha parameterisation in this study is not 
from a high-yielding variety. However; it does show some adaptation to the local environment, and to the poor soil fertility. In addition jatropha's dependency on regular rainfall was highlighted by the limited soil water availability resulting from the sites shallow soil and limited root development.

\subsubsection{Pruning}

Pooled results for pruning scenarios do not show substantial differences. However, if we compare the pooled results for pruning scenarios with jatropha monoculture for the different pruning and planting density scenarios (Figure 6.2A) we see greater differences between pruning at alternate years and pruning every year, and for no pruning. Moreover in Chapter 4 two-year-old jatropha monoculture grown without external inputs, and at a plant spacing of $2 \mathrm{~m} \times 2 \mathrm{~m}$, and pruned to a height of $75 \mathrm{~cm}$, reduced yield by $75 \%$ compared with no pruning. Other jatropha monoculture studies with pruning treatments also show yield reductions when compared with no pruning treatments, although the degree of yield reductions varied with age, management practices (plant spacing, pruning heights, and fertiliser), and the environment (Ghosh et al., 2011; Singh et al., 2013).

Jatropha pruning research is still limited and no pruning standards exist; however the examples above show that pruning is not the sole factor for intercropping or monoculture. Pruning in combination with fertiliser and planting density can also change relative jatropha and maize yield relationships, which is discussed in Section 6.4.4.

\subsubsection{Planting density}

The examples given in the pooled planting density results show that although jatropha yield dominates maize, variations in planting density can change jatropha intra and interspecific competition. Resource capture for light, soil water and nutrients between jatropha and maize is influenced by planting density.

At small inter-row or high planting densities, jatropha benefited from reduced soil evaporation and nutrient access provided by maize. Widening the inter-row reduces jatropha light interception, soil water and nutrient access, and ultimately reduces jatropha's capacity to compete with maize, and with neighbouring jatropha shrubs. Similar effects have been observed between pigeon pea and sorghum (Daniel and Ong, 1990), with other tree/shrub species and maize (Lawson and Kang, 1990), and with sugar cane and cereals (Willey, 1990). Interspecific competition between jatropha and maize in this case was not a problem because the pooled yield effect was less than the intraspecific competition between jatropha (Ong et al., 1996). Losses in jatropha yield mean greater maize yields and this is especially important when socio-economic conditions favour maize over jatropha.

Tree canopy shading reduces solar radiation intensity thereby reducing soil evaporation. Reductions in soil evaporation can be effective in reducing crop transpiration rates that result in an increased water use 
efficiency (Ong et al., 2000; Ong et al., 2006; Lott et al., 2009). Shading also reduces leaf temperature, minimising heat stress, reducing air temperature, wind speed, and saturation deficit, effectively reducing water use (Monteith et al., 1991; Jonsson et al., 1999; Ong et al., 2000). In general, shading is beneficial; however, competition for soil water and nutrients, and light will still be present and favour the dominant species.

\subsubsection{Fertiliser, pruning, and planting density combination scenarios}

Assessment of all scenario PPF trends (Figure 6.4) shows several possibilities for maximising relative jatropha or maize yield. For jatropha, the combination that produces the greatest (maximum) relative yields are from mulch72P and unpruned jatropha; planted at the smallest maize planting density ( $2 \mathrm{~m}$ inter-row) with $2 \mathrm{~m}$ intra-row giving a larger yield than the $1 \mathrm{~m}$ inter-row. The next greatest jatropha yield was obtained from the 40N40P, and no mulch and no fertiliser scenarios with pruning at alternate years, planted at the widest intra-and inter-rows. Finally, mulch can give the best jatropha yield when it was pruned every year and was planted at $2 \mathrm{~m} \times 2 \mathrm{~m}$ spacing. For maize, greatest yield was also obtained from mulch72P, but only in combination with pruning every year. For this scenario, different planting densities did not increase maize yield substantially, although a slight increase in relative maize yield was obtained from $2 \mathrm{~m} \times 3 \mathrm{~m}$ spacing. The next greatest maize yield was obtained from mulch in combination with no pruning scenario, planted at the widest inter-row (5 m) and irrespective of intra-row spacing. The remaining fertiliser scenarios, 40N40P, and no mulch and no fertiliser had the smallest relative maize yields.

The reason certain scenario combinations produced greater relative yield for jatropha or maize is due to resource capture, use, and conversion efficiency. For example in the case of jatropha, the combinations of mulch72P, unpruned jatropha, and smallest inter-row $(2 \mathrm{~m})$ gave the greatest relative jatropha yield because $\mathrm{N}, \mathrm{P}$, and water uptake were the greater when compared with the other scenarios. Inter-row spacing of $2 \mathrm{~m}$ also had the lowest $\mathrm{N}$ leaching, probably for two reasons. Firstly, competition between jatropha and maize for belowground resources at $2 \mathrm{~m}$ inter-row would result in resources being used more efficiently. Secondly, jatropha roots grow deeper and potentially beneath the maize roots creating a 'safety-net' effect or filter function to capture $\mathrm{N}$ before it is lost. The 'safety-net' concept of Van Noordwijk et al. (1996) considers that deep rooting trees intercept nutrients which have leached below the crop rooting zone. The safety-net effect has already been tested in tropical alley cropping between maize and gliricidia, and with peltophorum (Peltophorum dasyrrachis) in North Lampung, Indonesia (Rowe et al., 1999), and in temperate alley cropping between cotton (Gossypium hirsutum) and pecan (Carya illinoensis) in Florida, USA (Allen et al., 2004) by measuring ${ }^{15} \mathrm{~N}$ uptake at various soil depths between crops and trees.

During maize destructive root sampling in Chapter 4 I observed many jatropha roots growing beneath the maize crop. RLD measurements for jatropha show greater root length density in the first $20 \mathrm{~cm}, 1 \mathrm{~cm} \mathrm{~cm}^{-3}$ to $0.8 \mathrm{~cm} \mathrm{~cm}^{-3}$, while in the second $20 \mathrm{~cm}$ depth it ranged from $0.09 \mathrm{~cm} \mathrm{~cm}^{-3}$ to $0.04 \mathrm{~cm} \mathrm{~cm}^{-3}$. The greater RLD in the first $20 \mathrm{~cm}$ indicates strong and direct competition by jatropha roots with the maize root system, 
resulting in reduced maize yield. Although RLD in the second $20 \mathrm{~cm}$ was less than the first $20 \mathrm{~cm}$, there is still a safety net effect. This is because RLD is not crucial and can be as low as $<1 \mathrm{~cm} \mathrm{~cm}^{-3}$ to $0.001 \mathrm{~cm} \mathrm{~cm}^{-}$ ${ }^{3}$, while the $\mathrm{N}$ residence time is more important (Van Noordwijk and Cadisch, 2002). For the $2 \mathrm{~m} \times 2 \mathrm{~m}$ spacing, the whole system safety-net effect was greater for mulchP2, followed by mulch, 40N40P, and no mulch and no fertiliser. Moreover, the whole system safety net effect across the different pruning scenarios was similar, $64 \%$. However, for the soil layer $20 \mathrm{~cm}$ to $30 \mathrm{~cm}$, the safety net effect for pruning every year was $21 \%$ while for pruning alternate years and no pruning it was $16 \%$. Pruning every year had a greater safety net effect probably because of increased $\mathrm{N}$ demand to rebuild aboveground biomass. Leaching is related to rainfall (intensity and amount), tree N demand, and RLD (Van Noordwijk and Cadisch, 2002) so management factors such as pruning timing and quality and fertiliser application are important considerations for the safety-net function (Cadisch et al., 1997).

Different pruning scenarios have different implications for nutrient and water uptake for jatropha and maize. While no pruning gave the greatest nutrient and water uptake for jatropha, pruning every year resulted in the smallest nutrient and water uptake. Therefore, competition belowground for water and nutrient with maize was reduced. Pruning every year also reduced jatropha aboveground competition therefore maize light interception increased. If the annual crop is planted at the time the tree is pruned then above and belowground competition by the tree is minimised, and the crop can be established before the tree canopy has fully recovered (Jackson et al., 2000).

When the different pruning scenarios were assessed, mulch produced the smallest jatropha yields. This is largely due to a reduced water uptake followed by a reduced nutrient uptake. The reduced soil evaporation and increased nutrients provided by mulch, affects maize directly as the mulch was incorporated directly into the soil where maize was grown. Maize therefore had direct access of those benefits whereas jatropha did not.

Pruning scenarios also have different implications for jatropha and maize. First, they confirm the previous findings that current jatropha pruning technique such as top pruning at certain heights needs to be improved if we are to maximise yields (Chapter 4). The objective of pruning jatropha is to encourage new shoot/branch development as flowering occurs on young wood/branch where the belief is that more branches equal more fruit. However, flowering only takes place on certain new branches (productive branches) and not on all branches (Chapter 3). Second, current jatropha pruning techniques benefit maize or other intercrops planted in between as pruning reduces both above and belowground competition, which can be a pruning objective in agroforestry systems.

Although (shoot) pruning can effectively minimise aboveground competition resulting in greater yields of the intercrop (Duguma et al., 1988), care does need to be taken with pruning frequency and height as they 
may limit total tree biomass production and nutrient recycling (Kang, 1993), and may change belowground root distribution and size. For instance, high frequency pruning of Senna siamea led to an increase in smaller and more superficial roots (Vanlauwe et al., 2002). A review of tree root characteristics by Schroth in (1995) showed that pruning increased root branching in the topsoil and restricted roots to shallower soil depths when compared with unpruned trees. A study involving five leguminous trees showed that a pruning height of $0.5 \mathrm{~m}$ aboveground produced a greater number of smaller more superficial roots than pruning to $0.75 \mathrm{~m}$ or $1 \mathrm{~m}$ aboveground, but had no effect on shoot : root ratios, or on the relative importance of the tap root (Hairiah et al., 1992). Changes in tree root distribution and size such as smaller superficial roots growth from pruning can increase water and nutrient competition for annual crop within the top soil.

In general shoot pruning causes a temporary reduction in root growth as defoliation disrupts the supply of photosynthate for root growth (Eissenstat and Duncan, 1992; Van Noordwijk et al., 1996). In citrus for example pruning reduced RLD by $20 \%$, however this was replaced within 9 weeks of pruning (Eissenstat and Duncan, 1992). The effects of pruning can be age related as fine root and nodule production, turnover, and decomposition was greater in 2-year old Erythrina poeppigiana than for the 8 year-old plants (Chesney and Nygren, 2002). Root and nodule decomposition will have a small but positive impact on soil nutrient status (Van Noordwijk et al., 1996).

Increasing inter-row distance to maximise maize yield from $2 \mathrm{~m}$ to $4 \mathrm{~m}$ or $5 \mathrm{~m}$ also effectively reduced the impact of tree shading, especially when jatropha is not pruned or only pruned at alternate years. Our findings are similar to those where maize yield was lower when intercropped with Leucaena leucocephala at $2 \mathrm{~m}$ spacing than at $4 \mathrm{~m}$ spacing. This was due to the greater shading effect (Lawson and Kang, 1990). For intercropping light capture is a function of the fraction of photosynthetically active radiation (PAR) intercepted by each species and the efficiency with which it is processed (Ong et al., 1996). Light capture is influenced by the heterogeneous nature of the canopies and planting time (Keating and Carberry, 1993; Ong et al., 1996).

In essence successful intercropping depends on achieving a balance between complementary (positive) and competitive (negative) interactions (Nair, 1993; Van Noordwijk et al., 2011). Since all plants compete for the same finite resources, the degree of complementarity or competition between tree and crop is dependent on efficiency. Complementarity may be either spatial or temporal (Ong et al., 1996) and should be considered in the context of niche differentiation (Anderson and Sinclair, 1993). It is possible however that intercropping may produce a synergy between tree and crop that results in a greater productivity than for a monoculture (Van Noordwijk and Tomich, 1995).

In this study, I measured biological production under different management scenarios; however activities such as harvesting fruit from unpruned jatropha and regular pruning are labour demanding and may not be easily accepted. Ultimately it comes down to the yield combinations that result from the fertiliser, pruning 
and plant spacing and fit best with farmers objectives such as the combinations that provide the highest total revenue per hectare depending on cultivation costs and market prices.

\subsubsection{Shape of production possibility frontier (PPF)}

When realistic sole crop scenarios are used for scaling, our results as shown in (Figure 6.4) differ substantively from the expectations of Figure 6.1. Similar discrepancies have been reported for intercropping of teak (Tectona grandis) and maize (Khasanah et al., 2015) where the predicted teak growth exceeded monoculture. Agroforestry experiments in France also showed that tree performance exceeded the monoculture control derived from forestry practice, despite a lower planting density (Balandier and Dupraz, 1998; Dupraz et al., 1999). In all these cases, the trees benefited from the nutrients provided to the crop. When 'farmer practice' is used as a point of reference for determining PPF then the typical convex or concave shapes may differ from standard theory shown in Figure 6.1.

\subsection{Conclusion}

Across the different fertiliser scenarios, mulch72P produced the greatest jatropha and maize yields. Mulch72P not only provides nutrients but also reduces soil evaporation. Maximum jatropha yield was obtained in the no pruning scenario when planted at $2 \mathrm{~m}$ inter-row. Smaller inter-row plantings maximise jatropha roots that then provide a safety-net effect. To maximise maize yield, jatropha should be pruned every year to reduce water and nutrient uptake, and aboveground competition for light during the crucial growth stages of maize. When jatropha is pruned every year the inter-row does not affect maize yield.

Long-term productivity of jatropha and maize was explored in a tree-crop intercropping system, using the agroforestry based WaNuLCAS model. There is considerable scope for jatropha and maize intercropping, especially if management practices such as fertiliser, pruning, and planting density are considered. Different management practices can reduce jatropha and maize competition and/or enhance complementarity. There remains however a yield trade-off due to the multiple objectives that exist within any intercropping system. If the objective is to maximise jatropha yield, then maize yield suffers, and vice versa. Ultimately, it comes down to the yield combinations of fertilising, pruning, and plant spacing that provide the highest total revenue per hectare depending on cultivation costs and market prices. The shapes of the production possibility frontier established in this study were different from common theory when the farmer's practice was used as a reference. 
Chapter 7 General discussion 


\subsection{Introduction}

In this final chapter, the main findings, their implications, and limitations are discussed. The thesis hypothesis was that jatropha growth, development, and yield is limited by the biophysical factors of plant characteristics, cropping systems, and management practices.

The review in Chapter 2 shows that despite the high expectations fuelled by market pull, technology push, and numerous actors the commercial potential for jatropha is further limited by policy and governance, economics, social technology, infrastructure and environmental factors, ultimately leading to disappointment. The research reported in Chapters 3 to 6 of this thesis provides answers to our hypothesis. In this final chapter I discuss the research findings and their relationship to future research in two main areas; plant characteristics (Section 7.2.1) and management (Section 7.2.3) within different cropping systems. Afterwards in Section 7.3, I revisit the claims of jatropha as a biofuel crop and further integrate our findings into constraints, challenges and opportunities for the improvement of jatropha plant characteristics, resource capture in different cropping systems and management. In Section 7.4 I present the lessons learnt from our review of the hype and disappointment cycle. I end this chapter with concluding remarks.

\subsection{Biophysical factors}

The biophysical factors and their implications for growth and development are discussed using empirical and/or mechanistic modelling approaches. Models allowed for hypotheses testing, synthesising knowledge, describing and understanding complex systems and interactions and in comparing different scenarios.

I first briefly remind the reader of the methods used and their construction in answering the research hypothesis. In Chapter 3 empirical modeling for allometric equations with power function and FBA model was used to determine above and belowground biomass, and HI. In Chapter 4 empirical modeling for polynomial with multivariate linear regression was used to determine relationship among seed yield and vegetative components under different management and cropping systems. In Chapter 5 a simple linear function of empirical model ( $\mathrm{I}=\mathrm{F} \pm \mathrm{C}$ ) was used to determine interactions (e.g. competition and complementarity/facilitation) of above and belowground environmental resources in maize/jatropha intercropping. In Chapter 6 the mechanistic model of WaNuLCAS was used to determine long-term productivity and yield trade-offs under different management scenarios for monoculture and intercropping.

The biophysical factors are approached from the perspectives of plant characteristics, system productivity, and management practices.

\subsubsection{Plant characteristics}

Understanding plant (phenotypic) characteristics of jatropha growth and yield is crucial to improving productivity, performance, and management. Plant characteristics are essentially genotype expression (G) as influenced by interactions with the environment (E) and management (M). FBA and yield studies for 
monoculture and intercropping used IP-1M planting material, a first improved jatropha population from Muktiharjo. IP-1M has vigorous vegetative growth that is more suited to revegetation and remedial purposes. The hedge study (Chapter 4) used a local Sumbawa provenance from Sumbawa Besar, NTB. I was unable to explore the difference and relationship on jatropha characteristics from various genotypes. The focus was to understand the characteristics within the existing genotypes grown within the study sites and in relation to the cropping system and existing management practices.

In Chapter 3, relationships between the above and belowground biomass were estimated from stem (base) diameter using an FBA allometric approach. The pattern showed increases in stem diameter resulted in increases in biomass. Comparison with other jatropha biomass research showed similar trends; however variation in the grouping patterns is likely caused by differences in planting material, location and management.

In Chapter 4, seed yield and vegetative characteristics such as plant height, stem diameter and length, LAI, canopy height, width, volume, number of branches, and number of productive and non-productive twigs were developed for the different cropping systems using simple polynomial approach. Overall results show that growth and yield of jatropha varies and is dependent on plant age, cropping system used, and management techniques. There was, however, a trend where seed yield across the three cropping systems can be determined by plant height and numbers of productive twigs, although numbers of inflorescence clusters per productive twig may be more important.

Comparisons with other studies show variable results for seed yield and its relationship with other vegetative characteristics. Plant height had significant relationship with seed yield consistent with Rao et al. (2008), Tripathi et al. (2013), and Shabanimofrad et al. (2013). This is because plant height and seed yield have high heritability, indicating genetic correlation is important in determining phenotypic correlation (Rao et al., 2008). Rafii et al. (2012) found no significant relationship between plant height and seed yield as the heritability of both traits is low which may indicate that $\mathrm{E}$ and $\mathrm{M}$ have more important roles than $\mathrm{G}$ in determining these traits. Such contradictory results can occur especially if plant height and seed yield are controlled by pleiotropic genes. This is because pleiotropic genes do not necessarily result in observable correlations as expression will depend on allele frequencies (Mode and Robinson, 1959; Falconer, 1989).

Despite the progress there is still limited available information relating to biomass partitioning or allocation into reproductive biomass of fruit and seeds in relation to vegetative above and belowground biomass partitioning, plant architecture and plasticity. Understanding these aspects of growth and development is vital to improving productivity, performance and management. 


\subsubsection{Above and belowground biomass, and harvest index}

Jatropha yield is a consequence of total biomass production and distribution. Therefore to understand partitioning of yield biomass, separation and determination of above and belowground biomass is needed.

In Chapter 3, jatropha biomass and plant architecture was studied using FBA model based on the 'pipe-stem model' (Van Noordwijk and Mulia, 2002). FBA allowed compatibility in the tree parameterisation module for WaNuLCAS model discussed in Chapter 6. The results of FBA simulations were evaluated and compared with biomass measurements obtained through destructive sampling. Adjustments were required to the FBA model in order to capture the multi-stemmed growth habit and heterogeneity of jatropha planting material used in this study. This included tapering coefficients for different branch diameter categorisations and fruit biomass on the terminal branch. Implementation of a revised FBA model provides variable estimations of total aboveground biomass for twig, leaf and branch biomass depending on how well the jatropha fit the fractal branching architecture. The adjustments made and the results obtained clearly support the strength of this model and confirm its application as a non-destructive technique for determining aboveground biomass.

Aboveground biomass is partitioned predominantly into supporting structures of stem, branch and twig, while fruit was found to account for the smallest portion of the samples taken. Fruit biomass was not well estimated therefore further research is required on fruit-bearing twigs and fruit dimensions to fine-tune the model. Below to aboveground biomass ratio was 0.5 which means larger biomass allocation to above than belowground biomass. According to the functional equilibrium approach (Brouwer and De Wit, 1969; De Willigen and Van Noordwijk, 1987) under environmental conditions that reduce the specific activity of the roots such as a decrease in water or nutrients availability, plants would increase the biomass allocation toward the roots. Likewise, conditions that decrease the specific activity of the shoot, such as a reduction in light intensity or $\mathrm{CO}_{2}$ concentration, increase the biomass allocation toward the shoots (Wilson, 1988). The larger aboveground biomass allocation in comparison to belowground found in this study was likely due to reduced light availability as the jatropha was already four-years-old, planted at $2 \mathrm{~m} \times 2 \mathrm{~m}$ and had achieved canopy closure.

Model results predicted a larger belowground biomass than expected for jatropha. Jatropha is reputed to be a drought tolerant species and this may be due to the roots serving as source of water storage. During monoculture cultivation jatropha roots experience diverse growth conditions and the fractal properties may be altered by growth responses to mechanical stimuli (Danjon et al., 2005), soil geometry (Nicoll et al., 2006), soil layer properties, and resource availability (Pierce et al., 2013). Even within a single plant, the applicability of fractal branching model (Soethe et al., 2007) may have its limitations.

In other jatropha studies, biomass production and allocation to above and belowground have been determined using destructive measurement (Rao et al., 2013) and non-destructive methods using allometric 
relationships (Ghezehei et al., 2009; Achten et al., 2010d; Firdaus and Husni, 2012; Makungwa et al., 2013; Baumert and Khamzina, 2015). Information on biomass partitioning in the reproductive part as fruit/seed yield or HI is limited, with exception of Ghezehei et al. (2015), direct (economic) yield is the most common measure used. The reason for this is likely due to the fact that jatropha is a perennial and yield may not be harvested until several years after planting, which unlike HI for annuals is easily determined on seasonal or annual basis.

Yield from destructive sampling showed that a $\mathrm{HI}$ of $1 \%$ is likely due to the small sample size and the age of planting material used. Research by Ghezehei et al. (2015) showed yearly variations of $\mathrm{HI}$ from $0.5 \%$ to 2.5 $\%$ in three year old jatropha-kikuyu grass silvopastoral, observed over a two year period. Our results are within these parameters. When compared with $46 \%$ to $55 \%$ for HI from commercial mature oil palm (Elaeis guineensis Jacq.) trees, (Wahid et al., 2005) the results are very low. In some ways the comparison of HI with oil palm is not fair as jatropha breeding is a long way behind and the planting materials used in both studies were not high yielding varieties; effectively they are still wild-types.

HI for many crop plants is sensitive to management and environmental factors such as the cropping system (Reganold et al., 2001), planting system and density (Palmer, 1988; Robinson and Lakso, 1991), water status and nitrogen availability (Donald and Hamblin, 1976), including its genotype, age, and plant size or developmental stage (Cannell, 1985; Pulkkinen et al., 1989). The influence of these various factors was obvious in the yield results and comparisons in Chapter 4. Although HI was not directly generated we can see that the proportion of yield and aboveground biomass varied between monoculture, intercropping, and hedges as they interact with different management practices such as shoot pruning, root pruning, mulching, plant spacing, and intercropping. This study used HI to determine biomass allocation to fruit or seed yield and also to make comparisons between the different plant parts.

\subsubsection{Plant architecture}

Plant architecture has been long recognised as an important component of horticultural crops (Oldeman, 1974; Hallé et al., 1978). Architecturally modified plants can be planted at higher densities and support greater yields (Peng et al., 1999; Hedden, 2003) thereby reducing the requirements for land, water, pesticide, and fertiliser (Scorza et al., 1999; Scorza, 2005). A reduction in overall tree size can often result in a reduction in branch numbers and changes in branch orientation that can influence pruning and light penetrance (Scorza et al., 1984; Atkinson and Else, 2001). Despite the importance of plant architecture in other crop plants, information on growth habits and branching pattern in relation to fruiting habit and yield in jatropha is still limited.

In Chapter 3, jatropha plant architecture was studied using the FBA model that takes into account fractal (self-repeating) branching architecture and measures branch length and diameter, in fractal relationship. The study found jatropha fruit only developed on certain productive twigs which we called fruit-bearing twigs. 
These fruit-bearing twigs had a linear relationship between length and diameter, unlike the relationships of the other branch diameter categories. Fruit-bearing twigs are predominantly situated on twigs with lengths ranging from $4 \mathrm{~cm}$ to $65 \mathrm{~cm}$ and diameters ranging from $0.9 \mathrm{~cm}$ to $1.4 \mathrm{~cm}$. Moreover, one fruit-bearing twig can bear multiple numbers of inflorescences or fruit clusters. For instance, once the first inflorescence has developed and set on the young twig, the twig continues to grow or elongate, producing consecutive inflorescences, while the section where the first inflorescence was initiated develops into fruit.

In Chapter 4 we discussed the observation that the numbers of inflorescences or fruit clusters vary depending on plant age, management, and cropping systems used. Jatropha has short stem resulting from the multistemmed growth habit and branching pattern showed sympodial growth with some dichasial and multiple branching. The branching pattern in this study follows the Leeuwenberg model (Hallé et al., 1978). The indeterminate nature of jatropha branching patterns has the potential to increase harvesting costs if the plants are not pruned to keep the plant height in check.

\subsubsection{Plasticity}

Jatropha planting material used in this study shows high heterogeneity or plasticity in the phenotypic/morphological characteristics. For example the FBA model produced variable results in the crown/canopy height and width. Some jatropha with wide crowns were underestimated while narrow crowns were overestimated. FBA measurements and schematic drawings on jatropha roots showed root structure modification such as intermediate branching pattern between herringbone and dichotomous patterns (Appendix 4). This is in response to differences in resources availability and intra and/or inter-plant root competition (Fitter et al., 1991).

Variations in resource availability may be responsible for variations in yield, leafiness, and canopy shape between the two Sumbawa hedge studies. The two hedge studies were conducted at the same location, using the same planting material and treatments $(75 \mathrm{~cm}$ height and planting distance of $10 \mathrm{~cm})$, but planted on opposite sides of the field (Chapter 4).

Research by others have identified large variations in jatropha genotypes that are not limited to vegetative characteristics such as plant height, stem diameter, number of branch, but also in the reproductive characteristics such as seed and oil yield (Ginwal et al., 2004; Rao et al., 2008; Shabanimofrad et al., 2013; Osorio et al., 2014; Tripathi et al., 2015).

Although jatropha phenotypic characteristics show large variations, genetic variation or diversity of most jatropha genotypes assessed by various molecular (DNA) markers are relatively low or narrow, with the exception of genotypes from Central America (Chapter 1). Jatropha's narrow genetic diversity is likely due to propagation by cuttings (Achten et al., 2010e; Sanou et al., 2015), by selfing (Divakara et al., 2010; Negussie 
et al., 2014) and apomixis (Chang-Wei et al., 2007; Achten et al., 2010e; Bressan et al., 2013; Sanou et al., 2015).

\subsubsection{Intraspecific (tree-tree) and interspecific (tree-crop) interactions}

Resource capture of crop plants not only depends on genotype, but also on the interactions with neighbouring plants (intraspecies/intraspecific) or other crop plants (interspecies/interspecific). These interactions may be competitive or complementary depending on access and utilisation of soil water, nutrients, and light. The focus of resource capture in this study draws heavily on intercropping and monoculture.

\subsubsection{Above and belowground resources: competition or complementarity}

In Chapter 5, to reduce aboveground or light competition with maize, aboveground jatropha was managed with shoot pruning. The potential for leaf prunings as a by-product to benefit maize yield within the jatrophamaize intercropping system were also explored. To assess the belowground competition, root pruning/trenching followed by vertical polythene root barrier installation was also performed. Assessment of above and belowground competition or complementarity effect of jatropha on maize was performed by measuring maize yield in intercropping and monocultures. Maize productivity under intercropping was analysed using simple empirical model developed by Ong (1995) and Ong (1996). In this model the interaction (I) of resource capture was determined as a function of fertility (F) and additive competition (C) components and expressed in terms of crop yields.

My results showed that aboveground/shoot pruning was effective in managing aboveground competition for light. Moreover root pruning and root barriers also effectively managed competition belowground for soil water and nutrient. The results also show that jatropha leaf prunings applied as mulch for maize provided a limited, but positive fertility effect. Jatropha mulch not only improves soil fertility but also helps alleviate problems associated with soil saturation during high rainfall and minimises soil evaporation during low rainfall. In terms of quality, jatropha mulch is categorised as a high quality organic resource with immediate mineralisation potential, however the $\mathrm{P}$ content is quite low. The best interaction occurred when the $\mathrm{F}$ value was small and $\mathrm{C}$ had a negative value. A small $\mathrm{F}$ value indicated a soil that had no major nutrient limitations and an intercrop in competition balance. Ultimately it is light and soil moisture that determines if the interaction is to be positive or negative (Van Noordwijk et al., 1998). In general, competition only becomes a problem if it affects the desired outcome, albeit commercial or otherwise (Van Noordwijk et al., 1996). The results from this study agree with Sanchez (1995) and Giller (2001) who state that for tree and crop intercropping to be successful, soil fertility should be good and rainfall adequate.

There is a disadvantage in using such a simple additive interaction model, as the sum of the components used in the equation ( $\mathrm{F}$ and $\mathrm{C}$ ) cannot cope with situations where two components/parameters interact. To understand the competition and complementarity in capturing water, nutrients, and light resources as results of management practices (e.g. fertilisation, pruning, and planting density) and cropping systems (e.g. 
intercropping and monoculture), long-term performance of jatropha-maize intercropping where compared to monoculture scenarios using mechanistic model of WaNuLCAS (Chapter 6). Yields predicted from WaNuLCAS management scenarios were assessed for trade-offs between jatropha and maize by comparing jatropha and maize grown as intercropping and monoculture. The trade-off scenarios were assessed using Willey's (1979) first scenario for yield advantage. This is where intercropping gives full yield of the main crop and some yield for the secondary crop. For this scenario two options were used. The first was to treat jatropha as the main crop and maize as the secondary crop with the aim of maximising jatropha yield. Currently, this situation is somewhat unlikely from a farmer's perspective given the current commercial circumstances where jatropha yields and price are both low and uncertain (Van Eijck et al., 2014a). Given that this situation may change in future, there was however a need to consider this option. The second option was to treat maize as the main crop and jatropha as the secondary crop with the objective to maximise maize yield. This is the predominant situation for local farmers wishing to plant jatropha as a means of gaining extra income, minimising their risk or aiming for yield stability.

The effects of jatropha interspecies resource competition with maize in intercropping and with gliricidia in mixed hedges, including the intraspecies resource competition within jatropha monoculture on yield were assessed in Chapters 4 and 6. In Chapter 4, the differences in inflorescence distribution between intercropping and monoculture may be due to the different ages and above and belowground competition. In monoculture, the jatropha is two-year-old and experienced aboveground intra-species competition. This resulted in increased flowering on new productive twigs. In intercropping, the jatropha is four-year-old and experienced above-ground inter-species competition with maize. Instead of allocating resources to new productive twigs for flowering, allocation was to flowering on the already existing productive twigs. Although this hypothesis has not been fully tested as we did not have a control of four year-old jatropha in the intercropping, it does raise some interesting issues and provides new insight into jatropha reproductive behaviour, highlighting a future direction for research.

In Chapter 6, intercropping simulations of close jatropha inter-rows (high planting densities), showed that jatropha benefited from reduced soil evaporation and access to nutrients applied to the maize inter-row. Widening the jatropha inter-row may reduce light interception, soil water and nutrient access, but it ultimately reduces jatropha's capacity to compete with maize, and with neighbouring jatropha shrubs. Interspecific competition between jatropha and maize in this case was not a problem because the pooled yield effect was less than the intraspecific competition between jatropha. Losses in jatropha yield mean greater maize yields and this is especially important when socio-economic factors favour maize over jatropha.

\subsubsection{Water, nutrients, light capture and interactions}

The underlying concept of resource capture is that competitive or complementary interactions between species are dependent on the effective capture and utilisation of the most limiting growth resources 
(Monteith, 1981; Monteith et al., 1994). This is a function of the conversion coefficient of the species involved, environmental influences and management practices as well as numbers, area, and distribution of above and belowground biomass (Ong et al., 1996).

For example, in Chapter 6 competition for water and nutrients between jatropha and maize occur heavily in the first top $20 \mathrm{~cm}$ as jatropha RLD in that zone was greater than in the $20 \mathrm{~cm}$ below. However the combination of mulch72P, unpruned jatropha, and smallest inter-row $(2 \mathrm{~m})$ produced the best relative jatropha yield because N, P, and water uptake were the largest when compared with the other scenarios. Inter-row spacing of $2 \mathrm{~m}$ also had the least $\mathrm{N}$ leaching, probably for two reasons. Firstly, competition between jatropha and maize for belowground resources at $2 \mathrm{~m}$ inter-row would result in resources being used more efficiently. Secondly, jatropha roots grow deeper and have the potential to grow beneath the maize roots creating a 'safety-net' effect or filter function to capture $\mathrm{N}$ before it is lost. The 'safety-net' concept of Van Noordwijk et al. (1996) considers that deep rooting trees intercept nutrients which have leached below the crop rooting zone. The safety-net effect has already been tested in tropical alley cropping between maize and gliricidia, and with peltophorum in North Lampung, Indonesia (Rowe et al., 1999). Mulch72P and mulch also effectively reduces soil evaporation by minimising the impact of solar radiation, and by minimising soil surface air flow (Riha and McIntyre, 1999). Mulch72P had lower soil evaporation than mulch, possibly because the addition of $\mathrm{P}$ enhanced rooting close to the soil surface thereby increasing root water uptake (Riha and McIntyre, 1999).

Competition for water and nutrients between tree and crop occur spatially, but also with phenology and age (Muthuri et al., 2005; Gao et al., 2013), especially during the crop growing period. For example, in Chapter 6 different pruning scenarios have different implications for nutrient and water uptake of jatropha and maize. While no pruning gave the largest nutrient and water uptake for jatropha, pruning every year resulted in the smallest jatropha nutrient and water uptake. Therefore, competition belowground for water and nutrients with maize was reduced.

Competition for light through shading is a key component of tree/crop interaction. Shading is influenced by environmental and plant factors such as tree leaf area, leaf phenology, crown structure and crown management (Ong et al., 1996). Pruning every year also reduced jatropha aboveground competition therefore maize light interception increased. If the annual crop is planted at the time the tree is pruned then above and belowground competition by the tree is minimised, and the crop can be established before the tree canopy has fully recovered (Jackson et al., 2000). For example, in Chapter 6 when jatropha is pruned every year, maize growth limitation by light interception (relative to maize monoculture) is only $2 \%$ to $9 \%$. If jatropha is pruned at alternate years, the smallest inter-row limits potential maize growth by about $14 \%$, while the wider inter-row spacings only reduce yield by about $3 \%$ to $9 \%$. If jatropha is not pruned, the smallest interrow spacing limits yield by about $40 \%$, while the wider spacing limits yield by about $4 \%$ to $11 \%$. 
In Chapter 4 when jatropha hedges were planted at wider spacing, yields increased. While the higher yields are likely due to increased access to soil moisture and nutrients, hedges are single row plantings therefore each plant already has unlimited access to resources either side of the planting. Close spacing might however lead to intraspecies root competition. The greater aboveground biomass for $20 \mathrm{~cm}$ jatropha-gliricidia plantings may be due to positive interactions between the jatropha and gliricidia. Gliricidia is a nitrogen fixing tree that can increase nitrogen and organic matter availability through leaf and root turnover (Giller, 2001). It is important to remember that jatropha hedges are planted as protection barriers and not for yield.

\subsubsection{Management}

While there are no standardised jatropha management practices currently available, resource management strategies for this thesis focused on fertiliser application, pruning, and plant spacing and in doing so provide a valuable source of information.

\subsubsection{Fertiliser application}

Fertiliser applications in this study were performed only in jatropha intercropping systems, and not in monoculture or hedge plantings. This is consistent with Indonesian jatropha intercropping farming practice. Discussions with farmers confirmed the long-term use of jatropha hedges; planting was easy as they use cuttings and no fertilisers are used. Farmers also indicated that given current yields and seed price it was not economically profitable to fertilise jatropha.

Jatropha leaf mulch incorporated into the jatropha inter-row (maize alley) effectively provided $\mathrm{N}$ at $91 \mathrm{~kg} \mathrm{~N}$ $\mathrm{ha}^{-1}$, sufficient to meet maize requirements, but supplied only a small amount of $\mathrm{P}\left(6.2 \mathrm{~kg} \mathrm{ha}^{-1}\right)$ necessary for high yields. Additional P was added for field experiments (Chapter 4 and Chapter 5) and compared with mulch $+\mathrm{P}$ applied at $72 \mathrm{~kg} \mathrm{ha}^{-1}$ (mulch72P) in the management simulation. The results showed a major portion of $\mathrm{N}$ added from the mulch was tied up in the soil organic matter and some may have been lost through leaching. Overall mulch is beneficial in the long-term soil fertility as it improves the level of organic $\mathrm{N}$ in the soil (Palm, 1995). In Chapter 6 simulations for maize monoculture and intercropping scenarios show that the addition of jatropha leaf prunings as mulch or mulch $+\mathrm{P}$ applied at $72 \mathrm{~kg} \mathrm{ha}^{-1}$ (mulch72P) can effectively increase jatropha and maize long-term productivity.

The simulation highlighted that the most limiting factor for jatropha was water, while for maize it was N. The results are understandable as maize has been bred for high yield with high nutrient demand, especially $\mathrm{N}$, therefore if $\mathrm{N}$ is limited; growth and yield are low and will decline over time. Jatropha on the other hand is a perennial with a longer lifespan and has yet to achieve the level of breeding that exists in maize. Breeders will most certainly need to consider these consequences when breeding for improved yields. Jatropha does have an advantage over maize in that its roots are able to utilise a larger volume of belowground resources (Van Noordwijk et al., 1996). This is especially true if jatropha is well established prior to the maize planting. Jatropha that has never been pruned will have an extensive root system that 
allows it to capture resources from a larger area (Ong et al., 1996). While the jatropha parameterisation in this study is not from high-yielding varieties, the results do show some adaptation to the local environment, and to the poor soil fertility.

Our simulations are in line with studies that show the addition of $\mathrm{P}$ in combination with organic matter can increase maize N and P uptake and consequently lead to higher maize yields (Wyatt, 1982; Kwabiah et al., 2003; Das, 2014) in intercropping as opposed to monocultures (Akinnifesi et al., 2007; De Jongh and Nielsen, 2011). Applications of N, P, K have been shown to increase growth and yield in jatropha monocultures (Laviola and Dias, 2008; Yong et al., 2010; Mohapatra and Panda, 2011; De Oliveira Borges and Ribeiro, 2014). However, during the hype jatropha was promoted as crop plant that had a low nutrient requirement and was able to thrive in marginal lands. For this reason, many jatropha plantings belonging to the smallholder farmers in Indonesia were planted in marginal lands and not fertilised. With the low yields and prices for jatropha seed it is clear that there was no advantage to be gained from fertilising jatropha monoculture plantings. There is however an advantage to be gained in fertilising the jatropha/maize intercropping system as jatropha roots received an added benefit from fertiliser applied to the maize intercrop alley (Chapters 4, 5 and 6). While jatropha has been shown to respond well to fertiliser applications (Laviola and Dias, 2008), the specifics of these responses are not well understood, and the optimum levels of inorganic fertilisers vary with age (Achten et al., 2008).

\subsubsection{Pruning}

Prior to this study it was assumed that shoot pruning would increase the numbers of new branches and promotes new inflorescence development. Our results however show that not all new jatropha branches produced inflorescences (Chapters 3 and 4). Jatropha inflorescences develop at the ends of the (new) branches and pruning induces branching, leading to a belief that more branches equals more fruit (Gour, 2006; Brittaine and Lutaladio, 2010; Everson et al., 2013), larger yields and improved HI. On the other hand the already productive twig/branches may increase their number of inflorescence clusters. Despite an extensive literature search, no studies were found that assess the effects of pruning on twig/branch productivity.

The shoot pruning for this study was a top prune with final height of $0.75 \mathrm{~m}$ aboveground which is a common practice in Indonesia (field observations), India (Ghosh et al., 2011; Singh et al., 2013), South Africa (Everson et al., 2013), and Thailand (Suriharn et al., 2011). In Chapter 4, the effect of shoot pruning was assessed in combination with root pruning (+ polythene root barrier) and mulch treatments on jatropha seed yield and vegetative plant components. Shoot and root pruning reduced jatropha seed yield substantially regardless of mulch treatments; however it did not reduce vegetative plant components significantly. It is possible that shoot pruning offset the reduction caused by root pruning as shoots and roots are interconnected (Geisler and Ferree, 1984). Shoot pruning alone also offers a convenient way to manage belowground biomass/competition and likewise, root pruning also affects shoot biomass/competition (Geisler and Ferree, 
1984; Van Noordwijk et al., 1996). The root pruning removed belowground competition between jatropha and maize; however the addition of polythene plastic barrier reduced soil volume for maize root growth in the outer rows. Consequently, maize yield did not increase as much as anticipated.

Further, shoot pruning in monoculture jatropha reduced vegetative growth and yield in comparison to no pruning, and the contribution of plant components to yield determination was changed. The plant component that contributed to yield before pruning was plant height and after pruning it was the numbers of productive twig and LAI. In the intercropping system of four-year-old jatropha, the plant component that contributed to yield after shoot pruning was number of inflorescence clusters. Intercropping under root pruning/mulch treatments showed a shift in the distribution of inflorescence clusters when compared with the monoculture. The differences in inflorescence distribution between intercropping and monoculture may be due to different age and above and/or belowground competition with maize. In hedge systems, the plant component that contributed to yield after pruning was plant height.

Simulations in Chapter 6 showed that pooled results for pruning scenarios (i.e. pruning at alternate years, every year, and not pruning) do not show substantial differences. However, if we compare the pooled results for pruning scenarios with jatropha monoculture for the different pruning and planting density scenarios, we see greater differences between pruning at alternate years and pruning every year, and for no pruning. Moreover, a previous study showed that two-year-old jatropha monoculture grown without external inputs, and at a plant spacing of $2 \mathrm{~m} \times 2 \mathrm{~m}$, and pruned to a height of $75 \mathrm{~cm}$, reduced yield by $75 \%$ compared with no pruning (Chapter 4).

Other jatropha monoculture studies with pruning treatments also show yield reductions when compared with no pruning treatments, although the degree of yield reductions varied with age, management practices (plant spacing, pruning heights, and fertiliser), and the environment (Ghosh et al., 2011; Singh et al., 2013). Root pruning is a common practice in tree-crop alley cropping to remove belowground competition between tree and crop (Hairiah et al., 1992; Rao et al., 2004; Wajja-Musukwe et al., 2008) and in orchards to control fruit tree growth and size (e.g. dwarfing) (Geisler and Ferree, 1984; Ferree et al., 1992; Khan et al., 1998). Jatropha shoot and root pruning research is limited and no pruning standards exist; however, the examples above show that pruning is not the only factor influencing yield in intercropping or monoculture. Pruning in combination with fertiliser and planting density can also change relative jatropha and maize yield relationships.

\subsubsection{Plant spacing}

Plant spacing is a powerful tool for managing shoot and root interactions. Biophysically, optimal spacing and planting arrangement depend on finding a balance between two conflicting objectives: the maximisation of root development within the soil and nutrient cycles, and minimal resource competition with others. 
In Chapter 6, jatropha planting density simulations for monoculture showed as density increased, jatropha yield decreased. Singh et al. (2013) suggested for monoculture that a density planting of 2,500 plants per ha ( $2 \mathrm{~m} \times 2 \mathrm{~m}$ spacing) would be the optimal starting point for plantations under rain fed conditions. Thinning or removing rows or individuals of relatively weak performance may be necessary.

In jatropha-maize intercropping, the pooled planting density results show that although jatropha yield dominates maize, variations in planting density can change jatropha intra and interspecific competition. Resource capture for light, soil water and nutrients between jatropha and maize is influenced by planting density. In intercropping simulation, at small inter-row or high planting densities, jatropha benefited from reduced soil evaporation and nutrient access provided by maize.

Results of field research for jatropha monoculture plantings at different spacing scenarios are quite variable, even within one location or between multi-locations (Singh et al., 2013) and indeed between researchers (Ghosh et al., 2007b; Behera et al., 2010). This is due to the variations and interactions of $\mathrm{M}$ with $\mathrm{G}$ and $\mathrm{E}$. In jatropha-kikuyu grass (Pennisetum clandestinum) silvopastoral systems, manipulation of jatropha arrangement/configuration without changing the planting density had no consistent effects on jatropha productivity (Ghezehei et al., 2015). This is important as it highlights the possibility that plantings can be arranged to suit individual requirements.

\subsection{Biophysical constraints, challenges, and opportunities}

Ultimately commercial jatropha cultivation aims to maximise yield and like any new crop, development is often handicapped by a lack of understanding of the biophysical factors necessary for success. The biophysical constraints, challenges and opportunities are outlined.

\subsubsection{Constraints}

The expectation that jatropha would provide high yields even on marginal and dry lands without inputs such as irrigation, fertilisers, and pesticide was at the least somewhat naive. While the overall understanding of jatropha growth and development is improving, there remains a significant amount of research necessary to develop high yielding varieties suitable for areas that do not compete with existing food crops and minimise environmental impacts. At the moment this lack of elite planting material is the most limiting factor. In addition to this are the issues of water availability and associated stress that limits jatropha growth and yield. Jatropha planted under such conditions will potentially be more predisposed to pests and diseases attack.

\subsubsection{Challenges}

At present yields are in the order of $2 \mathrm{t} \mathrm{ha}^{-1}$ (Achten et al., 2008; Van Eijck et al., 2014a) while global prediction is circa $5 \mathrm{t} \mathrm{ha}^{-1}$ (Achten et al., 2014). Factors responsible for low yields have been documented as low sex ratio which varies significantly among genotypes (Chang-Wei et al., 2007; Kaur et al., 2011; Ahoton and Quenum, 2012); asynchronised flowering and fruiting maturation (Fairless, 2007; Rao et al., 2008; Abdelgadir et al., 2010; Brittaine and Lutaladio, 2010; Ahmad and Sultan, 2015), pests, diseases, and water- 
logging susceptibility, and phorbol esters toxicity (Achten et al., 2010e; Divakara et al., 2010; Carels, 2013). These factors provide researchers with a multitude of research possibilities; however some degree of research synergy would be beneficial.

The jatropha conventional breeding programme in Indonesia still has a long way to go in producing high yielding varieties. Conventional jatropha breeding started in 2005 with exploration, collection, evaluation, and selection of jatropha germplasm. Breeding for all accessions was achieved through repeated negative mass selection to attain improved populations (IP). So far, these selections have produced three populations that have been released as National Jatropha curcas L. improved populations, IP-1A (from Asembagus East Java), IP-1M (from Muktiharjo - Central Java) and IP-1P (from Pakuwon - West Java). In 2007, the third cycle of selection resulted IP-3A, 3M, and 3P that has yield potential greater than the first and second cycles. Yield potential for the first to third cycles is said to be $1 \mathrm{t} \mathrm{ha}^{-1}, 2 \mathrm{tha}^{-1}$, and $3 \mathrm{t} \mathrm{ha}^{-1}$, respectively (Heliyanto et al., 2008). These yield figures were based on assumption and may not reflect reality. In 2007 to 2010 selected jatropha parents were crossed and the progenies were evaluated resulting in nine potential genotypes that have undergone multi-locations trials in Indonesia. In these multi-location trials, Purwati et al. (2015) found significant interaction yield responses between genotypes and the environment over a 3-year period. Genotypes which produced good seed yields in one environment did not always produce high yields in others. In these cases the genotype was considered to be more adapted to the specific location or environment. The average of the best genotype still only yielded about $1 \mathrm{tha}^{-1}$ with oil content above $35 \%$.

A review of the jatropha conventional breeding progress by Yue et al. (2013) found many institutions are progressing with testing and evaluation. This takes time, as it is necessary for jatropha to mature so that growth and development, especially flowering and fruiting can be assessed. Research is also concentrating on germplasm collection, characterisation, and evaluation of the existing diversity of phenotypic and genotypic variations. As jatropha's rotational age can be as long as 40 years (Dias et al., 2012) a balance has to be found between rotation age and delayed returns on investment (Dias et al., 2012; Spinelli et al., 2015). This aspect is challenging.

Management is another aspect that poses multiple challenges for growers. Harvesting fruit from unpruned jatropha is more labour intensive while regular pruning is labour demanding and may not be easily accepted. Further field research is required to determine optimal pruning techniques and indeed if jatropha is even capable of tolerating regular pruning and the effects this might have on the above and belowground biomass. Ultimately it comes down to the yield combinations that result from fertiliser, pruning, and plant spacing and which of these fit best with farmers' objectives of high total revenue per hectare relative to cultivation costs and market prices.

Contrary to the claim that jatropha is tolerant to pests and diseases, research reports varying levels of occurrence. This is despite jatropha's toxic nature and insecticidal properties (Anitha and Varaprasad, 2012; 
Machado and Pereira, 2012; Terren et al., 2012). Pest and disease attacks did occur in my study; however they were manageable using readily available pesticides and fungicides. Potentially the effectiveness of jatropha chemical defences may be compromised due to abiotic stress (Kozlowski et al., 1991; Kozlowski and Pallardy, 1997) therefore care will need to be taken.

Jatropha is similar to other undomesticated perennials in that it maximises vegetative growth in the early years and bears fruit only when the plants have matured. Fruiting usually occurs on the upper and outer parts of the plant so shading by adjacent plants may be a potential issue (Jackson, 1989). Although FBA produced variable results in jatropha biomass, the model provided some insight into jatropha growth habits, branching patterns, fruit-bearing twigs, and allocation of jatropha biomass to fruit, leaf, branch, stem, and roots. Further research will be necessary to improve jatropha's commercial potential.

\subsubsection{Opportunities}

Despite the numerous constraints and challenges that impact jatropha, there are many windows of opportunities.

\subsubsection{Plant characteristics}

This study found that the allocation of aboveground biomass to fruit needs further research, especially into the different growth habit, branching patterns, or plant architecture in relation to increasing the numbers of productive twig/branch and number of inflorescences per productive branch. Based on this knowledge appropriate breeding and selection goals and management techniques to maximise seed yield can be developed.

Jatropha breeding will need to address the requirements for the different cropping systems. For example the essential difference between hedges and monoculture/intercropping is that yield is not the primary objective for planting hedges. If hedges are expected to be both protective and productive then it raises a series of different issues that need to be addressed. Molecular breeding using -omics strategies will play a major role in any future breeding programme.

Results have shown that overexpression of jatropha Flowering Locus T (FT) homologue gene produces transgenic jatropha with early flowering time and higher yield in a shorter time ( $\mathrm{Li}$ et al., 2014a; Ye et al., 2014a). Overexpression of glycine betaine produces transgenic jatropha with increased drought tolerance (Tsuchimoto et al., 2012) and overexpression of SbNHX1 (vacuolar $\mathrm{Na}^{+} / \mathrm{H}^{+}$antiporter gene that maintains ion homeostasis) produces transgenic jatropha with increased salt tolerance (Joshi et al., 2013). RNAi silencing in JcFAD2-1 gene (responsible for the production of linoleic acid) produces marker-free transgenic jatropha with increased high quality seed oil (Qu et al., 2012). RNAi silencing in the curcin gene creates transgenic (Patade et al., 2014) and marker-free transgenic jatropha (Gu et al., 2015) with curcin-deficient non-toxic seeds and in casbene synthase homologue genes to create transgenic jatropha with reduced phorbol 
esters in seed ( $\mathrm{Li}$ et al., 2015). There are now marker-free transgenic jatropha that show resistance to larvae of tortix moth (Archips micaceanus) that feed on jatropha leaf as it expresses Bacillus thuringiensis (Bt) $\delta$ endotoxin ( $\mathrm{Gu}$ et al., 2014). Transgenic jatropha have been produced with resistance to jatropha mosaic disease caused by a geminivirus strain of Indian cassava mosaic virus (ICMV) as the homologue key genes in ICMV are silenced (Ye et al., 2014b).

The above examples show characteristics or traits consistent with seed and oil yield. Other secondary traits that may have correlation with seed and oil yield are seed size (Kaushik et al., 2007b), female to male flower ratio, plant height, number of branches (Rao et al., 2008), stem diameter, branch length (Kumar et al., 2008; Das et al., 2010; Shabanimofrad et al., 2013), canopy area and volume (Srivastava et al., 2011; Wani and Chander, 2012). There are many other desirable traits that are considered important such as biotic (pests and diseases) stress resistant, abiotic (drought, salinity, water-logging) stress tolerance, flowering and fruiting synchronisation, oil quality, low or no phorbol esters (Divakara et al., 2010; Johnson et al., 2011). Exploiting natural variation, in particular the use of non-toxic varieties will likely open up more debate on the socioeconomic aspects including the food versus fuel issue.

\subsubsection{Resource capture}

Jatropha is reputed to be a drought tolerant species, however when grown for commercial gain this has proven not to be the case. Jatropha normally shed their leaves gradually when confronted with drought. These leaves have a higher adaxial stomatal density. This controlled shedding allows the jatropha to balance leaf water loss during drought (Holl et al., 2007; Maes et al., 2009; Achten et al., 2010d; Everson et al., 2013). This is interesting from a water planning perspective as it seems that jatropha is unlikely to compete for scarce water resources, however growing trees to produce biodiesel is complex and will vary by region and country (Everson et al., 2013). Research into water requirements, productivity, and use efficiency, especially on jatropha monoculture system is on-going. In essence understanding the magnitude and dynamics of the different components of the jatropha water balance is crucial to the development and management of sustainable water and nutrient resources. The objective after all is to increase jatropha biomass and $\mathrm{HI}$ while reducing transpiration.

Jatropha nutrient requirements are a potential area of opportunity. Jatropha adapts to low fertility soil for survival growth, however for commercial purposes soil fertility will play an important role if yield potential is to be realised. The incorporation of jatropha mulch into the soil has been shown to be advantageous, especially for intercropping systems. This aspect, which has the potential to help farmers to increase yields, improve the soil biota, and reduce costs, will require further research.

While research onto the effects of water and nutrients on jatropha is accumulating, research into light interception, conversion and use, and relative productivity is still limited. Biomass or dry matter production has already been linearly related to accumulated light interception for potatoes (Solanum tuberosum L.), 
sugar beet (Beta vulgaris), barley (Hordeum vulgare L.), apple (Malus pumila M.) (Monteith, 1977), onion (Allium cepa L.) (Brewster et al., 1986), willow (Salix alba L.) (Cannell et al., 1987), and evergreen forest stands (Linder, 1985). From field observations by Ghosh et al. (2011) it seems that jatropha branches require exposure to sunlight in order to bear flowers and fruit. If this is correct then research is needed to examine the relationship between light interception and jatropha productivity. The effects of light distribution, intensity, and quality within the canopy and upon flowering and fruit production and synchronisation, the possibilities and limitations of canopy manipulation for the optimum utilisation of light by selection of genotype (e.g. growth habit and branching patterns), pruning, and plant spacing will also need to be evaluated.

\subsubsection{Management}

Management of jatropha growth and development is another area where research is lacking. Jatropha has been shown to respond well to fertiliser applications (Laviola and Dias, 2008), however the specifics of these responses are not well understood and the optimum levels of inorganic fertilisers do vary with age (Achten et al., 2008). Site-specific fertiliser trials will need to be established for trees of different ages and over a number of seasons (Brittaine and Lutaladio, 2010) and possibly for different genotypes. The incorporation of leaf biomass from prunings incorporated into the soil as mulch has been shown to provide a limited, but positive fertility effect. Further research will be required to determine quality and quantity combinationa using other mixtures (e.g. maize/agricultural residues, jatropha pressed seed cake), including optimal application times and rates.

Plant architecture is an interesting area of opportunity as lessons can be learnt from fruit orchards where management is used to change the plants' partitioning of resources from vegetative to reproductive (Jackson, 1989). Shoot pruning techniques have been used successfully in fruit trees to maximise yields using formative pruning to create a strong framework to support heavy fruit loads, and maintenance pruning to remove superfluous vegetative growth and promote generative growth (Brunner, 1990; Grossman and DeJong, 1998; Van Eijck et al., 2010). Techniques include open-centre crown (vase shape) pruning for peach, nectarine, and plum trees (Brunner, 1990; Grossman and DeJong, 1998), and spindle crown (central leader) pruning for apple and pear trees (Brunner, 1990). Coffee is another example where selective pruning and grafting of productive horizontal (plagiotropic) branches with shorter internodes and high numbers of fruit clusters has been successful (Anim-Kwapong and Adomako, 2010; Gichimu and Omondi, 2010). The suitability of these pruning techniques for improving yield in jatropha remains to be investigated.

Managing plant architecture or tree size with pruning involves aboveground (shoot) belowground (root) pruning. Our study showed no difference in shoot growth and development irrespective of whether the roots were pruned or not. The effect of shoot or root pruning on monoculture and hedge systems however may need further research to determine if they will respond in a similar manner. 
Tree training builds a strong and permanent branch framework and encourages increased axillary bud development and the production of vertical branches is a possibility for jatropha. Research on the training of jatropha branches is limited; however the branch training through bending is a common practice by local growers at one of the jatropha sites in Indonesia. The locals believe that bending jatropha branches will encourage flowering and fruiting. The branches that grow vertical or oblique are bent to approximately $50^{\circ}$ to $70^{\circ}$ so that they exhibit plagiotropic like growth. This bending was performed in both monoculture and intercropping systems once jatropha was one to two-years-old. This process is repeated multiple times while the jatropha branches were still young and relatively pliable; the process did not break the branches. The local bending is done manually, without supporting wires or poles for support, and without the knowledge of tree form. While no research data is available to determine if bending by smallholder farmers results in higher seed yields, research by (Ping et al., 2012) has confirmed that branch angle significantly influenced sprout number and distribution, the type of sprout and the fruit bearing capacity per inflorescence of jatropha. This is an opportunity for future research.

Dwarf rootstock and grafting are other fruit orchard techniques that might have potential for preferential determinate growth and high seed and oil yield. Jatropha grafting research has already been performed, however these did not specifically use dwarf rootstock with the aim of reducing scion vigor, or increase fruit biomass. The grafting research used interspecies rootstock of $J$. gossypifolia and J. pohliana with the intention of exploring propagation methods (De Resende et al., 2012), to increase longevity and abiotic stress resistance (Panghal et al., 2013; Cholid et al., 2014), and to increase root rot resistant (Dhillon et al., 2009). One et al. (2014) produced semi-dwarf to dwarf architecture in jatropha genotypes by crossing Jatropha curcas with Jatropha integerrima, however improving yield was not the objective of their research.

There may also be some potential for modifying the jatropha perennial habit to be treated as annual and accelerate cultivar improvement time schedules. A number of perennial crop plants have been modified by selection to the extent that they are now commonly treated as annuals. This is the case for cotton and tomato (Lycopersicon spp.), and is increasingly the case for strawberry (Fragaria $\times$ ananassa) (Jackson, 1989) and castor (Singh, 1976). The overall advantages of the perennial habit are largely to do with competition and survival whereas the disadvantages are those of the maintenance energy requirements of the perennial parts and the likely build-up of pests and diseases (Jackson, 1989).

Plant growth regulators (PGRs) offer opportunities to promote branching and improve flowering and yield. Paclobutrazol (PBZ) is a PGR that improved flowering and fruiting in pruned shrubs and partially made up for the yield loss as well as reducing plant height with smaller leaves and enhanced chlorophyll and nitrogen (Ghosh et al., 2011). PBZ once optimised could significantly reduce unwanted vegetative growth, with a concomitant improvement in yield and seed oil content of jatropha. Ghosh et al., (2010) showed that PBZ was capable of increasing seed yield by $1,127 \%$ relative to controls from one unproductive jatropha germplasm. PBZ treatments greatly retarded vegetative growth and improved reproductive growth. Xu et al. 
(2013) reported that the lengths of new branches were greatly decreased, and the number of fruits per inflorescence, fruit-bearing branches per tree, and total fruit load per tree increased.

Benzyl adenine (BA) has been shown to increase the total number of flowers per inflorescence. Furthermore, BA treatments induced bisexual flowers, which were not found in control inflorescences, and a substantial increase in the female-to-male flower ratio. Consequently, a 4.5 -fold increase in fruit number and a 3.3 -fold increase in final seed yield were observed in inflorescences (Pan and $\mathrm{Xu}, 2011$ ). Foliar applications of BA significantly increased branches in both the pot and field trials compared to manual pruning (Abdelgadir et al., 2009), producing more flowers per plant, more fruits per bunch, and heavier and bigger fruits and seeds with more oil compared to manual pruning (Abdelgadir et al., 2010). Thidiazuron has also been reported to increase fruit numbers in jatropha by promoting pistil development which significantly increased the number of female flowers along with the development of inflorescence meristems, reversed stamen abortion and female flowers and induced bisexual flowers, which largely depends on the development stage of the inflorescence meristems (Pan et al., 2016). Future PGR studies must focus on accurate chemical delivery to the target tissue ensuring maximum results with minimum environmental contamination.

\subsection{Lessons learnt from the hype and disappointment}

Production and use of biofuels has experienced remarkable growth over the last decade; however jatropha performance has been very disappointing despite claims of drought tolerance, low nutrient requirements, pests and diseases resistance, high yields, poverty reduction, and high returns on investment, all on marginal land (Chapter 2). Jatropha has failed to achieve these expectations, possibly even bringing misery to millions of the world's poorest people (Kant and Wu, 2011). Ebrahim and Baker (2012a) put it rather aggressively stating that it was difficult to imagine a more inappropriate crop for resource-poor farmers.

Governments, academia and university research and their funders, private companies, and NGOs were all instrumental in fuelling the hype, each for their own reasons. Our assessment of the jatropha hype and disappointment highlights the possibility that many government policies were based on selective or ignored evidence to suit political agendas, rather than on scientific evidence. Our review further highlights the complex relationships that exist between evidence and policy, how governments operate and how research is funded and results are used. It is inevitable that no matter how much caution is advised there will always be entrepreneurs prepared to face the risks in an effort to capitalise on the rewards associated with new crops and early entry. In essence jatropha is a new crop and it needs people and funds to develop and promote it. Yet promotion based on a multitude of unfounded claims has not lead to a commercially successful jatropha production and biodiesel industry.

I conclude from Chapter 2 that realistic commercial development of jatropha biodiesel requires not only a well performing jatropha crop based on plant characteristics, systems productivity, and management (Section 7.3). It also needs well developed and implemented market pull factors of society, economy, environment 
and government support in terms of blending targets, subsidies, land allocation, and incentives to investors. Furthermore it requires the technology push factors of oil processing and value adding. Essentially these factors were either absent or weakly implemented and there were many mismatches in timing and aligning of push and pull factors. Furthermore, future profits were anticipated in marginal lands available for jatropha cultivation; high yielding jatropha seeds; high value by-products derived from press cake; and carbon credits. Combined with the lack of any long-term commitment or legal framework to protect industry participants, confidence in jatropha eroded.

The review of the factors responsible for the jatropha hype and disappointment provides us with the opportunity to learn from the mistakes of the past and to gain valuable insights into a potential future of jatropha for biodiesel. Key aspects emerging from the literature on the role of policy are:

- Governments should, in view of the long term relevance of biofuel, eliminate fossil diesel subsidies and allow market pricing: this will reduce fossil fuel consumption and free up government resources that could be effectively used for the further development of biofuels. Higher fossil fuel prices make it easier for biofuels to be competitive. It could be further argued that the removal of biofuel mandates should also be considered as there is no evidence to suggest that the economics of the biofuel industry is likely to change in the foreseeable future.

- Governments and industry should work together to develop an effective and efficient supply chain that stimulates and aligns all stages of the jatropha biodiesel process; from seed production through oil processing to the consumer. Each stage must be considered with regard to economics, technology, social and legal aspects, and the environment. The supply chain should ideally provide a win-win situation for all with benefits shared equally.

- $\quad$ Seed and oil producers and distributors must be encouraged to work actively with small producers and locally owned cooperatives so that they can all share equally in the economic gains and as such contribute to rural development.

- Foreign investors must be regulated by governments to minimise project failures and missed opportunities for wage earnings and revenue generation. Realistic and legally binding contracts must be made mandatory for large plantation projects as part of their official business plans, in particular land agreements to protect land holders.

- Information transparency and law enforcement is necessary, especially where there is a history of corruption. National and local governments could for instance consider the detailed accounting of jatropha production from both producers and buyers and make this information freely available in the public domain. This will help in detecting those investors who seek only short-term funding gains. When aiming for the engagement of smallholders, governments and industries need to follow the rules of free prior informed consent regarding land allocation to jatropha to prevent potential land conflicts. 
In re-assessing their regulatory and support mechanisms regarding the development of biofuel markets and infrastructure, governments can enforce and/or reform their policies already in place. My review further emphasises that there needs to be a comprehensive evaluation of past research to clearly identify and develop strategies for any and all outstanding or contradictory issues. Policy and decision makers must have a clear understanding of the consequences and trade-offs of pursuing jatropha biodiesel to avoid doing more harm than good to the community and the environment. The following key research domains have therefore been identified:

- $\quad$ There is an urgent need for improved genetic material with known yield characteristics over a wide range of climatic and agro-ecological conditions. This will require extensive plant breeding and molecular strategies to investigate systematically and scientifically jatropha's potential. Associated research on management will be needed to be able to reap the benefits from the improved varieties.

- The human welfare dimensions of jatropha production and use, and the role it can play needs to be understood. The impacts of jatropha expansion and the pressure and competition for limited resources are also important; particularly where deforestation or the loss of food crops is involved.

- A proper land classification system that identifies land suitable for jatropha (and similar crops) needs to be developed. Suitability may imply land with characteristics allowing for large jatropha yields, which may be on current fertile crop land, grazing land, irrigated areas or nature areas. Suitability may also imply land that is suitable because it has no or low productive land use, such as 'marginal or underutilised' lands. Allocation of suitable lands to bioenergy crops can then form the basis of political decisions that take into account the value of alternative land uses.

- $\quad$ Research into mechanisation is required. Jatropha mechanisation might help to minimise or resolve conflicts arising from competition between jatropha and food crop labour.

- Continued research into jatropha oil quality and quantity is required to target higher value markets. The potential for jatropha by-products needs further investigation and analysis to determine cost effectiveness, sustainability and market possibilities. It will be important to ensure that where multiple benefits are claimed, that there will be no conflicts in regard to land degradation or in water-limited environments when additional biomass is removed.

- Sound technical and agronomic jatropha advice and support capable of maximising the efficient and effective use of resources whilst minimising the impact on the environment and biodiversity must be developed, documented and distributed. The environmental aspects of jatropha biodiesel production and use must be assessed in terms of its impact on GHGs emissions.

Jatropha is in essence a new crop and with that must come the realisation that time is needed for commercial development. If we look in detail at any of the successful new crops we become very aware that domestication is a long-term process. Unfortunately the true extent of their perceived 'overnight success' is 
not always acknowledged, appreciated or understood, a fact that seems to have been overlooked when considering jatropha as a commercial crop.

Cereals such as wheat (Triticum spp. L.), rice and maize for example all have long histories of domestication through on farm selection; however it is only since the early years of the $19^{\text {th }}$ century that real improvements have been made using conventional and molecular breeding techniques (Lupton, 1987). Oil palm is another more recent addition to the long list of wild plants now domesticated crops only becoming a commercially viable crop in 1902 (Hartley, 1988). In some ways it might be considered unfair to compare jatropha with food crops; it might be a more realistic comparison to use non-food crops such as rubber and cotton, although the breeding histories are shorter.

There is no disputing that the successful development of new crops has major economic implications for the world economy. The challenges are how to use plant breeding to produce high yielding, high quality crops with resistance to pests, diseases and environmental stresses while satisfying business challenges, research and development obstacles, production problems, quality and processing issues, and policy issues. To achieve commercial success these all need to be bought together in a cohesive and efficient way.

Another aspect important to the success of jatropha, but often fraught with emotion and accompanied by a distinct lack of rational thinking is the food versus fuel debate. There is a heavy focus on jatropha for its claimed ability to perform in marginal areas, thus avoiding the conflict associated with food crop competition. It is now a well-established fact that jatropha in its current form does not produce high yields on marginal lands; to do so generally requires extensive inputs. The question then becomes one of why exclude jatropha from fertile soils? Jatropha has the potential to be a cash-crop like cotton or rubber (Hevea brasiliensis $\mathrm{M}$.) which are both equally non edible but seem to be well accepted and not seen as a threat to food production. The same could be argued for all non-food crops grown on fertile land.

It is clear that this study highlights the many concerns that need to be addressed before a viable jatropha based biodiesel industry can be developed. While not directly involved in producing food, jatropha has the potential to make substantial contributions to society through biodiesel and high value by-products derived from press cake; and carbon credits. From this perspective there is no rational reason to exclude jatropha production from fertile soils, especially when it has the potential to provide farmers with an income to sustain or improve their socioeconomic status.

\subsection{Concluding remarks}

The jatropha experience provides valuable insights into the future of jatropha and any similar 'silver bullet' new crops or technologies that may emerge in the future. From the biophysical perspective there is a need for high yielding jatropha varieties. There is also an urgent need for a simple and reliable production and management system that maximises commercial potential, but not at the expense of the environment. 
The potential for jatropha intercropping is high, especially if management practices such as fertiliser, pruning, and planting density are considered. While this study has focussed on maize as the intercrop this may not be the only possibility. For the jatropha-maize combination it has been shown that different management practices can reduce jatropha and maize competition and/or enhance complementarity. Our results show that if the objective is to maximise jatropha yield, then maize yield suffers, and vice versa.

Clearly there is no single, generic or even correct solution. Growers must blend the best available choices to maximise plant growth and development relative to their location and circumstances. No matter how skilled the grower if the seed produced cannot be sold profitably because the market calls for different characteristics, then the planting material must be changed. Breeding programmes must be flexible enough to accommodate change; however the problem becomes one of reaction time.

An assessment of trade-offs will always be necessary due to the multiple objectives that exist within any production and management system. The reality is that it simply comes down to what combinations provide the highest total revenue per hectare relative to production and management costs and market prices. The difficult part is to know where to start developing a jatropha biodiesel system. We need people and resources to start developing the crop, the supply chain and markets, so we need exposure, attention and promotion. However promoting business or smallholder investments based on unfounded expected benefits has proven not to lead to viable biodiesel development, but only to successful capture of subsidies by some policy entrepreneurs and professional 'innovation' investors.

While the continued development of alternative energy strategies is crucial and must concentrate on finding a balance between energy needs, socioeconomic conditions and the environment, based on our study we currently cannot promote jatropha based biodiesel. With the current uncertainty that surrounds jatropha yields and its socioeconomic benefits, jatropha will remain a minor player in tropical landscapes for a variety of uses, and it should not be promoted as a smallholder or plantation crop.

Only when the identified policy and research concerns presented in Section 7.4 have been addressed will a well performing jatropha crop in a suitable cropping system be able to generate socioeconomic and environmental benefits that will be conducive to a successful jatropha biodiesel industry in the future. This study provides the reader with the background necessary to contribute to such a future. 


\section{References}

Abdelgadir HA, Jäger AK, Johnson SD, Van Staden J. (2010) Influence of plant growth regulators on flowering, fruiting, seed oil content, and oil quality of Jatropha curcas. South African Journal of Botany 76: 440-446.

Abdelgadir HA, Johnson SD, Van Staden J. (2009) Promoting branching of a potential biofuel crop Jatropha curcas L. by foliar application of plant growth regulators. Plant Growth Regulation 58: 287-295.

Abhilash PC, Srivastava P, Jamil S, Singh N. (2011) Revisited Jatropha curcas as an oil plant of multiple benefits: critical research needs and prospects for the future. Environmental Science and Pollution Research 18: 127-131.

Abugre S, Oti-Boateng C, Yeboah M. (2011) Litter fall and decomposition trend of Jatropha curcas L. leaves mulches under two environmental conditions. Agriculture and Biology Journal of North America 2: 462-470.

Acheampong E, Campion BB. (2014) The effects of biofuel feedstock production on farmers' livelihoods in Ghana: the case of Jatropha curcas. Sustainability 6: 4587-4607.

Achten WMJ, Akinnifesi FK, Maes WH, Trabucco A, Aerts R, Mathijs E, Reubens B, Singh VP, Verchot L, Muys B. (2010a) Jatropha integrated agroforestry systems - biodiesel pathways towards sustainable rural development. In: Ponterio C, Ferra C (eds) Jatropha curcas as a premier biofuel: cost, growing and management. Nova Science, New York, pp 85-102.

Achten WMJ, Almeida J, Fobelets V, Bolle E, Mathijs E, Singh VP, Tewari DN, Verchot LV, Muys B. (2010b) Life cycle assessment of Jatropha biodiesel as transportation fuel in rural India. Applied Energy 87: 3652-3660.

Achten WMJ, Maes WH, Aerts R, Verchot L, Trabucco A, Mathijs E, Singh VP, Muys B. (2010c) Jatropha: from global hype to local opportunity. Journal of Arid Environments 74: 164-165.

Achten WMJ, Maes WH, Reubens B, Mathijs E, Singh VP, Verchot L, Muys B. (2010d) Biomass production and allocation in Jatropha curcas L. seedlings under different levels of drought stress. Biomass and Bioenergy 34: 667-676.

Achten WMJ, Mathijs E, Verchot L, Singh VP, Aerts R, Muys B. (2007) Jatropha biodiesel fueling sustainability? Biofuels, Bioproducts and Biorefining 1: 283-291.

Achten WMJ, Nielsen LR, Aerts R, Lengkeek AG, Kjær DK, Trabucco A, Hansen JK, Maes WH, Graudal L, Akinnifesi FK, Muys B. (2010e) Towards domestication of Jatropha curcas. Biofuel 1: 91-107.

Achten WMJ, Sharma N, Muys B, Mathijs E, Vantomme P. (2014) Opportunities and constraints of promoting new tree crops - lessons learned from jatropha. Sustainability 6: 3213-3231.

Achten WMJ, Verchot L, Franken YJ, Mathijs E, Singh VP, Aerts R, Muys B. (2008) Jatropha bio-diesel production and use. Biomass and Bioenergy 32: 1063-1084.

Afiff S. (2014) Engineering the jatropha hype in Indonesia. Sustainability 6: 1686-1704. 
Agarwal D, Agarwal AK. (2007) Performance and emissions characteristics of Jatropha oil (preheated and blends) in a direct injection compression ignition engine. Applied thermal engineering 27: 23142323.

Agoramoorthy G, Hsu MJ, Chaudhary S, Shieh P-C. (2009) Can biofuel crops alleviate tribal poverty in India's drylands? Applied Energy 86: S118-S124.

Ahmad S, Sultan SM. (2015) Physiological changes in the seeds of Jatropha curcas L. at different stages of fruit maturity. Brazilian Archives of Biology and Technology 58: 118-123.

Ahoton LE, Quenum F. (2012) Floral biology and hybridization potential of nine accessions of physic nut (Jatropha curcas L.) originating from three continents. Tropicultura 30: 193-198.

Aikio S, Markkola MA. (2002) Optimality and phenotypic plasticity of shoot-to-root ratio under variable light and nutrient availabilities. Evolutionary Ecology 16: 67-76.

Akinnifesi FK, Makumba W, Sileshi G, Ajayi OC, Mweta D. (2007) Synergistic effect of inorganic N and P fertilizers and organic inputs from Gliricidia sepium on productivity of intercropped maize in Southern Malawi. Plant and Soil 294: 203-217.

Al-Riffai P, Dimarananm B, Laborde D. (2010) European Union and United States biofuel mandates impacts on world markets. Technical Notes No.IDB-TN-191. Inter-American Development Bank, Washington, DC, pp 1-77.

Alkemade F, Suurs RAA. (2012) Patterns of expectations for emerging sustainable technologies. Technological Forecasting and Social Change 79: 448-456.

Allen SC, Jose S, Nair PKR, Brecke BJ, Nkedi-Kizza P, Ramsey CL. (2004) Safety-net role of tree roots: evidence from a pecan (Carya illinoensis K. Koch) - cotton (Gossypium hirsutum L.) alley cropping system in the southern United States. Forest Ecology and Management 192: 395-407.

Amir S, Nurlaila I, Yuliar S. (2008) Cultivating energy, reducing poverty: biofuel development in an Indonesian village. Perspectives on Global Development and Technology 7: 113-132.

Anders MM, Potdar MV, Francis CA. (1994) Significance of intercropping in cropping systems. In: Ito O, Johansen C, Adu-Gyamfi JJ, Katayama K, Kumar Rao JVDK, Rego TJ (eds) Proceeding of the international workshop on dynamics of roots and nitrogen in cropping systems of the semi-arid tropics, November 12-25; Patancheru, Andhra Pradesh, India. Japan International Research Center for Agricultural Sciences, Japan, pp 1-307.

Anderson LS, Sinclair FL. (1993) Ecological interactions in agroforestry systems. Forestry Abstract 6: 5791.

Anim-Kwapong E, Adomako B. (2010) Genetic and environmental correlations between bean yield and agronomic traits in Coffea canephora. Journal of Plant Breeding and Crop Science 2: 64-72.

Anitha K, Varaprasad KS. (2012) Jatropha pests and diseases: an overview. In: Carels N, Sujatha M, Bahadur B (eds) Jatropha, challenges for a new energy crop, Volume 1: farming, economics and biofuel. Springer, New York, pp 175-218.

Ariati R. (2007) National policy on bioenergy. Presentation by the Director for New Renewable Energy and Energy Conservation (Ministry of Energy and Mineral Resources), at The Asian Science and 
Technology Seminar, Jakarta, 8 March 2007. Retrieved from www.jst.go.jp/asts/asts_j/files/ppt/08_ppt.pdf.

Ariza-Montobbio P, Lele S. (2010) Jatropha plantations for biodiesel in Tamil Nadu, India: viability, livelihood trade-offs, and latent conflict. Ecological Economics 70: 189-195.

Ariza-Montobbio P, Lele S, Kallis G, Martinez-Alier J. (2010) The political ecology of Jatropha plantations for biodiesel in Tamil Nadu, India. The Journal of Peasant Studies 37: 875-897.

Arndt C, Hussain MA, Jones ES, Nhate V, Tarp F, Thurlow J. (2012) Explaining the evolution of poverty: the case of Mozambique. American Journal of Agricultural Economics 94: 854-872.

Arolu IW, Rafii MY, Hanafi MM, Mahmud TMM, Latif MA. (2012) Molecular characterization of Jatropha curcas germplasm using inter simple sequence repeat (ISSR) markers in Peninsular Malaysia. Australian Journal of Crop Science 6: 1666-1673.

Atabani AE, Silitonga AS, Ong HC, Mahlia TMI, Masjuki HH, Badruddin IA, Fayaz H. (2013) Non-edible vegetable oils: a critical evaluation of oil extraction, fatty acid compositions, biodiesel production, characteristics, engine performance and emissions production. Renewable and Sustainable Energy Reviews 18: 211-245.

Atkinson C, Else M. (2001) Understanding how rootstocks dwarf fruit trees. Compact Fruit Tree 34: 46-49.

Axelsson L, Franzén M, Ostwald M, Berndes G, Lakshmi G, Ravindranath N. (2012) Jatropha cultivation in southern India: assessing farmers' experiences. Biofuels, Bioproducts and Biorefining 6: 246-256.

Bailis R, McCarthy H. (2011) Carbon impacts of direct land use change in semiarid woodlands converted to biofuel plantations in India and Brazil. Global Change Biology Bioenergy 3: 449-460.

Balandier P, Dupraz C. (1998) Growth of widely spaced trees: a case study from young agroforestry plantations in France. Agroforestry Systems 43: 151-167.

Bandyopadhyay KR. (2015) Biofuel promotion in India for transport: exploring the grey areas. Policy BriefThe Energy and Resources Institute (TERI), New Delhi, India, pp 1-12.

Basha SD, George F, Makkar HPS, Becker K, Sujatha M. (2009) A comparative study of biochemical traits and molecular markers for assessment of genetic relationships between Jatropha curcas L. germplasm from different countries. Plant Science 176: 812 - 823.

Basha SD, Sujatha M. (2007) Inter and intra-population variability of Jatropha curcas L. characterized by RAPD and ISSR markers and development of population-specific SCAR markers. Euphytica 156: $375-386$.

Basha SD, Sujatha M. (2009) Genetic analysis of jatropha species and interspecific hybrids of Jatropha curcas using nuclear and organelle specific markers. Euphytica 168: 197-214.

Baumert S, Khamzina A. (2015) Allometric relations in Jatropha curcas production systems of Burkina Faso. Journal of Arid Environments 120: 95-104.

Beamon BM. (1998) Supply chain design and analysis: models and methods. International journal of production economics 55: 281-294. 
Behera SK, Srivastava P, Tripathi R, Singh JP, Singh N. (2010) Evaluation of plant performance of Jatropha curcas L. under different agro-practices for optimizing biomass - A case study. Biomass \& Bioenergy 34: 30-41.

Berchmans HJ, Hirata S. (2008) Biodiesel production from crude Jatropha curcas L. seed oil with a high content of free fatty acids. Bioresource Technology 99: 1716-1721.

Bhering LL, Barrera CF, Ortega D, Laviola BG, Alves AA, Rosado TB, Cruz CD. (2013) Differential response of jatropha genotypes to different selection methods indicates that combined selection is more suited than other methods for rapid improvement of the species. Industrial Crops and Products 41: 260-265.

Bijman J, Slingerland M, Van Baren S. (2009) Contractual arrangements for smallholders in biofuel chains: a case study of jatropha in Mozambique. VII international PENSA conference, November 26-28, Sao Paulo - Brazil.

Boehme J. (1986) Innovationsforderung durch kooperationen: zwischenbetriebliche zusammenarbeit als instrument des innovationsmanagements in kleinen und mittleren unternehmen bei einfuhrung der mikroelektronik in produkte und verfahren (In German). Erich Schmidt Verlag, Berlin.

Borman GD, Von Maltitz GP, Tiwari S, Scholes MC. (2013) Modelling the economic returns to labour for Jatropha cultivation in southern Africa and India at different local fuel prices. Biomass and Bioenergy 59: 70-83.

Bormann FH. (2011) An Investment of the economic sustainability of jatropha-based Initiatives implications for labour and rural livelihoods (MSc Thesis). Faculty of Science. University of the Witwatersrand, Johannesburg, pp 1-108.

Borup M, Brown N, Konrad K, Van Lente H. (2006) The sociology of expectations in science and technology. Technology Analysis \& Strategic Management 18: 285-298.

Brem A, Voigt K-I. (2009) Integration of market pull and technology push in the corporate front end and innovation management - Insights from the German software industry. Technovation 29: 351-367.

Bressan EA, Sebbenn AM, Ferreira RR, Lee TSG, Figueira A. (2013) Jatropha curcas L.(Euphorbiaceae) exhibits a mixed mating system, high correlated mating and apomixis. Tree Genetics \& Genomes 9: 1089-1097.

Brewster JL, Mondal FM, Morris GEL. (1986) Bulb development in onion (Allium cepa L.) IV. Influence on yield of radiation interception, its efficiency of conversion, the duration of growth and dry-matter partitioning. Annals of Botany 58: 221-233.

Brittaine R, Lutaladio N. (2010) Jatropha: a smallholder bioenergy crop. The potential for pro-poor development. FAO, Rome, pp 1-96.

Bromokusumo A. (2007) Indonesia biofuels annual 2007. USDA Foreign Agricultural Service, GAIN Report Number ID7019, June, pp 1-7.

Brouwer R, De Wit CT. (1969) A simulation model of plant growth with special attention to root growth and its consequences. In: Whittington WJ (ed). Root growth. Butterworth Publishers, London, pp 224244. 
Brunner T. (1990) Physiological fruit tree training for intensive growing. Akadémiai Kiadó, Budapest, pp 1286.

Bullinger HJ. (1994) Einführung in das technologiemanagement: modelle, methoden, praxisbeispiele (In German). Teubner, Stuttgart.

Bulman T, Fengler W, Ikhsan M. (2008) Indonesia's oil subsidy opportunity. Far Eastern Economic Review 171: 14-18.

Cadisch G, Handayanto E, Malama C, Seyni F, Giller KE. (1998) N recovery from legume prunings and priming effects are governed by the residue quality. Plant and Soil 205: 125-134.

Cadisch G, Rowe E, Van Noordwijk M. (1997) Nutrient harvesting-the tree-root safety net. Agroforestry Forum 8: 31-33.

Campiche JL, Bryant HL, Richardson JW, Outlaw JL. (2007) Examining the evolving correspondence between petroleum prices and agricultural commodity prices. Selected paper prepared for presentation at the American Agricultural Economics Association Annual Meeting, July 29-August 1, Portland, OR, pp 1-15.

Cannell MGR. (1985) Dry matter partitioning in tree crops. In: Cannell MGR, Jackson JE (eds) Attributes of trees as crop plants. Wilson \& Son Ltd, Cumbria, Great Britain, pp 160-193.

Cannell MGR, Milne R, Sheppard LJ, Unsworth MH. (1987) Radiation interception and productivity of willow. Journal of Applied Ecology: 261-278.

Carels N. (2009) Jatropha curcas: a review. In: Jean-Claude K, Michel D (eds) Advances in Botanical Research. Elsevier Ltd, pp 39-86.

Carels N. (2013) Towards the domestication of jatropha: the integration of sciences. In: Bahadur B, Sujatha M, Carels N (eds) Jatropha, challenges for a new energy crop, Volume 2: genetic improvement and biotechnology. Springer, London, pp 263-299.

Castellanos-Navarrete A, Tittonell P, Rufino MC, Giller KE. (2015) Feeding, crop residue and manure management for integrated soil fertility management - A case study from Kenya. Agricultural Systems 134: 24-35.

Castro Gonzáles NF. (2015) Potenziale des Jatropha curcas - anbaus für eine nachhaltige produktion von biodiesel in Bolivien: am beispiel einer fallstudie in der Bolivianischen Region El Gran Chaco des Departamentos Santa Cruz. Verlag Shaker The scientific publisher Shaker, Germany and The Netherlands pp 1-260.

Ceasar SA, Ignacimuthu S. (2011) Applications of biotechnology and biochemical engineering for the improvement of jatropha and biodiesel: a review. Renewable and Sustainable Energy Reviews 15: 5176-5185.

Chang-Wei L, Kun L, You C, Yong-Yu S. (2007) Floral display and breeding system of Jatropha curcas L. Forestry Studies in China 9: 114-119.

Chen H, Felker S, Sun S. (2010) Allometry of within-fruit reproductive allocation in subtropical dicot woody species. American Journal of Botany 97: 611-619. 
Chen H, Niklas KJ, Yang D, Sun S. (2009) The effect of twig architecture and seed number on seed size variation in subtropical woody species. New Phytologist 183: 1212-1221.

Chen H, Xu M-1, Guo Q, Yang L, Ma Y. (2016) A review on present situation and development of biofuels in China. Journal of the Energy Institute 89: 248-255.

Chesney P, Nygren P. (2002) Fine root and nodule dynamics of Erythrina poeppigiana in an alley cropping system in Costa Rica. Agroforestry Systems 56: 259-269.

Cholid M, Sudiarto K, Winarno D. (2007) The effect of pruning on the growth and production of Jatropha curcas (In Indonesian). In: Heliyanto B, Soetopo D, Purwati DR, Yulianti T, Mardjono R, Hariyono B, Tirtosuprobo S, Asbani N, Hartono J (eds) Proceedings of the third national workshop - Jatropha technology innovation to support self-sufficient energy villages, November 5th. Indonesian Sweetener and Fiber Crops Research Institute (Balittas), Malang, Indonesia, pp 252 - 257.

Cholid M, Susanto S, Purwoko BS. (2014) Effects of grafting time and grafting methods used on scion and rootstock compatibility of physic nut (Jatropha curcas L.). Asian Journal of Agricultural Research 8: 150-163.

Ciampitti IA, Vyn TJ. (2012) Physiological perspectives of changes over time in maize yield dependency on nitrogen uptake and associated nitrogen efficiencies: a review. Field Crops Research 133: 48-67.

Cilas C, Bar-hen A, Montagnon C, Godin C. (2006) Definition of architectural ideotypes for good yield capacity in Coffea canephora. Annals of Botany 97: 405-411.

Cochet H. (2015) Comparative agriculture. Springer, Dordrecht, The Netherlands, pp 1-159.

CONAFOR. (2009) Reglas de operación ProArbol 2009. Secretaria de medio ambiente y recursos naturales (http://www.conafor.gob.mx), México, DF.

Connor DJ, Loomis RS, Cassman KG. (2011) Crop ecology: productivity and management in agricultural systems. Cambridge University Press, Cambridge, UK, pp 1- 569.

Contran N, Chessa L, Lubino M, Bellavite D, Roggero PP, Enne G. (2013) State-of-the-art of the Jatropha curcas productive chain: from sowing to biodiesel and by-products. Industrial Crops and Products 42: 202-215.

Costes E, Lauri PE, Regnard JL. (2006) Analyzing fruit tree architecture: implications for tree management and fruit production. Horticultural reviews 32: 1-61.

Cotula L, Dyer N, Vermeulen S. (2008) Fuelling exclusion? The biofuels boom and poor people's access to land. International Institute for Environmental and Development and Food and Agriculture Organization of the United Nations, London.

Da Silva Neto JA, De Souza CMA, Da Silva CJ, Da Fonseca PRB. (2015) Productivity of maize hybrids in single and growing with intercropped jatropha. Scientia Agraria Paranaensis 14: 43-48.

Dal Belo Leite JG, Bijman J, Giller K, Slingerland M. (2013) Biodiesel policy for family farms in Brazil: one-size-fits-all? Environmental Science \& Policy 27: 195-205.

Dal Belo Leite JG, Silva JV, Van Ittersum MK. (2014) Integrated assessment of biodiesel policies aimed at family farms in Brazil. Agricultural Systems 131: 64-76. 
Daniel JN, Ong CK. (1990) Perennial pigeonpea: a multi-purpose species for agroforestry systems. Agroforestry Systems 10: 113-129.

Danjon F, Fourcaud T, Bert D. (2005) Root architecture and wind-firmness of mature Pinus pinaster. New Phytologist 168: 387-400.

Das N. (2014) Comparative growth analysis ad yield performance of Glycine max under Jatropha curcas based agrisilviculture system of agroforestry in the northern part of Bangladesh. Journal of Forests 1: $37-46$.

Das S, Misra RC, Mahapatra AK, Gantayat BP, Pattnaik RK. (2010) Genetic variability, character association and path analysis in Jatropha curcas. World Applied Sciences Journal 8: 1304-1308.

De Jongh J, Nielsen F. (2011) Lessons learned: jatropha for local development. FACT Foundation: Wageningen, The Netherlands, pp 1-60.

De Oliveira Borges LF, Ribeiro RP. (2014) Response of Jatropha curcas plants to changes in the availability of nitrogen and phosphorus in Oxissol. African Journal of Agricultural Research 9: 3581-3586.

De Reffye P, Heuvelink E, Guo Y, Hu B-G, Zhang B-G. (2009) Coupling process-based models and plant architectural models: a key issue for simulating crop production. In: Cao W, White J, Wang E (eds) Crop modeling and decision support. Springer Berlin Heidelberg, pp 130-147.

De Resende JCF, Da Silva JTA, Simão FR, De Azevedo Pimentel RM, Morais DDL. (2012) Phytotechnical aspects of Jatropha farming in Brazil. In: Carels N, Sujatha M, Bahadur B (eds) Jatropha, challenges for a new energy crop, Volume 1: farming, economics and biofuel. Springer, New York, pp 239-261.

De Willigen P, Van Noordwijk M. (1987) Roots, plant production and nutrient use efficiency, PhD thesis. Wageningen Agricultural University, Wageningen.

De Wit CT. (1992) Resource use efficiency in agriculture. Agricultural Systems 40: 125-151.

De Wit CT, Van den Bergh JP. (1965) Competition between herbage plants. Nehterland Journal of Agricultural Science 13: 212-221.

Dedehayir O, Steinert M. (2016) The hype cycle model: a review and future directions. Technological Forecasting and Social Change 108: 28-41.

Dehgan B, Webster GL. (1979) Morphology and infrageneric relationships of the genus Jatropha (Euphorbiaceae). University of California Press, Volume 74, Berkeley and Los Angeles, California USA, pp 1-139.

Demirbas A. (2006) Global biofuel strategies. Energy Education Science and Technology 17: 27-63.

Deng X, Fang Z, Liu Y-h. (2010) Ultrasonic transesterification of Jatropha curcas L. oil to biodiesel by a two-step process. Energy conversion and Management 51: 2802-2807.

Dhakshanamoorthy D, Selvaraj R, Chidambaram A. (2015) Utility of RAPD marker for genetic diversity analysis in gamma rays and ethyl methane sulphonate (EMS)-treated Jatropha curcas plants. Comptes Rendus Biologies 338: 75-82.

Dhillon RS, Hooda MS, Pundeer JS, Ahlawat KS, Kumari S. (2009) Development of efficient techniques for clonal multiplication of Jatropha curcas L., a potential biofuel plant. Current Science 96: 823-825. 
Dias LAS, Missio RF, Dias DCFS. (2012) Antiquity, botany, origin and domestication of Jatropha curcas (Euphorbiaceae), a plant species with potential for biodiesel production. Genetics and Molecular Research 11: 2719-2728.

Díaz-López L, Gimeno V, Simón I, Martínez V, Rodríguez-Ortega WM, García-Sánchez F. (2012) Jatropha curcas seedlings show a water conservation strategy under drought conditions based on decreasing leaf growth and stomatal conductance. Agricultural Water Management 105: 48-56.

Dillon HS, Laan T, Dillon HS. (2008) Biofuels, at what cost? Government support for ethanol and biodiesel in Indonesia. International Institute for Sustainable Development, Winnipeg - Manitoba, Canada, 1$86 \mathrm{pp}$.

Divakara BN, Upadhyaya HD, Wani SP, Gowda C, Laxmipathi L. (2010) Biology and genetic improvement of Jatropha curcas L.: a review. Applied Energy 87: 732-742.

Donald CM, Hamblin J. (1976) The biological yield and harvest index of cereals as agronomic and plant breeding criteria. Advances in Agronomy 28: 361-405.

Drabik D. (2011) The theory of biofuel policy and food grain prices. Working Paper No. 2011-20. Charles H. Dyson School of Applied Economics and Management, Cornell University, Ithaca, New York, pp $1-55$.

Duguma B, Kang BT, Okali DUU. (1988) Effect of pruning intensities of three woody leguminous species grown in alley cropping with maize and cowpea on an alfisol. Agroforestry Systems 6: 19-35.

Dupraz C, Simorte V, Dauzat M, Bertoni G, Bernadac A, Masson P. (1999) Growth and nitrogen status of young walnuts as affected by intercropped legumes in a Mediterranean climate. In Auclair D, Dupraz C (eds). Agroforestry for sustainable land-use fundamental research and modelling with emphasis on temperate and Mediterranean applications. Springer Netherlands, pp 71-80.

Duursma RA, Mäkelä A. (2007) Summary models for light interception and light-use efficiency of nonhomogeneous canopies. Tree Physiology 27: 859-870.

Ebrahim Z, Baker P. (2012a) Jatropha-an update. Part 2: Jatropha in India. CABI, Wallingford, UK, pp 1-5.

Ebrahim Z, Baker P. (2012b) Jatropha-an update. Part 3: Jatropha in China. CABI, Wallingford, UK, pp 1-4.

Ebrahim Z, Baker P. (2012c) Jatropha-an update. Part 4: Jatropha in East Africa. CABI, Wallingford, UK, pp $1-5$.

Edrisi SA, Dubey RK, Tripathi V, Bakshi M, Srivastava P, Jamil S, Singh HB, Singh N, Abhilash PC. (2015) Jatropha curcas L.: a crucified plant waiting for resurgence. Renewable and Sustainable Energy Reviews 41: 855-862.

Efendi R, Suwardi. (2010) Response of hybrid maize to nitrogen application and population density (In Indonesian). In: ICRI (ed) Increasing the role of cereals research towards sustainable food security Proceedings of the $10^{\text {th }}$ National Seminar, July 27-28. Indonesian Cereals Research Institute (ICRI), Maros, South Sulawesi - Indonesia, pp 260-268.

Effendi DS, Taher S, Rumini W. (2007) The effect of intercropping and planting distance on the growth and yield of Jatropha curcas L. (in Indonesian). In: Heliyanto B, Soetopo D, Purwati DR, Yulianti T, Mardjono R, Hariyono B, Tirtosuprobo S, Asbani N, Hartono J (eds) The third national workshop - 
jatropha technology innovation to support self-sufficient energy villages. Indonesian Sweetener and Fiber Crops Research Institute, Malang, Indonesia, pp 232-238.

Eissenstat D, Duncan L. (1992) Root growth and carbohydrate responses in bearing citrus trees following partial canopy removal. Tree Physiology 10: 245-257.

European Commission. (2007) Renewable energy road map; Renewable energies in the 21st Century: building a more sustainable future - Impact assessment. (Commission Staff Working Document SEC [2006] 1719; Accompanying Document to the Communication from the Commission to the Council and the European Parliament). European Commission, Belgium, Brussels, pp 1-64.

Everson CS, Mengistu MG, Gush MB. (2013) A field assessment of the agronomic performance and water use of Jatropha curcas in South Africa. Biomass and Bioenergy 59: 59-69.

Fageria NK, Baligar VC, Donald LS. (2005) Enhancing nitrogen use efficiency in crop plants. Advances in Agronomy 88: 97-185.

Fairless D. (2007) Biofuel: the little shrub that could - maybe. Nature 449: 652-655.

Falconer DS. (1989) Introduction to quantitative genetics. 3rd ed. Longman Science \&Technical, London, 1$438 \mathrm{pp}$.

FAO. (2006) Food security. Policy Brief, Issue 2. FAO's Agriculture and Development Economics Division (ESA) with support from the FAO Netherlands Partnership Programme (FNPP) and the EC-FAO Food Security Programme, pp 1-4.

FAO. (2008) The state of food and agriculture, biofuels: prospects, risks and opportunities. Food and Agriculture Organisation, Rome, pp 1-138.

Fargione J, Hill J, Tilman D, Polasky S, Hawthorne P. (2008) Land clearing and the biofuel carbon debt. Science 319: 1235-1238.

Fatimah YA, Raven RPJM, Arora S. (2015) Scripts in transition: protective spaces of Indonesian biofuel villages. Technological Forecasting and Social Change 99: 1-13.

Fatimah YA, Yuliar S. (2009) Opening the Indonesian bio-fuel box: how scientists modulate the social. International Journal of Actor-Network Theory and Technological Innovation 1: 1-12.

Favretto N, Stringer LC, Dougill AJ. (2012) Cultivating clean energy in Mali: policy analysis and livelihood impacts of Jatropha curcas. Sustainability Research Institute Working Paper No 84 and Centre for Climate Change Economics and Policy Paper No 28, Leeds, London, pp 1-26.

Fenn J, Raskino M. (2008) Mastering the hype cycle: how to choose the right innovation at the right time. Harvard Business Press, Boston, Massachusetts, pp 1-237.

Ferree DC, Myers SC, Schupp JR. (1992) Root pruning and root restriction of fruit trees - current review. Acta Horticulturae 322: 153-166.

Firdaus MS, Husni MHA. (2012) Planting Jatropha curcas on constrained land: emission and effects from land use change. The Scientific World Journal 2012: 1 - 7.

Fitter AH, Stickland TR, Harvey ML, Wilson GW. (1991) Architectural analysis of plant root systems 1. Architectural correlates of exploitation efficiency. New Phytologist 118: 375-382. 
Foidl N, Foidl G, Sanchez M, Mittelbach M, Hackel S. (1996) Jatropha curcas L. as a source for the production of biofuel in Nicaragua. Bioresource Technology 58: 77-82.

Francis CA. (1989) Biological efficiencies in multiple-cropping systems. Advances in Agronomy 42: 1-42.

Francis G. (2012) Jatropha seeds oil and products: important properties with respect to uses. In: Carels N, Sujatha M, Bahadur B (eds) Jatropha, challenges for a new energy crop, Volume 1: farming, economics and biofuel. Springer, New York, pp 343-354.

Francis G, Edinger R, Becker K. (2005) A concept for simultaneous wasteland reclamation, fuel production, and socio-economic development in degraded areas in India: need, potential and perspectives of jatropha plantations. Natural Resources Forum 29: 12-24.

Gachengo CN, Palm CA, Jama B, Othieno C. (1999) Tithonia and senna green manures and inorganic fertilizers as phosphorus sources for maize in Western Kenya. Agroforestry Systems 44: 21-35.

Gao L, Xu H, Bi H, Xi W, Bao B, Wang X, Bi C, Chang Y. (2013) Intercropping competition between apple trees and crops in agroforestry systems on the loess plateau of China. PLoS ONE 8: e70739.

Garcia-Almodovar C, Gimeno V, Nieves M, Diaz-Lopez L, Simon I, Garcia-Sanchez F. (2014) Improving the tolerance of Jatropha curcas L. plants to abiotic stresses. CAB Reviews 9: 1-10.

Garg KK, Karlberg L, Wani SP, Berndes G. (2011) Jatropha production on wastelands in India: opportunities and trade-offs for soil and water management at the watershed scale. Biofuels, Bioproducts and Biorefining 5: 410-430.

Gasparatos A, Lee LY, Von Maltitz GP, Mathai MV, Puppim de Oliveira JA, Willis KJ. (2012) Biofuels in Africa: impacts on ecosystem services, biodiversity and human well-being. United Nations University - Institute of Advanced Studies, Yokohama, Japan, pp 1-114.

Gasparatos A, Stromberg P (eds). (2012) Socioeconomic and environmental impacts of biofuels: evidence from developing nations. Cambridge University Press, USA.

Gaul M. (2012) Evaluating the performance of rural energy service pathways and their impacts on rural livelihoods - An analysis model tested on Jatropha-based energy services in Sumbawa, Indonesia. PhD thesis. Von der Fakultät III - Prozesswissenschaften der Technischen Universität Berlin, Berlin, pp 1-238.

Geisler D, Ferree DC. (1984) Response of plants to root pruning. In: Janick J (ed) Horticultural reviews, Volume 6. AVI Publishing, Westport, Connecticut, pp 155-188.

German L, Schoneveld G, Skutsch M, Andriani R, Obidzinski K, Pacheco P, Komarudin H, Andrianto A, Lima M, Dayang Norwana AAB. (2010) The local social and environmental impacts of biofuel feedstock expansion: a synthesis of case studies from Asia, Africa and Latin America. Info brief no.34, Center for International Forestry Research (CIFOR), Bogor, Indonesia.

GEXSI. (2008) Global market study on Jatropha - final report. Prepared for the World Wide Fund for Nature (WWF). Global Exchange for Social Investment (GEXSI), London/Berlin, pp 1-187.

Ghezehei SB, Annandale JG, Everson CS. (2009) Shoot allometry of Jatropha curcas. Southern Forests 71: 279-286. 
Ghezehei SB, Everson CS, Annandale JG. (2015) Can productivity and post-pruning growth of Jatropha curcas in silvopastoral systems be regulated by manipulating tree spacing/arrangement without changing tree density? Biomass and Bioenergy 74: 233-243.

Ghosh A, Chaudhary DR, Reddy MP, Rao SN, Chikara J, Pandya JB, Patolia JS, Gandhi MR, Adimurthy S, Vaghela N, Mishra S, Rathod MR, Prakash AR, Shethia BD, Upadhyay SC, Balakrishna V, Prakash R, Ghosh PK. (2007a) Prospects for jatropha methyl ester (biodiesel) in India. International Journal of Environmental Studies 64: 659-674.

Ghosh A, Chikara J, Chaudhary D, Prakash AR, Boricha G, Zala A. (2010) Paclobutrazol arrests vegetative growth and unveils unexpressed yield potential of Jatropha curcas. Journal of Plant Growth Regulation 29: 307-315.

Ghosh A, Chikara J, Chaudhary DR. (2011) Diminution of economic yield as affected by pruning and chemical manipulation of Jatropha curcas L. Biomass and Bioenergy 35: 1021-1029.

Ghosh A, Patolia JS, Chaudhary DR, Chikara J, Rao SN, Kumar D, Boricha GN, Zala A. (2007b) Response of Jatropha curcas under different spacing to jatropha de-oiled cake. FACT Seminar on Jatropha curcas L. Agronomy and Genetics, FACT Foundation, Wageningen, The Netherlands.

Gichimu BM, Omondi CO. (2010) Morphological characterization of five newly developed lines of arabica coffee as compared to commercial cultivars in Kenya. International Journal of Plant Breeding and Genetics 4: 238-246.

Giller KE. (2001) Nitrogen fixation in tropical cropping systems. 2nd ed. CABI, Wallingford, UK.

Ginwal H, Rawat P, Srivastava R. (2004) Seed source variation in growth performance and oil yield of Jatropha curcas Linn. in central India. Silvae Genetica 53: 186-191.

Gmünder S, Singh R, Pfister S, Adheloya A, Zah R. (2012) Environmental impacts of Jatropha curcas biodiesel in India. BioMed Research International 2012.

Gmünder SM, Zah R, Bhatacharjee S, Classen M, Mukherjee P, Widmer R. (2010) Life cycle assessment of village electrification based on straight jatropha oil in Chhattisgarh, India. Biomass and Bioenergy 34: 347-355.

Goswami K, Hazarika A. (2016) Supply chain network of Jatropha based biodiesel industry in North East India. Sustainable Production and Consumption 6: 38-50.

Gour VK. (2006) Production practices including post harvest management of Jatropha curcas. In: Singh B, Swaminathan R, Ponraj V (eds) Biodiesel conference towards energy independence-focus on Jatropha. Rashtrapati Bhawan New Delhi, Bolaram - Hyderabab, India, pp 223-251.

Government of India. (2003) Report of the committee on the development of bio-fuel. Planning Commission, Government of India, New Delhi, India, pp 1-214.

GRAIN. (2008) Agrofuels in India, private unlimited. Seedling, April. GRAIN, Spain, pp 3-11.

Grams TE, Andersen CP. (2007) Competition for resources in trees: physiological versus morphological plasticity. In: Esser K, Löttge U, Beyschlag W, Murata J (eds) Progress in botany. Springer, Berlin Heidelberg, pp 356-381. 
Grativol C, da Fonseca Lira-Medeiros C, Hemerly AS, Ferreira PCG. (2011) High efficiency and reliability of inter-simple sequence repeats (ISSR) markers for evaluation of genetic diversity in Brazilian cultivated Jatropha curcas L. accessions. Molecular biology reports 38: 4245-4256.

Green L. (2009) Jatropha as biofuel: an analysis of the possible implications for food Security in Mali. BSc thesis. Science in Environmental Science and International Development Studies. Dalhousie University, pp 1-75.

Grimsby LK, Borgenvik EJL. (2013) Fuelling sawdust stoves with jatropha fruit coats. Sustainable Energy Technologies and Assessments 2: 12-18.

Grossman YL, DeJong TM. (1998) Training and pruning system effects on vegetative growth potential, light interception, and cropping efficiency in peach trees. Journal of the American Society for Horticultural Science 123: 1058-1064.

GSI. (2008) Biofuels - at what cost? Government support for ethanol and biodiesel in China. Global Subsidies Initiative (GSI) of the International Institute for Sustainable Development (IISD), Geneva, Switzerland, pp 1-78.

GTZ. (2009) Jatropha reality check: a field assessment of the agronomic and economic viability of jatropha and other oilseed crops in Kenya. Study conducted by Endelevu Energy with World Agroforestry Center and Kenya Forestry Research Institute, Nairobi.

Gu K, Mao H, Yin Z. (2014) Production of marker-free transgenic Jatropha curcas expressing hybrid Bacillus thuringiensis $\delta$-endotoxin $\mathrm{Cry} 1 \mathrm{Ab} / 1 \mathrm{Ac}$ for resistance to larvae of tortrix moth (Archips micaceanus). Biotechnology for Biofuels 7: 1-9.

Gu K, Tian D, Mao H, Wu L, Yin Z. (2015) Development of marker-free transgenic Jatropha curcas producing curcin-deficient seeds through endosperm-specific RNAi-mediated gene silencing. BMC Plant Biology 15: 242.

Gui MM, Lee K, Bhatia S. (2008) Feasibility of edible oil vs. non-edible oil vs. waste edible oil as biodiesel feedstock. Energy 33: 1646-1653.

Gunawan. (2014) Why and how did farmers in Gunungkidul, Yogyakarta, participate in Jatropha projects? In: Vel JAC, Simandjutak, D (eds) JARAK, the short history of Jatropha projects in Indonesia. IIAS. E-publication available at http://jarak.iias.asia;, Leiden.

Haider MH, Dummer NF, Knight DW, Jenkins RL, Howard M, Moulijn J, Taylor SH, Hutchings GJ. (2015) Efficient green methanol synthesis from glycerol. Nature Chemistry 7: 1028-1032.

Hairiah K, Dewi S, Agus F, Velarde SJ, Ekadinata A, Rahayu S, Van Noordwijk M. (2011) Measuring carbon stocks across land use systems: a manual. World Agroforestry Centre-ICRAF, South East Asia Regional Office, Bogor, Indonesia.

Hairiah K, Van Noordwijk M, Santoso B, Syekhfani MS. (1992) Biomass production and root distribution of eight trees and their potential for hedgerow intercropping on an ultisol in southern Sumatra. Agrivita 15: 54-68.

Hallé F, Oldeman RAA, Tomlinson PB. (1978) Tropical trees and forests: an architectural analysis. Springer-Verlag, New York, 1-441 pp. 
Handayanto E, Giller K. (1994) Nitrogen release from prunings of legume hedgerow trees in relation to quality of the prunings and incubation method. Plant and Soil 160: 237-248.

Hanudin E, Nurdin M, Purnomo JW. (2012) Mangan concretions characteristic in Mollisols at Bunder Forest, Gunungkidul. The third Agroforestry National Seminar, Yogyakarta 29 May 2012.

Hariyadi, Purwoko BS, Raden I. (2011) The effect of pruning and primary branch development on the photosynthesis and seed production of Jatropha curcas L. Journal Agronomi Indonesia 39: 205-209.

Hartati RRS, Setiawan A, Heliyanto B, Pranowo D, Sudarsono. (2009) Morphologies and yield performance of 60 selected genotypes of physic nut (Jatropha curcas L.) at Pakuwon experimental station, Sukabumi (In Indonesian). Jurnal Penelitian Tanaman Industri 15: 152-161.

Hartati RRS, Sudarsono. (2015) Combining ability and heterosis of vegetative, generative, and yield potential of physic nut (Jatropha curcas L.) using diallel analysis (In Indonesian). Jurnal Penelitian Tanaman Industri 21: 9-16.

Hartley CWS. (1988) The oil palm (Elaeis guineesis Jacq.). 2nd ed. Longman Scientific \& Technical, England pp 1-716.

Hasan F. (2012) Energy and food security. In: Toth FL (ed) Energy for development: Resource, Technologies, Environment. Springer, Dordrecht, pp 219-233.

Hasnam, Hartati RRS. (2006) The availability of improved populations for Jatropha curcas L seed (in Indonesian). In: ICECRD (ed) Status of cultivation technology for Jatropha curcas L in Indonesia Proceedings of the $1^{\text {st }}$ National workshop, April, 11-12 Indonesian Centre for Estate Crops Research \& Development (ICECRD), Jakarta, pp 1-69.

Hauck RD, Bremner JM. (1976) Use of tracers for soil and fertilizer nitrogen research. Advances in Agronomy 28: 219-266.

Hay RKM. (1995) Harvest index: a review of its use in plant breeding and crop physiology. Annals of Applied Biology 126: 197-216.

Hay RKM, Gilbert RA. (2001) Variation in the harvest index of tropical maize: evaluation of recent evidence from Mexico and Malawi. Annals of Applied Biology 138: 103-109.

Hedden P. (2003) The genes of the green revolution. TRENDS in Genetics 19: 5-9.

Heliyanto B, Hasnam, Hartati RS, Syukur C, Pranowo D, Susilowati SE, Purlani E, Sudarmo H, Mardjono R, Deciyanto S, Indrawanto C. (2008) Development of jatropha planting material and cluster pioneer concept (in Indonesian). In: Nurdjajati E, Sunaryuni E, Utami ADP, Prabowo H, Bahri S (eds) Acceleration of technology innovation of Jatropha curcas L to energy self-sufficiency. Surya Pena Gemilang, Malang-Indonesia, pp 1-9.

Heller J. (1996) Physic nut - Jatropha curcas L. Promoting the conservation and use of underutilized and neglected crops. 1. Institute of Plant Genetics and Crop Plant Research, Gatersleben/ International Plant Genetic Resources Institute, Rome, Italy, pp 1-66.

Henning RK. (2001) Fighting desertification by production and use of jatropha oil. In: Pasternak D, Schlissel A (eds) Combating desertification with plants. Springer, New York, pp 283-288. 
Henning RK, Sidibe Y, Sanankoua O. (1994) Intermediate report of the project production and use of plant oil as fuel. PN 93 2202.5-01.100. Projet Pourghère DNHE - GTZ, Bamako.

Holl MA, Gush MB, Hallowes J, Versfeld DB (eds). (2007) Jatropha curcas in South Africa: an assessment of its water use and bio-physical potential. Water Research Commission, Pretoria, South Africa, 1$154 \mathrm{pp}$.

Hunsberger C, Alonso-Fradejas A. (2016) The discursive flexibility of 'flex crops': comparing oil palm and jatropha. The Journal of Peasant Studies 43: 225-250.

ICECRD. (2006) The general guidelines on Jatropha curcas L. (In Indonesian). In: Hasnam, Mahmud Z (eds). Indonesian Centre for Estate Crop Research \& Development (ICECRD), Bogor.

Iiyama M, Newman D, Munster C, Nyabenge M, Sileshi G, Moraa V, Onchieku J, Mowo J, Jamnadass R. (2013) Productivity of Jatropha curcas under smallholder farm conditions in Kenya. Agroforestry Systems 87: 729-746.

Jackson JE. (1989) The manipulation of fruiting. In: Wright CJ (ed) Manipulation of fruiting. 47th Nottingham Easter School, Butterworths, London, pp 3-12.

Jackson NA, Wallace JS, Ong CK. (2000) Tree pruning as a means of controlling water use in an agroforestry system in Kenya. Forest Ecology and Management 126: 133-148.

Jama BA, Nair PKR. (1996) Decomposition-and nitrogen-mineralization patterns of Leucaena leucocephala and Cassia siamea mulch under tropical semiarid conditions in Kenya. Plant and Soil 179: 275-285.

JATROPT. (n.d.) JATROPT project portal. Retrived from www.jatropt.eu

Jenkinson DS, Fox RH, Rayner JH. (1985) Interactions between fertilizer nitrogen and soil nitrogen - the so called 'priming'effect. Journal of Soil Science 36: 425-444.

Jha A. (2008) Jatropha-fuelled plane touches down after successful test flight. The Guardian, December 30. Retrieved from https://www.theguardian.com/environment/2008/dec/30/biofuel-test-plane.

Ji S, Unger PW. (2001) Soil water accumulation under different precipitation, potential evaporation, and straw mulch conditions. Soil Science Society of America Journal 65: 442-448.

Jingura RM. (2012) Socio-economy, agro-ecological zones, agronomic practices and farming system of Jatropha curcas L. in Sub-Saharan Africa. In: Carels N, Sujatha M, Bahadur B (eds) Jatropha, challenges for a new energy crop, Volume 1: farming, economics and biofuel. Springer New York, pp 53-69.

Jingura RM, Kamusoko R. (2016) Evaluation of life-cycle assessment of Jatropha biodiesel. Energy Sources, Part B: Economics, Planning, and Policy 11: 396-403.

Johnson TS, Eswaran N, Sujatha M. (2011) Molecular approaches to improvement of Jatropha curcas Linn. as a sustainable energy crop. Plant Cell Reports 30: 1573-1591.

Jones N, Miller JH. (1993) Jatropha curcas: a multipurpose species for problematic sites. Land Resources Series No 1: 1-12. 
Jongschaap REE, Corré WJ, Bindraban PS, Brandenburg WA. (2007) Claims and facts on Jatropha curcas L.: global Jatropha curcas evaluation, breeding and propagation programme. Plant Research International, B.V, Wageningen, The Netherlands.

Jonsson K, Ong C, Odongo J. (1999) Influence of scattered nere and karite trees on microclimate, soil fertility and millet yield in Burkina Faso. Experimental Agriculture 35: 39-53.

Jose S, Gillespie AR, Seifert JR, Biehle DJ. (2000) Defining competition vectors in a temperate alley cropping system in the midwestern USA: 2. Competition for water. Agroforestry Systems 48: 41-59.

Joshi M, Jha A, Mishra A, Jha B. (2013) Developing transgenic jatropha using the SbNHX1 gene from an extreme halophyte for cultivation in saline wasteland. PLoS ONE 8: e71136.

Jull C, Redondo PC, Mosoti V, Vapnek J. (2007) Recent trends in the law and policy of bioenergy production, promotion and use. FAO legal papers no 68. FAO, Rome, Italy, pp 1-60.

Jupesta J, Harayama Y, Parayil G. (2011) Sustainable business model for biofuel industries in Indonesia. Sustainability Accounting, Management and Policy Journal 2: 231-247.

Kalam M, Ahamed J, Masjuki H. (2012) Land availability of jatropha production in Malaysia. Renewable and Sustainable Energy Reviews 16: 3999-4007.

Kang BT. (1993) Alley cropping: past achievements and future directions. Agroforestry Systems 23: 141155.

Kang BT, Reynolds L, Atta Krah AN. (1990) Alley farming. Advances in Agronomy 43: 315-359.

Kang BT, Sipkens L, Wilson GF, Nangju D. (1981) Leucaena (Leucaena leucocephala (Lam) de Wit) prunings as nitrogen source for maize (Zea mays L.). Fertilizer Research 2: 279-287.

Kang BT, Wilson GF. (1987) The development of alley cropping as a promising agroforestry technology. In: Steppler HA, Nair PKR (eds) Agroforestry: a decade of development. International Council for Research in Agroforestry, Nairobi, Kenya, pp 227-243.

Kant P, Wu S. (2011) The extraordinary collapse of Jatropha as a global biofuel. Environmental Science \& Technology 45: 7114-7115.

Karama S. (2013) The miracle that never was: an exploratory study on the propagation of jatropha in Kenya and its effect on smallholders (MSc Thesis). Department of Earth Sciences. Uppsala University, Uppsalla, Sweden, pp 1-47.

Kaur K, Dhillon GPS, Gill RIS. (2011) Floral biology and breeding system of Jatropha curcas in northwestern India. Journal of Tropical Forest Science 23: 4-9.

Kaushik N, Kumar K, Kumar S. (2007a) Potential of Jatropha curcas for biofuels. Journal of Biobased Materials and Bioenergy 1: 301-314.

Kaushik N, Kumar K, Kumar S, Kaushik N, Roy S. (2007b) Genetic variability and divergence studies in seed traits and oil content of jatropha (Jatropha curcas L.) accessions. Biomass and Bioenergy 31: 497-502.

Keating BA, Carberry PS. (1993) Resource capture and use in intercropping: solar radiation. Field Crops Research 34: 273-301. 
Khan ZU, McNeil DL, Samad A. (1998) Root pruning reduces the vegetative and reproductive growth of apple trees growing under an ultra high density planting system. Scientia Horticulturae 77: 165-176.

Khasanah N, Perdana A, Rahmanullah A, Manurung G, Roshetko J, Van Noordwijk M. (2015) Intercropping teak (Tectona grandis) and maize (Zea mays): bioeconomic trade-off analysis of agroforestry management practices in Gunungkidul, West Java. Agroforestry Systems: 1-15.

Kimetu JM, Mugendi DN, Palm CA, Mutuo PK, Gachengo CN, Bationo A, Nandwa S, Kungu JB. (2004) Nitrogen fertilizer equivalencies of organics of differing quality and optimum combination with inorganic nitrogen source in Central Kenya. Nutrient Cycling in Agroecosystems 68: 127-135.

Koh MY, Ghazi TIM. (2011) A review of biodiesel production from Jatropha curcas L. oil. Renewable and Sustainable Energy Reviews 15: 2240-2251.

Kottek M, Grieser J, Beck C, Rudolf B, Rubel F. (2006) World map of the Köppen-Geiger climate classification updated. Meteorologische Zeitschrift 15: 259-263.

Koizumi T. (2013) The Japanese biofuel program - developments and perspectives. Journal of Cleaner Production 40: 57-61.

Kozlowski TT, Kramer PJ, Pallardy SG. (1991) The physiological ecology of woody plants. Academic Press, San Diego, New York, Boston, pp 1-657.

Kozlowski TT, Pallardy SG. (1997) Physiology of woody trees. 2nd ed. Academic Press, San Diego, CA, pp $1-411$.

Krijtenburg F, Evers S. (2014) Putting a spin on jatropha: how conservationist rhetoric drove Bedford Biofuels out of Tana Delta-Kenya. Sustainability 6: 2736.

Krishnamurthy L, Zaman-Allah M, Marimuthu S, Wani SP, Kesava Rao AVR. (2012) Root growth in Jatropha and its implications for drought adaptation. Biomass and Bioenergy 39: 247-252.

Kumar A, Sharma S. (2008) An evaluation of multipurpose oil seed crop for industrial uses (Jatropha curcas L.) : a review. Industrial Crops and Products 28 (1): 1-10.

Kumar A, Sharma S. (2011) Potential non-edible oil resources as biodiesel feedstock: an Indian perspective. Renewable and Sustainable Energy Reviews 15: 1791-1800.

Kumar MS, Ramesh A, Nagalingam B. (2003) An experimental comparison of methods to use methanol and Jatropha oil in a compression ignition engine. Biomass and Bioenergy 25: 309-318.

Kumar RV, Tripathi YK, Izhaki I, Yadav VP, Ahlawat SP. (2008) Intraspecific variation and interrelationships between morphology, nutritional content and enzymatic activity of Jatropha curcas L. Current Science 95: 239-243.

Kumar S, Chaube A, Jain SK. (2012) Critical review of jatropha biodiesel promotion policies in India. Energy Policy 41: 775-781.

Kuntashula E, Van der Horst D, Vermeylen S. (2014) A pro-poor biofuel? Household wealth and farmer participation in Jatropha curcas seed production and exchange in eastern Zambia. Biomass and Bioenergy 63: 187-197. 
Kuyah S, Dietz J, Muthuri C, Jamnadass R, Mwangi P, Coe R, Neufeldt H. (2012) Allometric equations for estimating biomass in agricultural landscapes: II. Belowground biomass. Agriculture, Ecosystems \& Environment 158: 225-234.

Kwabiah AB, Stoskopf NC, Palm CA, Voroney RP, Rao MR, Gacheru E. (2003) Phosphorus availability and maize response to organic and inorganic fertilizer inputs in a short term study in western Kenya. Agriculture, Ecosystems \& Environment 95: 49-59.

Lacointe A. (2000) Carbon allocation among tree organs: a review of basic processes and representation in functional-structural tree models. Annals of Forest Science 57: 521-533.

Lal R. (1974) Soil temperature, soil moisture and maize yield from mulched and unmulched tropical soils. Plant and Soil 40: 129-143.

Larrauri JMA. (2011) Jatropha curcas L. development explained by nutrient status, MSc thesis. Wageningen University, Wageningen, The Netherlands.

Laviola BG, Dias LAS. (2008) Teor e acúmulo de nutrientes em folhas e frutos de pinhão-manso (In Portuguese). Revista Brasileira de Ciência do Solo 32: 1969-1975.

Lawson TL, Kang BT. (1990) Yield of maize and cowpea in an alley cropping system in relation to available light. Agricultural and Forest Meteorology 52: 347-357.

Legowo IEH, Kussuryani Y, Reksowardojo IK. (2008) Biofuel development in Indonesia. USDA Global Conference on Agricultural Biofuels: Research and Economic. Minneapolis, Minnesota, August 2022, 2007.

Lestari D. (2012) Non-food applications of Jatropha proteins, PhD thesis. Wageningen University, Wageningen, The Netherlands, pp 1-138.

Li C, Luo L, Fu Q, Niu L, Xu Z-F. (2014a) Isolation and functional characterization of JcFT, a FLOWERING LOCUS T (FT) homologous gene from the biofuel plant Jatropha curcas. BMC Plant Biology 14: 125

Li C, Ng A, Xie L, Mao H, Qiu C, Srinivasan R, Yin Z, Hong Y. (2015) Engineering low phorbol ester Jatropha curcas seed by intercepting casbene biosynthesis. Plant Cell Reports: 1-12.

Li J, Bluemling B, Mol A, Herzfeld T. (2014b) Stagnating jatropha biofuel development in southwest China: an institutional approach. Sustainability 6: 3192-3212.

Li X, Li ZL, He XY, Wang F, Jiang JC. (2008) Study on producing biodiesel fuel from Jatropha curcas oil sources catalized by whole cell biocatalyst. Modern Chemical Industry 28: 57-59.

Lima MGB. (2012) An Institutional analysis of biofuel policies and their social implications: lessons from Brazil, India, and Indonesia. Occasional paper 9: social dimensions of green economy and sustainable development. United Nations Research Institute for Social Development (UNRISD), Geneva, Switzerland, pp 1-22.

Linder S. (1985) Potential and actual production in Australian forest stands. In: Landsberg JJ, Parsons W (eds) Research for forest management. CSIRO, Melbourne, Australia, pp 11-35.

Littell RC, Stroup WW, Milliken GA, Wolfinger RD, Schabenberger O. (2006) SAS for mixed models. SAS institute. 
Liu X, Ye M, Fang YM, Ye X. (2010) Reconsideration upon bio-diesel industry of Jatropha curcas: a case study of Panzhihua. Forestry Economics 7: 86-89.

Liu X, Ye M, Pu B, Tang Z. (2012) Risk management for Jatropha curcas based biodiesel industry of Panzhihua prefecture in southwest China. Renewable and Sustainable Energy Reviews 16: 17211734.

Lizaso JI, Melendez LM, Ramirez R. (2001) Early flooding of two cultivars of tropical maize. I. Shoot and root growth. Journal of Plant Nutrition 24: 979-995.

Lizaso JI, Ritchie JT. (1997) Maize shoot and root response to root zone saturation during vegetative growth. Agronomy Journal 89: 125-134.

Loague K, Green RE. (1991) Statistical and graphical methods for evaluating solute transport models: overview and application. Journal of Contaminant Hydrology 7: 51-73.

Löffler H, Afiff SA, Burgers P, Govers C, Heeres HJ, Karyanto O, Manurung R, Vel JAC, Visscher S, Zwaagstra T. (2014) Agriculture beyond food: experiences from Indonesia. NWO/WOTRO, The Hague, The Netherlands, pp 1-121.

Lott JE, Ong CK, Black CR. (2009) Understorey microclimate and crop performance in a Grevillea robustabased agroforestry system in semi-arid Kenya. Agricultural and Forest Meteorology 149: 1140-1151.

Luo C, Li K, Chen Y, Sun Y, Yang W. (2007) Pollen viability, stigma receptivity and reproductive features of Jatropha curcas L.(Euphorbiaceae). Acta Botanica Boreali-Occidentalia Sinica 27: 1994-2001.

Lupton FGH. (1987) History of wheat breeding. In: Lupton FGH (ed). Wheat breeding: its scientific basis. Springer Netherlands, Dordrecht, pp 51-70.

MacFarlane D, Kuyah S, Mulia R, Dietz J, Muthuri C, Noordwijk M. (2014) Evaluating a non-destructive method for calibrating tree biomass equations derived from tree branching architecture. Trees 28: 807-817.

Machado AR, Pereira OL. (2012) Major diseases of the biofuel plant, physic nut (Jatropha curcas). In: Zhen F (ed) Biodiesel - feedstocks, production and applications. INTECH Open Access Publisher.

Maes WH, Achten WMJ, Reubens B, Raes D, Samson R, Muys B. (2009) Plant-water relationships and growth strategies of Jatropha curcas L. seedlings under different levels of drought stress. Journal of Arid Environments 73: 877-884.

Mafongoya PL, Giller KE, Palm CA. (1997) Decomposition and nitrogen release patterns of tree prunings and litter. Agroforestry Systems 38: 77-97.

Mafongoya PL, Nair PKR. (1997) Multipurpose tree prunings as a source of nitrogen to maize under semiarid conditions in Zimbabwe 1. Nitrogen-recovery rates in relation to pruning quality and method of application. Agroforestry Systems 35: 31-46.

Maftuchah, Reswari HA, Ishartati E, Zainudin A, Sudarmo H. (2015) Heritability and correlation of vegetative and generative character on genotypes of jatropha (Jatropha curcas Linn.). Energy Procedia 65: 186-193.

Magcale-Macandog DB, Abucay ER. (2007) Predicting the long-term productivity, economic feasibility and sustainability of smallholder hedgerow agroforestry systems using the WaNuLCAS model. In: 
Harrison S, Bosch A, Herbohn J (eds) Improving the triple bottom line returns from small-scale forestry Proceedings of an International Conference, Philippine, June 19-21, 20017. The University of Queensland, Qld, Australia, pp 229-234.

Maghuly F, Jankowicz-Cieslak J, Pabinger S, Till BJ, Laimer M. (2015) Geographic origin is not supported by the genetic variability found in a large living collection of Jatropha curcas with accessions from three continents. Biotechnology Journal 10: 536-551.

Mäkelä A. (1986) Implications of the pipe model theory on dry matter partitioning and height growth in trees. Journal of Theoretical Biology 123: 103-120.

Mäkelä A. (2002) Derivation of stem taper from the pipe theory in a carbon balance framework. Tree Physiology 22: 891-905.

Mäkelä A, Albrektson A. (1992) An analysis of the relationship between foliage biomass and crown surface area in Pinus sylvestris in Sweden. Scandinavian Journal of Forest Research 7: 297-307.

Mäkelä A, Valentine HT. (2006) Crown ratio influences allometric scaling in trees. Ecology 87: 2967-2972.

Makungwa S, Chittock A, Skole D, Kanyama-Phiri G, Woodhouse I. (2013) Allometry for biomass estimation in jatropha trees planted as boundary hedge in farmers' fields. Forests 4: 218-233.

Makwana V, Robin P. (2013) Interaction between GA and Ethrel in inducing female flowers in Jatropha curcas. International Journal of Biotechnology and Bioengineering Research 4: 465-472.

Martin NA, Chappelka AH, Loewenstein EF, Keever GJ, Somers G. (2012) Predictive open-grown crown width equations for three oak species planted in a southern urban locale. Arboriculture and Urban Forestry 38: 58 .

Martínez-Herrera J, Siddhuraju P, Francis G, Dávila-Ortíz G, Becker K. (2006) Chemical composition, toxic/antimetabolic constituents, and effects of different treatments on their levels, in four provenances of Jatropha curcas L. from Mexico. Food Chemistry 96: 80-89.

Matthews RB, Stephen W (eds). (2002) Crop-soil models: application in developing countries. CAB International, Wallingford, UK, pp 1-304.

Maurya R, Gupta A, Singh SK, Rai KM, Chandrawati, Katiyar R, Sawant SV, Yadav HK. (2015) Genomicderived microsatellite markers for diversity analysis in Jatropha curcas. Trees 29: 849-858.

McGrath M. (2014) Desert 'carbon farming' to curb $\mathrm{CO}_{2}$. BBC News, August 1. Retrieved from: http://www.bbc.com/news/science-environment-23518879.

Mead R, Willey RW. (1980) The concept of a 'Land Equivalent Ratio' and advantages in yields from intercropping. Experimental Agriculture 16: 217-228.

Meyer WS, Barrs HD, Mosier AR, Schaefer NL. (1987) Response of maize to three short-term periods of waterlogging at high and low nitrogen levels on undisturbed and repacked soil. Irrigation Science 8: 257-272.

Min EZ, Du ZX. (2010) Perspective of biodiesel industry in China. Engineering Science 12: 11-15.

Minengu JD, Mobambo P, Mergeai G. (2015) Analysis of the technical/economic performance of four cropping systems involving Jatropha curcas L. in the Kinshasa Region (Democratic Republic of the Congo). Tropicultura 33: 1-10. 
Mode CJ, Robinson HF. (1959) Pleiotropism and the genetic variance and covariance. Biometrics 15: 518537.

Mohapatra S, Panda PK. (2011) Effects of fertilizer application on growth and yield of Jatropha curcas L. in an aeric tropaquept of eastern India. Notulae Scientia Biologicae 3: 95-100.

Mokany K, Raison RJ, Prokushkin AS. (2006) Critical analysis of root:shoot ratios in terrestrial biomes. Global Change Biology 12: 84-96.

Monteith JL. (1977) Climate and the efficiency of crop production in Britain. Philosophical Transactions of the Royal Society of London 281: 277-294.

Monteith JL. (1981) Does light limit crop production? In: Johnson JB (ed) Physiological processes limiting plant productivity. Butterworths, London, pp 23-39.

Monteith JL, Ong CK, Corlett JE. (1991) Microclimatic interactions in agroforestry systems. Forest Ecology and Management 45: 31-44.

Monteith JL, Scott RK, Unsworth MH (eds). (1994) Resource capture by crops, Proceedings of the 52nd University of Nottingham Easter Schools in Agricultural Science. Nottingham University Press, Nottingham, 469 pp.

Moschini GC, Cui JB, Lapan H. (2012) Economics of biofuels: an overview of policies, impacts and prospects. Bio-based and Applied Economics 1: 269-296.

Moser SB, Feil B, Jampatong S, Stamp P. (2006) Effects of pre-anthesis drought, nitrogen fertilizer rate, and variety on grain yield, yield components, and harvest index of tropical maize. Agricultural Water Management 81: 41-58.

Mshandete AM. (2011) Biofuels in Tanzania: status, opportunities and challenges. Journal of Applied Biosciences 40: 2677-2705.

Mugendi DN, Nair PKR. (1996) Predicting the decomposition patterns of tree biomass in tropical highland microregions of Kenya. Agroforestry Systems 35: 187-201.

Mujumdar AM, Upadhye AS, Misar AV. (2000) Studies on antidiarrhoeal activity of Jatropha curcas root extract in albino mice. Journal of Ethnopharmacology 70: 183-187.

Mukhtar S, Kanwar RS, Baker JL. (1990) Corn grown as affected by excess soil water. American Society of Agricultural Engineers 33: 437-442.

Mukuralinda A, Tenywa JS, Verchot L, Obua J, Nabahungu NL, Chianu JN. (2010) Phosphorus uptake and maize response to organic and inorganic fertilizer inputs in Rubona, Southern Province of Rwanda. Agroforestry Systems 80: 211-221.

Mulia R, Dupraz C, Van Noordwijk M. (2010) Reconciling root plasticity and architectural ground rules in tree root growth models with voxel automata. Plant and Soil 337: 77-92.

Muok B, Källbäck L. (2008) Feasibility study of Jatropha curcas as a biofuels feedstock in Kenya. African Centre for Technology Studies. Retrieved from http://kerea.org/media/2012/12/Feasibility-Study-of-Jatropha-Curcas-as-a-Biofuel-Feedstock-inKenya.pdf, London/Berlin, pp 1-67. 
Mupangwa W, Twomlow S, Walker S. (2012) Reduced tillage, mulching and rotational effects on maize (Zea mays L.), cowpea (Vigna unguiculata (Walp) L.) and sorghum (Sorghum bicolor L. (Moench)) yields under semi-arid conditions. Field Crops Research 132: 139-148.

Muthuri CW, Ong CK, Black CR, Ngumi VW, Mati BM. (2005) Tree and crop productivity in Grevillea, Alnus and Paulownia-based agroforestry systems in semi-arid Kenya. Forest Ecology and Management 212: 23-39.

Myers RJK, Palm CA, Cuevas E, Gunatilleke IN, Brossard M. (1994) The synchronisation of nutrient mineralisation and plant nutrient demand. In: Woomer PL, Swift MJ (eds) The biological management of tropical soil fertility. John Wiley and Sons, Chichester, UK, pp 81-116.

Myers RJK, Van Noordwijk M, Vityakon P. (1997) Synchrony of nutrient release and plant demand: plant litter quality, soil environment and farmer management options. In: Cadisch G, Giller KE (eds) Driven by nature: plant litter quality and decomposition. CAB International, Wallingford, UK, pp 215-229.

Nair PKR. (1993) An introduction to agroforestry. Kluwer Academic Publishers, Netherlands, pp 1-601.

Ndong R, Montrejaud-Vignoles M, Saint Girons O, Gabrielle B, Pirot R, Domergue M, Sablayrolles C. (2009) Life cycle assessment of biofuels from Jatropha curcas in West Africa: a field study. GCB Bioenergy 1: 197-210.

Negussie A, Achten WMJ, Verboven HAF, Hermy M, Muys B. (2014) Floral display and effects of natural and artificial pollination on fruiting and seed yield of the tropical biofuel crop Jatropha curcas L. GCB Bioenergy 6: 210-218.

Nicoll BC, Berthier S, Achim A, Gouskou K, Danjon F, Van Beek LPH. (2006) The architecture of Picea sitchensis structural root systems on horizontal and sloping terrain. Trees 20: 701-712.

Nielsen F, Raghavan K, De Jongh J, Huffman D. (2013) Jatropha for local development, after the hype. Hivos, The Hague, The Netherlands, pp 1-68.

Niklas KJ. (1993) The allometry of plant reproductive biomass and stem diameter. American Journal of Botany 80: 461-467.

Nogueira LAH. (2004) Perspectivas de un programa de biocombustibles en América Central (in Spanish). Naciones Unidas-Comisión Económica para America Latina y el Caribe (CEPAL).

Nziguheba G, Merckx R, Palm CA, Rao MR. (2000) Organic residues affect phosphorus availability and maize yields in a Nitisol of western Kenya. Biology and Fertility of Soils 32: 328-339.

Oikeh SO, Carsky RJ, Kling JG, Chude VO, Horst WJ. (2003) Differential N uptake by maize cultivars and soil nitrate dynamics under $\mathrm{N}$ fertilization in West Africa. Agriculture, Ecosystems \& Environment 100: 181-191.

Oldeman R. (1974) L'architecture de la forêt guyanaise (In French). Mémoires ORSTOM 73, Paris pp 1-204.

One KT, Muakrong N, Phetcharat C, Tanya P, Srinives P. (2014) Inheritance of dwarfiness and erect growth habit in progenies of Jatropha curcas $\times$ Jatropha integerrima. Journal of the American Society for Horticultural Science 139: 582-586. 
Ong CK. (1995) The "dark side" of intercropping: manipulation of soil resources. In: Sinoquet H, CRUZ p (eds) Proceeding of the international conference on ecophysiology of intercropping. INRA, Science Update, Guadeloupe, pp 45-46.

Ong CK. (1996) A framework for quantifying the various effects of tree-crop interactions. In: Ong CK, Peter $\mathrm{H}$ (eds) Tree-crop interactions - a physiological approach. CAB International, Wallingford, UK, pp $1-24$.

Ong CK, Black CR, Marshall FM, Corlett JE. (1996) Principles of resource capture and utilization of light and water. In: Ong CK, Huxley P (eds) Tree-crop interactions - a physiological approach. CAB International, Wallingford, UK, pp 73-158.

Ong CK, Black CR, Muthuri CW. (2006) Modifying forestry and agroforestry to increase water productivity in the semi-arid tropics. CAB Reviews Perspectives in Agriculture, Veterinary Science, Nutrition and Natural Resources 1: 1-19.

Ong CK, Black CR, Wallace JS, Khan AAH, Lott JE, Jackson NA, Howard SB, Smith DM. (2000) Productivity, microclimate and water use in Grevillea robusta-based agroforestry systems on hillslopes in semi-arid Kenya. Agriculture, Ecosystems \& Environment 80: 121-141.

Ong CK, Corlett JE, Singh RP, Black CR. (1991) Above and below ground interactions in agroforestry systems. Forest Ecology and Management 45: 45-57.

Openshaw K. (2000) A review of Jatropha curcas: an oil plant of unfulfilled promise. Biomass and Bioenergy 19: 1-15.

Orwa C, Mutua A, Kindt R, Jamnadass R, Simons A. (2009) Agroforestree database: a tree reference and selection guide. Version 4.0. ICRAF, Nairobi.

Osorio LRM, Salvador AFT, Jongschaap REE, Perez CAA, Sandoval JEB, Trindade LM, Visser RGF, Van Loo EN. (2014) High level of molecular and phenotypic biodiversity in Jatropha curcas from Central America compared to Africa, Asia and South America. BMC Plant Biology 14: 1-77.

Ou X, Zhang X, Chang S, Guo Q. (2009) Energy consumption and GHG emissions of six biofuel pathways by LCA in (the) People's Republic of China. Applied Energy 86: S197-S208.

Ovando-Medina I, Adriano-Anaya L, Vázquez-Ovando A, Ruiz-González S, Rincón-Rabanales M, Salvador-Figueroa M. (2013) Genetic diversity of Jatropha curcas in Southern Mexico. In: Bahadur B, Sujatha M, carels N (eds) Jatropha, challenges for a new energy crop, Volume 2: genetic improvement and biotechnology. Springer, New York, pp 219-250.

Ovando-Medina I, Sánchez-Gutiérrez A, Adriano-Anaya L, Espinosa-García F, Núñez-Farfán J, SalvadorFigueroa M. (2011) Genetic diversity in Jatropha curcas populations in the State of Chiapas, Mexico. Diversity 3: 641-659.

Palm CA. (1995) Contribution of agroforestry trees to nutrient requirements of intercropped plants. In: Sinclair FL (ed) Agroforestry: science, policy and practice. Springer Netherlands, Dordrecht, pp 105-124. 
Palm CA, Gachengo CN, Delve RJ, Cadisch G, Giller KE. (2001) Organic inputs for soil fertility management in tropical agroecosystems: application of an organic resource database. Agriculture, Ecosystems \& Environment 83: 27-42.

Palm CA, Myers RJK, Nandwa SM. (1997) Combined use of organic and inorganic nutrient sources for soil fertility maintenance and replenishment. In: Buresh RJ, Sanchez PA, Calhoun F (eds) Replenishing soil fertility in Africa. Soil Science Society of America and American Society of Agronomy, Madison, USA, pp 193-217.

Palmer JW. (1988) Annual dry matter production and partitioning over the first 5 years of a bed system of Crispin/M.27 apple trees at four spacings. Journal of Applied Ecology 25: 569-578.

Pan B-Z, Luo Y, Song L, Chen M-S, Li J-L, Xu Z-F. (2016) Thidiazuron increases fruit number in the biofuel plant Jatropha curcas by promoting pistil development. Industrial Crops and Products 81: 202-210.

Pan B-Z, Xu Z-F. (2011) Benzyladenine treatment significantly increases the seed yield of the biofuel plant Jatropha curcas. Journal of Plant Growth Regulation 30: 166-174.

Pandey RK, Maranville JW, Admou A. (2000) Deficit irrigation and nitrogen effects on maize in a Sahelian environment: I. Grain yield and yield components. Agricultural Water Management 46: 1-13.

Panghal S, Beniwal VS, Soni SS. (2013) Generation of superior germplasm of Jatropha curcas through ex vitro grafting. Agroforestry Systems 87: 1023-1029.

Patade VY, Khatri D, Kumar K, Grover A, Kumari M, Gupta SM, Kumar D, Nasim M. (2014) RNAi Mediated curcin precursor gene silencing in Jatropha (Jatropha curcas L.). Molecular Biology Reports 41: 4305-4312.

Patil V, Singh K. (1991) Oil gloom to oil boom - Jatropha curcas a promising agro-forestry crop. Shree Offset Press, Nashik, India.

Patolia JS, Ghosh A, Chikara J, Chaudhary DR, Parmar DR, Bhuva HM. (2007) Response of Jatropha curcas grown on wasteland to N and P fertilization. Expert seminar on Jatropha curcas L. agronomy and genetics. pp 26-28.

Pecina-Quintero V, Anaya-López JL, Colmenero AZ, García NM, Colín CAN, Bonilla JLS, Aguilar-Rangel MR, Langarica HRG, Bustamante DJM. (2011) Molecular characterisation of Jatropha curcas L. genetic resources from Chiapas, Mexico through AFLP markers. Biomass and Bioenergy 35: 18971905.

Peng J, Richards DE, Hartley NM, Murphy GP, Devos KM, Flintham JE, Beales J, Fish LJ, Worland AJ, Pelica F. (1999) 'Green revolution'genes encode mutant gibberellin response modulators. Nature 400: 256-261.

Peng Y, Niu J, Peng Z, Zhang F, Li C. (2010) Shoot growth potential drives N uptake in maize plants and correlates with root growth in the soil. Field Crops Research 115: 85-93.

Pierce SC, Koontz MB, Pezeshki SR, Kröger R. (2013) Response of Salix nigra (Marsh.) cuttings to horizontal asymmetry in soil saturation. Environmental and Experimental Botany 87: 137-147. 
Ping T, Guo Dong G, Jie A, Jian Xun L. (2012) Effect of branch bending angle on the sprouting and fruiting of Jatropha curcas plants (In Chinese). Journal of Southwest Forestry University 32: 98-101.

Pompelli MF, Antunes WC, Ferreira DTRG, Cavalcante PGS, Wanderley-Filho HCL, Endres L. (2012) Allometric models for non-destructive leaf area estimation of Jatropha curcas. Biomass and Bioenergy 36: 77-85.

Portner B, Ehrensperger A, Nezir Z, Breu T, Hurni H. (2014) Biofuels for a greener economy? Insights from jatropha production in Northeastern Ethiopia. Sustainability 6: 6188-6202.

Practical Action Consulting. (2009) Small-scale bioenergy initiatives: brief description and preliminary lessons on livelihood impacts from case studies in Asia, Latin America and Africa. Food and Agriculture Organisation of the United Nations (FAO) and Policy Innovation Systems for Clean Energy Security (PISCES) Rome, Italy, pp 1-142.

Pradhan S, Ruysenaar S. (2014) Burning desires: untangling and interpreting "pro-poor" biofuel policy processes in India and South Africa. Environment Planning A 46: 299-317.

Prueksakorn K, Gheewala SH. (2008) Full chain energy analysis of biodiesel from Jatropha curcas L. in Thailand. Environmental Science \& Technology 42: 3388-3393.

Prusinkiewicz P. (2004) Modeling plant growth and development. Current Opinion in Plant Biology 7: 7983.

Pulkkinen P, Pöykkö T, Tigerstedt PMA, Velling P. (1989) Harvest index in northern temperate cultivated conifers. Tree Physiology 5: 83-98.

Purwati DR, Hariyono B. (2008) Technology applications in radiation breeding in Jatropha curcas Balittas. In: Mugiono (ed) Proceeding symposium and exhibition application of isotopes and radiation technology. National nuclear energy agency (BATAN), Jakarta, August 5-6, 2008, pp 1-307.

Purwati RD, Sudarmo H, Djumali. (2015) Adaptability of potential genotypes of Jatropha curcas L. as bioenergy source in three locations. Energy Procedia 65: 317-323.

Putrasari Y, Praptijanto A, Santoso WB, Lim O. (2016) Resources, policy, and research activities of biofuel in Indonesia: a review. Energy Reports 2: 237-245.

Qu J, Mao H-Z, Chen W, Gao S-Q, Bai Y-N, Sun Y-W, Geng Y-F, Ye J. (2012) Development of markerfree transgenic Jatropha plants with increased levels of seed oleic acid. Biotechnology for Biofuels 5:10: $1-11$

Rafii MY, Arolu IW, Omar MHA, Latif MA. (2012) Genetic variation and heritability estimation in Jatropha curcas L. population for seed yield and vegetative traits. Journal of Medicinal Plants Research 6: 2178-2183.

Rajagopal D. (2008) Implications of India's biofuel policies for food, water and the poor. Water Policy 10: 95-106.

Rajaona Arisoa M, Brueck H, Asch F. (2011) Effect of pruning history on growth and dry mass partitioning of jatropha on a plantation site in Madagascar. Biomass and Bioenergy 35: 4892-4900. 
Rajcaniova M, Ciaian P, Drabik D. (2015) International policies on bioenergy and biofuels. In: Von Mark VC, Dierig DA (eds) Industrial crops: breeding for bioenergy and bioproducts. Springer, New York, pp 381-406.

Raju AS, Ezradanam V. (2002) Pollination ecology and fruiting behaviour in a monoecious species Jatropha curcas L. (Euphorbiaceae). Current Science Bangalore 83: 1395-1397.

Ramos LP, Wilhelm HM. (2005) Current status of biodiesel development in Brazil. Applied Biochemistry and Biotechnology 121-124: 807-819.

Ranganathan R. (1992) Production possibility frontiers and estimation of competition effects: the use of a priori information on biological processes in intercropping. Experimental Agriculture 28: 351-368.

Ranganathan R, Fafchamps M, Walker TS. (1991) Evaluating biological productivity in intercropping systems with production possibility curves. Agricultural Systems 36: 137-157.

Rao AVRK, Wani SP, Singh P, Srinivas K, Rao CS. (2012) Water requirement and use by Jatropha curcas in a semi-arid tropical location. Biomass and Bioenergy 39: 175-181.

Rao GR, Korwar GR, Shanker AK, Ramakrishna YS. (2008) Genetic associations, variability and diversity in seed characters, growth, reproductive phenology and yield in Jatropha curcas (L.) accessions. Trees 22: 697-709.

Rao GR, Prasad JVNS, Reddy PS, Kumar PS. (2013) Carbon sequestration potential of Jatropha curcas in semiarid regions of southern India. In: Kumar S, Tyagi SK (eds) Recent Advances in Bioenergy Research. SSS-NIRE, India, 275 - 286.

Rao MR, Nair PKR, Ong CK. (1997) Biophysical interactions in tropical agroforestry systems. Agroforestry Systems 38: 3-50.

Rao MR, Schroth G, Williams SE, Namirembe S, Schaller M. (2004) Managing below-ground interactions in agroecosystems. In: Van Noordwijk M, Cadisch G, Ong CK (eds) Below-ground interactions in tropical agroecosystems: concepts and models with multiple plant components. CABI Publishing, Wallingford, UK, pp 309-328.

Ravindranath NH, Sita Lakshmi C, Manuvie R, Balachandra P. (2011) Biofuel production and implications for land use, food production and environment in India. Energy Policy 39: 5737-5745.

Reganold JP, Glover JD, Andrews PK, Hinman HR. (2001) Sustainability of three apple production systems. Nature 410: 926-930.

Reinhardt G, Gärtner S, Rettenmaier N, Münch J, Von Falkenstein E. (2007) Screening life cycle assessment of Jatropha biodiesel. Institute for Energy and Environmental Research, Heidelberg, Germany, pp 162.

Retnowati I, Surahman M. (2013) Growth and production of physic nut (Jatropha curcas L.) genotypes on acid soil (In Indonesian). Agrohorti 1: 23-33.

Reubens B, Achten WMJ, Maes WH, Danjon F, Aerts R, Poesen J, Muys B. (2011) More than biofuel? Jatropha curcas root system symmetry and potential for soil erosion control. Journal of Arid Environments 75: 201-205. 
Riha SJ, McIntyre BD. (1999) Water management with hedgerow agroforestry systems. In: Buck LE, Lassoie JP, Fernandes ECM (eds) Agroforestry in sustainable agricultural systems. CRC Press, USA, pp 1-411.

Rivaie AA, Fauzi A, Allorerung D, Mahrnud Z, Effendi DS, Sumanto, Syahrial T. (2006) Physical characterisation of Jatropha curcas planting at Cikeusik, Banten (In Indonesian). In: Budiharto A, Evawati, Nahrowi (eds) Technology status of Jatropha curcas. Indonesian Centre for Estate Crops Research and Development, Bogor.

Robinson TL, Lakso AN. (1991) Bases of yield and production efficiency in apple orchard systems. Journal of the American Society for Horticultural Science 116: 188-194.

Romijn HA. (2011) Land clearing and greenhouse gas emissions from Jatropha biofuels on African Miombo Woodlands. Energy Policy 39: 5751-5762.

Rosado TB, Laviola BG, Faria DA, Pappas MR, Bhering LL, Quirino B, Grattapaglia D. (2010) Molecular markers reveal limited genetic diversity in a large germplasm collection of the biofuel crop Jatropha curcas L. in Brazil. Crop science 50: 2372-2382.

Rowe EC, Hairiah K, Giller KE, Van Noordwijk M, Cadisch G. (1999) Testing the safety-net role of hedgerow tree roots by $\mathrm{N}^{15}$ placement at different soil depths. In: Auclair D, Dupraz C (eds) Agroforestry for sustainable land-use fundamental research and modelling with emphasis on temperate and Mediterranean applications. Springer, Netherlands, pp 81-93.

Ruef A, Markard J. (2010) What happens after a hype? How changing expectations affected innovation activities in the case of stationary fuel cells. Technology Analysis \& Strategic Management 22: 317338.

Salas E, Ozier-Lafontaine H, Nygren P. (2004) A fractal root model applied for estimating the root biomass and architecture in two tropical legume tree species. Annals of Forest Science 61: 337-345.

Salvador-Figueroa M, Magaña-Ramos J, Vázquez-Ovando JA, Adriano-Anaya ML, Ovando-Medina I. (2015) Genetic diversity and structure of Jatropha curcas L. in its centre of origin. Plant Genetic Resources 13: 9-17.

Sanchez PA. (1995) Science in agroforestry. Agroforestry Systems 30: 5-55.

Sanou H, Angulo-Escalante MA, Martínez-Herrera J, Koné S, Nikiema A, Kalinganire A, Hansen JK, Kjær ED, Graudal L, Nielsen LR. (2015) Loss of genetic diversity of Jatropha curcas L. through domestication: implications for its genetic improvement. Crop Science 55: 749-759.

Santos Martin F, Navarro-Cerrillo RM, Mulia R, Van Noordwijk M. (2010) Allometric equations based on a fractal branching model for estimating aboveground biomass of four native tree species in the Philippines. Agroforestry Systems 78: 193-202.

Santoso BB, Aryana IGPM. (2011) Seedling performance and yield potential at at the first year of Jatropha curcas $\mathrm{L}$ genotype from the first mass selection (first improved population = IP-1). Agroteksos 21: 89-94.

Sarin R, Sharma M, Sinharay S, Malhotra RK. (2007) Jatropha-palm biodiesel blends: an optimum mix for Asia. Fuel 86: 1365-1371. 
Scheffer M, Vergnon R, Cornelissen JHC, Hantson S, Holmgren M, Van Nes EH, Xu C. (2014) Why trees and shrubs but rarely trubs? Trends in Ecology \& Evolution 29: 433-434.

Schroth, G., 1995. Tree root characteristics as criteria for species selection and systems design in agroforestry. In Sinclair, FL (Ed) Agroforestry: science, policy and practice. Springer Netherlands, pp. 125-143.

Scorza R. (2005) Theory and practice of genetically manipulating peach tree architecture. New York Fruit Quarterly 13: 27-31.

Scorza R, Bassi D, Dima A, Rizzo M. (1999) Developing new peach tree growth habits for higher density plantings. Presented at the 42nd Annual IDFTA Conference 20-24 February 1999 International Dwarf Fruit Tree Association, Hamilton, Ontario, Canada, pp 18-20.

Scorza R, Lightner CW, Gilreath LE, Wolf SJ. (1984) Reduced-stature peach tree growth types: pruning and light penetration. Acta Horticulturae 146: 159-164.

Shabanimofrad M, Rafii MY, Wahab PE, Biabani AR, Latif MA. (2013) Phenotypic, genotypic and genetic divergence found in 48 newly collected Malaysian accessions of Jatropha curcas L. Industrial Crops and Products 42: 543-551.

Sharma DK, Rana DS. (2014) Productivity, response to nitrogen and nutrient cycling of sole jatropha (Jatropha curcas) and intercropping system with baby corn (Zea mays) in India. Indian Journal of Agricultural Sciences 84: 1502-1507.

Shen J-1, Jia X-n, Ni H-q, Sun P-g, Niu S-h, Chen X-y. (2010) AFLP analysis of genetic diversity of Jatropha curcas grown in Hainan, China. Trees 24: 455-462.

Silitonga AS, Atabani AE, Mahlia TMI, Masjuki HH, Badruddin IA, Mekhilef S. (2011) A review on prospect of Jatropha curcas for biodiesel in Indonesia. Renewable and Sustainable Energy Reviews 15: 3733-3756.

Simandjuntak D. (2014) Riding the hype: the role of state-owned enterprise elite actors in the promotion of jatropha in Indonesia. Sustainability 6: 3780-3801.

Sinclair TR. (1998) Historical changes in harvest index and crop nitrogen accumulation. Crop Science 38: 638-643.

Singh B, Singh K, Rejeshwar Rao G, Chikara J, Kumar D, Mishra DK, Saikia SP, Pathre UV, Raghuvanshi N, Rahi TS, Tuli R. (2013) Agro-technology of Jatropha curcas for diverse environmental conditions in India. Biomass and Bioenergy 48: 191-202.

Singh D. (1976) Castor - Ricinus communis (Euphorbiaceae). In: Simmonds NW (ed) Evolution of crop plants. Longman, London, UK, pp 84-86.

Singh RA, Kumar M, Haider E. (2007) Synergistic cropping of summer groundnut with Jatropha curcas - a new two-tier cropping system for Uttar Pradesh. Journal of Semi-Arid Tropics Agricultural Research 5: $1-2$.

Singh RP, Saharan N, Ong CK. (1989) Above and below ground interactions in alley-cropping in semi-arid India. Agroforestry Systems 9: 259-274. 
Skutsch M, De los Rios M, Solis S, Riegelhaupt E, Hinojosa D, Gerfert S, Gao Y, Masera O. (2011) Jatropha in Mexico: environmental and social impacts of an incipient biofuel program. Ecology and Society 16: 1-17.

Slingerland M, Schut M. (2014) Jatropha developments in Mozambique: analysis of structural conditions influencing niche-regime interactions. Sustainability 6: 7541-7563.

Slingerland M, Tjeuw J, Suharsono S, Purwati DR. (2014) Is Jatropha a miracle crop producing high yields on marginal lands? In: Vel JAC, Simandjutak D (eds) JARAK, the short history of Jatropha projects in Indonesia. IIAS. E-publication available at http://jarak.iias.asia, Leiden.

Smith DM. (2001) Estimation of tree root lengths using fractal branching rules: a comparison with soil coring for Grevillea robusta. Plant and Soil 229: 295-304.

Soethe N, Lehmann J, Engels C. (2007) Root tapering between branching points should be included in fractal root system analysis. Ecological Modelling 207: 363-366.

Sorda G, Banse M, Kemfert C. (2010) An overview of biofuel policies across the world. Energy Policy 38: 6977-6988.

Spinelli VM, Dias LAS, Rocha RB, Resende MDV. (2015) Estimates of genetic parameters with selection within and between half-sib families of Jatropha curcas L. Industrial Crops and Products 69: 355361.

Srijono A, Sunarminto B. (2005) Landform controls in soil configuration at Karangmojo-Ponjong, Gunungkidul, Yogyakarta (In Indonesian). Proceedings joint convention Surabaya 2005 - HAGI IAGI -PERHAPI The 30th HAGI, The 34th IAGI, and The 14th PERHAPI Annual Conference and Exhibition: 692-698.

Srivastava P, Behera SK, Gupta J, Jamil S, Singh N, Sharma YK. (2011) Growth performance, variability in yield traits and oil content of selected accessions of Jatropha curcas L. growing in a large scale plantation site. Biomass and Bioenergy 35: 3936-3942.

Steduto P, Hsiao TC, Raes D, Fereres E. (2012) Crop yield response to water. FAO Irrigation and drainage paper no 66, Food and Agriculture Organization of the United Nations, Rome.

Steiner JL. (1989) Tillage and surface residue effects on evaporation from soils. Soil Science Society of America Journal 53: 911-916.

Steinert M, Leifer L. (2010) Scrutinizing Gartner's hype cycle approach. Portland International Center for Management of Engineering and Technology, Proceedings - Technology Management for Global Economic Growth, July 18-22. IEEE, Phuket, Thailand, pp 254-266.

Su Y, Zhang P, Su Y. (2015) An overview of biofuels policies and industrialization in the major biofuel producing countries. Renewable and Sustainable Energy Reviews 50: 991-1003.

Sujatha M, Prabakaran AJ. (2003) New ornamental jatropha hybrids through interspecific hybridization. Genetic Resources and Crop Evolution 50: 75-82.

Sun F, Liu P, Ye J, Lo LC, Cao S, Li L, Yue GH, Wang CM. (2012) An approach for jatropha improvement using pleiotropic QTLs regulating plant growth and seed yield. Biotechnology for Biofuels 5: 1-10. 
Sun QB, Li LF, Li Y, Wu GJ, Ge XJ. (2008) SSR and AFLP markers reveal low genetic diversity in the biofuel plant in China. Crop Science 48: 1865-1871.

Sunil N, Kumar V, Sujatha M, Rajeswara Rao G, Varaprasad KS. (2013) Minimal descriptors for characterization and evaluation of Jatropha curcas L. germplasm for utilization in crop improvement. Biomass and Bioenergy 48: 239-249.

Suriharn B, Sanitchon J, Songsri P, Kesmala T. (2011) Effects of pruning levels and fertilizer rates on yield of physic nut (Jatropha curcas L.). Asian Journal of Plant Sciences 10: 52-59.

Swift MJ, Heal OW, Anderson JM. (1979) Decomposition in terrestrial ecosystems. University of California Press, Berkeley and Los Angeles, pp 1-372.

Tahir M, Zelmer CD, McVetty PBE. (2012) Oilseed brassicas. In: Kole C, Joshi CP, Shonnard DR (eds) Handbook of bioenergy crop plants. CRC Press, Boca Raton, FL, pp 453-481.

Tamalampudi S, Talukder MR, Hama S, Numata T, Kondo A, Fukuda H. (2008) Enzymatic production of biodiesel from Jatropha oil: a comparative study of immobilized-whole cell and commercial lipases as a biocatalyst. Biochemical Engineering Journal 39: 185-189.

Taub DR, Goldberg D. (1996) Root system topology of plants from habitats differing in soil resource availability. Functional Ecology 10: 258-264.

Terren M, Mignon J, De Clerck C, Jijakli H, Savery S, Jacquet de Haveskercke P, Winandy S, Mergeai G. (2012) Principal disease and insect pests of Jatropha curcas L. in the lower valley of the Senegal river. Tropicultura 30: 222-229.

Tikkoo A, Yadav SS, Kaushik N. (2013) Effect of irrigation, nitrogen and potassium on seed yield and oil content of Jatropha curcas in coarse textured soils of northwest India. Soil and Tillage Research 134: $142-146$.

Tiwari AK, Kumar A, Raheman H. (2007) Biodiesel production from jatropha oil (Jatropha curcas) with high free fatty acids: an optimized process. Biomass and Bioenergy 31: 569-575.

Tolk JA, Howell TA, Evett SR. (1999) Effect of mulch, irrigation, and soil type on water use and yield of maize. Soil and Tillage Research 50: 137-147.

Trabucco A, Achten WMJ, Bowe C, Aerts RAF, Orshoven JV, Norgrove L, Muys B. (2010) Global mapping of Jatropha curcas yield based on response of fitness to present and future climate. GCB Bioenergy 2: 139-151.

Trianasari ME. (2009) Patterns of agricultural drought in the West Nusa Tenggara from 2007 to 2008 (In Indonesian). Thesis submitted to University of Indonesia, Faculty of Mathematics and Natural Sciences, Geography Program, pp 1-119.

Trienekens JH, Hagen JM, Beulens AJM, Omta S. (2003) Innovation through (international) food supply chain development: a research agenda. International Food and Agribusiness Management Review 1: $1-12$.

Tripathi A, Mishra DK, Shukla J. (2013) Genetic variability, heritability and genetic advance of growth and yield components of Jatropha (Jatropha curcas Linn.) genotypes. Trees 27: 1049-1060. 
Tripathi A, Mishra DK, Shukla JK. (2015) Genetic diversity and trait association between growth, yield and seed component of Jatropha curcas (L.) source collection from Indian sub-continent. Journal of Plant Breeding and Crop Science 7: 143-156.

Tsuchimoto S, Cartagena J, Khemkladngoen N, Singkaravanit S, Kohinata T, Wada N, Sakai H, Morishita Y, Suzuki H, Shibata D. (2012) Development of transgenic plants in jatropha with drought tolerance. Plant Biotechnology 29: 137-143.

Unger PW. (1978) Straw-mulch rate effect on soil water storage and sorghum yield. Soil Science Society of America Journal 42: 486-491.

Unger PW. (1986) Wheat residue management effects on soil water storage and corn production. Soil Science Society of America Journal 50: 764-770.

Valdés-Rodríguez OA, Sánchez-Sánchez O, Pérez-Vázquez A, Caplan JS, Danjon F. (2013) Jatropha curcas L. root structure and growth in diverse soils. The Scientific World Journal 2013: 1-9.

Valdés Rodríguez OA, Vázquez A, Muñoz Gamboa C. (2014) Drivers and consequences of the first Jatropha curcas plantations in Mexico. Sustainability 6: 3732-3746.

Van der Vossen and Herbert AM. (1985) Coffee selection and breeding. In: Clifford MN, Willson KC (eds) Coffee. Springer New York, pp 48-96.

Van Eijck J, Romijn H. (2008) Prospects for Jatropha biofuels in Tanzania: an analysis with strategic niche management. Energy Policy 36: 311-325.

Van Eijck J, Romijn H, Balkema A, Faaij A. (2014a) Global experience with jatropha cultivation for bioenergy: an assessment of socio-economic and environmental aspects. Renewable and Sustainable Energy Reviews 32: 869-889.

Van Eijck J, Romijn H, Smeets E, Bailis R, Rooijakkers M, Hooijkaas N, Verweij P, Faaij A. (2014b) Comparative analysis of key socio-economic and environmental impacts of smallholder and plantation based jatropha biofuel production systems in Tanzania. Biomass and Bioenergy 61: 25-45.

Van Eijck JAJ, Smeets EMW, Jongschaap REE, Romijn H, Balkema A. (2010) Jatropha assessment: agronomy, socio-economic issues and ecology, facts from literature. Copernicus Institute, Utrecht University, Eindhoven University of Technology and Wageningen PRI, Commissioned by Agentschap NL, Utrecht.

Van Keulen H. (1982) Graphical analysis of annual crop response to fertiliser application. Agricultural Systems 9: 113-126.

Van Noordwijk M, Agus F, Dewi S, Ekadinata A, Tata HL, Suyanto S, Galudra G, Pradhan UP. (2010) Opportunities for reducing emissions from all land uses in Indonesia: policy analysis and case studies. ASB Partnership for Tropical Forest Margins, Nairobi, Kenya.

Van Noordwijk M, Cadish G. (2002) Access and excess problems in plant nutrition. Progress in plant nutrition: plenary lectures of the XIV international plant nutrition colloquium. Springer Netherlands, pp 25-40.

Van Noordwijk M, Hairiah K, Lusiana B, Cadish G. (1998) Tree-soil-crop interactions in sequential and simultaneous agroforestry systems. In: Bergstrom L, Kirchmann $\mathrm{H}$ (eds) Carbon and nutrient 
dynamics in natural and agricultural tropical ecosystems. CAB International, Wallingford, UK, pp 173-190.

Van Noordwijk M, Khasanah N, Dewi S. (2016) Can intensification reduce emission intensity of biofuel through optimized fertilizer use? Theory and the case of oil palm in Indonesia. GCB Bioenergy (in press).

Van Noordwijk M, Lawson G, Soumaré A, Groot JJR, Hairiah K. (1996) Root distribution of trees and crops: competition and/or complementarity. In: Ong CK, Huxley P (eds) Tree-crop interactions - a physiological approach. CAB International, Wallingford, UK, pp 319-364.

Van Noordwijk M, Lusiana B. (1999) WaNuLCAS, a model of water, nutrient and light capture in agroforestry systems. Agroforestry Systems 43: 217-242.

Van Noordwijk M, Lusiana B, Khasanah N, Mulia R. (2011) WaNuLCAS 4.0, background on a model of water, nutrient and light capture in agroforestry system. World Agroforestry Center-ICRAF, SEA Regional Office, Bogor, Indonesia, pp 1-224.

Van Noordwijk M, Mulia R. (2002) Functional branch analysis as tool for fractal scaling above- and belowground trees for their additive and non-additive properties. Ecological Modelling 149: 41-51.

Van Noordwijk M, Purnomosidhi P. (1995) Root architecture in relation to tree-soil-crop interactions and shoot pruning in agroforestry. In: Sinclair FL (Ed) Agroforestry: science, policy and practice. Springer Netherlands, pp 161-173.

Van Noordwijk M, Spek L, Willigen P. (1994) Proximal root diameter as predictor of total root size for fractal branching models. I. Theory. Plant and Soil 164: 107-117.

Van Noordwijk M, Tomich TP. (1995) Agroforestry technologies for social forestry: tree-crop interactions and forestry-farmer conflicts. Simon H, Hartadi, Sabarnurdin S, Sumardi and Iswantoro H (eds) Social Forestry and Sustainable Forest Management Perum Perhutani, Jakarta, pp 168-193.

Van Raij B, Cantarella H. (1996) A quadratic model for fertilizer recommendations based on results of soil analyses. Communications in Soil Science \& Plant Analysis 27: 1595-1610.

Van Rooijen L. (2014a) How have policy makers used the concept of "marginal land" to legitimize target areas suitable for Jatropha and what effect did this have? In: Vel JAC, Simandjutak D (eds) JARAK, the short history of Jatropha projects in Indonesia. IIAS. E-publication available at http://jarak.iias.asia, Leiden.

Van Rooijen L. (2014b) Pioneering in marginal fields: jatropha for carbon credits and restoring degraded land in Eastern Indonesia. Sustainability 6: 2223-2247.

Vanlauwe B, Akinnifesi FK, Tossah BK, Lyasse O, Sanginga N, Merckx R. (2002) Root distribution of Senna siamea grown on a series of derived-savanna-zone soils in Togo, West Africa. Agroforestry Systems 54: 1-12.

Vel JAC. (2014a) Trading in discursive commodities: biofuel brokers' roles in perpetuating the jatropha hype in Indonesia. Sustainability 6: 2802-2821.

Vel JAC. (2014b) What is JARAK? In: Vel JAC, Simandjutak D (eds) JARAK, the short history of Jatropha projects in Indonesia. IIAS. E-publication available at http://jarak.iias.asia, Leiden. 
Vel JAC, Simandjuntak D, Van Rooijen L, Widjaja H, Afiff S, Van Klinken G, Tjeuw J, Slingerland M, Semedi P, Schulte Nordholt H, Gunawan, Persoon G, Otto JM, Suharsono S, Snelder D, Orij R, Dieleman M, Bedner A, McCarthy J. (2013) Jatropha: from an iconic biofuel crop to a green policy parasite. IIAS Newsletter 66: 1-15.

Verrastro F, Ladingow S. (2007) Providing energy security in an interdependent world. Washington Quarterly 30: 95-104.

Von Maltitz G, Gasparatos A, Fabricius C. (2014) The rise, fall and potential resilience benefits of jatropha in southern Africa. Sustainability 6: 3615-3643.

Vos J, Evers JB, Buck-Sorlin GH, Andrieu B, Chelle M, De Visser PHB. (2010) Functional - structural plant modelling: a new versatile tool in crop science. Journal of Experimental Botany 61: 2101-2115.

Vyas AP, Subrahmanyam N, Patel PA. (2009) Production of biodiesel through transesterification of Jatropha oil using $\mathrm{KN}_{3} / \mathrm{Al}_{2} \mathrm{O}_{3}$ solid catalyst. Fuel 88: 625-628.

Wahid MB, Abdullah SNA, Henson IE. (2005) Oil palm-achievements and potential. Plant Production Science 8: 288-297.

Wahl N, Hildebrandt T, Moser C, Lüdeke-Freund F, Averdunk K, Bailis R, Barua K, Burritt R, Groeneveld J, Klein A-M. (2013) Insights into jatropha projects worldwide-key facts \& figures from a global survey. Centre for Sustainability Management (CSM), Leuphana Universität Lüneburg, pp 1-72.

Wahl N, Jamnadass R, Baur H, Munster C, Liyama M. (2009) Economic viability of Jatropha curcas L. plantations in Northern Tanzania - assessing farmers' prospects via cost-benefit analysis. ICRAF Working Paper No 97. World Agroforestry Center, Nairobi Kenya.

Wajja-Musukwe TN, Wilson J, Sprent JI, Ong CK, Deans JD, Okorio J. (2008) Tree growth and management in Ugandan agroforestry systems: effects of root pruning on tree growth and crop yield. Tree Physiology 28: 233-242.

Wang JX. (2008) Discussion on economic benefit and related policy of rapeseed bio-diesel project. Chemical Industry 26: 8-10.

Wang Z. (2012) Producing jatropha biodiesel in China: policies, performance and challenges. In: Carels N, Sujatha M, Bahadur B (eds) Jatropha, Challenges for a New Energy Crop, Volume 1. Springer New York, pp 95-121.

Wang Z, Calderon MM, Lu Y. (2011) Lifecycle assessment of the economic, environmental and energy performance of Jatropha curcas L. biodiesel in China. Biomass and Bioenergy 35: 2893-2902.

Wang Z, Lu Y, Li S. (2010) Producing biodiesel from Jatropha curcas L. in Yunnan, China: lifecycle environmental, economic and energy performance. EEPSEA Research Report No 2009-RR12. Economy and Environment Program for Southeast Asia, Singapore.

Wani SP, Chander G. (2012) Jatropha curcas biodiesel, challenges and opportunities: is it a panacea for energy crisis, ecosystem service and rural livelihoods? In: Carels N, Sujatha M, Bahadur B (eds) Jatropha, challenges for a new energy crop, Volume 1: farming, economics and biofuel. Springer, New York, pp 311-331. 
Wani SP, Chander G, Sahrawat KL, Srinivasa Rao C, Raghvendra G, Susanna P, Pavani M. (2012) Carbon sequestration and land rehabilitation through Jatropha curcas (L.) plantation in degraded lands. Agriculture, Ecosystems \& Environment 161: 112-120.

Watanabe K, Bijman J, Slingerland M. (2012) Institutional arrangements in the emerging biodiesel industry: case studies from Minas Gerais—Brazil. Energy Policy 40: 381-389.

Wen MF, Wang HY, Xia ZQ, Zou ML, Lu C, Wang WQ. (2010) Development of EST-SSR and genomicSSR markers to assess genetic diversity in Jatropha curcas L. BMC Research Notes 3: 1-8.

Westoby M, Wright IJ. (2003) The leaf size-twig size spectrum and its relationship to other important spectra of variation among species. Oecologia 135: 621-628.

Weyerhaeuser H, Tennigkeit T, Yufang S, Kahrl F. (2007) Biofuels in China: an analysis of the opportunities and challenges of Jatropha curcas in Southwest China. World Agroforestry Centre, ICRAF Working Paper 53.

Wickens GE. (2001) Marketing of crops and crop products. Economic botany: principles and practices. Springer New York, pp 121-126.

Wicks GA, Crutchfield DA, Burnside OC. (1994) Influence of wheat (Triticum aestivum) straw mulch and metolachlor on corn (Zea mays) growth and yield. Weed Science 42: 141-147.

Widjaya H. (2014) How did patronage networks play a role as business intermediaries in Jatropha projects? In: Vel JAC, Simandjutak D (eds) JARAK, the short history of Jatropha projects in Indonesia. IIAS. E-publication available at http://jarak.iias.asia, Leiden.

Widodo TW, Rahmarestia E. (2008) Current status of bioenergy development in Indonesia. Proceedings of the Regional Forum on Bioenergy Sector Development: challenges, opportunities and the way forward, January 23-25. Economic and Social Commission for Asia and the Pacific (ESCAP) and Asian and Pacific Centre for Agricultural Engineering and Machinery (APCAEM), Bangkok, Thailand, pp 49-66.

Wiesenhütter J. (2003) Use of the physic nut (Jatropha curcas L.) to combat desertification and reduce poverty. Possibilities and limitations of technical solutions in a particular socio-economic environment, the case of Cape Verde. Deutsche Gesellschaft für Technische Zusammenarbeit (GTZ)-Convention Project to Combat Desertification (CCD Project), Bonn, Germany, pp 1-18.

Wiggins S, Keane J, Kennan J, Leturque H, Stevens C. (2011) Biofuels in Eastern Africa: dangers yes, but much potential as well. Project Briefing No 66. Overseas Development Institute (ODI) \& Bioenergy in Africa (BIA), UK, pp 1-4.

Willey RW. (1979) Intercropping - its importance and research needs. 1. Competition and yield advantages. Field Crop Abstracts 32: 1-10.

Willey RW. (1990) Resource use in intercropping systems. Agricultural Water Management 17: 215-231.

Willey RW, Osiru DSO. (1972) Studies on mixtures of maize and beans (Phaseolus vulgaris) with particular reference to plant population. The Journal of Agricultural Science 79: 517-529.

Wilson JB. (1988) A review of evidence on the control of shoot:root ratio, in relation to models. Annals of Botany 61: 433-449. 
Wu W, Huang J, Deng X. (2010) Potential land for plantation of Jatropha curcas as feedstocks for biodiesel in China. Science in China Series D: Earth Sciences 53: 120-127.

Wyatt R. (1982) Inflorescence architecture: how flower number, arrangement, and phenology affect pollination and fruit-set. American Journal of Botany: 585-594.

Xu G, Luo R, Yao Y. (2013) Paclobutrazol improved the reproductive growth and the quality of seed oil of Jatropha curcas. Journal of Plant Growth Regulation 32: 875-883.

Ye J, Geng Y, Zhang B, Mao H, Qu J, Chua N-H. (2014a) The jatropha FT ortholog is a systemic signal regulating growth and flowering time. Biotechnology for Biofuels 7: 1-11.

Ye J, Qu J, Mao H-Z, Ma Z-G, Rahman NEB, Bai C, Chen W, Jiang S-Y, Ramachandran S, Chua N-H. (2014b) Engineering geminivirus resistance in Jatropha curcas. Biotechnology for Biofuels 7: 1-11.

Yeh S, Berndes G, Mishra GS, Wani SP, Elia Neto A, Suh S, Karlberg L, Heinke J, Garg KK. (2011) Evaluation of water use for bioenergy at different scales. Biofuels, Bioproducts and Biorefining 5: 361-374.

Yi C, Zhang S, Liu X, Bui HT, Hong Y. (2010) Does epigenetic polymorphism contribute to phenotypic variances in Jatropha curcas L.? BMC Plant Biology 10: 1-9.

Yong JWH, Ng YF, Tan SN, Chew AYL. (2010) Effect of fertilizer application on photosynthesis and oil yield of Jatropha curcas L. Photosynthetica 48: 208-218.

Yue GH, Sun F, Liu P. (2013) Status of molecular breeding for improving Jatropha curcas and biodiesel. Renewable and Sustainable Energy Reviews 26: 332-343.

Zah R, Böni H, Gauch M, Hischier R, Lehmann M, Wäger P. (2007) Life cycle assessment of energy products: environmental impact assessment of biofuels. Empa Technology and Society Lab St. Gallen, Switzerland.

Zaidi P, Sultana R, Singh RP, Yadav M, Srivastava A. (2008) Relationship between drought and excess moisture tolerance in tropical maize (Zea mays L.). Australian Journal of Crop Science 1: 215-215.

Zaidi PH, Rafique S, Rai PK, Singh NN, Srinivasan G. (2004) Tolerance to excess moisture in maize (Zea mays L.): susceptible crop stages and identification of tolerant genotypes. Field Crops Research 90: 189-202. 


\section{Appendices}

Appendix 1: Methods: FBA field measurements.

The FBA protocol required the development of a fractal tree model based on the natural form of the tree with each section or internodes referred to as links. Links were individual sections of wood (stem), branch, or twig between two branching points. For aboveground, the initial link was the wood (diameter $\leq 7 \mathrm{~cm}$ ), and the stem divides into branches (diameter from $2 \mathrm{~cm}$ to $6.99 \mathrm{~cm}$ ) and twigs (diameter $\leq 1.99 \mathrm{~cm}$ ) to form the crown. These links allow length-diameter scaling relationships to be determined. Tree stem lengths varied from $2 \mathrm{~cm}$ to $40 \mathrm{~cm}$ from soil surface therefore DBH normally used for developing the tree allometric equation was replaced with stem base diameter measured at the middle of stem height. Belowground biomass was determined in much the same manner as for aboveground, except that proximal root measurements were used. Proximal roots had wood root (diameter $\geq 2 \mathrm{~cm}$ ), branch roots (diameter from 0.5 $\mathrm{cm}$ to $1.99 \mathrm{~cm}$ ), and twig roots (diameter $<0.5 \mathrm{~cm}$ ). FBA simulated only root biomass of one proximal root therefore a summation was necessary to estimate total proximal root biomass.

Prior to biomass determination, schematic diagrams were prepared for all aboveground branching patterns with field data measurements for diameter and length links. Accuracy required two measurements for each data point, the second measure at 90 degrees to the first and at three link points, proximal, middle, and distal. The main stem is link 0 , the next link 1 , and subsequent offspring numbered sequentially as link 2 and link 3 until all links were completed. Data collection included leaf numbers and fruit for each link. To ensure reliable estimates data were collected for a minimum of 100 branching point for each tree as recommended by Van Noordwijk and Mulia (2002).

To calculate biomass it was necessary to determine the probability distributions of $p$ and $q$. The scaling factor for $p$ is a transfer coefficient that denotes a change in total cross-sectional area at branching points. This was calculated as the ratio between sum of squared diameters before and after branching. The scaling factor for $q$ is an allocation coefficient that denotes relative size of the largest link at a branching point. This was calculated as the ratio between the largest squared diameter after branching and sum of squared diameter after branching.

Prior to biomass determination, schematic diagrams were prepared for all belowground branching patterns. Collection of field data for link diameter and length was in a manner similar to that for aboveground. Belowground FBA uses proximal root terms that have the same meaning to lateral or horizontal root terms. This study uses proximal root term when explaining the model and uses lateral root when explaining other researchers' findings. Root diameter and length data recording started with the first proximal root and continued for a minimum of 100 links. Horizontal proximal roots are 0 to 45 degrees angle from soil surface and vertical proximal root as more than 45 degrees. 
Appendices

Appendix 2: Statistical criteria for model evaluation result (Loague and Green, 1991).

\begin{tabular}{|c|c|c|c|c|}
\hline Criterion & Symbol & Formula & Range & Optimum \\
\hline Maximum error & $\mathrm{ME}$ & $\operatorname{Max}\left|P_{1}-0_{1}\right| \frac{n}{i n}$ & $\geq$ & 0 \\
\hline Root mean square & RMSE & $\left(\sum_{i=1}^{n} \frac{\left.\left(P_{i}-O_{i}\right)^{2}\right)}{n}\right) * \frac{100}{O_{\text {mean }}}$ & $\geq$ & 0 \\
\hline Coefficient of determination & $\mathrm{CD}$ & $\frac{\sum_{i=1}^{n}\left(O i-O_{\text {mean }}\right)^{2}}{\sum_{i=1}^{n}\left(P_{i}-O_{\text {mean }}\right)^{2}}$ & $\geq$ & 1 \\
\hline Modelling efficiency & $\mathrm{EF}$ & $\frac{\sum_{i=1}^{n}\left(O_{i}-O_{\text {mean }}\right)^{2}-\sum_{i=1}^{n}\left(P_{i}-O_{i}\right)^{2}}{\sum_{i=1}^{n}\left(O_{i}-O_{\text {mean }}\right)^{2}}$ & $\leq$ & 1 \\
\hline Coefficient of residual mass & CRM & $\frac{\sum_{i=1}^{n} O_{i}-\sum_{i=1}^{n} P_{1}}{\sum_{i=1}^{n} O_{i}}$ & $\leq$ & 0 \\
\hline
\end{tabular}


Appendix 3 Schematic drawing of an unpruned 4-year-old showing above and belowground architecture following FBA numbering.

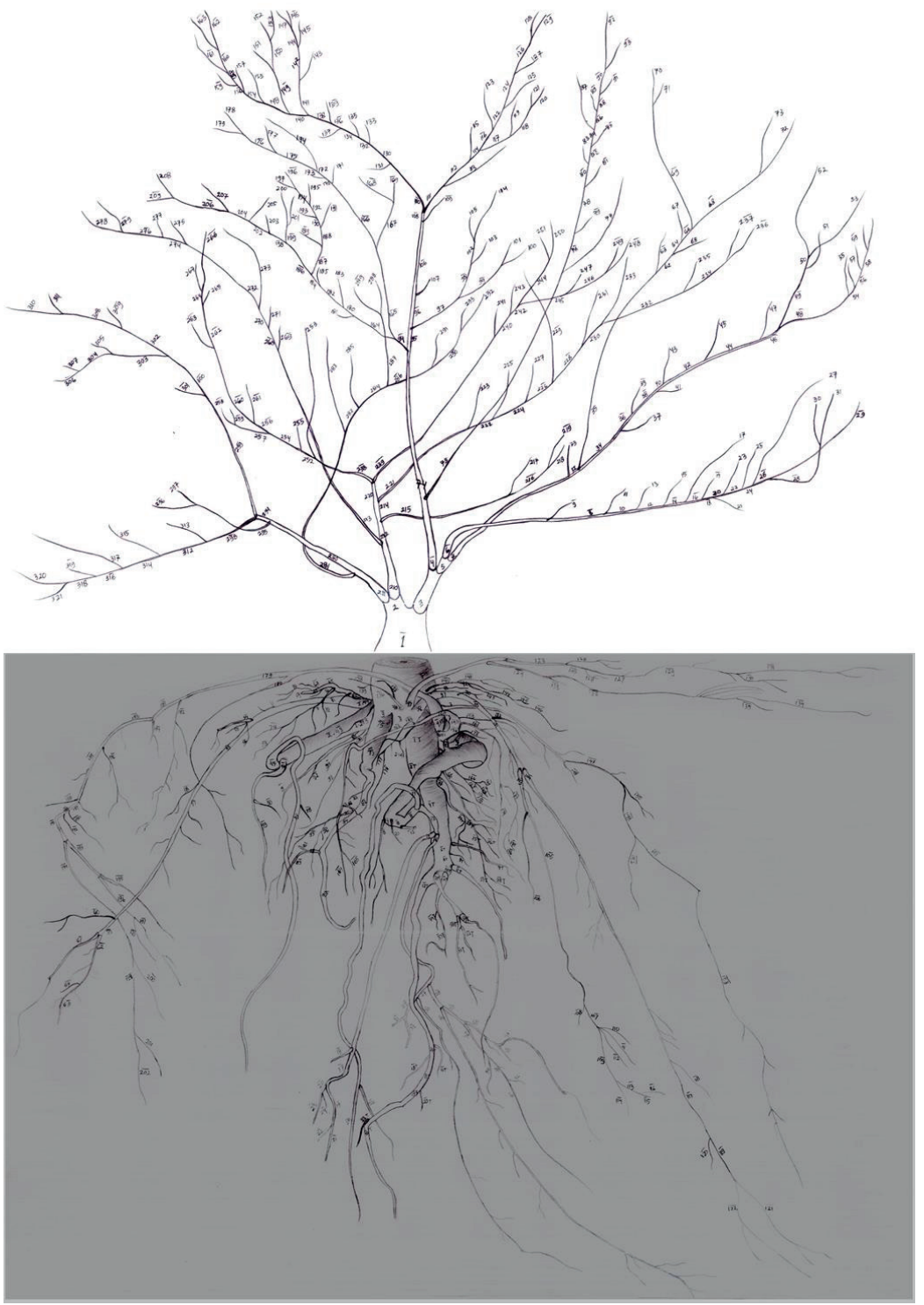


Appendix 4: Distribution of $p$ (top) and $q$ (bottom) factors as a function of link diameter.
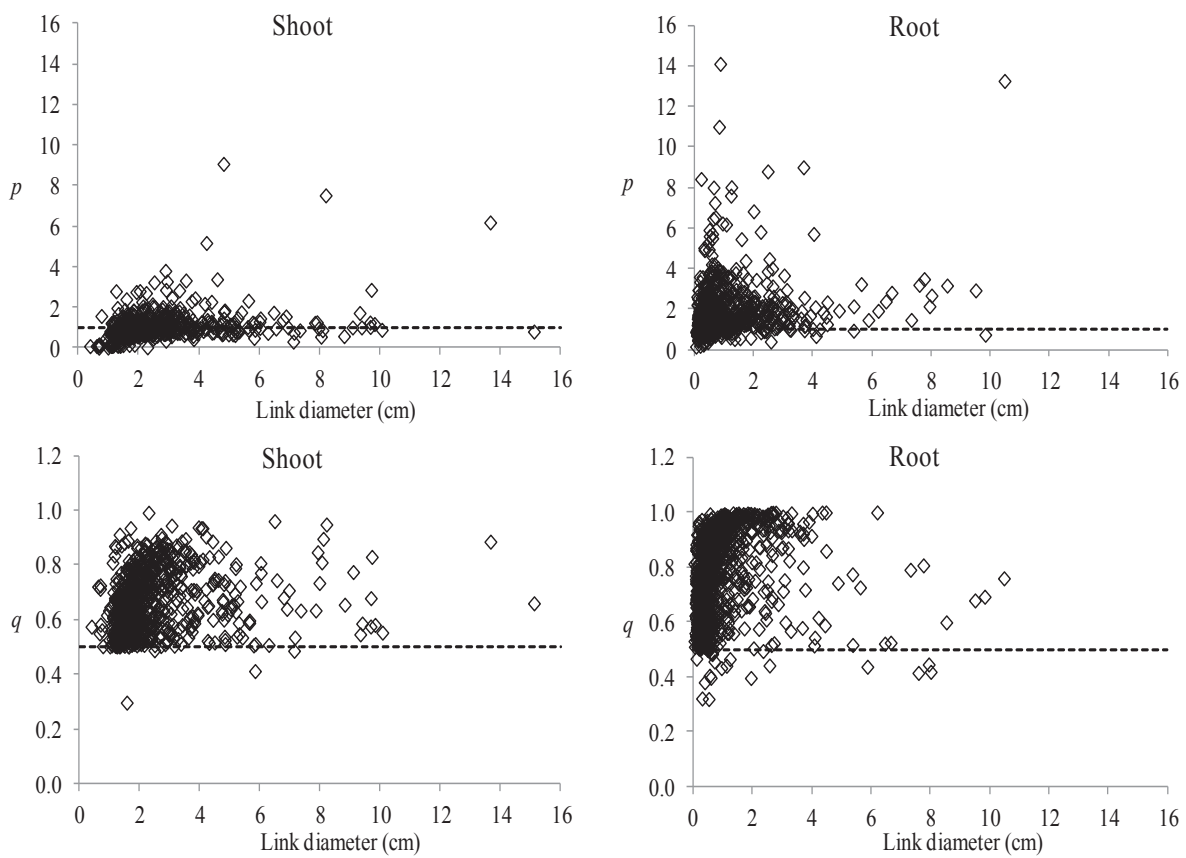

Distribution of $p$ (top) and $q$ (bottom) factors as a function of link diameter. The horizontal line in $p$ represent a conservation of cross sectional area across a branching point $(p=1)$. The horizontal line in $q$ represents a perfect fork $(q=0.5)$. 
Appendix 5: Aboveground or shoot link length and diameter relationship for twig, branch, and wood categories.
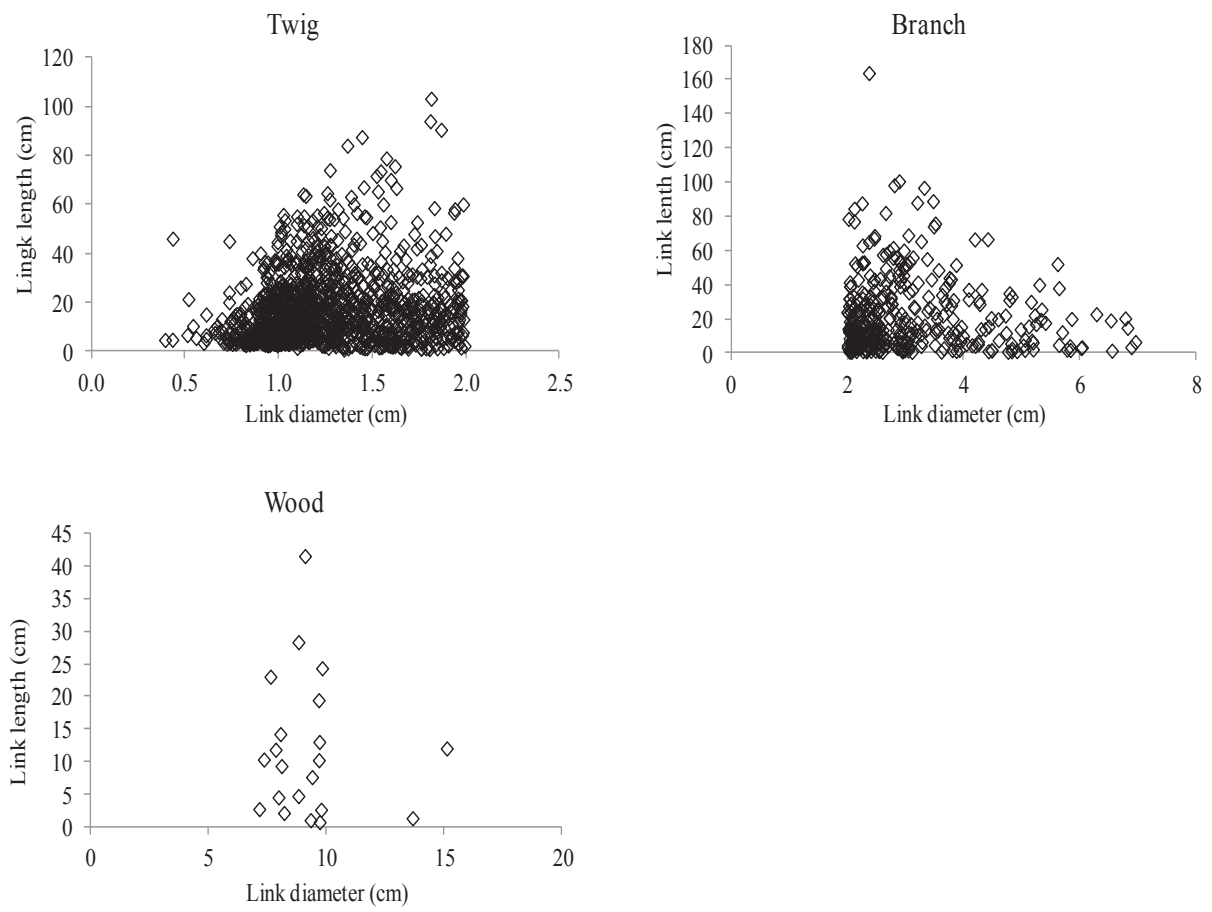
Appendices

Appendix 6: Allometric constants and scaling coefficients for taproot of 10 jatropha.

\begin{tabular}{cc}
\hline $\begin{array}{c}\text { Least trimmed squared } \\
\text { (LTS) }\end{array}$ & Taproot \\
\hline$a$ & 0.01802 \\
$b$ & 1.33340 \\
$R^{2}$ & 0.94000 \\
$p$ & $<0.00010$ \\
$\mathrm{cf}$ & 1.55600 \\
\hline
\end{tabular}

$\mathrm{cf}=$ correction factor. 
Appendix 7: FBA parameterisation for above and belowground.

\begin{tabular}{|c|c|c|c|c|}
\hline \multicolumn{2}{|c|}{ Parameters } & \multirow{2}{*}{$\begin{array}{c}\text { Units } \\
-\end{array}$} & \multirow{2}{*}{$\begin{array}{l}\text { Shoot } \\
1.000\end{array}$} & \multirow{2}{*}{$\begin{array}{l}\text { Root } \\
0.000\end{array}$} \\
\hline Simulation type & Root or shoot & & & \\
\hline \multirow[t]{2}{*}{ Range of simulation } & D low & $\mathrm{cm}$ & 5.000 & 2.000 \\
\hline & D high & $\mathrm{cm}$ & 15.000 & 10.000 \\
\hline \multirow[t]{2}{*}{ Branching pattern } & Number of branching & - & 2.010 & 2.170 \\
\hline & How is $\mathrm{p}$ generated in the model & - & 0.000 & 0.000 \\
\hline \multirow[t]{2}{*}{ If generated with Cauchy } & Locality parameter & - & 0.876 & 1.313 \\
\hline & Scale parameter & - & 0.163 & 0.332 \\
\hline \multirow[t]{6}{*}{ If non-parametric } & $\mathrm{p}<0.5$ & - & 0.050 & 0.010 \\
\hline & p $0.5<$ p $<0.75$ & - & 0.180 & 0.030 \\
\hline & p $0.75<$ p $<0.9$ & - & 0.270 & 0.070 \\
\hline & p $0.9<$ p $<1.1$ & - & 0.210 & 0.160 \\
\hline & $\mathrm{p} 1.1<\mathrm{p}<1.25$ & - & 0.100 & 0.120 \\
\hline & $\mathrm{p}>1.25$ & - & 0.180 & 0.610 \\
\hline \multirow[t]{5}{*}{$\mathrm{q}$ distribution is non-parametric } & p $0.5<\mathrm{q}<0.6$ & - & 0.360 & 0.180 \\
\hline & p $0.6<\mathrm{q}<0.7$ & - & 0.300 & 0.190 \\
\hline & p $0.7<\mathrm{q}<0.8$ & - & 0.210 & 0.180 \\
\hline & p $0.8<$ q $<0.9$ & - & 0.120 & 0.200 \\
\hline & p $0.9<\mathrm{q}<1.0$ & - & 0.020 & 0.250 \\
\hline \multirow[t]{2}{*}{ Diameter } & Average D min & $\mathrm{cm}$ & 0.433 & 0.150 \\
\hline & Range D min & $\mathrm{cm}$ & 0.100 & 0.360 \\
\hline Link length & Single L-D relationship? & - & 0.000 & 0.000 \\
\hline \multirow[t]{3}{*}{ If yes } & Intercept & $\mathrm{cm}$ & 15.810 & 17.366 \\
\hline & Slope & $\mathrm{cm}$ & 0.810 & 0.569 \\
\hline & Range L & - & 0.086 & 0.115 \\
\hline \multirow[t]{3}{*}{ If no then for class 'twig' } & Intercept & $\mathrm{cm}$ & 15.990 & 16.213 \\
\hline & Slope & $\mathrm{cm}$ & 0.000 & 0.000 \\
\hline & Range L & - & 0.00041 & 0.751 \\
\hline \multirow[t]{3}{*}{ For class 'branch' } & Intercept & $\mathrm{cm}$ & 21.980 & 16.444 \\
\hline & Slope & $\mathrm{cm}$ & 0.000 & 0.000 \\
\hline & Range L & - & 0.121 & 0.973 \\
\hline \multirow[t]{3}{*}{ For class 'wood' } & Intercept & $\mathrm{cm}$ & 11.640 & 10.925 \\
\hline & Slope & $\mathrm{cm}$ & 0.000 & 0.000 \\
\hline & Range L & - & 0.440 & 0.738 \\
\hline
\end{tabular}


Appendix 7 continued.

\begin{tabular}{|c|c|c|c|c|}
\hline \multicolumn{2}{|c|}{ Parameters } & \multirow{2}{*}{$\begin{array}{l}\text { Units } \\
\mathrm{g} \mathrm{cm}^{-3}\end{array}$} & \multirow{2}{*}{$\begin{array}{l}\text { Shoot } \\
0.306\end{array}$} & \multirow{2}{*}{$\begin{array}{l}\text { Root } \\
0.489\end{array}$} \\
\hline Woody part & Twig density & & & \\
\hline & Branch density & $\mathrm{g} \mathrm{cm}^{-3}$ & 0.324 & 0.368 \\
\hline & Wood density & $\mathrm{g} \mathrm{cm}^{-3}$ & 0.336 & 0.260 \\
\hline & Twig diameter & $\mathrm{cm}$ & 2.000 & 0.500 \\
\hline & Branch diameter & $\mathrm{cm}$ & 7.000 & 2.000 \\
\hline \multirow[t]{4}{*}{ Final links } & Length bare tip & $\mathrm{cm}$ & 0.000 & 0.000 \\
\hline & D high density & $\mathrm{cm}$ & 1.099 & 0.499 \\
\hline & D zero density & $\mathrm{cm}$ & 1.260 & 0.700 \\
\hline & Leaf density & $\mathrm{cm}^{-1}$ & 0.429 & 0.279 \\
\hline \multirow[t]{3}{*}{ Leaves } & Specific leaf area & $\mathrm{cm}^{-2} \mathrm{~g}^{-1}$ & 140.442 & 140.442 \\
\hline & Leaf area & $\mathrm{cm}^{-2}$ & 61.619 & 61.619 \\
\hline & Leaf area index & - & 4.118 & 4.118 \\
\hline \multirow[t]{2}{*}{ Fine roots } & Fine root length & $\mathrm{cm}$ & 3.000 & 4.744 \\
\hline & Specific root length & $\mathrm{cm} \mathrm{g}^{-1}$ & 30000 & 548.470 \\
\hline \multirow[t]{3}{*}{ Additional parameters } & Linear or logarithmic step? & - & 1.000 & 1.000 \\
\hline & Number of iteration & - & 100 & 100 \\
\hline & Random seed & - & 62240 & 62240 \\
\hline \multirow[t]{5}{*}{ Tapering coefficient with Cauchy } & Locality parameter for twig & $\mathrm{cm}$ & 0.024 & 0.005 \\
\hline & Locality parameter for branch & $\mathrm{cm}$ & 0.024 & 0.010 \\
\hline & Locality parameter for wood & $\mathrm{cm}$ & 0.042 & 0.050 \\
\hline & Scale parameter & $\mathrm{cm}$ & 0.035 & 0.018 \\
\hline & Allow thickening? & - & 0.000 & 0.000 \\
\hline \multirow[t]{3}{*}{ Main stem } & Intercept & $\mathrm{cm}$ & 11.640 & 10.925 \\
\hline & Slope & $\mathrm{cm}$ & 0.000 & 0.000 \\
\hline & Range L & - & 0.440 & 0.738 \\
\hline \multirow[t]{4}{*}{ Fruits } & D high density fruit & $\mathrm{cm}$ & 1.483 & 0.970 \\
\hline & D zero density fruit & $\mathrm{cm}$ & 0.902 & 1.590 \\
\hline & Fruit density & $\mathrm{cm}^{-1}$ & 0.010 & 0.100 \\
\hline & Fruit dry weight & g & 3.200 & 3.200 \\
\hline
\end{tabular}


Appendix 8: Tree growth characteristics applied in the model.

\begin{tabular}{|c|c|c|c|}
\hline \multicolumn{2}{|r|}{ Parameters } & \multirow{2}{*}{$\begin{array}{l}\text { Units } \\
\text { Days }\end{array}$} & \multirow{2}{*}{$\begin{array}{c}\text { Jatropha } \\
365\end{array}$} \\
\hline Growth stage & Length of vegetative cycle & & \\
\hline & Length of generative cycle & Days & 30 \\
\hline & Earliest day to flower in a year & $\begin{array}{l}\text { Julian } \\
\text { day }\end{array}$ & 305 \\
\hline & Latest day to flower in a year & $\begin{array}{c}\text { Julian } \\
\text { day }\end{array}$ & 195 \\
\hline & Initial stage & - & 0.1 \\
\hline & Stage after pruning & - & 1 \\
\hline & Maximum growth rate & $\mathrm{kg} \mathrm{m}^{-2}$ & 0.0035 \\
\hline \multirow[t]{5}{*}{ Growth } & Fraction of growth reserve & - & 0.025 \\
\hline & Leaf weight ratio & - & 0.58 \\
\hline & Specific leaf area & $\mathrm{m}^{2} \mathrm{~kg}^{-1}$ & 14.04 \\
\hline & Water requirements for dry matter production & $1 \mathrm{~kg}^{-1}$ & 252 \\
\hline & Tree growth follows Rubber tree rules? & - & 0 \\
\hline \multirow[t]{2}{*}{ Fruit } & Fruit growth follows Oil Palm rules? & - & 0 \\
\hline & Fraction biomass allocated to fruit & - & 0.125 \\
\hline \multirow[t]{5}{*}{ Crown } & Maximum crown height above bare stem & $\mathrm{m}$ & 1.938 \\
\hline & Ratio between crown width and height & - & 1.094 \\
\hline & Maximum crown radius & $\mathrm{m}$ & 3.032 \\
\hline & Maximum leaf area index & - & 4.554 \\
\hline & Ratio leaf area index minimum and maximum & - & 0.200 \\
\hline \multirow[t]{3}{*}{ Light capture } & Growth & - & 1 \\
\hline & $\begin{array}{l}\text { Relative light density at which shading start to affect tree } \\
\text { growth }\end{array}$ & - & 0.7 \\
\hline & Extinction light coefficient & - & 1 \\
\hline $\begin{array}{l}\text { Rain } \\
\text { interception }\end{array}$ & Rainfall water stored at leaf surface & $\mathrm{mm}$ & 0.00001 \\
\hline \multirow[t]{3}{*}{ Tree water } & Coefficient related to tree root conductivity & $\mathrm{cm}_{\text {day }}{ }^{-1}$ & -1000 \\
\hline & Plant potential for maximum transpiration & $\mathrm{cm}$ & -3000 \\
\hline & Plant potential for minimum transpiration & $\mathrm{cm}$ & 0.00 \\
\hline
\end{tabular}


Appendix 8: Continued.

\begin{tabular}{|c|c|c|c|}
\hline & Parameters & Units & Jatropha \\
\hline $\mathrm{N}$ fixation & Type of $\mathrm{N}_{2}$ fixation & - & 0.00 \\
\hline & Proportion of $\mathrm{N}$ from atmosphere & - & 0.00 \\
\hline & Fraction of reserve pool for $\mathrm{N}_{2}$ fix & - & 0.00 \\
\hline & Dry weight cost for $\mathrm{N}_{2}$ fixation & - & 0.00 \\
\hline & Responsiveness of $\mathrm{N}_{2}$ fixation to $\mathrm{N}$ stress & - & 0.00 \\
\hline $\mathrm{N}$ concentration & $\mathrm{N}$ concentration in carbohydrate reserves & $\mathrm{g} \mathrm{g}^{-1}$ & 0.22 \\
\hline & $\mathrm{N}$ concentration in leaf component & $\mathrm{g} \mathrm{g}^{-1}$ & 0.0261 \\
\hline & $\mathrm{N}$ concentration in twig component & $\mathrm{g} \mathrm{g}^{-1}$ & 0.0068 \\
\hline & $\mathrm{N}$ concentration in wood component & $\mathrm{g} \mathrm{g}^{-1}$ & 0.0034 \\
\hline & $\mathrm{N}$ concentration in fruit component & $\mathrm{g} \mathrm{g}^{-1}$ & 0.0177 \\
\hline & $\mathrm{N}$ concentration in root development & $\mathrm{g} \mathrm{g}^{-1}$ & 0.0151 \\
\hline & Lignin fraction of pruned biomass & - & 0.1683 \\
\hline & Lignin fraction of root & - & 0.1395 \\
\hline & Polyphenol fraction of litter fall & - & 0.0371 \\
\hline & Polyphenol fraction of pruned biomass & - & 0.0314 \\
\hline & Polyphenol fraction of root & - & 0.0968 \\
\hline Allometric branching & Apply allometric equation? & - & 1 \\
\hline (Above ground) & Intercept for total biomass equation & $\mathrm{kg}$ & 0.0090 \\
\hline & Power for total biomass equation & $\mathrm{cm}^{-1}$ & 2.583 \\
\hline & Intercept for branch biomass equation & $\mathrm{kg}$ & 0.0088 \\
\hline & Power for branch biomass equation & $\mathrm{cm}^{-1}$ & 2.267 \\
\hline & Intercept for leaf \& twig biomass equation & $\mathrm{kg}$ & 0.0085 \\
\hline & Power for leaf $\&$ twig biomass equation & $\mathrm{cm}^{-1}$ & 2.121 \\
\hline & Intercept for litter fall equation & $\mathrm{kg}$ & 0.001 \\
\hline & Power for litter fall equation & $\mathrm{cm}^{-1}$ & 2.583 \\
\hline & Wood density & $\mathrm{Kg} \mathrm{m}^{-3}$ & 336.334 \\
\hline Roots & Root tip diameter & $\mathrm{cm}$ & 0.1 \\
\hline & Maximum root length density in layer $1-$ zone 1 & $\mathrm{~cm} \mathrm{~cm}^{-3}$ & 0.0356 \\
\hline & Maximum root length density in layer $1-$ zone 2 & $\mathrm{~cm} \mathrm{~cm}^{-3}$ & 0.9075 \\
\hline & Maximum root length density in layer $1-$ zone 3 & $\mathrm{~cm} \mathrm{~cm}^{-3}$ & 0.7878 \\
\hline & Maximum root length density in layer $1-$ zone 4 & $\mathrm{~cm} \mathrm{~cm}^{-3}$ & 0.00 \\
\hline & Maximum root length density in layer 2 - zone 1 & $\mathrm{~cm} \mathrm{~cm}^{-3}$ & 0.00 \\
\hline & Maximum root length density in layer $2-$ zone 2 & $\mathrm{~cm} \mathrm{~cm}^{-3}$ & 0.1960 \\
\hline & Maximum root length density in layer $2-$ zone 3 & $\mathrm{~cm} \mathrm{~cm}^{-3}$ & 0.4964 \\
\hline
\end{tabular}


Appendix 8: Continued.

\begin{tabular}{ccc}
\hline Parameters & Units & Jatropha \\
\hline Maximum root length density in layer 2 - zone 4 & $\mathrm{cm} \mathrm{cm}^{-3}$ & 0.00 \\
Maximum root length density in layer 3 - zone 1 & $\mathrm{cm} \mathrm{cm}^{-3}$ & 0.00 \\
Maximum root length density in layer 3 - zone 2 & $\mathrm{cm} \mathrm{cm}^{-3}$ & 0.0853 \\
Maximum root length density in layer 3 - zone 3 & $\mathrm{cm} \mathrm{cm}^{-3}$ & 0.0815 \\
Maximum root length density in layer 3 - zone 4 & $\mathrm{cm} \mathrm{cm}^{-3}$ & 0.00 \\
Maximum root length density in layer 4 - zone 1 & $\mathrm{cm} \mathrm{cm}^{-3}$ & 0.00 \\
Maximum root length density in layer 4 - zone 2 & $\mathrm{cm} \mathrm{cm}^{-3}$ & 0.00 \\
Maximum root length density in layer 4 - zone 3 & $\mathrm{cm} \mathrm{cm}^{-3}$ & 0.0382 \\
Maximum root length density in layer 4 - zone 4 & $\mathrm{cm} \mathrm{cm}^{-3}$ & 0.00 \\
\hline
\end{tabular}


Appendix 9: Crop growth characteristics applied in the model.

\begin{tabular}{|c|c|c|c|}
\hline & Parameters & Units & Maize \\
\hline \multirow[t]{2}{*}{ Crop Stage } & Length of generative stage & days & 40 \\
\hline & Length of vegetative stage & days & 60 \\
\hline \multirow[t]{3}{*}{ Annual or Perennial? } & Is it annual crop? $1=y e s, 0=$ no & - & 1 \\
\hline & Earliest day to flower in a year & Julian day & 1 \\
\hline & Latest day to flower in a year & Julian day & 365 \\
\hline \multirow[t]{5}{*}{ Crop Growth } & Production of dry matter per day & $\mathrm{kg}\left(\mathrm{m}^{-2}\right.$ day $\left.^{-1}\right)$ & 0.014 \\
\hline & Seed weight & $\mathrm{kg} \mathrm{m}^{-2}$ & 0.004 \\
\hline & Water requirement for dry matter production & $1 \mathrm{~kg}^{-1}$ & 300 \\
\hline & Ratio of height increment to biomass incr. & $\mathrm{m} \mathrm{kg}^{-2}$ & 7 \\
\hline & $\begin{array}{l}\text { Maximum proportion of crop biomass } \\
\text { remobilized as } \\
\text { storage component }\end{array}$ & 1 day $^{-1}$ & 0.05 \\
\hline \multirow[t]{2}{*}{ Light Capture } & Extinction light coefficient & - & 0.65 \\
\hline & $\begin{array}{l}\text { Relative light intensity at which shading } \\
\text { starts to } \\
\text { affect crop growth }\end{array}$ & - & 1 \\
\hline Canopy & Maximum Leaf Area Index & - & 5 \\
\hline Rain Interception & Rainfall water stored at leaf surface & $\mathrm{mm}$ & 1 \\
\hline \multirow[t]{3}{*}{ Water Uptake } & Hydraulic conductivity of roots & $\mathrm{cm} \mathrm{day}^{-1}$ & $1.0 \mathrm{E}-05$ \\
\hline & Maximum plant potential & $\mathrm{cm}$ & -5000 \\
\hline & Minimum plant potential & $\mathrm{cm}$ & -15000 \\
\hline \multirow[t]{6}{*}{ Nutrient Uptake } & Canopy biomass for closed canopy & $\mathrm{kg} \mathrm{m}^{-2}$ & 0.2 \\
\hline & $\mathrm{N}$ concentration in crop tissue & - & 0.01 \\
\hline & $\mathrm{P}$ concentration in crop tissue & - & 0.0025 \\
\hline & $\mathrm{N}$ concentration in young crop biomass & - & 0.015 \\
\hline & $\mathrm{P}$ concentration in young crop biomass & - & 0.007 \\
\hline & $\mathrm{N}$ concentration in roots & - & 0.01 \\
\hline
\end{tabular}


Appendix 9 continued.

\begin{tabular}{|c|c|c|c|c|}
\hline \multirow{2}{*}{ N Fixation } & & \multirow{2}{*}{$\begin{array}{l}\text { Parameters } \\
\text { Type of } \mathrm{N}_{2} \text { fixation }\end{array}$} & \multirow{2}{*}{$\begin{array}{c}\text { Units } \\
-\end{array}$} & \multirow{2}{*}{$\begin{array}{c}\text { Maize } \\
0\end{array}$} \\
\hline & $\mathrm{N}$ fixation & & & \\
\hline & Constant & Proportion of $\mathrm{N}$ from atmosphere & - & 0 \\
\hline & $\begin{array}{l}\text { Responsive } \\
\text { to N stress }\end{array}$ & Responsiveness of $\mathrm{N}_{2}$ fix. to $\mathrm{N}$ stress & - & 1 \\
\hline & & Fraction of reserve pool for $\mathrm{N}_{2}$ fix. & 1 day $^{-1}$ & 0.1 \\
\hline & & Dry weight cost for $\mathrm{N}_{2}$ fixation & $\begin{array}{l}\mathrm{kg}(\mathrm{DW}) \mathrm{g}^{-} \\
{ }^{1}(\mathrm{~N})\end{array}$ & 0.01 \\
\hline & & Parameters & Units & Maize \\
\hline \multirow[t]{11}{*}{ Root } & All root type & Root tip diameter & $\mathrm{cm}$ & 0.02 \\
\hline & Root type 0 & Max. root length density in layer1 & $\mathrm{cm} \mathrm{cm}^{-3}$ & 5 \\
\hline & & Max. root length density in layer2 & $\mathrm{cm} \mathrm{cm}^{-3}$ & 3 \\
\hline & & Max. root length density in layer3 & $\mathrm{cm} \mathrm{cm}^{-3}$ & 0.3 \\
\hline & & Max. root length density in layer4 & $\mathrm{cm} \mathrm{cm}^{-3}$ & 0 \\
\hline & Root type 1 & Total root length per unit area & $\mathrm{cm} \mathrm{cm}^{-2}$ & 100 \\
\hline & $\begin{array}{l}\text { Root types } \\
\quad 1 \& 2\end{array}$ & Decrease of root with depth & $1 \mathrm{~m}^{-1}$ & 7 \\
\hline & Root type 2 & Length per unit root dry weight & $\mathrm{m} \mathrm{g}^{-1}$ & 200 \\
\hline & & Root half life & days & 50 \\
\hline & & Root affected by water or nutrient stress & - & 2 \\
\hline & & Root distribution by depth in good uptake & - & 1 \\
\hline \multicolumn{2}{|c|}{ Mycorrhizal fraction } & Fraction of roots infected by mycorrhiza & - & 0.25 \\
\hline \multirow{3}{*}{\multicolumn{2}{|c|}{ Crop effects on nutrient mobility }} & Reduction of constant $\mathrm{P}$ by root activity & $\mathrm{mg} \mathrm{cm}^{-1}$ & 0.00 \\
\hline & & Relative transfer rate for $\mathrm{N}$ pool & $\mathrm{cm}^{2}$ day $^{-1}$ & 0.00 \\
\hline & & Relative transfer rate for $\mathrm{P}$ pool & $\mathrm{cm}^{2}$ day $^{-1}$ & 0.00 \\
\hline \multirow{4}{*}{\multicolumn{2}{|c|}{ Litter Quality }} & Lignin fraction of crop residue & - & 0.20 \\
\hline & & Lignin fraction of crop root residue & - & 0.20 \\
\hline & & Polyphenol fraction of crop residue & - & 0.00 \\
\hline & & Polyphenol fraction of crop root residue & - & 0.00 \\
\hline \multicolumn{2}{|l|}{ Soil Erosion } & Crop cover efficiency factor & - & 0.30 \\
\hline
\end{tabular}


Appendices

Appendix 9 continued.

\begin{tabular}{llcc}
\hline & Parameters & Units & Maize \\
\hline Sensitivity to pest damage & Fraction of crop eaten by pigs & - & 0.00 \\
& Fraction of crop eaten by monkeys & - & 0.00 \\
& Fraction of crop eaten by locust & - & 0.00 \\
& Fraction of crop eaten by nematode & - & 0.00 \\
& Fraction of crop eaten by goat & - & 0.00 \\
& Fraction of crop eaten by buffalo & - & 0.00 \\
Agronomic Yield & Fraction of crop eaten by birds & - & 0.00 \\
& Standard moisture content & - & 0.15 \\
\hline
\end{tabular}




\section{Summary}

Jatropha has been hailed as a miracle biofuel crop, yet there is a little scientifically-sound information to support these claims. The majority of the claims were based on optimistic assumptions rather than on fact, especially where yield is concerned. Claims that jatropha could produce high yield (12 $\mathrm{t} \mathrm{ha}^{-1} \mathrm{yr}^{-1}$ with averages of around $5 \mathrm{t} \mathrm{ha}^{-1} \mathrm{yr}^{-1}$ ) on poor soils resulted in hype and venture capital started to flow and projects commenced. When it became clear that actual yields were on average only around 0.1 to 1 or $2 \mathrm{t} \mathrm{ha}^{-1} \mathrm{yr}^{-1}$ the $^{-}$ hype turned to disappointment. There were early warnings advising caution; yet it seems these were largely ignored, buried or overtaken by the wave of hype.

My modified Gartner hype and disappointment cycle (Chapter 2) highlights the fact that this is not the first time that jatropha has experienced hype; in fact jatropha has been through multiple hype cycles dating back to 1945-50. The disappointment observed during the first hype could simply be attributed to a very specific need that was no longer required. The second and subsequent cycles share many similarities and resemble other miracle new crops. In essence it was in fact a combination of market pull (society, economy, environment and government mandates, subsidies, land allocation, and investors) and technology push factors (oil processing and value adding) that were not sufficiently well prepared or developed, and implemented within the framework and guidelines necessary for realistic commercial development.

From the JARAK research in Indonesia which aimed to separate fact from fiction in the development of jatropha as a new biodiesel crop, it is clear that jatropha hype was used by many to exploit the system. Policies were often influenced by a network of powerful entrepreneurs who manipulated the process for personal gain. Companies and NGO's were able to access subsidies or bank loans and investment funds to develop large or smallholder jatropha plantations, while brokers successfully managed to get a piece of the subsidy cake. Researchers were able to access numerous research funds. While smallholders were often depicted as victims of land grab there were many who joined in the exploitation of jatropha. In hindsight it is easy to see why the jatropha hype ended in disappointment.

This $\mathrm{PhD}$ thesis is the result of the plant production component of the JARAK programme. The thesis hypothesis is that jatropha growth and yield were limited by a lack of understanding of plant characteristics, cropping systems, and management. The overall aim was therefore to understand the above-and belowground biomass allocation and harvest index using a functional branch analysis (FBA) model based approach that included plant architecture. To then use this knowledge to evaluate growth and yield in the monoculture, hedge, and intercropping systems with different management options that can be incorporated into the water, nutrient and light capture in agroforestry systems (WaNuLCAS) model to determine longterm productivity and trade-off analysis.

This study was based on field experiments in Indonesia from 2011 to 2013 and was conducted at two separate locations. Monoculture and intercropping studies from 2012 to 2013 in Mulo Village in the 
Wonosari District, Gunungkidul Regency of Special Province Yogyakarta. A hedge study was conducted from 2011 to 2013 in Leseng Village in Moyo Hulu District, Sumbawa Besar Regency, Nusa Tenggara Barat.

To increase our understanding of the complexity and relationship between jatropha biomass and its allocation/partitioning to various plant parts the FBA model was used. Using the key elements in FBA measurements it became apparent that fruit-bearing twigs occurred predominantly on branches that have diameter from $0.9 \mathrm{~cm}$ to $1.4 \mathrm{~cm}$, and that not all twigs produced fruit. To capture jatropha plasticity or heterogeneity including the short, multi-stemmed growth habit, adjustments to fine-tune the FBA model were required to determine aboveground biomass. Jatropha roots were found to have storage capacity which resulted in the belowground biomass prediction having greater bias than actual. Throughout the study allometric equations were produced and used in preference to destructive sampling to determine biomass. Interestingly and according to the FBA criteria, the jatropha in this study are categorised as shrubs and not trees. Overall the study of jatropha biomass using the FBA model produced variable results depending how well the plant architecture fitted the model (Chapter 3).

Allometric equations from the FBA were used to determine jatropha aboveground biomass from monoculture, intercropping, and hedge cropping systems, including direct measurements of other plant vegetative components and yield. Jatropha yield was then determined from several management practices (e.g. aboveground/shoot and belowground/root pruning and incorporation of jatropha leaf as mulch) in combination with the three cropping systems. Monoculture produced the largest yield, followed by intercropping, and hedges. Variations in yield were not only due to cropping system selection, but also to planting material age and management practices. Shoot pruning in two-year-old monocultures reduced yield from $109 \mathrm{~kg} \mathrm{ha}^{-1}$ to $28 \mathrm{~kg} \mathrm{ha}^{-1}$ due to a $40 \%$ decrease in canopy volume and LAI. In four-year-old jatropha intercropped with maize, root pruning and root barriers reduced yields $80 \%$ by limiting jatropha root access to soil moisture and nutrients in the maize plantings. Intercropping without root barriers and with leaf mulch produced the largest yields of $25 \mathrm{~kg} \mathrm{ha}^{-1}$. In hedge plantings, plant height and planting density influenced yield. Single rows of one-year-old jatropha produced $0.97 \mathrm{~g} \mathrm{~m}^{-1}$ at $10 \mathrm{~cm}$ spacing, $1.69 \mathrm{~g} \mathrm{~m}^{-1}$ at $30 \mathrm{~cm}$, and $0.14 \mathrm{~g} \mathrm{~m}^{-1}$ for $20 \mathrm{~cm}$ of mixture of jatropha- and the nitrogen-fixing legume tree Gliricidia sepium. Pruning significantly decreased LAI with $20 \mathrm{~cm}$ spacing indicating a higher proportion of above-ground biomass was allocated to wood growth. Seed yield for the three cropping systems can be determined by plant height and numbers of productive twigs, although number of inflorescence clusters per productive twig may be more important. Cutting all branches back to $75 \mathrm{~cm}$ above-ground as a pruning technique reduced yields. This effect may be due to interactions between genotype, planting age, and soil water and nutrient availability. Available soil water and the addition of soil nutrients favours yield as observed for pruned trees in the intercropping experiment. If hedges are to be considered as viable options for jatropha seed production, growers will need to consider lower planting densities and nutrient management (Chapter 4). 
Intercrop interactions between jatropha and maize were assessed using a simple additive linear equation where interaction equals fertility plus competition effects. An increase in fertility was produced by the addition of mulch improving soil fertility and effectively modifying the micro-environment by reducing soil evaporation and lowering soil temperature. Competition effects between above and belowground biomass were managed through shoot pruning and root pruning and root barriers respectively. For the competition interaction to have positive net benefit soil fertility must be good and rainfall adequate. However, empirical tree-crop interactions pose a problem as the equation is not able to handle two interacting components at the same time (Chapter 5).

Long-term jatropha and maize productivity was explored over a 20 -year period using the WaNuLCAS model. Relative jatropha and relative maize yields were evaluated in response to different combinations of fertiliser, pruning, and planting density. Intercropping performance was characterised by production possibility frontier (PPF) with attention to two specific points; maize yield when jatropha yield is maximised and jatropha yield when maize yield is maximised. Fertiliser for the maize crops included mulch with $\mathrm{P}$ applied at $72 \mathrm{~kg} \mathrm{ha}^{-1}$, mulch, $\mathrm{N}$ and $\mathrm{P}$ applied at $40 \mathrm{~kg} \mathrm{ha}^{-1}$, and a no-fertiliser no-mulch (control). Pruning scenarios included no pruning, pruning every year and pruning alternate years. Planting density comprised 14 combinations generated from five intra-rows ( $1 \mathrm{~m}$ to $5 \mathrm{~m}$ ) and four inter-row ( $2 \mathrm{~m}$ to $5 \mathrm{~m}$ ) spacings. Our results show application of mulch with $\mathrm{P}$ applied at $72 \mathrm{~kg} \mathrm{ha}^{-1}$ gave the maximum yield for both jatropha and maize. Jatropha maximum relative yield of $250 \%$ of a non-fertilised sole crop plus a relative maize yield of $35 \%$ was obtained from no pruning with a $2 \mathrm{~m}$ inter-row spacing when compared with monocultures. Maximum maize relative yield of $101 \%$ and a jatropha relative yield of $62 \%$ of the sole crop were obtained from pruning every year. Inter-row distance did not affect maize yield when jatropha was pruned each year. There is considerable scope for jatropha and maize intercropping, especially when fertiliser, pruning, and planting density management is considered. Different management practices can reduce jatropha and maize competition and/or enhance complementarity, responding to shifting farmer priorities within the PPF. There remains however a yield trade-off due to the multiple objectives that exist within any intercropping system. If the objective is to maximise jatropha yield, then maize yield suffers, and vice versa. Ultimately, it comes down to the yield combinations of fertiliser, pruning, and plant spacing that provide the highest total revenue per hectare relative to production costs and market prices. The shape of the PPF established in this study differed from common theory when the farmer's practice was used as a reference (Chapter 6).

Finally, the general discussion brings together the main findings, their implications, and limitations. My review of the jatropha hype and disappointment cycle clearly shows that jatropha is now in the reality phase. It will be important that any strategies developed be designed to foster energy development and improve socioeconomic conditions so as to instil the confidence necessary to once again adopt jatropha. The biophysical results from this study highlight a need for high yielding jatropha varieties suitable for areas that do not compete with existing food crops. Production management systems that maximise commercial potential will also need to be developed, but not at the expense of the environment. Our jatropha - maize 
intercropping results show that different management practices such as fertiliser, pruning, and planting density can reduce competition and/or enhance complementarity. Popular belief is that if the objective is to maximise jatropha yield, then maize yield suffers, and vice versa, although this may not be the full story. While intercropping with maize has been the study focus there may be other more suitable crops. In essence there is no single, generic or even correct solution so for growers to maximise plant growth and yield relative to their location and circumstances, they must understand that trade-offs are a necessary part of any multiple objective system. In reality for farmers it is simply yield and what combinations will provide the highest return on investment. Irrespective of how skilled the grower, if the planting material does not perform then breeding programmes must be flexible enough to accommodate change. The problem becomes one of reaction time.

The yield and social benefit uncertainties outlined in our study confirm that jatropha should not be promoted as a smallholder or plantation crop. Only when the underlying causes of the jatropha hype and disappointment have been addressed and satisfied will we see improved commercial performance and socioeconomic conditions and environmental concerns conducive to a successful jatropha biodiesel industry (Chapter 7). 


\section{Samenvatting}

Jatropha is aangeprezen als een wondergewas voor biobrandstof maar er is slechts weinig wetenschappelijke literatuur beschikbaar dat de claims onderbouwt. Optimistische opbrengst schattingen waren aannnames, geen feitelijke waarnemingen. De claim dat Jatropha opbrengsten van $12 \mathrm{t} \mathrm{ha}^{-1}$ jaar $^{-1}$ met gemiddeldes rond 5 $\mathrm{t} \mathrm{ha}^{-1}$ jaar $^{-1}$ mogelijk waren op arme gronden resulteerde in een rage fase, waarin investeringen op gang kwamen en projecten van start gingen. Toen duidelijk werd dat feitelijke opbrengsten gemiddeld 0.1 tot 1 of $2 \mathrm{t} \mathrm{ha}^{-1}$ jaar $^{-1}$ waren, ging de rage over in teleurstelling. Er waren al vroeg aanwijzingen $\mathrm{t}$ die tot voorzichtigheid maanden, maar die werden grotendeels genegeerd, toen de rage golf eenmaal in beweging gekomen was.

Mijn aangepaste Gartner model voor de rage en teleurstellings fase (Hoofdstuk 2) benadrukt dat dit niet de eerste keer was dat Jatropha to een rage leidde; meerdere rage cycli gaan terug tot de periode 1945-50. De teleurstelling van de eerste rage cycluswas toe te schrijven aan een specifieke behoefte aan producten die verdween toen andere oplossing voorhanden kwamen. De tweede en volgend rage cycli hebben eigenschappen gemeen met andere 'wonder' gewassen. De combinatie van markt-gedreven vraag (maatschappelijk draagvlak, economie, milieu en beleidsdoelstellingen, subsidies, landgebruiksrechten en beleggers) en technologisch aanbod (olie verwerking, toegevoegde waarde) waren onvoldoende voorbereid,ontwikkeld en afgestemd op de richtlijnen voor een realistische bedrijfsmatige commerciele ontwikkeling.

Het JARAK onderzoeksprogramma in Indonesia dat tot doel had om feiten boven water te krijgen over de werkelijke mogelijkheden van jatropha as grondstof voor biodiesel, heeft duidelijk gemaakt dat de jatropha rage door velen gebruikt werd om hun eigen doelen te bereiken ten koste van het systeem. Beleid werd beinvloed door een netwerk van machtige investeerders die het proces uitbaatten voor eigen gewin. Bedrijven en NGO's hadden toegang to subsidies, bank leningen en beleggings fondsen om grootschalige jatropha plantages op te zetten of kleine boeren tot productie aan te zetten, terwijl kennis en advies bedrijven een deel van de subsidie cake bemachtigden. Voor onderzoekers was er toegang tot onderzoeksfondsen. Terwijl kleine boeren vaak als slachtoffers van 'landje pik' worden afgeschilderd, waren er velen die aan de jatropha uitbating deelnamen. Terugblikkend is het makkelijk te zien waarom de jatropha rage op een teleurstelling uitdraaide.

Dit proefschrift is gebaseerd op de gewasproductie component van het JARAK programma. De basis hypothese van het proefschrift was dat de groei en opbrengst van jatropha werden beperkt door een beperkt begrip van planteigenschappen, teeltsystemen en management. De algemene doelstelling was allereerst de boven- en ondergrondse verdeling van biomassa over de diverse organen, en dan met name de fractie die naar de vruchten gaat, te begrijpen met behulp van een modelmatige aanpak gebaseerd op plant architectuur, de zogenaamde "Functional Branch Analysis" (FBA). Vervolgens werd deze kennis gebruikt om de groei en de opbrengst van jatropha in monocultuur, mengteelt en heg systemen te voorspellen bij gebruik van 
verschillende management opties. Hierbij werd een model (WaNulCAS) gebruikt voor de benutting van water, nutriënten en licht in agroforestry systemen om inzicht te krijgen in de lange-termijn productie en interactie tussen systeem componenten en functies.

De studie was gebaseerd op veldexperimenten in Indonesië van 2011 tot 2013 en werd uitgevoerd op twee verschillende locaties. Monocultuur en mengteelt studies van 2012 tot 2013 in het dorp Mulo in Wonosari District, Gunungkidul Regency van de Speciale Provincie Yogyakarta. Een heggen studie werd uitgevoerd van 2011 tot 2013 in het dorp Leseng in Moyo Hulu District, Sumbawa Besar Regency, Nusa Tenggara Barat Provincie.

Om ons begrip te vergroten van de complexiteit en de relatie tussen jatropha biomassa en de verdeling over verschillende plantendelen werd het FBA-model gebruikt. Uit de FBA metingen bleek dat vruchtdragende twijgen met name voorkwamen op takken met diameters van $0,9 \mathrm{~cm}$ tot $1,4 \mathrm{~cm}$, en dat niet alle twijgen vruchten produceerden. Om recht te doen aan jatropha plasticiteit en heterogeniteit, met inbegrip van de korte, meerstammige groeiwijze, moest het FBA model aangepast worden om met hoge precisie de bovengrondse biomassa te bepalen. Jatropha wortels bleken grote opslagcapaciteit te hebben waardoor model aanpassing noodzakelijk was omdat de initieel voorspelde waarde van de ondergrondse biomassa een grotere bias had dan de werkelijke waarde. Gedurende het verdere onderzoek werden allometrische vergelijkingen afgeleid met FBA gebruikt om biomassa te bepalen, in plaats van destructieve bemonstering. Interessant voor bepaalde beleidsdiscussies is dat volgens de FBA criteria Jatropha in deze studie gecategoriseerd is als struik en niet als boom. De studie van jatropha biomassa met behulp van het FBA model produceerde wisselende resultaten, afhankelijk van hoe goed de plant architectuur bij het model paste (Hoofdstuk 3).

Directe metingen van vegetatieve componenten en opbrengst samen met allometrische vergelijkingen gebaseerd op stamdiameter werden gebruikt om bovengrondse biomassa in jatropha monocultuur, mengteelt en heg systemen te bepalen. De jatropha opbrengst werd vervolgens bepaald voor verschillende management praktijken (bijv snoei van bovengrondse scheuten en ondergrondse wortels en gebruik van jatropha blad als mulch) in combinatie met de drie teeltsystemen. Monocultuur produceerde de hoogste opbrengst, gevolgd door mengteelt en heggen. Variaties in opbrengst hingen niet alleen af van de selectie van teeltsysteem, maar ook van leeftijd van het plantmateriaal en management praktijken. Snoei van scheuten in twee-jarige monoculturen verminderde de opbrengst van $109 \mathrm{~kg} \mathrm{ha}^{-1}$ tot $28 \mathrm{~kg} \mathrm{ha}^{-1}$ door een $40 \%$ daling in kroon volume en blad-oppervlakte index (LAI). In vier jaar oude jatropha in mengteelt met maïs, verminderden wortel snoei en wortel barrières de jatropha opbrengsten met $80 \%$ door het beperken van de toegang van de jatropha wortels tot bodemvocht en voedingsstoffen in de maïs aanplant. Mengteelt zonder wortel barrière en met blad mulch produceerde de grootste jatropha opbrengst van $25 \mathrm{~kg} \mathrm{ha}^{-1}$. In heg aanplant werd opbrengst beïnvloed door planthoogte en plantafstand. Enkele rijen van één jaar oude jatropha produceerden $0,97 \mathrm{~g} \mathrm{~m}^{-1}$ bij $10 \mathrm{~cm}$ afstand, $1,69 \mathrm{~g} \mathrm{~m}^{-1}$ bij $30 \mathrm{~cm}$ en $0,14 \mathrm{~g} \mathrm{~m}^{-1}$ voor een plantafstand van $20 \mathrm{~cm}$ in mengteelt van jatropha met de stikstofbindende vlinderbloemige boom Gliricidia sepium. Snoeien leidde tot een significant 
lagere LAI bij een plantafstand van $20 \mathrm{~cm}$ hetgeen wijst op een grotere toewijzing van de bovengrondse biomassa aan houtgroei. Zaadopbrengst voor de drie teelten kan worden bepaald door planthoogte en het aantal productieve twijgen, hoewel het aantal clusters van bloeiwijzen per productieve twijg belangrijker kan zijn. Afsnijden van alle takken tot $75 \mathrm{~cm}$ boven de grond als snoei techniek verminderde de opbrengsten. Dit effect kan het gevolg zijn van interacties tussen genotype, planten leeftijd en de beschikbaarheid van water en voedingsstoffen in de bodem. Beschikbaar bodemwater en de toevoeging van voedingsstoffen lijken opbrengsten te bevorderen zoals geobserveerd werd in de gesnoeide bomen in het mengteelt experiment. Mochten heggen als haalbare opties voor jatropha zaadproductie overwogen worden, dan moeten telers lagere plantdichtheden en actief nutriëntenbeheer overwegen (Hoofdstuk 4).

Interacties tussen jatropha en maïs in mengteelt werden beoordeeld met behulp van een eenvoudige additief lineaire vergelijking waarin interactie het resultaat is van effecten via bodemvruchtbaarheid en concurrentie. Een verhoging van de bodemvruchtbaarheid werd bereikt door het toevoegen van mulch, leidend tot verbetering van bodemvruchtbaarheid en het effectief veranderen van de micro-omgeving door het verminderen van bodemverdamping en verlagen van de bodemtemperatuur. Concurrentie tussen boven en ondergrondse biomassa werd gemanaged door respectievelijke snoei van scheuten en wortels en aanleg van barrières in de wortel zone. Om een positief netto voordeel te hebben van de interactie, moeten bodemvruchtbaarheid goed en regenval voldoende zijn. Empirische boom-gewas interacties vormen een probleem omdat de vergelijking geen twee interacterende componenten tegelijkertijd kan voorspellen (Hoofdstuk 5).

Jatropha en maïs productiviteit op de lange termijn werden onderzocht over een periode van 20 jaar met behulp van het WaNuLCAS model. Relatieve jatropha en relatieve maïs opbrengsten werden geëvalueerd in reactie op verschillende combinaties van bemesting, snoeien en plantdichtheid. Mengteelt prestaties werden gekenmerkt door een productiemogelijkhedencurve (PPF) met aandacht voor twee specifieke punten; opbrengst van maïs als jatropha opbrengst wordt gemaximaliseerd en jatropha opbrengst wanneer opbrengst van maïs wordt gemaximaliseerd. De gebruikte meststoffen voor maïs gewassen bestonden uit mulch plus 72 $\mathrm{kg} \mathrm{P} \mathrm{ha}{ }^{-1}$, mulch zonder meststoffen, $40 \mathrm{~kg} \mathrm{~N}$ en $40 \mathrm{~kg} \mathrm{P} \mathrm{ha}{ }^{-1}$, en een geen-bemesting geen-mulch behandeling (controle). Snoeiscenario's bestonden uit geen snoei, snoei elk jaar en snoei om het jaar. Plantdichtheid bestond uit 14 combinaties gegenereerd op basis van vijf binnen-rij ( 1 tot $5 \mathrm{~m}$ ) en vier tussenrij (2 tot $5 \mathrm{~m})$ afstanden.

Maximale opbrengsten voor zowel maïs als jatropha werden verkregen met mulch en $72 \mathrm{~kg} \mathrm{P} \mathrm{ha-1}$. Een relatieve Jatropha opbrengst van $250 \%$ vergeleken met een onbemeste monocultuur en een relatieve maïs opbrengst van $35 \%$ werden verkregen in een ongesnoeide jatropha bestand met $2 \mathrm{~m}$ afstand tussen de rijen. Maximale relatieve maïs opbrengst van $101 \%$ en een relatieve jatropha opbrengst van $62 \%$ van de monocultuur werden verkregen bij jaarlijks snoeien. Rijafstand had geen invloed op opbrengst van maïs als jatropha elk jaar werd gesnoeid. Er zijn veel mogelijkheden voor jatropha-maïs mengteelt, vooral als 
kunstmest, snoeien en plantdichtheid als management maatregelen in aanmerking genomen worden. Verschillende management praktijken kunnen de concurrentie tussen jatropha en maïs verminderen en/of complementariteit verhogen, in reactie op verschuiving van boeren prioriteiten binnen de PPF. Er blijft echter een afruil in opbrengsten als gevolg van de vele doelstellingen die bestaan in ongeacht welk mengteelt systeem. Als het doel is om jatropha opbrengst te maximaliseren, dan zal de maïs opbrengst lijden, en vice versa. Uiteindelijk komt het neer op de opbrengst combinaties van mest, snoeien en plant afstanden die de hoogste totale opbrengst per hectare opleveren in relatie tot productiekosten en marktprijzen. De vorm van de PPF die in dit onderzoek vastgesteld is, verschilt van de gangbare theorie waarin de boerenpraktijk als referentie gebruikt wordt (Hoofdstuk 6).

Ten slotte brengt de algemene discussie de belangrijkste bevindingen, de implicaties en beperkingen daarvan samen. Mijn analyse van de jatropha rage en teleurstelling cyclus geeft duidelijk aan dat jatropha zich nu in de realiteits fase van deze cyclus bevind. Het is nu belangrijk dat ongeacht welke strategie wordt ontworpen, deze in staat moet zijn om energie-ontwikkeling te bevorderen en sociaal-economische condities te verbeteren, teneinde het vertrouwen te kweken dat nodig is om jatropha opnieuw te adopteren. De biofysische resultaten van deze studie benadrukken de behoefte aan hoog producerende jatropha rassen geschikt voor gebieden die niet concurreren met de bestaande voedselgewassen. Productie management systemen die commercieel potentieel maximaliseren zullen ook moeten worden ontwikkeld, maar niet ten koste van het milieu. Onze jatropha/maïs mengteelt resultaten laten zien dat verschillende managementpraktijken zoals kunstmest, snoeien en plantdichtheid concurrentie kunnen verminderen en/of complementariteit kunnen verhogen. Veel mensen denken dat als het doel is om jatropha opbrengst te maximaliseren, dat dan de maïs opbrengst lijdt, en vice versa, maar dat is misschien niet het volledige verhaal. Terwijl de studie gericht was op mengteelt met maïs kunnen er andere, meer geschikte gewassen zijn. In wezen is er geen enkele, generieke of zelfs correcte oplossing, dus voor telers om de groei van planten en ontwikkeling te maximaliseren met betrekking tot hun locatie en omstandigheden, moeten ze begrijpen dat afruil een noodzakelijk onderdeel is van een systeem met meervoudige doelen. In de werkelijkheid voor de boeren is het gewoon opbrengst en welke combinaties de hoogste return on investment bieden. Ongeacht hoe vaardig de teler is, als het plantmateriaal niet voldoet dan moet een veredelingsprogramma flexibel genoeg zijn om verandering op te vangen. Het probleem wordt dan de reactietijd. De onzekerheden in oogst en sociale opbrengsten zoals beschreven in onze studie bevestigen dat jatropha niet moet worden aanbevolen als een kleine boeren of plantage gewas. Alleen wanneer de biofysische en non-biofysische problemen zijn opgelost, zullen we uitzicht hebben op verbeterde commerciële jatropha prestaties, sociaal-economische condities en de zorg voor het milieu die bevorderlijk voor een succesvolle jatropha biodiesel industrie (Hoofdstuk 7). 


\section{Rangkuman}

Beberapa waktu yang lalu tanaman jarak pagar (Jatropha curcas L.) dielu-elukan sebagai 'miracle plant' sumber biofuel, namun tidak ada dasar ilmiah yang mendukung klaim tersebut. Mayoritas klaim tersebut dibangun berdasarkan asumsi optimis bukannya fakta, terutama yang berkaitan dengan hasil panen. Klaim bahwa jarak pagar memiliki potensi panen (biji kering) hingga $12 \mathrm{t} \mathrm{ha}^{-1}$ tahun $^{-1}$ dengan rata-rata panen $5 \mathrm{tha}^{-}$ ${ }^{1}$ tahun $^{-1}$ pada lahan kritis menyebabkann melambungnya ('hype') minat terhadap jarak pagar dan mulainya aliran modal usaha serta munculnya berbagai proyek. Namun, faktanya rata-rata panen berkisar 0,1 sampai 1 atau $2 \mathrm{t} \mathrm{ha}^{-1} \operatorname{tahun}^{-1}$. Akibatnya 'hype' jarak pagar akhirnya berubah menjadi kekecewaan ('disappointment'). Meskipun sebelumnya ada peringatan perihal propaganda jarak pagar, namun hal ini tidak dihiraukan justru terkubur atau tertutupi oleh besarnya gelombang propaganda.

Pada Bab 2, modifikasi siklus 'hype' dan 'disappointment' Gartner digunakan untuk menjelaskan bahwa melambungnya minat terhadap jarak pagar sudah terjadi berulang kali (hingga beberapa siklus) bahkan sejak tahun 1945-50. Pertama kali minat terhadap jarak pagar menurun dikarenakan hilangnya kebutuhan spesifik atas kegunaan jarak pagar. Pada siklus kedua dan selanjutnya terdapat kesamaan penyebab turunnya minat terhadap jarak pagar, yaitu jarak pagar masih merupakan tanaman baru/liar yang belum dimuliakan. Penyebab lainnya yaitu kombinasi berbagai faktor seperti kombinasi daya tarik pasar (yang berhubungan dengan kesejahteraan masyarakat, ekonomi, lingkungan, dukungan dari pemerintah berupa mandat, subsidi, alokasi lahan penanaman dan investor) serta daya dorong teknologi (yang berhubungan dengan pengolahan minyak dan peningkatan nilai tambah untuk produk jarak pagar) yang tidak disiapkan atau dibangun dan dikembangkan dalam kerangkan dan pedoman komersial yang realistis.

Berdasarkan penelitian dari tim JARAK di Indonesia yang bertujuan untuk membedakan fakta dari fiksi pada pengembangan jarak pagar sebagai tanaman biofuel, maka terlihat jelas bahwa 'hype' jarak pagar telah ditunggangi oleh berbagai pihak yang memanfaatkan sistem tersebut. Kebijakan pemerintah seringkali dipengaruhi oleh jaringan wirausahawan yang memanipulasi proses kebijakan untuk kepentingan pribadi atau golongan. Berbagai perusahaan dan lembaga swadaya masyarakat (LSM) mendapatkan akses subsidi atau pinjaman dana dari bank dan dana investasi untuk mengembangakan perkebunan besar atau pertanian jarak pagar, hingga makelar pun mendapat bagian dari subsidi. Tidak ketinggalan para peneliti juga mendapat hibah berbagai dana penelitaan. Lebih jauh, petani kecil yang sebelumnya sering digambarkan sebagai korban dari perampasan lahan juga turut serta mengambil keuntungan dari jarak pagar. Oleh karena itu tidak mengherankan bahwa jika dikilas balik besarnya gelombang minat pada jarak pagar berujung pada kekecewaan.

Disertasi S3 ini mencakup komponen produksi tanaman yang merupakan bagian dari program JARAK. Hipotesis disertasi ini adalah pertumbuhan dan produksi jarak dibatasi oleh kurangnya pengertian terhadap karakteristik tanaman, sistem tanam, dan manajemen. Tujuan umum disertasi ini yaitu: pertama, memahami 
faktor biofisik dari alokasi biomassa tajuk dan akar termasuk indeks panen dengan menggunakan model pendekatan analisis cabang fungsional (functional branch analysis; FBA) yang memperhitungkan arsitektur/percabangan tanaman. Kedua, menggunakan pengetahuan yang diperoleh sebelumnya untuk mengevaluasi pertumbuhan dan produksi pada sistem tanam monokultur, tumpang sari, dan pagar, yang dikombinasikan dengan perlakuan manajemen. Model simulasi air, hara, penangkapan cahaya dalam sistem wanatani (water, nutrient and light capture in agroforestry systems; WaNulCAS) digunakan untuk mengevaluasi produktivitas jangka panjang beserta interaksi antara komponen dan fungsi sistem yang berbeda, berikut analisa'trade-off'.

Disertasi ini disusun berdasarkan percobaan lapangan di Indonesia yang dilaksanakan pada tahun 2011 hingga 2013. Penelitian sistem monokultur dan tumpangsari dipelajari pada tahun 2012 hingga 2013 di Desa Mulo, Kecamatan Wonosari, Kabupaten Gunungkidul, Daerah Istimewa Yogyakarta. Penelitian sistem pagar dipelajari pada tahun 2011 hingga 2013 di Desa Leseng, Kecamatan Moyo Hulu, Kabupaten Sumbawa Besar, Provinsi Nusa Tenggara Barat.

Model FBA digunakan untuk meningkatkan pemahaman kita terhadap kompleksitas dan hubungan antara biomassa dan alokasi ke berbagai organ jarak pagar. Berdasarkan pengukuran dengan karakterisasi FBA, cabang pembawa buah mempunyai kisaran diameter dari $0,9 \mathrm{~cm}$ hingga 1,4 cm (disebut sebagai cabang produktif) dan tidak semua cabang berbunga/berbuah. Selain itu jarak pagar mempunyai plastisitas dan heterogenitas seperti berbatang pendek dan bercabang lebih dari satu, maka diperlukan penyesuaian terhadap model FBA dalam menentukan biomassa tajuk. Akar jarak pagar diduga mempunyai fungsi sebagai tempat penyimpanan sehingga terdapat penyimpangan antara biomassa pendugaan dan aktual. Penelitian ini menghasilkan beberapa persamaan alometrik yang dapat digunakan untuk menentukan biomassa jarak pagar tanpa menggunakan metode sampel destruktif. Berdasarkan kriteria FBA, jarak pagar yang digunakan pada penelitian ini dikategorikan sebagai perdu dan bukan pohon. Secara umum penelitian biomassa jarak pagar dengan menggunakan model FBA memberikan hasil yang bervariasi tergantung pada kemiripan arsitektur tanaman yang digunakan dengan model (Bab 3).

Selanjutnya persamaan alometrik dari model FBA digunakan untuk menentukan biomassa tajuk pada sistem monokultur, tumpang sari, dan pagar, sedangkan komponen vegetatif lain dan hasil panen jarak pagar diukur secara langsung. Hubungan antara hasil panen dan komponen vegetatif tanaman jarak pagar dikembangkan pada sistem tanam yang berbeda yang dikombinasi dengan perlakuan manajemen (seperti pemangkasan tajuk dan akar, dan pemberian mulsa dari pangkasan daun jarak). Sistem monokultur menghasilkan panen tertinggi, diikuti dengan sistem tumpang sari dan pagar. Variasi pada hasil panen tidak hanya disebabkan oleh sistem tanam yang berbeda namun juga disebabkan oleh umur dan perlakuan manajemen yang berbeda. Pemangkasan tajuk jarak pagar yang berumur 2 tahun pada sistem monokultur mengurangi hasil panen dari $109 \mathrm{~kg} \mathrm{ha}^{-1}$ menjadi $28 \mathrm{~kg} \mathrm{ha}^{-1}$ yang disebabkan oleh penurunan $40 \%$ volume kanopi dan indeks luas daun (leaf area index; LAI). Pada sistem tumpang sari, semua tajuk jarak pagar dipangkas pada umur 4 tahun. 
Selanjutnya pada perlakuan yang akarnya dipangkas serta diberi plastik penghalang akar di antara barisan jarak pagar dengan tanaman sela jagung, hasil panen jarak pagar berkurang hingga $80 \%$. Adanya plastik penghalang menghambat akar jarak pagar dalam mengambil air dan unsur hara yang berada pada tanaman sela jagung. Tumpang sari jarak pagar tanpa plastik penghalang akar namun diberi mulsa daun jarak menghasilkan panen terbesar yaitu $25 \mathrm{~kg} \mathrm{ha}^{-1}$. Pada sistem pagar, tinggi tanaman mempengaruhi hasil panen jarak pagar. Jarak pagar yang ditanam dalam satu baris dan berumur 1 tahun menghasilkan panen sebesar $0.97 \mathrm{~g} \mathrm{~m}^{-1}$ untuk jarak tanam $10 \mathrm{~cm}$, sebesar 1,69 $\mathrm{g} \mathrm{m}^{-1}$ untuk jarak tanam $30 \mathrm{~cm}$, dan sebesar $0,14 \mathrm{~g} \mathrm{~m}^{-1}$ untuk jarak tanam $20 \mathrm{~cm}$ pada jarak pagar yang ditanam berselang-seling dengan gamal (Gliricidia sepium); pohon legum pengikat nitrogen. Pemangkasan secara signifikan menurunkan LAI pada jarak tanam $20 \mathrm{~cm}$ dikarenakan porsi biomassa tajuk lebih banyak dialokasikan untuk pertumbuhan kayu. Hasil panen pada tiga sistem tanam menunjukkan bahwa produksi dapat ditentukan berdasarkan tinggi tanaman dan jumlah cabang produktif, walaupun ada kemungkinan jumlah bunga majemuk pada setiap cabang produktif dapat menjadi faktor penentu. Pemangkasan tajuk hingga tinggi jarak pagar $75 \mathrm{~cm}$ mengakibatkan penurunan hasil panen. Hal ini mungkin dapat disebabkan oleh interaksi antara genotipe, umur, dan kondisi air/lengas dan hara tanah. Ketersediaan air tanah dan penambahan unsur hara mendukung peningkatan panen seperti pada percobaan tumpang sari. Pada sistem pagar, untuk meningkatkan hasil panen perlu dipertimbangkan penambahan jarak tanam dan manajemen hara tanah (Bab 4).

Interaksi antara jarak pagar dengan jagung dinilai berdasarkan persamaan linear aditif sederhana yaitu perbaikan kesuburan tanah ditambah dengan kompetisi air, hara, dan cahaya. Perbaikan kesuburan tanah berasal dari penambahan mulsa daun jarak yang dapat meningkatkan kesuburan tanah dan secara tidak langsung mengubah mikroklimat akibat berkurangnya penguapan dan suhu tanah. Pengaruh kompetisi jarak pagar terhadap jagung pada biomassa tajuk dan akar dapat dikelola melalui pemangkasan tajuk dan akar disertai dengan pemberian plastik penghalang akar. Agar kompetisi mempunyai interaksi yang bernilai positif maka kesuburan tanah dan curah hujan harus memadai. Hanya saja persamaan di atas tidak mampu menilai dua komponen yang berinteraksi pada waktu bersamaan (Bab 5).

Produktivitas jangka panjang jarak pagar dan jagung dieskplorasi selama 20-tahun periode tanam dari jarak pagar dengan menggunakan model WaNuLCaS. Hasil panen relatif jarak pagar dan jagung merupakan perbandingan hasil panen jarak atau jagung dari tumpang sari dibandingkan dengan hasil panen jarak atau jagung dari monokultur. Hasil panen relatif jarak pagar dan jagung dievaluasi dengan kombinasi perlakuan pemupukan, pemangkasan, dan jarak tanam. Tumpang sari dinilai dengan kurva kemungkinan produksi (production possibility frontier; PPF) pada dua kondisi; hasil panen jagung pada saat hasil panen jarak pagar maksimal dan hasil panen jarak pagar pada saat hasil panen jagung maksimal. Pemupukan jagung meliputi pemberian mulsa daun pangkasan jarak pagar ditambah dengan $72 \mathrm{~kg} \mathrm{ha}^{-1}$ pupuk anorganik $\mathrm{P}$, mulsa daun jarak pagar saja, pupuk anorganik $\mathrm{N}$ dan $\mathrm{P}$ masing-masing sebanyak $40 \mathrm{~kg} \mathrm{ha}^{-1}$, beserta tanpa mulsa daun pangkasan jarak dan tanpa pupuk anorganik (kontrol). Perlakuan pemangkasan mencakup tidak ada pemangkasan, pemangkasan setiap tahun dan dua tahun sekali. Perlakuan jarak tanam meliputi 14 kombinasi 
yang berasal dari 5 variasi jarak tanam yang berbeda dalam satu baris (yaitu dari 1 m hingga $5 \mathrm{~m}$ ) dan 4 variasi jarak tanam yang berbeda antar baris (yaitu dari $2 \mathrm{~m}$ hingga $5 \mathrm{~m}$ ). Perlakuan pemupukan dengan mulsa daun pangkasan jarak dengan $72 \mathrm{~kg} \mathrm{ha}^{-1}$ pupuk anorgnaik $\mathrm{P}$ menghasilkan panen relatif maksimal untuk tumpang sari jarak pagar dan jagung. Perlakuan jarak tanam $2 \mathrm{~m}$ di dalam baris dengan jarak pagar yang tidak dipangkas menghasilkan panen relatif maksimum untuk jarak pagar tumpang sari hingga $250 \%$ lebih banyak dibandingkan dengan panen jarak pagar monokultur yang tidak dipupuk, dan ditambah $35 \%$ panen jagung. Pemangkasan jarak pagar setiap tahun menghasilkan panen relatif maksimal untuk tanaman sela jagung sebesar $101 \%$ dan ditambah dengan hasil panen relatif jarak pagar sebesar $62 \%$. Variasi jarak tanam di dalam baris jarak pagar tidak mempengaruhi hasil panen tanaman sela jagung apabila jarak pagar dipangkas setiap tahun. Peluang untuk mengembangkan tumpang sari jarak pagar dan tanaman sela jagung timbul apabila faktor manajemen seperti pemupukam, pemangkasan, dan pengaturan jarak tanam dipertimbangkan. Perlakuan manajemen yang berbeda dapat mengurangi kompetisi jarak pagar dan tanaman sela jagung atau justru meningkatkan efek saling menguntungkan, dan PPF dapat berubah mengikuti perubahan prioritas petani. 'Trade-off' hasil panen dalam sistem tumpang sari dikarenakan ada beberapa sasaran pencapaian hasil panen yang berbeda. Apabila tujuannya untuk memaksimalkan hasil panen jarak pagar saja, maka hasil panen jagung akan berkurang, dan sebaliknya. Pertimbangan terakhir akan ditentukan berdasarkan hasil panen dengan kombinasi perlakuan pemupukan, pemangkasan, dan jarak tanam yang memberikan total pendapatan terbesar per hektar relatif terhadap biaya produksi dan harga pasar. Selanjutnya, bentuk PPF yang dihasilkan oleh studi ini berbeda dengan teori umum apabila referensi yang digunakan adalah dari praktek petani (Bab 6).

Akhirnya, bab diskusi umum menyatukan temuaan utama, implikasi dan keterbatasan dari studi ini. Tinjauan pustaka terhadap 'hype' dan 'disappointment' menunjukkan bahwa jarak pagar sekarang berada pada fase menghadapi kenyataan 'reality phase'. Kedepannya perlu dipertimbangkan bahwa strategi yang dirancang oleh pihak manapun, perlu sepenuhnya mendukung pengembangan di bidang energi dan sosial ekonomi sehingga kepercayaan untuk mengadopsi jarak pagar dapat dipulihkan kembali. Hasil biofisik dari studi ini menggarisbawahi perlunya pengembangan varietas unggul jarak pagar yang disesuaikan pada kondisi lahan setempat tanpa bersaing dengan tanaman pangan yang sudah ada. Sistem manajemen produksi yang memaksimalkan potensi komersial juga perlu dikembangkan, namun dengan tidak mengorbankan aspek lingkungan. Hasil tumpang sari jarak pagar dan jagung menunjukkan bahwa perlakuan manajemen yang berbeda seperti pemupukan, pemangkasan, dan jarak tanam dapat mengurangi kompetisi dan/atau meningkatkan pengaruh yang saling menguntungkan. Namun, masalah sebenarnya jauh lebih kompleks daripada sekedar memaksimalkan hasil panen jarak pagar atau jagung. Studi ini menggunakan tanaman sela jagung meskipun bisa saja diaplikasikan pada tanaman lain yang lebih sesuai. Intinya tidak ada solusi yang dapat diberikan kepada para petani sebagai rekomendasi universal untuk memaksimalkan pertumbuhan dan hasil panen tanaman yang berlaku pada semua lahan dan kondisi petani, karena selalu ada 'trade-off' terutama apabila sistem tanam yang digunakan mempunyai beberapa tujuan. Namun, pada akhirnya petani akan mempertimbangkan kombinasi perlakuan yang dapat memberikan keuntungan maksimal. Terlepas dari 
keterampilan yang dimiliki oleh petani, apabila benih/bibit/bahan tanam yang digunakan tidak menguntungkan maka pemuliaan tanaman seharusnya cukup fleksibel untuk mengakomodasi perubahan yang ada. Masalahnya respon perubahan pada pemuliaan tanaman memerlukan waktu yang lama.

Ketidakpastian hasil panen dan manfat sosial yang dipaparkan pada studi ini menegaskan bahwa jarak pagar seharusnya tidak dipromosikan kepada petani dan sebagai tanaman perkebunan. Apabila permasalahan biofisik dan non-biofisik telah ditanggulangi seperti peningkatan hasil panen komersial dan kondisi sosial ekonomi serta lingkungan, maka pengembangan industri biodiesel jarak pagar akan menjadi kondusif (Bab 7). 


\section{Acknowledgements}

My PhD studying Jatropha curcas in Indonesia has been a long and challenging one. I started late in 2010, at a time when the jatropha hype in Indonesia was already in the disappointment phase. As my research was affiliated with the JARAK cluster program, it quickly became apparent that a review of the jatropha hype and disappointment, as well as biophysical aspects would be required to provide research synergy.

The downside of the jatropha disappointment was a lack of suitable jatropha research sites. Jatropha companies were going bankrupt; farmers were uprooting or abandoning their jatropha, all because jatropha was unable to fulfil the role of miracle biofuel plant. I explored 15 different sites from Bengkulu (western part of Indonesia) to Jayapura (eastern part of Indonesia) involving private jatropha companies, research institutions, universities, to local farmers in order to identify suitable research sites.

While there were challenges along the way I learned so much about jatropha during my field explorations, observations, and discussions with the different people I encountered. My appreciation of the complexity of plants in general and more specifically jatropha has increased enormously. This $\mathrm{PhD}$ has taught me to be more patient, caring, and understanding. The aspect that surprised me the most is my tenacity to keep on trying, to adapt and to rethink, turning adversity to my advantage. The $\mathrm{PhD}$ has cultivated my feelings of sympathy and gratitude towards life, family, friends, and people that I have encountered along the way. There are many people who have contributed to, and assisted me during my journey from the field work and research, to paper publication and to the final thesis writing. I am grateful to them all and would like to convey my most sincere and heartfelt gratitude and thanks. If I have missed anyone then please accept my apologies for it is not intentional.

First of all I thank KNAW-NWO, Netherlands for providing funding for my PhD study within the JARAK cluster: 'The Commoditisation of An Alternative Biofuel Crop in Indonesia' under the AbF programme. Thank you to Van Vollenhoven Institute Law Department, Leiden University with whom I was affiliated together with Plant Production Systems Group from Wageningen University, The Netherlands. Many thanks for the administrative and financial support throughout my study. Thank you also to Research Centre for Bioresources \& Biotechnology of Agricultural from the IPB University in Bogor, Indonesia who served as the Indonesian affiliation, and provided administrative assistance during my field research. Thank you to ICRAF Bogor, Indonesia for their support and use of their facilities during my research analysis.

To my first promoter, Prof. Dr. Ken E Giller I would like to express my heartfelt thanks for selecting me as a $\mathrm{PhD}$ candidate with your chair group, PPS, Wageningen University. Your positive feedback and support during my study have been an inspiration. The social events you held in your house and the warmth shown by your family was really nice and relaxing; I have many great memories! To my second promoter, Prof. Dr. Meine van Noordwijk, thank you so much Pak for all the wonderful times I had at ICRAF in Bogor, 
Indonesia. Thank you for the email feedback and support meetings while I was learning the FBA model, tree-crop-soil interactions, WaNuLCAS model, and data analysis in general. I enjoyed our discussions and your guidance, and appreciated your interest and involvement in my study. Thank you also for including me in the ICRAF circle as it has widened my networking and contacts. To my co-promotor, Dr. Maja Slingerland, thank you so very much for your continual support, feedback, and motivational comments. From the development of my thesis proposal to our field trips to find my research sites, to finding additional research funds, and for your help in our papers and my thesis corrections. You were always there for me right from the start until the end and I thank you for that. Thank you for the wonderful dinner with your family that I enjoyed so much.

I am grateful to Dr. Jacqueline Vel and the JARAK team members. It was a unique and interesting experience to be affiliated with scientists from JARAK cluster of Van Vollenhoven Institute Law; Leiden University. The symposium, seminar, discussions about the social, political, law, and anthropological aspects of jatropha in Indonesia have increased my understanding of the complexity of my own country in general and in particularly for jatropha biofuel. I am thankful to the all JARAK members especially to Prof. Dr. Gerard Persoon, Dr. Suraya Affif, Dr. Pujo Semedi, Dr. Deasy Simandjuntak, Gunawan, Henky, and Loes whom I had a close association with, and received great support throughout my study.

I am thankful also to Raymond Jongschaap and Frank de Ruijter from PRI WUR for their kind assistance in allowing me access in their jatropha research site in Sumbawa Besar, NTB in Indonesia. Special thanks again to Raymond for the many jatropha papers and EndNote links he provided at the start of my PhD study.

As with any $\mathrm{PhD}$ there are many people who are not directly affiliated with the $\mathrm{PhD}$, but who in their own way make substantial contributions to the successful completion. I sincerely thank the following organisations and people according to their location.

\section{Bengkulu}

\section{PT. Kandiyasa Energi Utama}

Ir. Halim Fathoni for the valuable discussions on the planting, performance, and planning for valorisation of jatropha at Muko-muko.

\section{Toloram Group}

Mr. H.K. Arora for the valuable discussions on the planting, performance, and planning for valorisation of jatropha at Manna.

\section{West Java}

\section{IPB University Bogor}

IPB University in Bogor for their assistance and support, in particular:

Research Centre for Bioresources \& Biotechnology of Agricultural

Thank you to Prof. Dr. Sony Suharsono for providing administrative support, and insight into field research situations in Indonesia, in particular for arranging a visit and discussion with PT. JEDO. 


\section{Department of Geophysics and Meteorology}

Pak Ir. Bregas Budianto for providing technical advice and support for equipment I used at my research site.

\section{ICRAF Bogor}

I would like to acknowledge and thank ICRAF Bogor for their assistance and support, in particular:

\section{Ecological Modelling Unit}

Degi Harja Asmara, Lisa Tanika, and Betha Lusiana for the discussions in modelling and agroforestry research, Rachmat Mulia and Ni'matul Khasanah for guidance in FBA and WaNuLCAS modelling, to Ibu Gita for the administrative assistance, and to Bapak Yusi for the IT assistance, and Economics and Policy Analysis Unit.

Thank you to Muhammad Sofiyuddin for the discussions about jatropha economic analysis.

\section{Indonesian Spice and Industrial Crops Research Institute (Balittri) in Sukabumi}

Thank you for the opportunity to visit and discuss IP-P development, cultivation, and valorisation. Special thanks to Pak Deden Syafaruddin and Pak Maman Herman for chairing the discussion.

\section{Indonesian Soil Research Institute (Balittanah) in Bogor}

Thank you for providing soil and plant analysis. Special thanks to Ibu Nurjanah and Ibu Ika for administration assistance, Pak Sambas and Dr. Ladiyani Retno for individual training on soil sampling and analysis.

\section{PT. Bumi Mas Eka Persada in Cikarang}

Thank you to Pak Daud Dharsono for allowing me to visit their jatropha site and to Pak Roy Hendroko, Sakri, and Matori for the tour and subsequent discussions. Special thanks again to Pak Roy for the invitation to join the EBTKE conference.

\section{Banten}

\section{PT. JEDO}

Mr. Murakami Kazuaki for the opportunity to visit and discuss jatropha development and processing. Special thanks to Pak Heri for providing the field information and showing Maja and I around the site.

\section{Center for Science, Research, and Technology (PUSPITEK) in Serpong;}

Pak Johadi for providing the bio-fungicide Trichoderma used during my research.

\section{Central Java}

\section{PT. Jatropha Green Energy Kudus}

Thank you for allowing me to visit and conduct my research experiments at the Gunungkidul site and for the use of your planting material. Special thanks to Pak Agung and Hartoyo for their advice and discussions regarding jatropha plantings, and to Mas Topan for showing me the farmers' jatropha plantings.

\section{University of Gadjah Mada (UGM) in Yogyakarta}

I would like to acknowledge and thank the University of Gadjah Mada (UGM) in Yogyakarta for their assistance and support, in particular:

\section{Faculty of Agriculture - Department of Agronomy}

Dr. Taryono for taking the time to show me the Madukismo jatropha site, to Ir. Supriyanta M.P for taking the time to show me the UGM jatropha site at Purworejo Regency, to Dr. Nasrullah, Panjisakti Basunanda S.P. 
M.P, and Rudi Hari Mukti for the statistics discussions, to Dr. Endang Sulistyaningsih and Prof. Dr. Didik Indradewa for providing interested students to assist me with my field research, and for allowing me to use your laboratory equipment, and also to Ir. Sri Muhartini MS for allowing me to use your laboratory equipment, and finally to Eka Tarwaca Susila P. S.P. M.P for discussions in plant research.

\section{Faculty of Agriculture - Department of Soil Sciences}

Ir. Suci Handayani M.P for the discussions of physical soil properties and analysis. To Ir. Susilo for taking the time to identify and classify my soil profile samples from Gunungkidul and Sumbawa; I do appreciate the time you took to teach me about soil identification and classification and to Prof. Dr. Bambang Hendro for giving me the opportunity to survey a possible jatropha research site at Kalitirto.

\section{Faculty of Agriculture - Department of Agricultural Socio-Economics}

Ir. Ken Suratiyah M.S for the socio-economic discussions and for providing student projects in jatropha socioeconomics at the Gunungkidul site, and to Pak Wid, Pak Dadi, and Bu Atun for their technical laboratory assistance.

\section{Faculty of Forestry - Department of Forest Management}

Dr. Ris Hadi Purwanto for the discussions in forest allometry research and for providing interested students to assist me with my field research.

\section{Faculty of Forestry - Department of Silvicultural and Agroforestry}

Dr. Budiadi for the discussions in agroforestry and for the perspective of where jatropha is situated within the agroforestry perspective and to Dr. Priyono Suryanto for the agroforestry research papers.

\section{Faculty of Agricultural Technology - Department of Agricultural Engineering}

Ir. Murtiningrum M.Eng, Ir. Sukirno M.S and Dr. Bayu Dwi Apri Nugroho for providing equipment, advice, and students for my field research and to Pak Sanyoto for providing technical assistance. A special thanks to the many students from the Faculty of Agriculture, Faculty of Forestry, and Faculty of Agricultural Technology for assisting with field and/or laboratory research.

\section{University of National Development 'Veteran' in Yogyakarta}

I would like to acknowledge and thank the University of National Development "Veteran" in Yogyakarta for their assistance and support, in particular:

\section{Faculty of Agriculture}

Thank you to Dr. Muhammad Nurcholis, Dr. Abdul Rizal and Ir. Siwi Hardiastutio EK, S.H.M.P for the opportunity to visit the jatropha site at Potorono, and to survey possible research sites at Sempu, Wedomartani.

\section{University of Muhammadiyah in Yogyakarta}

I would like to acknowledge and thank the University of Muhammadiyah in Yogyakarta for their assistance and support, in particular:

\section{Faculty of Agriculture}

Thank you to Dr. Indira Prabasari for providing the opportunity to use the lab equipment. Special thanks to Pak Sukirno for the technical assistant in the lab. 


\section{Department of Forestry and Estate Crops in Gunungkidul}

Thank you to Ir. Anik Indarwati M.P and Pak Suhartoto for providing data from jatropha farmers in Gunungkidul.

\section{Local farmers}

I am indebted to the many farmers in Gunungkidul who took the time to answer all my questions and assist me in my research. Special thanks to the female farmers who so meticulously and carefully dug up the jatropha roots. I enjoyed eating braised Bauhinia leaf and teak cocoons, including fried grasshopper you brought from time to time. Special thanks to Mbok Supri for providing me accommodation during the first few weeks in Gunungkidul and to Mbah Hadi for taking me under your wing and caring for me.

\section{Friends}

To Ibu Ira and family from Yogyakarta who are wonderful friends. Thank you for your generosity in providing many wonderful teas and allowing me to stay with you and for sharing your networks.

\section{East Java}

\section{University of Brawijaya in Malang}

I would like to acknowledge and thank the University of Brawijaya for their assistance and support, in particular:

\section{Faculty of Agriculture}

Prof. Dr. Kurniatun Hairiah for your support, positive encouragement, and teachings about forest carbon measurement and conducting experiments in tree-soil-crop interactions, and root measurements. Your feedback, comments and suggestions were most appreciated. Dr. Didik Suprayogo and Ir. Widianto M.Sc for soil discussions in Gunungkidul, especially to Pak Didik for the numerous discussions about the inverted soil condition experienced in Sumbawa, and for the comments and suggestions about lysimeter, sap-flow, and WaNuLCAS. I appreciate your generosity and giving the time and allowing discussions at your house and at JARAK workshop in Yogyakarta.

Dr. Eko Widaryanto and Dr. Kurniawan Puji Wicaksono for the interesting discussions and jatropha site visit.

\section{University of National Development 'Veteran' in East Java}

I would like to acknowledge and thank the University of National Development 'Veteran' in East Java for their assistance and support, in particular:

\section{Faculty of Agriculture}

Dr. Rossyda Priyadarshini from the Faculty of Agriculture at the University of National Development 'Veteran' in East Java for the soil and WaNuLCAS discussions.

\section{The Indonesian Sweetener and Fiber Crops Research Institute (Balittas) in Malang}

Thank you to Dr. Bambang Heliyanto for the opportunity to visit Balittas and chairing the discussion when Maja and I visited. Special thanks to Dr. Rully Diah Purwati for jatropha breeding information and development, including providing time for the discussion at JARAK workshop, Yogyakarta. Thanks to Nur Asbani, M.Si for the discussions, identification and natural control of jatropha pests and diseases, and to Ir. Budi Haryono M.P for discussions about jatropha cultivation and management. 


\section{Lombok, West Nusa Tenggara (NTB)}

\section{New World Energy}

Mike Vanstone and especially Gemma Dixon for the working visit to your sites.

\section{University of Mataram}

I would like to acknowledge and thank the University of Mataram for their assistance and support, in particular:

\section{Faculty of Agriculture}

Dr. Bambang B.S and Prof. Dr. I Komang Damar Jaya for the interesting discussions about jatropha and for access to the laboratory. Special thanks to Dr. I Gusti Made Arya P for sending me your PhD thesis on jatropha research at Purworejo.

\section{Sumbawa Besar, West Nusa Tenggara (NTB)}

\section{Jortech Biomass BV and PT. JORO}

Frans Serhalawan and late Ronald Serhalawan for the opportunity to work at the jatropha research site at Leseng. Special thanks to Rabina Ranteg and Darwin for assisting with field research and technical support.

\section{University of Samawa (UNSA)}

I would like to acknowledge and thank the University of Samawa (UNSA) for their assistance and support, in particular:

\section{Faculty of Agriculture}

Thank you to Heri Kusnayadi M.P and Ade Mariyam Oklima M.Si for providing technical support at the research site.

\section{Local Sumbawa people}

Pak Haji and Ibu Hajjah Ahmad Dahlan who took me under their wing and provided not only a boarding room, but also many great teas, stories and local knowledge which made my task easier.

\section{Local farmers}

Special thanks to the local farmers at Leseng who assisted the field work and the jatropha farmers in Sumbawa Besar with whom I had many fruitful discussions.

\section{Maumere - Flores, East Nusa Tenggara (NTT)}

\section{APEX - Dian Desa Foundation (YDD)}

Dr. Nao Tanaka for providing the opportunity to visit and discuss jatropha cultivation, management, and processing in Sikka District. Special thanks to Alex for arranging the visit to jatropha farmers' field. Thank you to Bapak Anton Sujarwo for the discussion about YDD jatropha programme with APEX

\section{Local jatropha growers}

Bapak Hendrik and Ibu Wilhemina for providing nice meal, transport, and network/contacts during my stay and possible jatropha research site in Maumere. I also thank Romo Pascalis for giving me the opportunity to survey church jatropha planting for possible research site. 


\section{Biak \& Sentani Jayapura, Irian Jaya}

\section{Eco-Emerald World}

Thank you to Dr. Anne-Claire Degail, Julien Chantry, and Oscar Mackbon for the opportunity to visit your jatropha sites. Special thanks to Pak Bayu Purnata for taking me to the many farmers jatropha planting in Biak, to Morganne Moenne for the generosity in providing accommodation during my stay in Sentani, and to Pak Ferdinando S for taking me to many farmers jatropha fields including to the University of Cendrawasih.

\section{Assessment Institute for Agricultural Technology (BPPT) Papua}

Dr. Fadjry Djufry for the discussions in modelling techniques you did for castor and contacts in IPB.

\section{University of Cendrawasih (UNCEN)}

I would like to acknowledge and thank the University of Cendrawasih for their assistance and support, in particular:

\section{Faculty of Mathematics and Natural Sciences}

Supeni Sufaati M.Sc for taking the time to provide information about available equipment in the laboratory. Many thanks for the opportunity to try traditional Papua dish, especially the papeda which I liked very much.

\section{Local farmers}

Special thanks to the jatropha farmers in Sentani and Biak for showing me their jatropha plantings and demonstrating their branch bending technique.

\section{Australia}

\section{University of Western Australia}

Thank you to Dr. Steve Burgess for making enquiries on my behalf to ICT International for the loan of their sap flow equipment for my research.

\section{ICT International}

Special thanks to Peter Cull for not only providing two sap-flow units, but for also continuously supporting my PhD study. I do appreciate your thoughtfulness. Although, the sap-flow data have not been used in this thesis there is possibility that I will use the data in a future publication. Thank you to Michael Forster and Alec Downey for various corresponding that lead me to Kazutomo Kobayashi (Kaz). Special thanks to Kaz for your technical support on sap-flow equipment.

\section{Wageningen University}

I thank you all for the support and companionship shown by the wonderful people in the Radix. I really did appreciate the encouragement, support, and social discussions from Martin, Mark, Pytrik, Katrien, Gerrie, Tom, Nico, Mink, Bert Rijk, Lenny, Joost, Rene, Andrew, Esther, and Sjanie. Special thanks to Peter for the plant and modelling discussions, to Wopke, Joost van Heerwaarden, and Bas Engels for the statistics discussions, to Jochem for the plant architecture, plasticity, and FSPM discussions, and to Jan Vos for the intercropping papers and plant discussions. Special thanks to Rob Verdooren for taking the time to visit radix for the statistics discussion. I am grateful to Ria, Charlotte, and Linda for providing administrative assistance during my stay at PPS. Special thanks to Marcel for providing IT assistance, and to Alex for ensuring the financial arrangements at PPS went smoothly. 
To my friends and colleagues with whom I shared the open space in the radix, coffee, cakes, and the many social events: Chris, Aisha, Naomi, Mezegebu, Lotte Klapwijk, Joao, Eskender, Aart, Alba, Idsert, Renske, Ezui, Guillaume, Jiska, Ilse, Allan, Alain, Comfort, Ashenafi, Junqi, Gou Fang, Bin Chen, Yang Yu, Clara, Herman, Marloes, Clint, and many others. Special thanks to Lotte Woittiez and Jannike Wichern for generously offering to help as paranymphs. Thank you all for making my stay at Wageningen so pleasant and special.

Thank you to the Indonesian student association (PPI) Wageningen and to all its members for providing support, encouragement, and social events that made my stay at Wageningen more like home. To Kiki, Aika, Feli, Rosa, Ines, Rani, Danang, Cece, Ilmi, Yani, Rizka, Dyah, Anan, Husein, Mbak Nurmi, Mbak Supriatin, Mbak Novi, Mbak Elie, Mbak Shinta, Mbak Aritta, Mbak Titis, Pak Indra, Pak Dazeb, Pak Taufik, Pak Indra, Pak Hidayat, Pak Iman, Pak Dikky, and many others. I thank you all for your friendship and generosity in giving a helping hand. May you all have a great life ahead and keep in touch!

Finally I am very thankful to my family, my in-laws, and my parents who have always encouraged and prayed for my success. Last but not least, I thank the most important and special person in my life, my dear husband. Thank you for being my greatest supporter and fan during this PhD journey. I am looking forward to us setting forth on our next adventure together. 


\section{Publication list}

Tjeuw J, Mulia R, Slingerland M, Van Noordwijk M. (2015) Tree or shrub: a functional branch analysis perspective of Jatropha curcas L. Agroforestry Systems 89: 841-856.

Tjeuw J, Slingerland M, Giller K. (2015) Relationships among Jatropha curcas seed yield and vegetative plant components under different management and cropping systems in Indonesia. Biomass and Bioenergy 80: 128-139.

Slingerland M, Tjeuw J, Suharsono S, Purwati DR. (2014) Is Jatropha a miracle crop producing high yields on marginal lands? In: Vel, JAC, Simandjutak, D (Eds) JARAK, the short history of Jatropha projects in Indonesia. IIAS. E-publication available at http://jarak.iias.asia, Leiden.

Slingerland M, Tjeuw J. (2014) What is Jatropha? In: Vel, JAC, Simandjutak, D (Eds) JARAK, the short history of Jatropha projects in Indonesia. IIAS. E-publication available at http://jarak.iias.asia, Leiden.

Vel J, Simandjuntak D, van Rooijen L, Widjaja H, Afiff S, van Klinken G, Tjeuw J, Slingerland M, Semedi P, Schulte Nordholt H. (2013) Jatropha: from an iconic biofuel crop to a green policy parasite. IIAS Newsletter 66: 15 .

Henderson W J, Purba O, Purba HI, Tjeuw J. (2014) Oil palm (Elaeis guineensis Jacq.) block sex ratio. Scientific Research Journal 2: 19-22.

Henderson W J, Tjeuw J, Purba O, Immanuella H. (2014) Oil palm block efficiency indicator. Scientific Research Journal 2: 1-4.

Henderson W J, Purba O, Purba HI, Tjeuw J. (2015) Oil palm (Elaeis guineensis Jacq.) bunch structure variation and limitations. Scientific Research Journal 3: 5-10. 


\section{Curriculum Vitae}

Juliana Tjeuw was born on the $8^{\text {th }}$ of April 1977 in Curup, Bengkulu Province - Indonesia. In 1994 she completed senior high school in Curup and in 1999 she completed her Bachelor of Science degree from School of Biology at the University of Atma Jaya Yogyakarta. After graduation, she worked at Energy Drink Company as the Chief of Laboratory \& Quality Control, but latter resigned to commence full time M.Sc. study with School of Life Sciences and Technology at Bandung Institute of Technology. In 2001 she completed her M.Sc. in plant genetics and molecular biology researching Flowering LFY gene in Tectona grandis L. From 2001 to 2003 she worked as the biology book editor for Erlangga Publisher, Jakarta. The non-plant related work was not satisfying so in 2003 she accepted a position with Sinar Mas Research Institute (SMARTRI) working at Dami Mas Oil Palm Seed Garden (DMSG) near Pekanbaru in Sumatera. As she always had an interest in plant breeding, working in the oil palm seed garden allowed her to pursue and develop an understanding of agro-climatic aspects that relate to oil palm. She was in charge of the laboratory and responsible for data collection, processing and statistical analysis, including the position of ISO 9001 document controller - 2000. In addition to this she was also edited the SMARTRI newsletter. In 2006 she resigned from DMSG when she married and moved with her husband to Papua New Guinea (PNG). Although the employment opportunities in PNG were limited, she planted and tended her vegetable and fruit garden, did voluntary work at Kimbe International School teaching home economics for grades 6 and 7. In addition she translated official documents from Indonesian to English for New Britain Palm Oil Limited, Dami Oil Palm Research Station management. While in PNG she was offered the opportunity to attend statistical analysis training by Prof. Rob Verdooren and that once again rekindled her interest in plant sciences. In 2009 she left PNG with her husband and returned to Indonesia. In 2010 where she was successful in gaining a $\mathrm{PhD}$ scholarship within the JARAK cluster under Agriculture beyond Food programme that had affiliation between Van Vollenhoven Institute Law Department, Leiden University and Plant Production Systems of Wageningen University. She can be contacted at julianatjeuw@gmail.com. 


\section{PE\&RC Training and Education Statement}

With the educational activities listed below the PhD candidate has complied with the educational requirements set by the C.T. de Wit Graduate School for Production Ecology and Resource Conservation (PE\&RC) which comprises of a minimum total of 32 ECTS (= 22 weeks of activities)

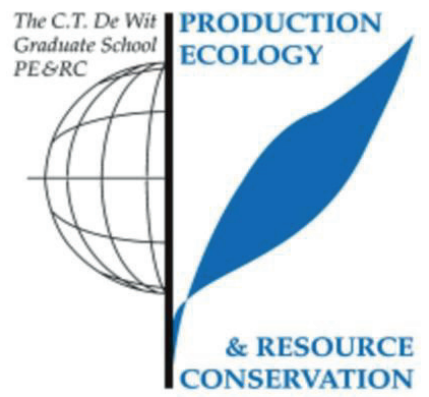

\section{Review of literature (6 ECTS)}

Reviewed literature related to the growth, development and production of Jatropha curcas around the world and in Indonesia.

\section{Writing of project proposal (4.5 ECTS)}

Growth, development, and production of Jatropha curcas in Indonesia

\section{Post-graduate courses (4.8 ECTS)}

- Functional Branch Analysis (FBA) and WaNuLCAS (Water, Nutrient, and Light Capture in Agroforestry Systems) modelling; ICRAF-Bogor (2011, 2014, 2015)

- Advanced statistics \& multivariate analysis; University of Indonesia (2013)

- Generalised linear models; PE\&RC (2014)

- Introduction to R for statistical analysis; PE\&RC (2014)

Laboratory training and working visits (4.5 ECTS)

Field training on jatropha cultivation and management practices: Jortech Biomass BV, Sumbawa; Indonesian Spice and Industrial Crops Research Institute-ISICRI (Balittri); Indonesian Tobacco and Fibre Crops Research Institute-IToFCRI (Balittas); Jatropha field of Agronomy Department of University of Brawijaya, Malang; Jatropha in Dian Desa-APEX, Maumere-Sikka, NTT; PT. JEDO, Banten; PT. BMEP, Cikarang; PT. Jatropha Solutions-Toloram group, Bengkulu; PT. New World Energy, Lombok; Eco Emerald, Irian Jaya; PT. JGE, Yogyakarta (2011)

\section{Invited review of journal manuscript (1 ECTS)}

Influence of seed age at room temperature, pre-sowing seed treatment, and fruit colour harvest index on germination and seedling growth of Jatropha curcas L (Agroforestry Systems; 2016)

Deficiency, refresh, brush-up courses (2.5 ECTS)

- System analysis, simulation and system management; PPS (2010)

- Agroforestry; FEM (2010)

Competence strengthening / skills courses (2.3 ECTS)

- Endnote introduction (2011)

- Forest carbon measurement in Semono Village - Gunungkidul; ICRAF Bogor \& University of Brawijaya Malang (2012) 
- Techniques for writing and presenting a scientific paper; WGS (2014)

PE \& RC annual meetings, seminar and the PE \& RC weekend (1.2 ECTS)

- PE\&RC day - Selling science (2010)

- $\mathrm{PhD}$ workshop carousel (2014)

- PE\&RC weekend (2014)

Discussion groups / local seminars / other scientific meetings (4.8 ECTS)

- Bioenergy PhD group (2010-2011)

- Revitalisation of jatropha programme, Sikka - NTT (2011)

- Agroforestry $3^{\text {rd }}$ Symposium, Yogyakarta (2012)

- Jarak workshop in Leiden \& Yogyakarta $(2011,2014)$

International symposia, workshops and conferences (5.5 ECTS)

- International conference on Jatropha curcas, Groningen (2010)

- Agriculture beyond Food workshop at Wageningen, Yogyakarta, and Jakarta - presenting research poster and attending workshop $(2011,2012,2014)$

- Renewable energy and energy conservation, Jakarta - presenting research poster and attending workshop (2012)

\section{Supervision of MSc and BSc students (4.5 ECTS)}

- Jatropha curcas L. accessions in Central Java, Indonesia; A selection for future breeding programmes (2013 - 2014)

- The effect of incorporation of leaf litter Jatropha curcas L. and $\mathrm{N}$ fertiliser on maize growth and grain yield (2012 - 2013)

- Changes in Jatropha curcas contribution to farmers income in Saptosari sub-district Gunungkidul District (2012 - 2013)

- The socio-economic analysis of farming Jatropha curcas L. at Kanigoro and Monggol Villages, Saptosari, Gunungkidul district (2012 - 2013) 


\section{Funding}

The research described in this thesis was financially supported as part of the research cluster for 'Jarak: the commodisation of an alternative biofuel crop in Indonesia' under Agriculture beyond Food (AbF) programme funded by KNAW-NWO (Grant Number W07.55.301.00).

Cover design by Juliana Tjeuw (Zentropha)

Printed by Digiforce - Proefschriftmaken, Wageningen, NL 